\title{
Local anesthetic interactions with G protein-coupled receptor signaling
}

Citation for published version (APA):

Hollmann, M. W. (2001). Local anesthetic interactions with G protein-coupled receptor signaling. [Doctoral Thesis, Maastricht University]. Shaker. https://doi.org/10.26481/dis.20020301mh

Document status and date:

Published: 01/01/2001

DOI:

10.26481/dis.20020301mh

Document Version:

Publisher's PDF, also known as Version of record

\section{Please check the document version of this publication:}

- A submitted manuscript is the version of the article upon submission and before peer-review. There can be important differences between the submitted version and the official published version of record.

People interested in the research are advised to contact the author for the final version of the publication, or visit the DOI to the publisher's website.

- The final author version and the galley proof are versions of the publication after peer review.

- The final published version features the final layout of the paper including the volume, issue and page numbers.

Link to publication

\footnotetext{
General rights rights.

- You may freely distribute the URL identifying the publication in the public portal. please follow below link for the End User Agreement:

www.umlib.nl/taverne-license

Take down policy

If you believe that this document breaches copyright please contact us at:

repository@maastrichtuniversity.nl

providing details and we will investigate your claim.
}

Copyright and moral rights for the publications made accessible in the public portal are retained by the authors and/or other copyright owners and it is a condition of accessing publications that users recognise and abide by the legal requirements associated with these

- Users may download and print one copy of any publication from the public portal for the purpose of private study or research.

- You may not further distribute the material or use it for any profit-making activity or commercial gain

If the publication is distributed under the terms of Article $25 \mathrm{fa}$ of the Dutch Copyright Act, indicated by the "Taverne" license above, 


\title{
Local anesthetic interactions with G protein-coupled receptor signaling
}

\author{
PROEFSCHRIFT
}

ter verkrijging van de graad van doctor

aan de Universiteit Maastricht,

op gezag van de Rector Magnificus,

Prof. dr. A. Nieuwenhuijzen Kruseman,

volgens het besluit van het College van Decanen,

in het openbaar te verdedigen

op vrijdag 1 maart 2002 om 16.00 uur

door

Markus W. Hollmann 


\section{Promotor:}

Prof. dr. M.E. Durieux

\section{Beoordelingscommissie:}

Prof. dr. J.W. Cohen Tervaert (voorzitter), Universiteit Maastricht Dr. A.E. Marcus, academisch ziekenhuis Maastricht

Prof. dr. E. Martin, Universiteit Heidelberg

Prof. dr. H.W.M. Steinbusch, Universiteit Maastricht

Prof. dr. A. van Zundert, Catharina Ziekenhuis Eindhoven 


\title{
Berichte aus der Medizin
}

\author{
Markus W. Hollmann
}

\section{Local anesthetic interactions with G protein-coupled receptor signaling}




\section{Die Deutsche Bibliothek - CIP-Einheitsaufnahme}

Hollmann, Markus W.:

Local anesthetic interactions with G protein-coupled receptor signaling/

MarkusW. Hollmann.

Aachen: Shaker, 2001

(Berichte aus der Medizin)

Zugl.: Universiteit MaastrichtDiss., 2002

ISBN3-8265-9627-7

Cover: 3D-structure of the local anesthetic lidocaine next to a model of the receptor/Gprotein complex (reprinted from Pharmacol Ther, 80 (3) Wess J., Molecular basis of receptor/G protein-coupling selectivity, 239, 1998 with permission from Elsevier Science). The structure of the G-protein heterotrimer ( $\alpha$ dark blue; $\beta$ turquoise; $\gamma$ green) is based on an X-ray structure. White lanes indicate the approximate locations of the plasma membrane boundaries. The $N$-terminal $\alpha$-helix $(\alpha N)$ of $G \alpha$ points toward the viewer. Several $\mathrm{G} \alpha$ regions, including the C-terminal $(\mathrm{Ct})$, the $\alpha 5$ helix, and the $\alpha 4 / \beta 6$ loop are predicted to be contacted by GPCRs. The guanine nucleotide (GDP) is buried in a cleft between the $\alpha$-helical (left) and the ras like domain (right) of $G \alpha$ and is contacted by the $\beta 6 / \alpha 5$ loop (yellow).

Copyright Shaker Verlag 2001

All rights reserved. No part of this publication may be reproduced, stored in a retrieval system, or transmitted, in any form or by anymeans, electronic, mechanical, photocopying, recording or otherwise, without the prior permission of the publishers.

Printed in Germany.

ISBN 3-8265-9627-7

ISSN 0945-0890

Shaker Verlag GmbH • P.O. BOX 1290 - D-52013 Aachen

Phone: 0049/2407/9596-0 - Telefax: 0049/2407/9596-9

Internet:www.shaker.de·eMail:info@shaker.de 
to my wife Silke and my parents, who love and supported me 



\section{Contents}

Table of abbreviations 8

Chapter $1 \quad$ Introduction and aims 10

Chapter 2 Structure and function of $\mathrm{G}$ proteins and $\mathrm{G}$ protein-coupled receptors 13

Chapter 3 Local anesthetics: effects on the central nervous system and bronchial reactivity 35

Chapter $4 \quad$ Local anesthetic inhibition of $\mathrm{ml}$ muscarinic acetylcholine signaling $\mathbf{5 2}$

Chapter $5 \quad$ Inhibition of $\mathrm{m} 3$ muscarinic acetylcholine receptors by local anesthetics 74

Chapter 6 Local anesthetic inhibition of $\mathrm{G}$ protein-coupled receptor signaling by interference with $\mathrm{G} \alpha_{\text {Q }}$ protein function 93

Chapter 7 Local anesthetics: effects on inflammation, wound healing and coagulation 112

Chapter $8 \quad$ Local anesthetic effects on priming and activation of human neutrophils 127

Chapter 9 Epidural anesthesia prevents hypercoagulation in patients undergoing major orthopedic surgery 147

Chapter $10 \quad$ Summary and conclusions / Samenvatting en conclusies 159

Acknowledgments 165

List of publications 166

Curriculum vitae 171 
Table of abbreviations

AC Adenylyl cyclase

Ach Acetylcholine

ACT Activated clotting time

ADP Adenosine diphosphate

ARDS Adult respiratory distress syndrome

Asn Asparagine

BALF Bronchoalveolar lavage fluid

BIM Bisindolylmaleimide

BSA Bovine serum albumin

cAMP Cyclic adenosine monophosphate

cDNA Complementary deoxyribonucleic acid

CHO Chinese hamster ovaries

CITF Collagen-induced thrombus formation

CNS Central nervous system

CPB Cardiopulmonary bypass

cRNA Complementary ribonucleic acid

CSA Clot signature analysis/analyzer

Ct Chelerythrine

CT Clotting time

Cys Cysteine

4-DMAP 4-Diphenylacetoxy- $\mathrm{N}$-methylpiperidine

DAG Diacylglycerol

DVT Deep venous thrombosis

EA Epidural anesthesia

$\mathrm{EC}_{50} \quad$ Half-maximal effect concentration

$\mathrm{E}_{\max } \quad$ Maximal effect

fMLP N-formylmethionine-leucyl-phenylalanine

GA General anesthesia

GABA $\gamma$-aminobutyric acid

GAF Guanosine triphosphatase activating factor

GAP GTP activating protein

GDP Guanosine diphosphate

GEF Guanine nucleotide exchange factor

GM-CSF Granulocyte-macrophage colony stimulating factor

GPCR GTP-binding protein-coupled receptor

GTP Guanosine triphosphate

GTPYS Guanosine 5'-O-(-3-thiotriphosphate)

HBSS Hank's Balanced Salt Solution

$\mathrm{HCl} \quad \mathrm{Hydrochloric}$ acid

IC $_{50} \quad$ Half-maximal inhibitory effect concentration

ICaca) $\quad \mathrm{Ca}^{2+}$-activated $\mathrm{Cl}^{2}$ current

ICP Intracranial pressure

IL Interleukin

IP3 Inositol $(1,4,5)$-trisphosphate

LA Local anesthetics

LPA Lysophosphatidic acid

LPS Lipopolysaccharide (LPS)

LTD $_{4} \quad$ Leukotriene $\mathrm{D}_{4}$

LTB $_{4} \quad$ Leukotriene $\mathrm{B}_{4}$

MAC Minimal alveolar concentration 
MAP Mean arterial pressure

MCh Acetyl- $\beta$-methylcholine bromide

MEGX Mono-ethyl-glycinexylidide

MGluRs Metabotropic glutamate receptors

MLCK Myosin-light- chain kinase

MOPS 3-[N-Morpholino]propanesulphonic acid

NADPH Nicotinamide adenine dinucleotide phosphate

PAF Platelet-activating factor

PBR Peripheral benzodiazepine receptors

PHT Platelet-mediated hemostasis time

$\mathrm{PIP}_{2} \quad$ Phosphatidylinositol 4,5-bisphosphate

PIT Pericranial injection therapy

PKA Proteinkinase A

PKC Proteinkinase C

PLC Phospholipase C

PMA Phorbol myristate acetate

PMN Polymorphonuclear leukocytes

PTX Pertussis toxin

$\left[{ }^{3} \mathrm{H}\right] \mathrm{QNB}\left[{ }^{3} \mathrm{H}\right]$ quinuclydinyl benzylate

RCP Retrograde cerebral perfusion

RGS Regulator of $G$ protein signaling

RPP Rate-pressure product

Ser Serine

SOD Superoxide dismutase

SPECT Single photon emission computed tomography

TEG Thrombelastography

TM Transmembrane

TNF Tumor necrosis factor

U-73122 1-(6-[([17beta]-3-methoxyestra-1,3,5[10]-trien-17-yl)amino]hexyl)-1H-pyrrole-2,5dione

VTD Veratridine 


\section{CHAPTER 1}

\section{Introduction and aims}

\section{INTRODUCTION}

Local anesthetics are best known for their ability to block voltage-gated sodium channels, and it seems clear that this is the primary mechanism explaining their antinociceptive and antiarrhythmic effects. Studies in neurons and cardiac tissue, more recently supplemented by molecular biologic research on isolated $\mathrm{Na}$ channels, have provided a wealth of support for this statement. However, this clarity of understanding (which is in sharp contrast with the muddled situation concerning volatile anesthetic action) has led to the assumption - rarely articulated but widely held - that all local anesthetic actions can be explained by $\mathrm{Na}$ channel blockade. This is certainly not the case. Indeed, local anesthetics are known to have a variety of biologic effects mediated other than via tetrodotoxin (TTX)-sensitive Na channels, some of which effects are yet not elucidated in detail on a molecular/receptor level.

Especially those actions not or at least not solely explainable by sodium channel blockade are addressed in our investigations and will be summarized in this thesis. Particularly exciting is the realization that some of these actions are of potential great importance for perioperative medicine: modulation of inflammatory responses and prevention of hypercoagulability are just two examples of obvious interest to the anesthesiologist.

$\mathrm{Na}$ channel-independent effects of local anesthetics are demonstrated most clearly in cells that simply do not contain Na channels. Polymorphonuclear leukocytes (PMN) are an obvious example. No Na channels are present in these cells, yet local anesthetics affect them profoundly, decreasing PMN adhesion, chemotaxis, respiratory burst, and mediator secretion. As a result, local anesthetics inhibit inflammatory responses, and can be shown to have beneficial effects in a number of pathologic processes dependent on an overly active inflammatory response. For example, they have therapeutic effects in several animal models of ARDS and other types of lung injury and in ischemia-reperfusion injury. Clinically, they have been used in the treatment of inflammatory bowef syndrome with positive results. For further details, chapter seven provides a review on local anesthetic actions on the inflammatory response.

Interestingly, local anesthetics only attenuate a hyperactive inflammatory response, but do not suppress normal inflammation. This clearly separates them from other anti-inflammatory drugs, such as steroids. For example, local anesthetics are not known to increase infection rates or mortality from sepsis (except for one animal study where their effect was studied in the setting of gross bacterial contamination), and do not prevent wound healing. Obviously, this selectivity of action would be of great benefit in the clinical setting, since the body depends on inflammatory processes for wound healing after surgery.

Similarly, local anesthetics attenuate the hypercoagulated state, such as exists after surgery, as shown in studies of their effects on postoperative thrombosis and coagulation. However, they do not interfere with normal coagulation (i.e. they do not induce bleeding). The ability to separate these actions from Na channel blockade might yield a class of extraordinarily useful drugs.

Regarding the local anesthetic concentrations used in these various studies, in vitro studies have consistently required significantly (i.e. 100- to 1000-fold) greater local anesthetic concentrations than do in vivo studies. The concentrations required in vivo are usually similar to those attained in blood after IV or epidural infusion (approximately 0.5 to $5 \mu \mathrm{g} / \mathrm{ml}$, corresponding to 2 to $20 \mu \mathrm{M}$ ). It is therefore not clear if the actions observed in vitro can really explain the benefits in vivo. Several mechanisms could account for this discrepancy. (1) In vivo, local anesthetics might act on a sensitive target which has not yet been studied in vitro. (2) In vivo, local anesthetics might act on several interacting targets, yielding synergistic effects which can not be mimicked in vitro. (3) In vivo, local anesthetics are applied for considerably longer time periods than in vitro, and their effects may be time-dependent. (4) In vitro studies have usually been performed with cells from 
normal volunteers. Since local anesthetics only suppress hyperactive responses, without blocking normal function, such a model would not be expected to show profound effects of the compounds.

The inflammatory and hemostatic systems are closely interwoven, and some of these actions may result from similar or identical mechanisms. Many of the critical mediators in these systems act through $\mathrm{G}$ protein-coupled receptors (GPCR). Examples include thrombin, thromboxane, plateletactivating factor (PAF), ADP, the interleukins, as well as compounds with less well-established physiology, such as the platelet activator and polymorphonuclear granulocyte (PMN) chemoattractart lysophosphatidic acid (LPA). These findings, therefore, suggested that a potential interaction between local anesthetics and GPCR signaling systems might explain local anesthetic actions on inflammation and hemostasis.

Exploitation of this action might lead to new therapeutic opportunities for local anesthetics or local anesthetic derivatives. Using local anesthetics as lead compounds, such a program should eventually result in synthesis of drugs with the beneficial GPCR inhibiting properties of local anesthetics, but without the "side effect" of Na channel blockade. In order to compare the effects of local anesthetics on GPCR against a stable background, the Xenopus oocyte was used, a model system that allows expression of various GPCR under identical conditions. Receptors of interest can be expressed in this model by mRNA injection, and their function can be assessed by determining $\mathrm{Cl}$ currents through a channel activated by changes in intracellular $\mathrm{Ca}$ (Figure).

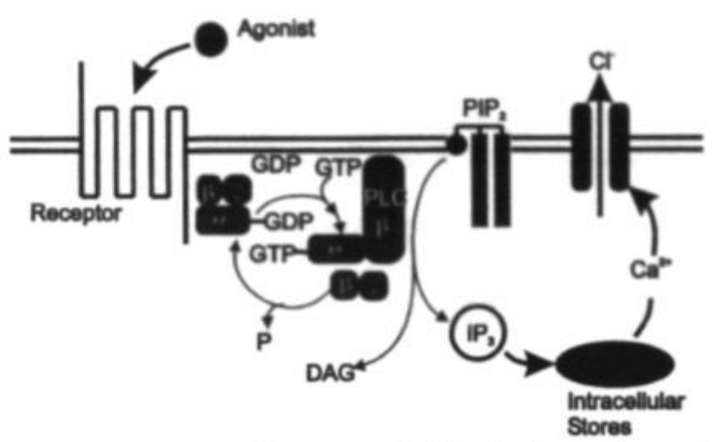

Figure: The figure shows what happens after stimulation of $a G$ protein coupled receptor by its agonist: After application of the agonist, the coupled G-protein becomes activated, which leads among other things to an increase in phospholipase Cactivity. followed by generation of inositoltrisphosphate $\left(I P_{1}\right)$ and diacylglycerol (DAG). Increase in IP causes then release of $\mathrm{Ca}$ from intracellular stores. In the oocyte, the increase in intracellular calcium concentration opens Ca-activated chloride channels, resulting in an efflux of chloride ions. The resulting inward peak current is then measured in $\mu \mathrm{A}$.

Results obtained in this recombinant model should then be confirmed in native human cells. We did so by expanding our investigations to two cellular models, namely human polymorphonuclear granulocytes (hPMNs) obtained from volunteers and human platelets acquired from patients undergoing major orthopedic sugery.

\section{AIMS}

We hypothesized that local anesthetics interfere with GPCR signaling pathways in various systems (e.g. Xenopus oocytes or hPMNs). These effects are most likely due to interaction with multiple sites on GPCRs and G proteins. Specifically, the goals of the study were to:

\section{Determine the inhibitory potency of local anesthetics on various GPCR signaling} pathways in our recombinant model.

2. Characterize in more detail the sites of action for local anesthetics within those GPCR signaling pathways, using Xenopus oocytes. 
3. Confirm and expand the results obtained in Xenopus oocytes using clinically relevant responses of native human cells (hPMNs and human platelets).

This thesis reports the results of investigations planned to accomplish these Aims. It is organized as follows:

- Chapter 2 provides a review of our current understanding of $\mathrm{G}$ protein-coupled receptors. The goal is not as much to be completely comprehensive, but rather to give a broad overview of the structure and classification of GPCRs and G proteins. In addition, ligand binding and receptor activation will be discussed.

- Chapter 3 (Progress in Anesthesiology: 14 (20):323-336, 2000) reviews the effects of local anesthetics on the central nervous system and bronchial reactivity. Molecular mechanisms that could be relevant to these actions are explained in the next three chapters.

- Chapter 4 (Anesthesiology 93 (2):497-509, 2000) describes the inhibition of ml muscarinic acetylcholine signaling by local anesthetics in Xenopus oocytes, and characterizes the localization and interaction between multiple binding sites for local anesthetics in the $\mathrm{ml}$ signaling pathway.

- Chapter 5 (Br J Pharmacology 133: 207-216, 2001) reports the inhibition of $\mathrm{m} 3$ muscarinic acetylcholine receptors by local anesthetics in Xenopus oocytes, and highlights the differences in local anesthetic inhibition on $\mathrm{ml}$ and $\mathrm{m} 3$ signaling using chimeric receptor constructs.

- Chapter 6 (Mol Pharmacol: 59:294-301, 2001) describes the characterization of a common site of action for local anesthetics within different GPCR signaling pathways in Xenopus oocytes.

- Chapter 7 (Progress in Anesthesiology: 14 (18):291-304, 2000) reviews the effects of local anesthetics on inflammation, wound healing and coagulation. Cellular actions that may explain those effects are studied in the next two chapters.

- Chapter 8 (Anesthesiology 95: 113-22, 2001) describes local anesthetic effects on priming and activation of human neutrophils, characterization of the priming pathway, and determination of the site of action for local anesthetics within this priming pathway.

- Chapter 9 (Reg Anesth Pain Med 26: 215-22, 2001) reports the results of a clinical study demonstrating that epidural anesthesia prevents postoperative hypercoagulation in patients undergoing major orthopedic surgery.

- Chapter 10 summarizes the reported results, and recommends further studies. 
CHAPTER 2

Structure and function of $\mathbf{G}$ proteins and $\mathbf{G}$ protein-coupled receptors Markus W. Hollmann 


\section{Structure and function of $\mathbf{G}$ proteins and $\mathbf{G}$ protein-coupled receptors}

\section{Introduction}

G Protein-coupled receptors (GPCRs) constitute one of the largest known protein families in mammals, including man. Nearly 2000 GPCRs have been reported since bovine opsin was cloned in 1983 and the $\beta$-adrenergic receptor in 1986. Current estimates are that approximately $1 \%$ (about 1000 ) of the genes present in a mammalian genome code for these types of receptors. They are of fundamental importance for intra- and intercellular communication pathways. The majority of transmembrane signal transduction in response to stimuli as diverse as light, gustatory compounds, odorants, neurotransmitters, neuropeptides, hormones and glycoproteins is mediated by GPCRs. Among the GPCRs that are particularly important for anesthesiologists are all the receptors involved in transducing the functions of the autonomic nervous system, receptors for transducing the action of opiate narcotics, adenosine and related compounds, serotonin and related compounds, and $\alpha_{2}$-adrenergic agonists. These receptors are complex intrinsic membrane proteins that report the presence of the extracellular ligand via transmembrane conformational changes to the intracellular environment.

Although the majority of GPCRs mediate signal transduction via $\mathrm{G}$ proteins, emerging evidence indicates that some of these receptors are also capable of coupling to alternative signal molecules, e.g. Jak2 kinase, phospholipase $\mathrm{C} \gamma(\mathrm{PL}-\mathrm{C} \gamma)$, or proteinkinase $\mathrm{C}$ (PKC). These alternative pathways are an indication of the overall diversity occuring in the GPCR superfamily. Furthermore, there are putative seven transmembrane molecules, which do not appear to be coupled to a $\mathrm{G}$ protein. The broad range of physiological functions associated with GPCRs explains why at least $50 \%$ of currently available medications targets this receptor family. A substantial number of GPCRs is still expected to be discovered in genome studies. It is obvious that GPCRs will remain a major target for next generations of drugs, and that better understanding of their mechanisms and regulation will generate unprecedented prospects for rational drug design and novel pharmacological intervention in a large variety of disease states.

\section{Structure of GPCRs}

For rational drug design, it is essential to gain insight, at the atomic level, of the structure of the ligand in the binding site, of its interaction pattern with the receptor and of the subsequent conformational changes in the receptor triggering the activated state. In spite of the increasing clinical and pharmacological relevance of the GPCRs, very little experimental information is available on their atomic structure. Despite the remarkable structural diversity of their activating ligands and their amino acid sequences, the superfamily of GPCRs shares essential structural and mechanistic features. All GPCRs have an extracellular $\mathrm{N}$-terminal segment, an intracellular Cterminal segment and are predicted to share a common three-dimensional fold consisting of seven transmembrane (TM) helices (TM I-VII), of sufficient length to span the lipid bilayer and form the TM core. This does not have a vacant pocket, channel or tunnel structure, as is sometimes thought.' The TM helices are linked by alternating intracellular (il-i3) and extracellular (02-04) loops (Fig.1).

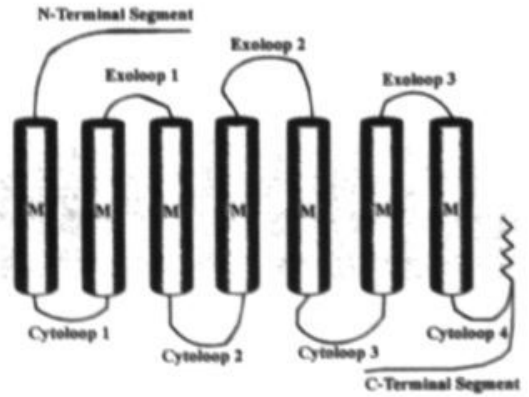

Figure 1: Schematic of a GPCR: The graphic illustrates a typical GPCR with its extracellular $N$ terminal segment and an intracellular $C$-terminal segment. The seven transmembrane (TM) spanning domains (TM 1-7) are linked by alternating intracellular (cytoloop 1-3) and extracellular (exoloops 1-3) loops. A fourth cytoplasmic loop(cytoloop 4 ) is formed when the $C$-terminal segment is palmitoylated at cysteine (Cys). 
A fourth cytoplasmic loop is formed when the C-terminal segment is palmitoylated at cysteine (Cys). Each of the seven TMs is generally composed of 20-27 amino acids. On the other hand, Nterminal segments (7-595 amino acids), loops (5-230 amino acids), and C-terminal segments (12359 amino acids) vary in size, an indication of their diverse structures and functions. Interestingly, there is a weak positive correlation between an $\mathrm{N}$-terminal segment's length and ligand size. The putative transmembrane domains exhibit more homology across the GPCRs than the intervening hydrophilic loops, which are exposed intra- and extracellularly. TMs I, IV and VII are significantly more hydrophobic than TMs II, III, V and VI. The latter contain several ionic and/or neutral residues, whereas some of the more hydrophobic TMs (I, IV and VII) have only one hydrophilic residue such as asparagine (Asn) or serine (Ser). TMs III, V and VI are suggested to protrude more than the others from the lipid bilayer toward the extracellular surface. The conserved residues in the transmembrane domains play probably an essential role in maintaining the structure of the protein, while those residues conserved only among major classes of receptors may determine their unique functional properties. The extracellular receptor surface (including the extracellular $\mathbf{N}$-terminal domain, different extracellular loops, and/or the exofacial portions of various TM domains) is known to be critically involved in ligand binding. ${ }^{2.3}$

On the other hand, the intracellular receptor surface (including different intracellular loops, the intracellular C-terminal domain, and the cytoplasmic ends of different TM helices) is known to be important for $\mathrm{G}$ protein recognition and activation. ${ }^{4,5}$

The amino-terminus of the polypeptide contains probable sites for $\mathrm{N}$-linked glycosylation. While glycosylation and ligand binding sites on the amino-terminus are variable, those on the carboxyterminus consist of consensus sequences for phosphorylation and palmitoylation, which are important for functional regulation, such as desensitization and internalization.

Despite the fact that the tertiary structure of GPCRs has thought to be insoluble because of the difficulty in extracting large amounts of pure protein from the natural membranes for crystallography studies, recently the first crystal structure of a GPCR has been reported. It pertains the bovine rod pigment rhodopsin, a member of a special subfamily of GPCRs, the visual pigments, and describes about $90 \%$ of the protein at a moderate $2.8 \AA$ resolution. This rather well defines the structure of the membrane domain, which allows homology modelling of this domain for other GPCRs. However, the ligand structure and its interaction with the receptor are poorly defined yet. A resolution of at least $2.0 \AA$ would be required. In addition, the structure of the active state and how this state is generated still remains fully unresolved.

The most widely cited structural model of GPCRs is the Baldwin model. ${ }^{6}$ The sequential arrangement of the helices in this model of rhodopsin is based on the fact that each of the interhelical hydrophilic loops is too short to permit any other arrangement. Thus, each helix is thought to be next to those closest to it in the amino acid sequence. The rotation of each of the helices in Baldwins model is based on the theory that conserved, hydrophilic residues are likely to face inward toward the other transmembrane domains. Site-directed mutagenesis data confirm this theory by showing that the important residues for binding and activation are on the inner face of the helix.?

The seven TMs are arranged in a counterclockwise direction from TM I to TM VII when viewed from the extracellular surface (Fig. 2).

The orientation of the TMs imposes a stereo- and geometric specificity on a ligand's entry into and binding to the TM core. In this arrangement the core is primarily comprised of TMs II, III, V, VI, and perhaps VII, whereas TMs I and IV are peripherally sequestered. In general, TMs I, II, and VII are apposed, consistent with the view that the more hydrophobic TMs I, IV and VII are exposed more to the lipid bilayer than the less hydrophobic TMs II, III, V, and VI. It is unknown whether there are GPCRs that are open looped or not closed between TMs I and VII. Different arrangements can provide interesting mechanisms for ligand binding and receptor activation. For example, if TM VII associates more closely with TM II than TM I, there will be a long crevice between TMs I and 


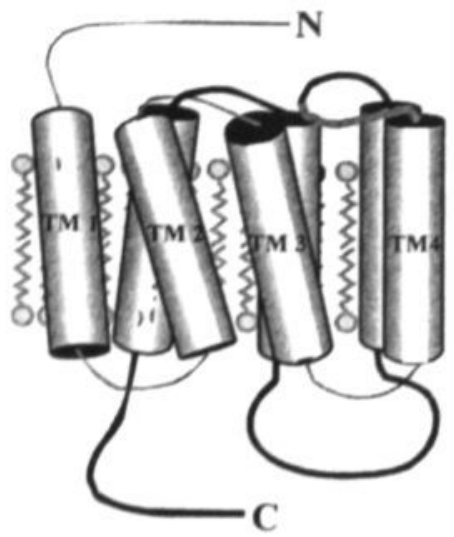

Figure 2: Arrangement of the transmembrane (TM) domains of a typical GPCR. The seven TMs are arranged in a counterclockwise direction from TM I to TM VII when viewed from the extracellular surface. In this arrangement the core is primarily comprised of TMs II, III, V, VI, and perhaps VII, whereas TMs I and IV are peripherally sequestered. In general, TMs I, II, and VII are apposed, consistent with the view that the more hydrophobic TMs I, IV and VII are exposed more to the lipid bilayer than the less hydrophobic TMs II, III, V, and VI. TM IV, VI and VII are orientated almost perpendicular to the plane of the membrane. In contrast, the axes of the remaining four TM helices (TM I, II, III and V) are predicted to be inclined from the normal to the membrane plane by about $25^{\circ}$ with TM III being most tilted by approximately $30^{\circ}$.

VII, which offers a binding site for, for example, the fatty chain of lysophosphatidic acid. Also, TMs I and VII of a GPCR may associate with TMs I and VII of another GPCR to form a dimer. ${ }^{8,9}$ Baldwin et al. ${ }^{10}$ proposed an updated model for the $\alpha$-carbon positions in the seven TM helices of receptors of the rhodopsin family. Consistent with electron density maps ${ }^{9}$, this model predicts that three of the TM helices (TM IV, VI and VII) are orientated almost perpendicular to the plane of the membrane. In contrast, the axes of the remaining four TM helices (TM I, II, III and V) are predicted to be inclined from the normal to the membrane plane by about $25^{\circ}$ with $\mathrm{TM}$ III being most tilted by approximately $30^{\circ}$. By studying the pattern of conserved versus nonconserved residues in closely related receptor families, Baldwin et al. ${ }^{10}$ were able to estimate the approximate lengths of the different TM helices and the degree to which the TM helices protrude into the extracellular and intracellular spaces. This analysis suggested that the seven TM helices have different lengths, with TM III being the longest and TM IV and VII being relatively short. All seven helices appear to extend into the cytoplasm by several residues; this phenomenon seems to be most pronounced in the case of TM III, V, and VI, which are predicted to protrude into the cytoplasm by 2-3 helical turns ( 9 or 10 amino acids). However, it remains still unclear how far the different TM helices extend into the extracellular space. The helices most exposed to the membrane lipid are predicted to be TM I, IV and V, whereas TM III is thought to be deeply buried inside the receptor protein, particularly on the intracellular side of the membrane, where it makes extensive contacts with TM II, IV, V and VI..' Because of the inclination of TM helices, the relative positions of TM III and IV are predicted to be reversed on the cytoplasmic side of the membrane. ${ }^{10}$ Several recent molecular genetic and biochemical studies suggest that the basic structural features of the original and redefined Baldwin model are probably correct. ${ }^{411-14}$

\section{Classification of GPCRs}

Different classification schemes can be used to subdivide the GPCR superfamily. One way to group GPCRs is based on ligand structure. Other important classification criteria are degree of amino acid similarity and $\mathrm{G}$ protein-coupling properties.

Based on sequence similarity, GPCRs can be classed into four major groups:

\section{Rhodopsin-type receptor family}

The rhodopsin-type receptors form by far the largest receptor subfamily and ligands acting on these receptors display a remarkable degree of structural diversity, ranging from sensory stimuli (e.g. rhodopsin and odorants), glycoprotein hormones (e.g. FSH, LH, TSH) and peptides (e.g. angiotensin, vasopressin, opioid petides) to biogenic amines (e.g. acetylcholine, dopamine, epinephrine, histamine) and others like adenosine, leukotrienes, PAF, prostanoids or thrombin. The 
hallmark of those receptors is a set of 20 amino acids that are highly conserved only in this GPCR subfamily. The majority of these amino acids are located in the cytoplasmic half of the TM receptor core. Mutagenesis data suggest that these highly conserved residues are required for protein stability and/or for mediating the conformational changes that accompany receptor activation. ${ }^{4,7}$

\section{Secretin/glucagon receptor family}

The secretin/glucagon receptor family makes up a relatively small group of peptide receptors (e.g. caltinonin, glucagon, secretin receptors). These receptors share several structural features, including approximately 20 identical amino acids and a relatively large $\mathbf{N}$-terminal extracellular domain that contains 6 well-conserved cysteine residues.

\section{Metabotropic ghutamate/calcium sensor receptor family}

This subfamily is composed of the metabotropic glutamate receptors (mGluRs; eight subtypes), the calcium sensor, the $\gamma$-aminobutyric acid (GABA) $)_{B}$ receptor, and a family of approximately 100 putative pheromone receptors present on basal vomeronasal neurons. The major hallmark of these receptors is an extraordinarily long $\mathrm{N}$-terminal extracellular domain that has been implicated in ligand binding. The mGluRs and the calcium sensor share approximately 20 conserved cysteine residues in the extracellular regions and the TM receptor core, which are likely to be involved in ligand binding and other important aspects of receptor function. ${ }^{15}$

\section{Gi vomeronasal pheromone receptors}

Another class of GPCRs, which are unrelated to any other GPCRs known so far, is formed by a group of approximately $30-40$ putative pheromone receptors that are selectively expressed in apical neurons of the vomeronasal organ. Receptors of this class have a relatively short $\mathrm{N}$-terminal extracellular segment and share between 47 and $87 \%$ sequence identity.

\section{G proteins}

$\mathrm{G}$ proteins comprise a large family of regulatory proteins that are involved in both intra- and intercellular signal transduction processes. They are molecular switches whose activities are determined in their interaction with guanine nucleotides, hence their name. G proteins cycle between an inactive, guanosine diphosphate (GDP)-bound form and an active guanosine triphosphate (GTP)-form. This cycle is regulated on one hand by a nucleotide exchange factor (GEF) and on the other by a guanosine triphosphatase (GTPase) activating factor (GAF). G proteins can be divided into two groups: heterotrimeric membrane bound proteins prominent in GPCR signaling, which will be discussed in detail in the following chapter, and smaller (20-30 kD), monomeric cytoplasmic $\mathrm{G}$ proteins involved in regulation of various intracellular processes.

Historically, heterotrimer $\mathrm{G}$ proteins are named after their $\alpha$-subunits. To date, more than 20 different $\alpha$-subunits (encoded by 17 distinct genes) have been identified. On the basis of amino acid similarity, the $G$ protein $\alpha$-subunits can be grouped into four major families: $G_{3}, G_{v 0}, G_{q / 1}, G_{12 / 13}$. ${ }^{16,17}$ The $G_{3}$ family includes several splice variants of $\alpha_{3}$, as well as $\alpha_{\text {olt, }}$ which is specifically expressed in olfactory epithelia. The $\mathrm{G}_{v_{0}}$ family consists of three different $\alpha_{i}$ species $\left(\alpha_{i 1}, \alpha_{i 2}\right.$, and $\alpha_{i 3}$, plus splice variants), $\alpha_{0}$ (which exists in two splice variants $\alpha_{01}$ and $\alpha_{02}$ ), the two retinal transducins $\left(\alpha_{11}\right.$ and $\left.\alpha_{22}\right)$, an $\alpha$-subunit found in gustatory epithelium $\left(\alpha_{\text {gust }}\right)$, and $\alpha_{2}$. The individual members of the $\mathrm{G}_{9 / 11}$ family are $\alpha_{4}, \alpha_{11}, \alpha_{14}, \alpha_{15}$, and $\alpha_{16}\left(\alpha_{15}\right.$ and $\alpha_{16}$ appear to be the murine and human versions of the same gene). The $\mathrm{G}_{12 / 13}$ family consists of only two members, $\alpha_{12}$ and $\alpha_{13}$. The $\alpha$ subunit consist of a polypeptide with a molecular weight of $40000-46000$. Most G protein $\alpha$ subunits are tightly associated with the cytosolic face of the plasma membrane. One source of this association is an anchoring effect of the $\beta \gamma$ subunits; $\alpha$ subunits do not associate with phospholipid vesicles unless $\beta \gamma$ subunits are present. ${ }^{18} \mathrm{~A}$ second source of this association may be covalent 
modification of the protein $\alpha$ subunits with fatty acids. The $\mathrm{N}$-terminal region is particular important for both association between $\alpha$ subunit and $\beta \gamma$ and membrane association. In contrast, the $\mathrm{C}$ terminal domain of the $\alpha$ subunit appears to play an important role in interactions with receptor and effector structures. ${ }^{19}$

The $\beta$ (35-36 kd) and $\gamma(8-9 \mathrm{kd})$ subunits remain closely associated with each other and are therefore usually regarded as one functional unit. At present, six different $G$ protein $\beta$ - and 12 distinct $\gamma$-subunits have been described. ${ }^{20}$ Whereas the different $\beta$ - subunits share a relatively high degree of sequence identity, the various $\gamma$-subunits are structurally more diverse. G protein $\beta \gamma$ complexes are extremely stable and, at least theoretically, the existence of six $\beta$ - and $12 \gamma$-subunits allows formation of 72 different $\beta \gamma$-complexes. The potential functional importance of such diversity is unclear at present, particularly because most $\beta \gamma$-complexes (except $\beta_{1} \gamma_{1}$ ) have been thought to exhibit similar functional properties. Most studies of $\mathrm{G}$ protein effector coupling do not support selectivity of $G \beta \gamma$ action. However, recent evidence supports that the $\beta$-isoform in the $\beta \gamma$ dimer can determine the specificity of signaling at both effectors and receptors. When $G$ protein $\beta \gamma$ dimers were explored by reconstituting them with $\mathrm{G \alpha}_{1}$ and receptors or effectors in the adenylyl cyclase cascade, the $\beta 4 \gamma 2$ dimer demonstrated the highest coupling efficiency to either $\beta 1$ adrenergic or A2a adenosine receptors (these receptors discriminate among the defined heterotrimers based solely on the $\beta$-isoform). The $\beta 5 \gamma 2$ dimer coupled poorly to each receptor, with $\mathrm{EC}_{50}$ values 40 to 200 -fold higher than those observed with $\beta 4 \gamma 2$. Strikingly, whereas the $\mathrm{EC}_{50}$ of the $\beta 1 \gamma 2$ dimer at the $\beta 1$-receptor was similar to $\beta 4 \gamma 2$, its $\mathrm{EC}_{50}$ was 20 -fold higher at the $\mathrm{A} 2 \mathrm{a}$ adenosine receptor. $\beta \gamma$-dimers containing $\mathrm{G} \beta 1-4$ were able to stimulate adenylyl cyclase type II (AC2) similarly. In contrast, $\beta 5 \gamma 2$ was much less potent. $\beta 1 \gamma 2, \beta 2 \gamma 2$, and $\beta 4 \gamma 2$ inhibited $\mathrm{AC1}$ equally, $\beta 3 \gamma 2$ was 10 -fold less effective, and $\beta 5 \gamma 2$ had no effect. ${ }^{21}$ In addition, selective activation of the phospholipase $C \beta$ pathway by $\mathrm{G} \beta \gamma$ complexes containing $\beta 1$-subunits have been demonstrated, whereas $\beta 2$-containing complexes produced no activation. ${ }^{22} \mathrm{~A}$ specialized role for the $\beta 5$-subunit in cell signaling was suggested, when $\beta 1$ and $\beta 2$ isoforms were shown to interact with $\alpha$-subunits from the $\alpha_{6}, \alpha_{4}$ and $\alpha_{4}$ families, whereas the structurally divergent $\beta 5$-subunit only interacts with $G \alpha_{4}{ }^{23}$ Although it is likely that most $\beta \gamma$ combinations can form, there is evidence that $\beta \gamma$ interactions may not be completely random. ${ }^{20} \beta \gamma$ dimers are tightly associated with the membrane and require detergent for extraction. Different isoprenyl groups are attached to different $\gamma$ subunit. When isoprenylation of $\gamma$ subunits is blocked, an inactive and soluble form of the $\beta \gamma$ dimer is produced. Several functions have been ascribed to the $\beta \gamma$ dimer: First, promoting the association of $\alpha_{\mathrm{GDP}}$ with the receptor. Second, decreasing nucleotide dissociation from $\alpha_{\mathrm{GDP}}$, thereby decreasing inadvertent signal transduction through the $\mathrm{G}$ protein cycle. Third, anchoring the $\mathrm{G}$ protein to the cytosolic surface of the membrane and fourth, direct roles in activating or inhibiting signal transduction pathways. The expression of specific $\beta$ and $\gamma$ subunits shows regional, tissue and developmental selectivity, emphasizing their active role in signal transduction. Moreover, $\beta$ subunits display specifity for receptor species. Details on the specificity of $\beta \gamma$ subunits for the different signal transduction pathways are rapidly emerging, and it is becoming abundantly evident that $\beta \gamma$ subunits are as important as $\alpha$ subunits in regulating the activity of cellular effector mechanisms, as pointed out later in this chapter.

As described later, activation of heterotrimeric G proteins by GPCRs leads to the formation of free $\alpha$-GTP and $\beta \gamma$-subunits that are able to interact with a diverse array of effector enzymes and/or ion channels to stimulate or inhibit the activity of these effector proteins. Within the $\alpha$ subunit resides the binding site for guanine nucleotides, a GTPase catalytic activity, amino acid residues that are substrates for adenosine diphosphate (ADP)-ribosylation by bacterial toxins (cholera and pertussis toxins), and sites involved in interactions with both receptors and effector mechanisms. Thus, most attention has focused on the $\alpha$ subunit. 
Activated $\alpha$-subunits are known to interact selectively with a specific set of effector molecules. For example, activated $\alpha_{3}$ and $\alpha_{1}$-subunits regulate intracellular cyclic AMP (cAMP) levels by mediating the activation and inhibition, respectively, of distinct isoforms of adenylyl cyclase. All $\alpha$ subunits of the $\mathrm{G}_{\sqrt{ } \text { II }}$ family can activate different isoforms of PLC $\beta$ (resulting in the breakdown of phosphatidylinositol 4,5-bisphosphate and the generation of the second messengers, inositol $(1,4,5)$ trisphosphate and diacylglycerol), and $\alpha_{1}$ mediates the stimulation of cyclic GMP phosphodiesterase. ${ }^{16,17}$ It has become clear over the past years that the $\beta \gamma$-subunits, in a fashion similar to the activated $\alpha$-subunits, can also bind to a great variety of effector molecules to regulate their activity. In many cases $\alpha$ - and $\beta \gamma$-subunits bind to the same effectors to mediate opposing or synergistic effects. However, there are also examples in which distinct effector molecules are exclusively regulated by either $\alpha$ - or $\beta \gamma$-subunits. ${ }^{20}$ Most effector molecules are members of protein families, and the individual members of these families frequently show different patterns of regulation by $\alpha$ - and $\beta \gamma$-subunits. For example, whereas all eight isoforms of adenylyl cyclase can be stimulated by $\alpha_{5}$ two isoforms, AC-II and AC-IV, can be activated synergistically by both $\alpha_{4}$ and $\beta \gamma$-subunits. ${ }^{24} \mathrm{On}$ the other hand, the activity of one isoform, AC-I, is inhibited by $\beta \gamma$ complexes. The family of PLCB isoforms (PLCB1-4) provides another example for convergent stimulation of effector molecules by both $\alpha$ - and $\beta \gamma$-subunits. In contrast to the effects of $\beta \gamma$ complexes on the activity of different adenylyl cyclase isoforms, the $\beta \gamma$ effects on different PLC $\beta$ species can be observed independently of activated $\alpha$-subunits. ${ }^{25.26}$ However, the different PLC $\beta$ subtypes vary considerably in their sensitivity to stimulation by different subtypes of the $\alpha_{\mathbf{v}} 11$ family and by $\beta \gamma$-subunits. Because of the diversity of $\mathrm{G}$ protein subunits and downstream effector molecules, the pattern of biochemical responses of a particular cell to stimulation of a given GPCR is quite complex. The nature of the observed responses critically depends on which $\mathrm{G}$ protein heterotrimers are recognized by the receptor and which specific effector molecules are present in the studied cell or tissue. Moreover, the magnitude of these responses is also modulated by the relative concentrations of the various components of the different receptor/G protein signaling pathways.

\section{Structural features of heterotrimeric $\mathbf{G}$ proteins}

The atomic structures of two different $G$ protein heterotrimers, $G \alpha_{i 1} \beta_{1} \gamma_{2}{ }^{27}$ and $G \alpha_{4} \beta_{1} \gamma_{1}{ }^{28}{ }^{28}$, have been resolved by $\mathrm{X}$-ray cristallography. The two structures show that the $\alpha$-subunit consists of two structural components between which the bound guanine nucleotide is deeply buried.

The $\beta$-subunit consists of an $\mathrm{N}$-terminal helical domain and seven similar $\beta$-sheets, each composed of four antiparallel $\beta$-strands that form the blades of a "propeller" structure. The $\gamma$-subunit binds to one side of the $\beta$ - propeller. The structure of the free $\beta \gamma$-complex is virtually identical to that found in the $\mathrm{G}$ protein heterotrimer. ${ }^{27,28}$ Therefore, because only free $\beta \gamma$-dimers can interact with downstream effectors, $\alpha$-subunits can be considered negative regulators of $\beta \gamma$ function. Whereas there appear to be no direct interactions between the $\alpha$ - and $\gamma$-subunits, extensive contacts occur between $\alpha$ and $\beta$. To understand the molecular mechanisms involved in receptor mediated $G$ protein activation, it is essential to know how the $\mathrm{G}$ protein heterotrimer is positioned relative to the plasma membrane. $G$ protein $\alpha$ - and $\beta$-subunits carry lipid modifications that are known to be critical for the attachment of $\mathrm{G}$ protein heterotrimers to the plasma membrane. The surface-exposed $\mathrm{C}$ terminus of $\mathrm{G \alpha}$ is thought to be directly involved in receptor binding. Thus, the $\mathrm{N}$ - and $\mathrm{C}$-termini of $\mathrm{G} \alpha$ and the $\mathrm{C}$-terminus of $\mathrm{G} \gamma$ define a surface on the $\mathrm{G}$ protein heterotrimer that is predicted to contact the plasma membrane and/or the receptor protein.

\section{Ligand binding and receptor activation}

Several distinct modes have been observed for high affinity ligand binding: to the TM core exclusively (photon, biogenic amines, eicosanoids and moieties of lipids (lysophosphatidic acid and sphingosine-1 phosphate)), to both the core and exoloops (peptides $\leq 40$ amino acids), to exoloops 
and $\mathrm{N}$-terminal segment (polypeptides $\leq 90$ amino acids), or exclusively to the $\mathrm{N}$-terminal segment (glycoproteins $\geq 30 \mathrm{kDa}$ ). The distinction between ligand binding and receptor activation is supported by the existence of antagonists that competitively inhibit agonist binding. Interactions of ligands and receptors seem to involve hydrogen bonds, ion pairs, and hydrophobic contacts.

Receptor activation may be divided into at least three steps, signal generation, TM signal transduction, and signal transfer to cytoplasmic signal molecules. For example, in biogenic amine receptors, TM III is believed to be the primary site for ligand binding whereas TMs V and VI are the signal generation site

Small ligands bind in a pocket located in the extracellular half of the transmembrane domain formed by the helical bundle. Nearly all sites that have been identified as modulating ligand binding lie in the lower two thirds of the membrane and point inward toward the other helices. With the exception of helix I, all helices appear to contribute to the ligand-binding site with strong involvement of helices III, V, VI and VII and a smaller contribution from II and IV. Because of the homology of the transmembrane domains among the GPCRs, one would expect a certain pattern of conservation of key binding residues across the family of receptors. This has proven to be the case. However, binding of peptide ligands differ somewhat from for example monoamide ligands because of the wide range of size. Given the larger surface area of peptides, it is probable that extracellular domains are also involved. ${ }^{29}$

\section{Receptor domains involved in $\mathbf{G}$ protein-coupling}

Data mainly derived from studies with muscarinic or adrenergic receptors strongly suggest that the selectivity of $\mathrm{G}$ protein recognition is determined by multiple intracellular receptor regions. The most critical regions are the second intracellular loop (i2) and the amino- (Ni3) and carboxytermina (Ci3) segments of the third intracellular loop. ${ }^{4}$ These regions are thought to act in a cooperative fashion to dictate proper $\mathrm{G}$ protein recognition and efficient $\mathrm{G}$ protein activation. ${ }^{30,31} \mathrm{~A}$ general principle that emerged from these studies is that the relative contributions of different intracellular receptor domains to the selectivity of $\mathrm{G}$ protein recognition varies among different classes of GPCRs and even among structurally closely related members of the same receptor subfamily. It has

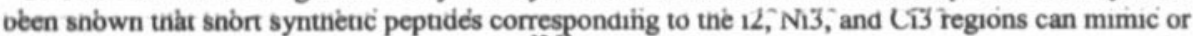
inhibit receptor interactions with $\mathrm{G}$ proteins. ${ }^{32,33}$ Several of the investigated peptides can activate $\mathrm{G}$ proteins directly, suggesting that these receptor derived sequences are not or at least not fully accessible to the $\mathrm{G}$ protein heterotrimer in the inactive state of the receptor. This is consistent with the concept that receptor activation is likely to involve an "opening" of the intracellular receptor surface, which enables the $G$ protein to contact previously buried receptor residues that are critical for $\mathrm{G}$ protein recognition and activation.

Regarding the G protein domains/residues predicted to interact with GPCRs, a large body of evidence indicates that the $\mathrm{C}$-terminal portions of $\mathrm{G} \alpha$ can directly contact the receptor protein ${ }^{11}$ and that the $\mathrm{C}$-terminal five amino acids of $\mathrm{G} \alpha$ subunits play a key role in dictating the specificity of receptor/G protein-coupling. ${ }^{34}$ Receptor coupling selectivity of $\mathrm{G}$ protein $\alpha$ subunits can be altered by single amino acid substitution in this region. ${ }^{34}$ Although precise positions of the $\mathrm{C}$-terminal $\mathrm{G} \alpha$ residues that are intimately involved in determining the selectivity of receptor/G protein interactions vary between different functional classes of $G \alpha$ subunits, in both $\alpha_{V_{0}}$ and $\alpha_{\alpha / 11}$ subunits, the -3 residue is of fundamental importance for proper receptor recognition. The residues at this position are perfectly conserved in individual $\mathrm{G} \alpha$ subfamilies and can correctly predict the coupling profile of a given $\mathrm{G} \alpha$ subunit. However the $\mathrm{C}$-terminal segment of $\mathrm{G} \alpha$ is not the only structural determinant of receptor/G protein-coupling selectivity. The $\mathrm{N}$-terminal portion of $\mathrm{G} \alpha$, which lies adjacent to the functionally critical $\mathrm{C}$-terminus of $\mathrm{G} \alpha$, has been shown to contribute also to receptor binding and the selectivity of receptor/G protein interactions. For example, the $\mathrm{N}$-terminal six amino acid extension characteristic for $\alpha_{4}$ and $\alpha_{11}$ subunits is critical for constraining the receptor coupling selectivity of these proteins. ${ }^{35}$ When this sequence was removed the resulting mutant $\alpha_{4}$ subunit gained the ability to be activated by various different $G_{3}$ and $G_{v_{0}}$-coupled receptors that 
normally do not couple efficiently to wild-type $\alpha_{\mathrm{s}}$.

Despite the fundamental importance of various regions of $G \alpha$ for proper receptor recognition, considerable evidence suggests that the $G$ protein $\beta \gamma$ complexes can also modulate the selectivity of receptor/G protein interactions. ${ }^{20.36} \mathrm{G}$ protein $\beta y$ subunits increase the affinity of GPCRs for the $G$ protein $\alpha$ subunits, and residues on the $\beta$-subunit, as well as on the $\gamma$-subunit may contribute to receptor binding. Whereas the different $\beta$-subunits share a high degree of amino acid homology, the various $\gamma$-subunits are structurally quite diverse, as mentioned before. The structural variability observed among $\gamma$-subunits may be relevant for regulating receptor/G protein-coupling selectivity. The isoprenoid moiety attached to the $\mathrm{C}$-terminus of $\gamma$-subunits, which is predicted to be located on the same face of the $\mathrm{G}$ protein heterotrimer as the $\mathrm{C}$ - and $\mathrm{N}$-termini of the $\alpha$ subunit, may participate in regulating receptor/G protein interactions. ${ }^{3.39}$

For the interested reader, a detailed overview of the relative contribution of different structural parts of GPCRs and G proteins for coupling selectivity is provided by Wess. ${ }^{40}$

\section{Proposed models for $\mathbf{G}$ protein activation}

\section{$G$ protein cycle}

All GPCRs are thought to operate through a similar molecular mechanism. The binding of extracellular ligands to GPCRs causes as yet poorly defined conformational changes in the receptor protein, changes that promote the receptor's association with distinct classes of the heterotrimeric $G$ proteins. The first model for the basic $G$ protein activation cycle (Fig 3) described that in the resting state, the G protein exists in its trimeric form with GDP occupying the nucleotide binding site on the $\alpha$ subunit. The guanine nucleotide, which is buried in a cleft between the $\alpha$ helical and the raslike domain of $\mathrm{G} \alpha$, is predicted to be located approxiamtely $30 \mathrm{~A}$ away from the plasma membrane. Because it is unlikely that the nucleotide can be contacted by the intracellular loops of the receptor protein (which are rather short in many cases), GPCRs are thought to trigger GDP release by an allosteric mechanism

Activation of G proteins involves the release of GDP and rapid binding of GTP to the $\alpha$ subunit. The binding of GTP induces the dissociation of receptor and $\mathrm{G}$ protein and the dissociation of the $\mathrm{G}$ protein into its $\alpha$ and $\beta \gamma$ subunits. The $\alpha_{\text {GTP }}$ and/or $\beta \gamma$ complex then interacts with various effectors (e.g. enzymes, ion channels), stimulating or inhibiting their activity. The activity of the $\alpha_{0 \mathrm{~T}}$ complex is terminated by hydrolysis of GTP by an intrinsic enzymatic activity. In the GDP-bound state, the $\alpha$ subunit reassociates with $\beta \gamma$ subunits and is subject to reactivation.

\section{G protein activation}

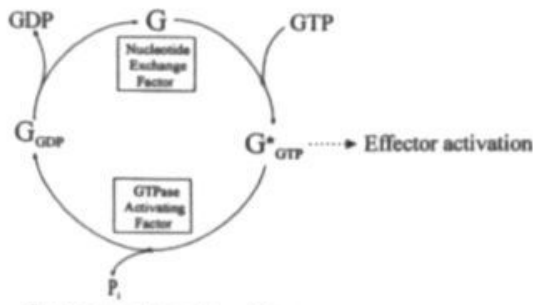

G protein inactivation
Figure 3: Cassel-Selinger G protein activation cycle Agonist-bound receptors (AR) activate GDP-bound (inactive) $G$ proteins ( $G$ ) by facilitating GDP-GTP exchange. Switching between the two states is controlled by nucleotide exchange and GTPase activating factors. In the resting state, $G$ proteins are $G D P$-bound and inactive $\left(G_{G D P}\right)$. GDP release (slow, reversible) is followed by GTP binding and $G$ protein activation $\left(G^{*}\right.$ GTP $)$. The active complex is unstable: the $G$ protein is a GTPase and deactivates spontaneously following irreversible GTP hydrolysis.

The association of $\mathrm{G}$ proteins and receptors has consequences for the receptor's binding properties: Receptors coupled to $\mathrm{G}$ proteins have a higher affinity for receptor agonists than receptors not coupled to $\mathrm{G}$ proteins. Thus, inclusion of guanine nucleotides in in vitro binding assays lowers agonist affinity by effectively dissociating receptor $G$ protein complexes. This guanine nucleotide-sensitivity of agonist binding is frequently used as an indication of receptor-G protein interactions. 
There are two critical points in the G protein cycle: the release of GDP from the $\alpha$ - subunit and the hydrolysis of GTP catalyzed by the $\alpha$ subunit. The lifetime of the $\alpha_{\text {GTP }}$ complex is several seconds, but the basal rate of GDP dissociation from the $\alpha$ subunit is even slower. Thus, under resting conditions most of the G protein is in the inactive, GDP-bound state. GDP release is catalyzed by an interaction with an activated neurotransmitter, sensory or hormonal receptor. The binding of an agonist to a receptor induces a conformational change in the receptor that promotes its association with the $\mathrm{G}$ protein trimer. As a consequence of its association with the activated receptor, there is a conformational change in the $\alpha$ subunit, and GDP is released. This release is a crucial step in signal transduction through $\mathrm{G}$ proteins.

The second control point is in the hydrolysis of GTP, which terminates G $\alpha$ regulation of the effector. This turnover is normally quite low. In the small signaling G proteins such as RAS, GTP hydrolysis requires the action of a GTP activating protein (GAP). It has also been demonstrated that an effector such as phospholipase $\mathrm{C}$ can stimulate $\mathrm{G}$ protein GTPase activity. Thus, effectors can mediate the fast physiologic deactivation of $\mathrm{G}$ protein mediated signaling, and represent a selflimiting mechanism. Another possibilty is that the $\alpha$ subunit incorporates a GAP-like domain.

\section{The ternary complex model}

Agonist-bound receptors (AR) activate GDP-bound (inactive) G proteins (G) by facilitating GDP-GTP exchange. This reaction is catalytic (i.e. each stimulated receptor activates several G proteins in turn). In the absence of GTP, agonists discriminate two GPCR binding states: the high and low affinity binding site. The ability of the ligand to activate $\mathrm{G}$ proteins is related to its ability to discriminate the two receptor states ${ }^{4, A 2}$, and the agonist potency, which is measured by the method of partial receptor activation $\left(\mathrm{EC}_{50}\right)$, can correlate with either the dissociation constants for the high or low affinity binding site, depending on the system studied. ${ }^{43}$ The ternary complex motel shown in Fig 4. is adequate for analysis of binding studies; in the absence of GTP, it predicts the existence of two agonist-binding states, high affinity corresponding to agonist-receptor-G protein (ARG) and low affinity corresponding to agonist-receptor (AR). The same model is used increasingly to define functional properties, including agonist efficacy and potency, which is not appropriate as pointed out later. 


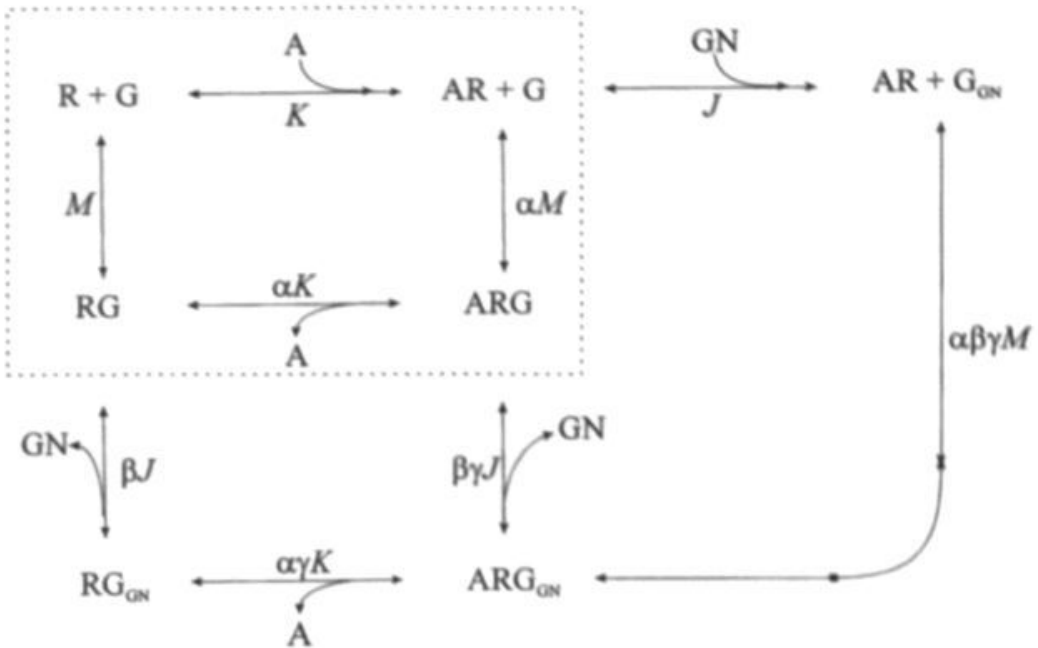

Figure 4: The ternary complex model is shown in the box. $R$ represents the receptor, $G$ the $G$ protein, $A$ the corresponding agonist, and the guanyl nucleotide (GDP or GTP) is represented as $G N$. The constants $\mathrm{K}, \mathrm{J}$ and $\mathrm{M}$ are affinity constants, and $\alpha \beta$ and $\gamma$ represent allosteric factors. Free, uncoupled receptors have low affinities for the agonist and $G$ protein (represented as $\mathrm{K}$ and M). Agonists increase the average receptor's affinity for the $G$ protein (from $\mathrm{M}$ to $a \mathrm{M}$ ) and vice versa. The allosteric factor $\alpha$ is therefore greater than I. The agonist equilibrium dissociation constants from ARG (agonist-receptor-G protein complex) are $\mathrm{K}_{H}=I /$ aK and $\mathrm{K}_{L}=I / \mathrm{K}$. Guanyl nucleotides inhibit the binding of agonists; $\alpha \gamma \mathrm{K}$ is lower than $\alpha \mathrm{K}$ so $\gamma$ must be lower than 1. The affinity of $G N$ for ARG $(\beta \gamma)$ is therefore lower than the affinity of $G N$ for $R G(\beta \gamma)$ : agonists inhibit the recognition of nucleotides by receptor-coupled $G$ proteins.

\section{The extended ternary complex model}

For GPCRs it is widely believed that the critical event in agonist action is the stabilization of the ternary complex of agonist/receptor/G protein ${ }^{44}$, and the better this ternary complex is stabilized, the more efficaceous is the agonist. First, the agonist interacts with the free receptor to form an agonist/receptor complex. This then interacts with the $\mathrm{G}$ protein leading to the formation of the ternary complex, the activated state. If the formation of this activated state determines the efficacy of signaling, the difference in free energy between the agonist/receptor complex in the ground and activated states determines efficacy. Since binding of the agonist to the free receptor uses some of the amino acid side chains that interact with the agonist in the activated state, it seems likely that it stabilizes the receptor in a conformation that partly resembles the activated state of the receptor. Therefore, the originally proposed ternary complex model is extended with a second conformation of the receptor $\left(\mathrm{R}^{*}\right)$, that couples to the $\mathrm{G}$ protein; free receptor can not couple in this model. Interaction with a $\mathrm{G}$ protein also can stabilise $\mathrm{R}^{*}$, as seen from agonist-independent activation observed for some receptors. ${ }^{44}$

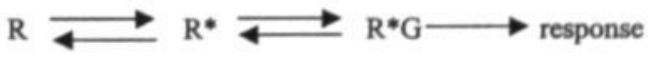

The extended ternary complex model. The receptor exists in $R$ and $R^{*}$ states, and the $R^{*}$ state is a partly activated state of the receptor that can couple to the $G$ protein to form $R^{\bullet} G$, the activated species. An agonist stabilises the activated state by binding with higher affinity to $R^{\bullet}$ than to $R$ and with higher affinity to $R^{*} G$, than to $R$. 
The ability of the ligand to stabilize ARG is often considered to be equivalent to its ability to activate $\mathrm{G}$ proteins. ${ }^{42, A 3}$ The ternary complex equations consider only three $\mathrm{G}$ protein species: $\mathrm{G}$, RG, and ARG. By using these equations to describe $G$ protein activation by GTP, it is implicitly assumed that GTP binding does not significantly affect the $\mathrm{G}$ protein population available to the receptor (i.e. the activated $G$ protein concentration remains very low even at saturating agonist concentrations). Because agonist can only affect receptor-coupled $\mathrm{G}$ proteins, their $\mathrm{EC}_{50}$ value must reflect their high affinities for the ternary complex ARG; this model can however not explain G protein activation through the low affinity, uncoupled receptor state. ${ }^{43,46}$

The ternary complex model has therefore been extended to the quaternary and quinternary complex models including recognition of guanyl nucleotides by the $\mathrm{G}$ protein ${ }^{47}$ and the effect of the nucleotides on the interaction of $\mathrm{G} \alpha-\mathrm{G} \beta \gamma$ subunits. ${ }^{48}$ Allosteric interactions are always reciprocal at equilibrium; because GTP inhibits agonist binding ${ }^{49}$, agonists must decrease the affinity of GTP for RG. Agonists cannot affect the nucleotide-binding properties of uncoupled $G$ proteins at equilibrium. Thus, a kinetic model of $\mathrm{G}$ protein activation was proposed (fig 5).

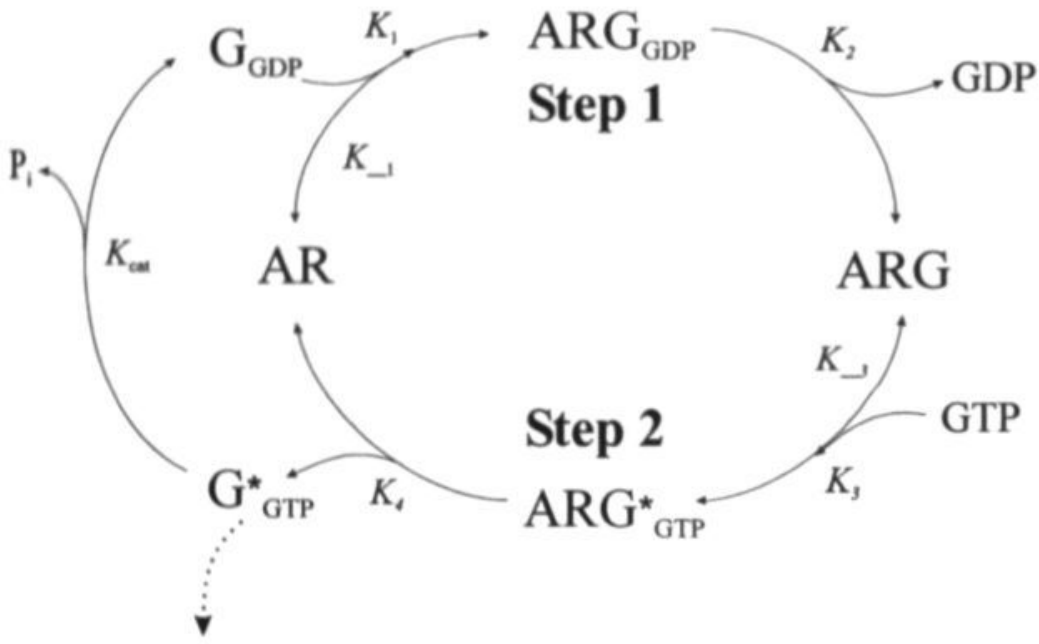

\section{Effector activation}

\section{Figure 5: Kinetic model of receptor-assisted $G$ protein activation}

Activated, agonist-bound receptors (AR) catalyse G protein activation in a two-step reaction. Stepl: agonists accelerate the GDP dissociation rate. Agonist-bound receptors must be able to recognize and affect inactive, GDP-bound $G$ proteins $\left(G_{G D P}\right)$. Within the ternary complex ARG (agonistreceptor- $G$ protein), the agonist is the stabilizing factor in the absence of GTP (see figure 3 ). causing the dissociation of GDP. Step 2:GTP recognizes the receptor-coupled, empty G protein, which results in the formation of the $A R G^{*}{ }_{\text {GIP }}$ complex. This quaternary complex is very unstable; the dissociation of $G^{\bullet} \mathrm{Gr}$ from the complex allows the agonist-bound receptor to enter another round of $G$ protein activation and also avoids the GTP-binding inhibition that would be observed if agonist-bound receptors wre able to trap empty $G$ proteins. The activated $G$ protein $G^{\bullet} G_{P}$ interacts with its cognate effectors and deactivates spontaneously by hydrolysing GTP to GDP. The rate constants $k_{1}, k_{2} k_{3}$ and $k_{4}$ measure the $G_{G D P}$ recognition, GDP release, GTP binding and GTP release; $k_{1}$ and $k_{3}$ measure the reverse (re-dissociation of $G$ protein and GTP) rate constants; $k_{\text {cat }}$ measures the rate of GTP hydrolysis. Abbreviation: $P_{b}$ inorganic phosphate 
G protein activation by GPCRs is a two step reaction (Fig 4) (1) the recognition of inactive G protein and GDP release is followed, in the presence of GTP, by (2) GTP binding and activated G protein release. Several authors describe that agonists catalytically induce $\mathrm{G}$ protein activation and that the agonist's $\mathrm{EC}_{50}$ values depend on $\mathrm{G}$ protein concentration. ${ }^{30.52}$ This can be explained as follows: if the $\mathrm{G}$ protein concentration is low, high agonist concentrations are required to recognize and stimulate uncoupled (low affinity) receptors, which in turn recognize GDP-bound G proteins and allow GDP release. If the G protein concentration is high, pre-coupled (high affinity) receptors accumulate; agonists might nevertheless stimulate $\mathrm{G}$ protein activation if they facilitate GTP binding or activated $\mathrm{G}$ protein release.

It is worth to notice that each receptor interacts with, at most, one $\mathrm{G}$ protein at any time but might activate several $\mathrm{G}$ proteins per minute.

If the G protein and GTP concentrations are saturating, all transiently uncoupled receptors (i.e. $\mathbf{R}$ and $A R$ ) will immediately encounter a new inactive $G$ protein ( $G_{O D P}$ ) and any transiently emptied $G$ proteins (i.e. RG and ARG) will immediately be re-occupied (by GTP). The G protein activation cycle (Fig 5) will turn faster if the intermediate complexes $\mathrm{ARG}_{\mathrm{opp}}$ and $\mathrm{ARG}{ }^{\bullet} \mathrm{or}$ do not accumulate; that is, if the GDP and activated $\mathrm{G}$ protein dissociation rate constants $\left(\mathbf{k}_{2}\right.$ and $\mathbf{k}_{4}$ in Fig 5 ) are large. ${ }^{50}$ If the $\mathrm{G}$ protein recognition is rate limiting, agonists might, in addition, stimulate $\mathrm{G}$ protein activation by facilitating the steady state receptor $G$ protein interaction. The definition of agonist efficacy, which measures the agonist's effect on the $\mathrm{G}$ protein activation rate therefore depends on the G protein and GTP concentration in the system. ${ }^{50}$ At low G protein concentrations, where agonists will stimulate $\mathrm{G}$ protein activation mainly through the low affinity state, their $\mathrm{EC}_{\mathbf{5}}$ value should be equivalent to $\mathrm{K}_{\mathrm{L}}$ the $\mathrm{K}_{\mathrm{D}}$ (equilibrium dissociation constant) of the low-affinity complex AR. In contrast, when $\mathrm{G}$ protein concentrations are high, agonists that not only speed up the $\mathrm{G}$ protein activation cycle but also facilitate the $\mathrm{G}$ protein recognition at steady state apparently might activate $\mathrm{G}$ proteins through high-affinity receptors. The $\mathrm{EC}_{\mathbf{s}_{0}}$ value expected at saturating $\mathrm{G}$ protein concentrations is not strictly equivalent but close to the high affinity (ternary complex) $\mathrm{K}_{\mathrm{D}}$ value $\mathrm{K}_{\mathrm{H}}$.

Summarized, the non equilibrium model is necessary to explain the observations that agonists catalyse GTP binding whereas GTP inhibits agonist binding, and that agonists activate G proteins either through high affinity or low affinity receptors, depending on the receptor and tissue studied. This model predict that $\mathrm{G}$ protein activation is fastest if the quaternary complexes $A R G_{\mathrm{GDP}}$ and $\mathrm{ARG}^{*} \mathrm{GTP}$ are unstable so that GDP and the activated $\mathrm{G}$ protein $\left(\mathrm{G}^{*} \mathrm{GTP}\right)$ dissociate rapidly from the ternary complex and from the agonist-receptor complex, respectively. Agonists that stabilize the ternary complex ARG increase the rate of dissociation of GDP from ARG ${ }_{\mathrm{CDP}}$, this is correlated with their efficacy, if the GDP release is rate limiting.

\section{Mechanisms involved in receptor-mediated $\mathbf{G}$ protein activation}

GPCR activation does not involve major conformational rearrangements of the receptor protein. ${ }^{4}$ It is accompanied by a relatively small outward movement of the cytoplasmic portion of TM III, a somewhat more pronounced outward movement of the cytoplasmic end of TM VI (as compared with TM III) associated with a clockwise rotation (viewed from the cell interior) of approximately $30^{\circ} 53$ and by yet undefined structural changes in the i2 loop. ${ }^{54}$ Relative movements between TM III and VI are involved in converting GPCRs into their active state, presumably by causing an "opening" of the intracellular receptor surface that enables the $G$ proteins to interact with previously inaccessible receptor residues, primarily located within the i2 and i3 loops. 4,11

Over the past few years, a great number of spontaneous and induced mutant GPCRs have been identified that can activate their target $\mathrm{G}$ proteins even in the absence of activating ligands. ${ }^{2,4,55}$ The identification of such mutations has led to the delineation of the prior described "extended ternary complex model". Many activating mutations are known to occur in the C-terminal segment of the i3 loop and the endofacial half of TM VI. However, such mutations can also be found in other TM domains and intracellular loops, as well as in extracellular portions of the receptor proteins. ${ }^{55}$ Considerable evidence support the view that all these different mutations induce the $R^{*}$ 
conformation by interfering either directly or indirectly with the proper packing of the TM receptor core, thus mimicking, at least partly, the opening of the intracellular receptor surface predicted to be induced by agonist ligands. Studies with constitutively active rhodopsin mutants indicate that a salt bridge between Lys 296 in TM VII and Glu113 in TM III maintains the protein in a constrained, inactive state, and that mutations that interfere with the formation of this salt bridge result in constitutive receptor activation. ${ }^{56}$ Molecular interactions between TM V and VI, including their cytoplasmic extensions, also appear to play an important role in maintaining GPCRs in the inactive state. $^{57.59}$

\section{Activation of $\mathbf{G}$ proteins}

The most important domains for activation of $\mathrm{G}$ proteins appear to be the intracellular areas, including the intracellular domain of transmembrane domain III, the cytoplasmic loop between transmembrane domains V and VI, and the carboxy-terminal region near transmembrane domain VII. ${ }^{60}$. Asp ${ }^{79}$ in transmembrane domain II is one of the most highly conserved residues throughout the GPCR family. Substitution with alanine decreases agonist efficacy with no change in antagonist binding consistent with a role for this residue in promoting receptor activation. ${ }^{61}$

A disulfide bridge between the cysteine at the extracellular end of transmembrane domain II and a cysteine in the extracellular loop between transmembrane domain IV and V occurs in more than $90 \%$ of GPCRs. Apparently its role is to stabilize the active form of the receptor. There appear to be specific sequence pattern for the association with the various $\mathrm{G}$ proteins. Coupling to a $\mathrm{G}$ protein responsible for a particular effect on an intracellular signalling pathway requires a specific structure in the cytoplasmic loops and carboxy-terminus of the GPCR. For example, inhibition of adenylate cyclase by activation of the Gi-protein requires a long third cytoplasmic loop and a short carboxyterminus, whereas stimulation of phosphoinositide hydrolysis via the Gq-protein requires a short third cytoplasmic loop and a long carboxy-terminus, and stimulation of adenylate cyclase by

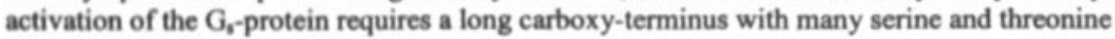
residues. However, there is a great promiscuity, in that a single receptor subtype is capable of activating several different $\mathrm{G}$ proteins in the same cell.

\section{Structural basis of receptor/G protein-coupling selectivity}

To understand the physiological actions of a given GPCR, it is essential to identify the specific G proteins with which it is able to interact. Such studies have shown that, when activated by the appropriate ligands, most GPCRs can recognize and activate only a distinct subset of the many structurally similar $\mathrm{G}$ protein heterotrimers that are expressed in a cell. ${ }^{4.36}$ Over the past few years, the G protein-coupling profiles of most GPCRs have been elucidated in considerable detail. Besides the structural information encoded by the receptor and $\mathrm{G}$ protein primary sequences, other factors including receptor ( $G$ protein) density, and perhaps restricted localization of specific $\mathrm{G}$ protein heterotrimers and receptors in the plasma membrane, may also contribute to the observed degree of coupling selectivity. ${ }^{36,62}$

On the basis of their $\mathrm{G}$ protein-coupling preference, GPCRs can be broadly subclassified into $\mathrm{G}_{\boldsymbol{\varepsilon}}$ -

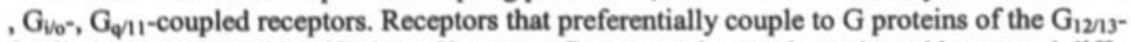
family have not been identified yet. However, $\mathrm{G}_{12}$ s -proteins can be activated by several different GPCRs, such as thrombin, thromboxane $\mathrm{A}_{2}$, or TSH receptors, which are also capable of efficiently activating other classes of $\mathrm{G}$ proteins. ${ }^{63,64} \mathrm{It}$ has also become clear that most GPCRs, although preferentially linked to a certain subfamily of $G$ proteins, can also couple to other classes of $G$ proteins, usually, however, with reduced efficiency. ${ }^{36,65}$ Therefore it must be emphasized that the $G$ protein-coupling preference displayed by an individual GPCR is relative rather than absolute. Many primarily $\mathrm{G}_{3}$-coupled receptors can also stimulate $\mathrm{G}_{9} / 1$-protein $\mathrm{s}^{36}$ and many receptors that preferentially couple to $\mathrm{G}_{v_{0}}$-proteins are able to interact with $\mathrm{G}_{\mathrm{w}}$, particularly when the receptors are expressed at relatively high levels and/or high concentrations of activating ligands are used. The most promiscuous GPCR studied to date appears to be the TSH receptor, which has been shown to couple to members of all four major classes of $G_{\text {proteins. }}{ }^{64}$ Conversely, $G_{15}$ and $G_{16}$ show very 
little receptor selectivity and can be activated by most GPCRs studied to date. ${ }^{66}$ The potential physiological relevance of such receptor-coupling promiscuity remains to be determined. Although in most cases in which sufficient data are available it appears that receptors are able to interact with most or all members of their preferred G protein family, there is evidence that some GPCRs are able to distinguish between different members of the $\mathrm{G}_{9 / 1}$-family. ${ }^{6,08}$

Interestingly, mutagenesis studies with GPCRs have shown that point mutations in regions that are unlikely to be part of the receptor/G protein interface can selectively abolish receptor coupling to one class of $\mathrm{G}$ proteins. ${ }^{69.70}$ The most straightforward explanation for these observations is that the conformational and structural requirements for productive coupling vary among different receptor/G protein complexes. Because all GPCRs and all heterotrimeric $\mathrm{G}$ proteins are thought to share a similar molecular architecture, it is likely that the overall geometry of different receptor/G protein complexes is generally conserved. However, the amino acids predicted to determine the coupling properties of a specific member of a given receptor subfamily are usually not well conserved among other GPCRs that display a similar G protein-coupling profile. ${ }^{5}$ In addition, there are different structural classes of GPCRs that share little or no sequence homology, but appear to couple to the same set of $\mathrm{G}$ proteins. Therefore, it is not possible at present to predict the $\mathrm{G}$ proteincoupling profile of a newly cloned GPCR based simply on its primary sequence, unless it shares a very high degree of sequence homology with a receptor whose $\mathrm{G}$ protein-coupling preference is already known. However, despite the enormous diversity of GPCR sequences, it is possible that the relative positions of the functionally critical receptor domains (amino acids) are generally conserved.

\section{Effects of post-translational modifications on receptor/G protein-coupling selectivity Receptor phosphorylation}

Work with the $\beta_{2}$-adrenergic receptor indicated that the selectivity of receptor/G proteincoupling may also be regulated by receptor phosphorylation. Protein kinase A (PK.A) phosphorylation was shown to reverse the $\mathrm{G}$ protein-coupling profile for those receptors. Whereas unphosphorylated receptors activated primarily $\mathrm{G}_{\mathrm{s}}$, the phosphorylated receptor showed a drastic reduction in its ability to couple to $\mathrm{G}_{3}$ and gained the ability to interact with $\mathrm{G}_{\mathbf{i}}$ with increased efficacy. ${ }^{71,72}$ Therefore, PKA phosphorylation might represent a switch mechanism for regulating the receptor/G protein-coupling selectivity.

\section{Receptor palmitoylation}

In addition, receptor palmitoylation may play a role in regulating the coupling selectivity of dually coupled GPCRs. Using endothelin peptide receptors it has been shown that palmitoylation is essential for coupling to $\mathrm{G}_{\mathrm{q}}$ and $\mathrm{G}_{\mathrm{i}}$-proteins, whereas ligand-induced stimulation of $\mathrm{G}_{\mathbf{3}}$ was unaffected by the lack of receptor palmitoylation. ${ }^{73,74}$

\section{Functional regulation of GPCRs}

For most GPCRs, agonist stimulation is followed by desensitization, in which there is a reduction in effector stimulation over time despite the continued presence of the stimulus. Regulation of GPCRs is divided into two distict time frames. In the short term especially alterations in the phosphorylation state alter the function of the receptor. For example, following prolonged exposure of the beta-adrenoceptor to agonist, the receptor becomes phosphorylated. ${ }^{\text {th }}$ The phosphorylated receptor is functionally uncoupled from the $\mathrm{G}$ protein and is therefore less capable of activating the corresponding effectors. ${ }^{76}$

Long-term regulation involves transcriptional activation, posttranscriptional effects (e.g. changes in mRNA stability), and posttranslational regulation of the turnover of the receptor. 


\section{Summary}

Recent experimental results have modified profoundly our understanding of $\mathrm{G}$ protein-mediated transmembrane signaling. The concept of signal transduction patways in a linear fashion, i.e. one receptor coupling to one $G$ protein that activates one effector, is inadequate to explain recent findings. The majority of seven transmembrane spanning receptors interact with diverse $\mathrm{G}$ proteins and elicit multiple intracellular signals. Interaction of a single $\mathrm{G}$ protein with a given receptor in a certain cell, however, may be regulated by a high degree of selectivity. $G$ protein-mediated signal transduction can be seen as a complex, highly organized signaling network with diverging and converging transduction steps at the ligand-receptor, receptor-G protein, and $\mathrm{G}$ protein-effector composition. Although, $\mathrm{G}$ proteins are termed according to their $\alpha$-subunit which gained most attention for their important role in interactions with receptor and effector structures, our knowledge of $\mathrm{G} \beta \gamma$ 's role in signal transduction has advanced from the assumption that it simply anchored and regulated $\mathrm{G} \alpha$ to the demonstration that the $\beta$-isoform in the $\beta \gamma$ dimer also can determine the specificity of signaling at both effectors and receptors.

A considerable task that remains is to resolve the atomic structure of a GPCR or, even better a receptor/G protein complex. Although such information would bring immediate answers to many yet unanswered questions, it would also lead to new hypotheses about the dynamics of receptor/G protein interactions that could then be tested experimentally. A high-resolution receptor structure would also help to understand how hundreds of different GPCRs with remarkably diverse amino acid sequences can all interact with a similar subset of $\mathrm{G}$ proteins. Finally, because GPCRdepending signaling pathways are known to be involved in numerous patho-physiological conditions, detailed knowledge of the molecular mechanisms governing receptor/G proteincoupling selectivity and receptor-mediated $\mathrm{G}$ protein activation eventually should be of great therapeutic benefit. 
1. Pebay-Peyroula E, Rummel G, Rosenbusch JP, Landau EM: X-ray structure of bacteriorhodopsin at 2.5 angstroms from microcrystals grown in lipidic cubic phases. Science 12-9-1997; 277:1676-81

2. Coughlin SR: Expanding horizons for receptors coupled to $\mathrm{G}$ proteins: diversity and disease. Curr.Opin.Cell Biol. 1994; 6:191-7

3. Strader CD, Fong TM, Tota MR, Underwood D, Dixon RA: Structure and function of G protein-coupled receptors. Annual Review of Biochemistry 1994; 63:101-32

4. Wess J: G protein-coupled receptors: molecular mechanisms involved in receptor activation and selectivity of G protein recognition. FASEB J 1997; 11:346-54

5. Hedin KE, Duerson K, Clapham DE: Specificity of receptor-G protein interactions: searching for the structure behind the signal. Cell Signal. 1993; 5:505-18

6. Baldwin JM: The probable arrangement of the helices in G protein-coupled receptors. EMBO J 1993; 12:1693-703

7. Baldwin JM: Structure and function of receptors coupled to G proteins. Curr.Opin.Cell Biol. $1994 ; 6: 180-90$

8. Mizobe T, Maze M, Lam V, Suryanarayana S, Kobilka BK: Arrangement of transmembrane domains in adrenergic receptors. Similarity to bacteriorhodopsin. J Biol.Chem. 2-2. $1996 ; 271: 2387-9$

9. Unger VM, Hargrave PA, Baldwin JM, Schertler GF: Arrangement of rhodopsin transmembrane alpha-helices. Nature 11-9-1997; 389:203-6

10. Baldwin JM, Schertler GF, Unger VM: An alpha-carbon template for the transmembrane helices in the rhodopsin family of $\mathrm{G}$ protein-coupled receptors. J Mol.Biol. 12-9-1997; 272:144-64

11. Bourne HR: How receptors talk to trimeric G proteins. Curr.Opin.Cell Biol. 1997; 9:134-42

12. Elling CE, Thirstrup K, Nielsen SM, Hjorth SA, Schwartz TW: Metal-ion sites as structural and functional probes of helix-helix interactions in 7TM receptors. Ann.N.Y.Acad.Sci. 24-4-1997; 814:142-51

13. Yang K, Farrens DL, Altenbach C, Farahbakhsh ZT, Hubbell WL, Khorana HG: Structure and function in rhodopsin. Cysteines 65 and 316 are in proximity in a rhodopsin mutant as indicated by disulfide formation and interactions between attached spin labels. Biochemistry 12-11-1996; 35:14040-6

14. Fu D, Ballesteros JA, Weinstein H, Chen J, Javitch JA: Residues in the seventh membranespanning segment of the dopamine D2 receptor accessible in the binding-site crevice. Biochemistry 3-9-1996; 35:11278-85

15. Brown EM, Gamba G, Riccardi D, Lombardi M, Butters R, Kifor O, Sun A, Hediger MA, Lytton J, Hebert SC: Cloning and characterization of an extracellular $\mathrm{Ca}(2+)$-sensing receptor from bovine parathyroid. Nature 9-12-1993; 366:575-80 
16. Conklin BR, Bourne HR: Structural elements of $G$ alpha subunits that interact with $G$ beta gamma, receptors, and effectors. Cell 21-5-1993; 73:631-41

17. Neer EJ: Heterotrimeric G proteins: organizers of transmembrane signals. Cell 27-1-1995; 80:249-57

18. Sternweis PC: The purified alpha subunits of Go and Gi from bovine brain require beta gamma for association with phospholipid vesicles. J Biol.Chem. 15-1-1986; 261:631-7

19. Masters SB, Sullivan KA, Miller RT, Beiderman B, Lopez NG, Ramachandran J, Bourne HR: Carboxyl terminal domain of $\mathrm{Gs}$ alpha specifies coupling of receptors to stimulation of adenylyl cyclase. Science 22-7-1988; 241:448-51

20. Clapham DE, Neer EJ: G protein beta gamma subunits. Annu.Rev.Pharmacol.Toxicol. 1997; 37:167-203

21. McIntire WE, MacCleery G, Garrison JC: The G protein beta subunit is a determinant in the coupling of $\mathrm{Gs}$ to the beta 1-adrenergic and A2 a adenosine receptors. J Biol.Chem. 115-2001; 276:15801-9

22. Diverse-Pierluissi M, McIntire WE, Myung CS, Lindorfer MA, Garrison JC, Goy MF, Dunlap $\mathrm{K}$ : Selective coupling of $\mathrm{G}$ protein beta gamma complexes to inhibition of $\mathrm{Ca} 2+$ channels. J Biol.Chem. 15-9-2000; 275:28380-5

23. Fletcher JE, Lindorfer MA, DePilippo JM, Yasuda H, Guilmard M, Garrison JC: The G protein betas subunit interacts selectively with the $\mathrm{Gq}$ alpha subunit. J Biol.Chem. 2-1$1998 ; 273: 636-44$

24. Sunahara RK, Dessauer CW, Gilman AG: Complexity and diversity of mammalian adenylyl cyclases. Annu.Rev.Pharmacol.Toxicol. 1996; 36:461-80

25. Exton JH: Regulation of phosphoinositide phospholipases by hormones, neurotransmitters, and other agonists linked to G proteins. Annu.Rev.Pharmacol.Toxicol. 1996; 36:481509

26. Rhee SG, Bae YS: Regulation of phosphoinositide-specific phospholipase C isozymes. J Biol.Chem. 13-6-1997; 272:15045-8

27. Wall MA, Coleman DE, Lee E, Iniguez-Lluhi JA, Posner BA, Gilman AG, Sprang SR: The structure of the G protein heterotrimer Gi alpha 1 beta 1 gamma 2. Cell 15-12-1995; 83:1047-58

28. Lambright DG, Sondek J, Bohm A, Skiba NP, Hamm HE, Sigler PB: The 2.0 A crystal structure of a heterotrimeric G protein. Nature 25-1-1996; 379:311-9

29. Fong TM, Huang RR, Strader CD: Localization of agonist and antagonist binding domains of the human neurokinin-1 receptor. J Biol.Chem. 25-12-1992; 267:25664-7

30. Blin N, Yun J, Wess J: Mapping of single amino acid residues required for selective activation of $\mathrm{G} q / 11$ by the $\mathrm{m} 3$ muscarinic acetylcholine receptor. J Biol.Chem. 28-7-1995; 270:17741-8 
31. Gomeza J, Joly C, Kuhn R, Knopfel T, Bockaert J, Pin JP: The second intracellular loop of metabotropic glutamate receptor 1 cooperates with the other intracellular domains to control coupling to G proteins. J Biol.Chem. 26-1-1996; 271:2199-205

32. Munch G, Dees C, Hekman M, Palm D: Multisite contacts involved in coupling of the betaadrenergic receptor with the stimulatory guanine-nucleotide-binding regulatory protein. Structural and functional studies by beta-receptor-site-specific synthetic peptides. Eur J Biochem. 1-6-1991; 198:357-64

33. Okamoto T, Nishimoto I: Detection of $\mathrm{G}$ protein-activator regions in M4 subtype muscarinic, cholinergic, and alpha 2-adrenergic receptors based upon characteristics in primary structure. J Biol.Chem. 25-4-1992; 267:8342-6

34. Kostenis E, Conklin BR, Wess J: Molecular basis of receptor/G protein-coupling selectivity studied by coexpression of wild type and mutant $\mathrm{m} 2$ muscarinic receptors with mutant $\mathrm{G}$ alpha(q) subunits. Biochemistry 11-2-1997; 36:1487-95

35. Kostenis E, Degtyarev MY, Conklin BR, Wess J: The N-terminal extension of Galphaq is critical for constraining the selectivity of receptor coupling. J Biol.Chem. 1-8-1997; 272:19107-10

36. Gudermann $T$, Kalkbrenner F, Schultz G: Diversity and selectivity of receptor-G protein interaction. Annu.Rev.Pharmacol.Toxicol. 1996; 36:429-59

37. Kisselev O, Ermolaeva M, Gautam N: Efficient interaction with a receptor requires a specific type of prenyl group on the $G$ protein gamma subunit. J Biol.Chem. 27-10-1995; 270:25356-8

38. Yasuda H, Lindorfer MA, Woodfork KA, Fletcher JE, Garrison JC: Role of the prenyl group on the $\mathrm{G}$ protein gamma subunit in coupling trimeric $\mathrm{G}$ proteins to $\mathrm{Al}$ adenosine receptors. J Biol.Chem. 2-8-1996; 271:18588-95

39. Linden J, Auchampach JA, Jin X, Figler RA: The structure and function of A1 and A2B adenosine receptors. Life Sciences 1998; 62:1519-24

40. Wess J: Molecular basis of receptor/G protein-coupling selectivity. Pharmacol.Ther. 1998; $80: 231-64$

41. De Lean A, Stadel JM, Lefkowitz RJ: A ternary complex model explains the agonist-specific binding properties of the adenylate cyclase-coupled beta-adrenergic receptor. J Biol.Chem. 10-8-1980; 255:7108-17

42. Costa T, Ogino Y, Munson PJ, Onaran HO, Rodbard D: Drug efficacy at guanine nucleotidebinding regulatory protein-linked receptors: thermodynamic interpretation of negative antagonism and of receptor activity in the absence of ligand. Mol.Pharmacol. 1992; $41: 549-60$

43. McKinney M, Anderson D, Vella-Rountree L: Different agonist-receptor active conformations for rat brain M1 and M2 muscarinic receptors that are separately coupled to two biochemical effector systems. Mol.Pharmacol. 1989; 35:39-47 
44. Lefkowitz RJ, Cotecchia S, Samama P, Costa T: Constitutive activity of receptors coupled to guanine nucleotide regulatory proteins. Trends in Pharmacological Sciences 1993; 14:303-7

45. Weiss JM, Morgan PH, Lutz MW, Kenakin TP: The cubic ternary complex receptoroccupancy model. III. resurrecting efficacy. J Theor.Biol. 21-8-1996; 181:381-97

46. Mak CK, Avalos M, Randall PK, Kwan SW, Abell CW, Neumeyer JL, Whisennand R, Wilcox RE: Improved models for pharmacological null experiments: calculation of drug efficacy at recombinant D1A dopamine receptors stably expressed in clonal cell lines. Neuropharmacology 1996; 35:549-70

47. Ehlert FJ, Rathbun BE: Signaling through the muscarinic receptor-adenylate cyclase system of the heart is buffered against GTP over a range of concentrations. Mol.Pharmacol. $1990 ; 38: 148-58$

48. Onaran HO, Costa T, Rodbard D: Beta gamma subunits of guanine nucleotide-binding proteins and regulation of spontaneous receptor activity: thermodynamic model for the interaction between receptors and guanine nucleotide-binding protein subunits. Mol.Pharmacol. 1993; 43:245-56

49. Mahle CD, Wiener HL, Yocca FD, Maayani S: Allosteric interactions between the binding sites of receptor agonists and guanine nucleotides: a comparative study of the 5hydroxytryptamine $1 \mathrm{~A}$ and adenosine A1 receptor systems in rat hippocampal membranes. J Pharmacol.Exp.Ther. 1992; 263:1275-84

50. Waelbroeck M, Boufrahi L, Swillens S: Seven helix receptors are enzymes catalysing G protein activation. What is the agonist Kact? J Theor.Biol. 7-7-1997; 187:15-37

51. Krumins AM, Lapeyre JN, Clark RB, Barber R: Evidence for the shuttle model for Gs alpha activation of adenylyl cyclase. Biochemical Pharmacology 1-7-1997; 54:43-59

52. Shea L, Linderman JJ: Mechanistic model of G protein signal transduction. Determinants of efficacy and effect of precoupled receptors. Biochemical Pharmacology 21-2-1997; 53:519-30

53. Farrens DL, Altenbach C, Yang K, Hubbell WL, Khorana HG: Requirement of rigid-body motion of transmembrane helices for light activation of rhodopsin. Science 1-11-1996; 274:768-70

54. Farahbakhsh ZT, Ridge KD, Khorana HG, Hubbell WL: Mapping light-dependent structural changes in the cytoplasmic loop connecting helices $\mathrm{C}$ and $\mathrm{D}$ in rhodopsin: a sitedirected spin labeling study. Biochemistry 11-7-1995; 34:8812-9

55. Schwartz TW, Rosenkilde MM: Is there a 'lock' for all agonist 'keys' in 7TM receptors? Trends in Pharmacological Sciences 1996; 17:213-6

56. Rao VR, Cohen GB, Oprian DD: Rhodopsin mutation G90D and a molecular mechanism for congenital night blindness. Nature 17-2-1994; 367:639-42

57. Porter JE, Hwa J, Perez DM: Activation of the alphalb-adrenergic receptor is initiated by disruption of an interhelical salt bridge constraint. J Biol.Chem. 8-11-1996; 271:28318-23 
58. Kudo M, Osuga Y, Kobilka BK, Hsueh AJ: Transmembrane regions V and VI of the human luteinizing hormone receptor are required for constitutive activation by a mutation in the third intracellular loop. J Biol.Chem. 13-9-1996; 271:22470-8

59. Hwa J, Graham RM, Perez DM: Chimeras of alphal-adrenergic receptor subtypes identify critical residues that modulate active state isomerization. J Biol.Chem. 5-4-1996; 271:7956-64

60. Kjelsberg MA, Cotecchia S, Ostrowski J, Caron MG, Lefkowitz RJ: Constitutive activation of the alpha 1B-adrenergic receptor by all amino acid substitutions at a single site. Evidence for a region which constrains receptor activation. J Biol.Chem. 25-1-1992; 267:1430-3

61. Strader CD, Sigal IS, Register RB, Candelore MR, Rands E, Dixon RA: Identification of residues required for ligand binding to the beta- adrenergic receptor.

Proc.Natl.Acad.Sci.U.S.A 1987; 84:4384-8

62. Raymond JR: Multiple mechanisms of receptor-G protein signaling specificity. Am.J Physiol 1995; 269:F141-F158

63. Offermanns S, Laugwitz KL, Spicher K, Schultz G: G proteins of the G12 family are activated via thromboxane $\mathrm{A} 2$ and thrombin receptors in human platelets. Proc.Natl.Acad.Sci.U.S.A 18-1-1994; 91:504-8

64. Laugwitz KL, Allgeier A, Offermanns S, Spicher K, van Sande J, Dumont JE, Schultz G: The human thyrotropin receptor: a heptahelical receptor capable of stimulating members of all four $\mathrm{G}$ protein families. Proc.Natl.Acad.Sci.U.S.A 9-1-1996; 93:116-20

65. Gudermann T, Schoneberg T, Schultz G: Functional and structural complexity of signal transduction via G- protein-coupled receptors. Annu.Rev.Neurosci. 1997; 20:399-427

66. Offermanns $\mathrm{S}$, Simon MI: $\mathrm{G}$ alpha 15 and $\mathrm{G}$ alpha 16 couple a wide variety of receptors to phospholipase C. J Biol.Chem. 23-6-1995; 270:15175-80

67. Amatruda TT, III, Gerard NP, Gerard C, Simon MI: Specific interactions of chemoattractant factor receptors with G- proteins. J Biol.Chem. 15-5-1993; 268:10139-44

68. Wu D, LaRosa GJ, Simon MI: G protein-coupled signal transduction pathways for interleukin-8. Science 2-7-1993; 261:101-3

69. Gilchrist RL, Ryu KS, Ji I, Ji TH: The luteinizing hormone/chorionic gonadotropin receptor has distinct transmembrane conductors for cAMP and inositol phosphate signals. J Biol.Chem. 9-8-1996; 271:19283-7

70. Perez DM, Hwa J, Gaivin R, Mathur M, Brown F, Graham RM: Constitutive activation of a single effector pathway: evidence for multiple activation states of a $\mathrm{G}$ protein-coupled receptor. Mol.Pharmacol. 1996; 49:112-22

71. Okamoto T, Murayama Y, Hayashi Y, Inagaki M, Ogata E, Nishimoto I: Identification of a Gs activator region of the beta 2-adrenergic receptor that is autoregulated via protein kinase A-dependent phosphorylation. Cell 15-11-1991; 67:723-30 
72. Daaka Y, Luttrell LM, Lefkowitz RJ: Switching of the coupling of the beta2-adrenergic receptor to different $G$ proteins by protein kinase A. Nature 6-11-1997; 390:88-91

73. Horstmeyer A, Cramer H, Sauer T, Muller-Esterl W, Schroeder C: Palmitoylation of endothelin receptor A. Differential modulation of signal transduction activity by posttranslational modification. J Biol.Chem. 23-8-1996; 271:20811-9

74. Okamoto $\mathrm{Y}$, Ninomiya H, Tanioka M, Sakamoto A, Miwa S, Masaki T: Palmitoylation of human endothelinB. Its critical role in $\mathrm{G}$ protein-coupling and a differential requirement for the cytoplasmic tail by G protein subtypes. J Biol.Chem. 22-8-1997; 272:21589-96

75. Yoshimasa T, Sibley DR, Bouvier M, Lefkowitz RJ, Caron MG: Cross-talk between cellular signalling pathways suggested by phorbol- ester-induced adenylate cyclase phosphorylation. Nature 7-5-1987; 327:67-70

76. Sibley DR, Strasser RH, Benovic JL, Daniel K, Lefkowitz RJ:

Phosphorylation/dephosphorylation of the beta-adrenergic receptor regulates its functional coupling to adenylate cyclase and subcellular distribution.

Proc.Natl.Acad.Sci.U.S.A 1986; 83:9408-12 


\section{CHAPTER 3}

Local anesthetics: effects on the central nervous system and bronchial reactivity

Markus W. Hollmann and Marcel E. Durieux

Published in: Progress in Anesthesiology: 14 (20):323-336, 2000 


\section{Local anesthetics: effects on the central nervous system and bronchial reativity}

\section{Introduction}

This chapter reviews the effects of local anesthetics (LA) on neuronal and neuromuscula pathways. Although we tend to consider LA interference with neuronal function a result of conduction block, it would be a mistake to attribute all actions in these areas to $\mathrm{Na}^{+}$channe blockade. Some of these effects may be of limited clinical relevance (e.g., target sites involsd in the complex mechanisms of LA antinociceptive effects), but demonstrate the variety of actiss of these compounds. Others (e.g., suppression of the bronchial responses to tracheal intubatiorare relevant to the clinical setting, but underlying mechanisms are poorly understood.

\section{Effects on CNS function}

\section{LA and Neurotransmitters}

LA affect a variety of receptors, in addition to their effects on sodium channels. The follwing section will describe some of these actions, particularly in regard to their interference with neurotransmitters.

Synaptic transmission in the spinal cord may be directly inhibited by LA through modulion of postsynaptic receptors as well as by blockade of presynaptic calcium channels. The nicotini acetylcholine receptor ( $\mathrm{ACh}$ ) is a prototypical postsynaptic receptor that mediates chemical transmission at the neuromuscular junction. It is inhibited by LA in concentrations similar those required for blocking nerve impulses. ${ }^{1-3}$ Etidocaine and procaine exert potent blocking activy at nicotinic ACh receptors in brainstem vagal motorneurons. ${ }^{4}$ This finding may explain why edural administration of etidocaine in humans produces a motor blockade that significantly outlasthe sensory blockade."

Cocaine abusers feel a cocaine-like "high" in response to intravenous procaine, consisterwith observed increases in synaptic dopamine levels induced by ester-LA, which produce subjecve effects such as euphoria and dysphoria. Interestingly, amide LA (such as lidocaine), which appear to lack such behavioral effects, do not affect dopamine metabolism. ${ }^{6}$

Most anesthesiologist are familiar with the fact that LA can cause convulsions when plasmaconcentrations increase above the therapeutic level, but anticonvulsant properties of LA, most likely due to GABA-ergic stimulation, are less well known. ${ }^{7}$ Tetracaine, the most potent GABA-ergic LA is also the most potent anticonvulsant. Nonetheless, at higher concentrations it has the highest convulsive potential, similar to the majority of GABA uptake blockers, which also, at higher doses, act as convulsants. In addition to effects on GABA signaling, the anticonvulsant property of lidocaine may be mediated through interactions with peripheral benzodiazepine receptors (PBR). Lidocaine potently inhibits agonist binding at the PBR. ${ }^{9}$ Antagonist-like interaction of lidocaine at PBR could be partially responsible not only for its anticonvulsant effect, but also for its antiarrhythmic action, since these receptors are present in heart. Cardiac PBR are concentrated in the ventricles, and lidocaine is known to produce its antiarrhythmic effects mainly on ventricular tissue. Carbamazepine, which also binds to PBR, shares anticonvulsant and antiarrhythmic activities with lidocaine.

Block of pain conduction by LA is often thought to be based on sodium channel blockade alone. However, the underlying mechanisms are more complex, and also include effects on resting membrane potential and neuronal firing, mediated, for example, by suppression of different types of $\mathrm{K}$-channels. At clinically relevant concentrations, LA block voltage activated $\mathrm{K}_{\mathrm{A}}$-channels, which play an important role in defining neuronal firing patterns. ${ }^{10}$ In addition, LA, in concentrations within the range measured in spinal cord after subarachnoid or epidural administration, inhibit tachykinin-mediated neurotransmission by reducting substance $\mathrm{P}$ binding to the NK1-receptor, thereby leading to modulation of pain and inflammation. " Additional important effects may involve inhibition of nerve growth factor secretion ${ }^{12-14}$ and inhibition of neuromodulator receptors. 
When addressing this issue we must separate reductions in hypnotic requirements for potent inhaled volatile or intravenous anesthetic agents due to epidural or spinal block from effects induced by LA alone. Potential general anesthetic effects produced by L.A and resulting reductions in inhaled volatile anesthetic requirements are of obvious clinical importance. Recently, Hodgson et al. ${ }^{15}$ demonstrated that epidural administration of lidocaine in humans (plasma concentrations 2-4 $\mu \mathrm{g} / \mathrm{ml}$ ) reduced MAC of sevoflurane in their study group by more than one half, from 1.18 to 0.52 Vol\%.

Since MAC determination in this study was defined by tetanic electrical stimulation, it is conceivable that the observed effects were due to direct neural blockade of spinal nerves, resulting in greater tolerance to tetanic electrical stimulation. However, tolerance to stimulation was determined at the fifth cervical vertebra (C5) level (by observing purposeful head movements), and the authors demonstrated that sensory block to cold perception was limited to a T1-T5 level 15 min after epidural LA administration. Since after this period of time further cephalad spread of the LA is unlikely, ${ }^{16}$ a direct effect on spinal nerve impulse conduction at the testing site also seems unlikely. Similar findings were obtained by other investigators. Tverskoy et al. reported that bupivacaineinduced spinal block significantly reduced the hypnotic requirements for thiopentone, midazolam and propofol. ${ }^{17,18}$ Since the magnitude of this effect differed among the drugs they suggest a mechanism in addition to spinal blockade. This group confirmed the hypothesis with observations that intramuscularly applied lidocaine or bupivacaine also significantly increased the hypnotic effect of intravenous propofol and thiopentone. ${ }^{19.20}$ (There are some reports in the literature that LA may be myotoxic, but long term damage seems extremely rare ${ }^{21}$ ).

Subarachnoid LA administration may reduce anesthetic requirements by a different mechanism, however. Eappen et al. ${ }^{22}$ showed in rats that subarachnoid bupivacaine reduced hypnotic requirements of thiopentone by $39 \%$, consistent with Tverskoy's findings in humans. ${ }^{20}$ In Eappen's study ${ }^{22}$ the observed effect was not due to rostral spread of L.A, since bupivacaine could not be detected in the brain or cervical spinal cord. In addition, no changes in thiopental pharmacokinetics were induced by spinal anesthesia. The proposed mechanism was a decrease in tonic afferent input induced by spinal block, resulting in turn in a decrease in descending facilitatory modulation. Afferentiation theory suggests that tonic sensory and muscle spindle activity maintains a state of wakefulness, and that reduction in tonic afferent input may decrease the level of consciousness, ${ }^{23}$ similar to the mechanism by which neuromuscular blocking drugs may reduce MAC of halothane by $25 \%{ }^{24}$

Another explanation for the MAC-reducing effects of LA would be a systemic general anesthetic effect. Several mechanisms may explain this. One possibility might be LA-induced inhibition of CNS muscarinic signaling in the central nervous system, as recently reported by Hollmann et al. ${ }^{25}$ Several authors reported reduction in requirements for general anesthetic agents in the range of 10$30 \%$ after intravenous administration of LA. ${ }^{26,27}$ Himes et al. confirmed these findings, showing that halothane and nitrous oxide concentrations necessary to achieve anesthesia are $10-28 \%$ less after administration of intravenous lidocaine (plasma concentrations 3-6 $\mu \mathrm{g} / \mathrm{ml}$ ). ${ }^{28}$ Surprisingly, this could be not confirmed by Hodgson et al., ${ }^{15}$ who found intravenous administration of lidocaine to be without significant effect on sevoflurane MAC. Whether this is suggestive of differences in mechanisms of anesthetic action between sevoflurane and other inhaled anesthetics, or whether it results from another, unknown reason, is at this time not known.

Two other issues regarding interactions with induction drugs are worthy of mention. First, in rats, the hypnotic effect of intravenous thiopentone and lidocaine (at $\mathrm{ED}_{50}, 17 \mathrm{mg} / \mathrm{kg}$ lidocaine and $13.7 \mathrm{mg} / \mathrm{kg}$ thiopental, determined by abolition of righting reflex) have been shown to be antagonistic. ${ }^{29}$ Nonetheless, the beneficial cerebral effects of LA and barbiturates are likely to be complementary, and we therefore not infrequently employ thiopental (1-10 mg/min)/lidocaine (1-2 $\mathrm{mg} / \mathrm{min}$ ) infusions as total intravenous anesthetic in patients with severely increased intracranial pressure. 
Second, concern has been expressed that lidocaine (1\%) added to propofol to reduce pain of injection, might alter altererations in propofol availability, decreasing propofol's anesthetic potency. However, the decrease in $\mathrm{pH}$ primarily responsible for reduction of pain on injection is not responsible for the observed decrease in anesthetic potency. ${ }^{30}$

\section{Neuroprotective effects}

During cerebral ischemia, decreased energy supplies result in inadequate active transport of ions, thereby depolarizing neuronal membranes. ${ }^{31} 32$ Several excitatory neurotransmitters are released in excessive amounts. ${ }^{9,34}$ The resulting $\mathrm{Ca}^{2+}$ influx into postsynaptic neurons activates detrimental enzymatic processes leading to irreversible neuronal damage. ${ }^{33}$ The excess release of, for example, glutamate during ischemia has been shown to be in part due to $\mathrm{Ca}^{2+}$-independent reversal of the $\mathrm{Na}^{+}$-co-transport system, an electrogenic $\mathrm{Na}^{+}$-glutamate symporter, that leads to unidirectional flux of cytoplasmatic glutamate. ${ }^{36}$ Blockade of $\mathrm{Na}^{4}$-channels by tetrodotoxin (TTX) or by local anesthetics (lidocaine and procaine have been studied) reduces the $\mathrm{Ca}^{2+}$-independent excitatory amino acid release, and it has been suggested that $\mathrm{Na}^{+}$channel blockade may at least take part in the inhibition of the release of excitatory amino acid, thereby reducing the glutamate toxicity. ${ }^{37-41}$ Terada et al. reported recently that intravenous or subarachnoid administration of lidocaine attenuates accumulation of glutamate in the hippocampal CAl area and in the cerebral cortex during transient forebrain ischemia in rats. ${ }^{42}$

Although the well-known $\mathrm{Na}^{+}$channel blocking properties of LA may reduce ischemia-induced neuronal damage, additional mechanisms may play a role in their cerebroprotective effects. Procaine has been shown to prevent increases in intracellular $\mathrm{Ca}^{2+}$ concentration, most likely by inhibiting ryanodine receptor-mediated $\mathrm{Ca}^{2+}$ release from the endoplasmic reticulum. Similarly, in vitro, preischemic treatment with lidocaine $(50-100 \mu \mathrm{M})$ suppressed hypoxia-induced increases in intracellular $\mathrm{Ca}^{2+}$ concentration by inhibiting release of $\mathrm{Ca}^{2+}$ from intracellular $\mathrm{Ca}^{2+}$ stores and by blocking influx from the extracellular space. ${ }^{43}$ The reduction of the intracellular $\mathrm{Ca}^{2+}$ concentration during the early stages of ischemia seems to play an important role in preventing the cascade eventually leading to neuronal damage; this might explain, at least in part, the neuroprotective effects of procaine observed in vivo and in vitro. ${ }^{37}$

Other mechanisms may play a role as well. Wang et al. ${ }^{44}$ demonstrated substantial ischemic neuropathologic injury in dog brain after two hours of retrograde cerebral perfusion (RCP) and one hour of cardiopulmonary bypass (CPB). Lidocaine (plasma levels in the range of 5-12 $\mu \mathrm{g} / \mathrm{ml}$ ) infused before, during and after RCP significantly reduced the number of ischemic cells in cortex, hippocampus and thalamus. In addition, plasma glucose concentrations were decreased, possibly due to increased depth of anesthesia and resultant decreased sympathetic activity. ${ }^{44}$ Low blood glucose concentrations are known to contribute to recovery from cerebral ischemia, ${ }^{45}$ and might explain some of the protective effects obtained with lidocaine. Lidocaine can reduce cerebral metabolism, an effect additive to that of hypothermia. ${ }^{46,47}$ Under normothermic conditions decreases in synaptic electrical activity due to $\mathrm{Na}^{+}$channel blockade reduce cerebral metabolism. During hypothermia, when neuronal electrical activity is already reduced, further protection is achieved by LA-induced decreases of ion leak currents $\left(\mathrm{Na}^{+}\right.$-influx and $\mathrm{K}$-efflux); in other words, less energy needs to be expended by the $\mathrm{Na}^{+}-\mathrm{K}^{+}$ATPase to maintain ionic homeostasis. ${ }^{48}$ This might at least contribute to the beneficial effects on the ischemic brain under normothermic as well as hypothermic conditions. The recovery of neurologic function in dogs after $90 \mathrm{~min}$ of hypothermic circulatory arrest and 7 days of survival was improved significantly by intravenous lidocaine $\left(4 \mathrm{mg} / \mathrm{kg}\right.$ before arrest and $2 \mathrm{mg} / \mathrm{kg}$ at the beginning of reperfusion). ${ }^{49}$ Moreover, pretreatment with lidocaine reduced cortical hypoperfusion and posttraumatic motor deficits following experimental fluid percussion injury in rats. ${ }^{50.51}$ In rats, reduced motor deficits were reported when lidocaine $(2 \mathrm{mg} / \mathrm{kg}$ ) was applied $30 \mathrm{~min}$ after experimental traumatic brain injury. Since pegorgotein, a superoxide anion scavenger, exerted the same beneficial effect, protection by lidocaine might be attributed at least in part to its anti-inflammatory action. 
The "alternative action" of LA studied in most detail is their effect on the airway system. Topical anesthesia of the upper airway is a technique commonly used to suppress upper airway reflexes during fiberoptic bronchoscopy or tracheal intubation. In addition, LA are thought to be potent inhibitors of bronchial hyperresponsiveness. Bronchial hyperreactivity is increased during high fever, after smoking, after viral infections of the upper airway, and in the presence of left heart failure or COPD. Patients suffering from any of these conditions are at risk for developing bronchospasm after any form of airway irritation. Intravenous administration of LA to patients with bronchial hyperreactivity is recommended in standard textbooks ${ }^{52.53}$ and review articles ${ }^{54,55}$ to mitigate bronchoconstriction during tracheal intubation.

Although multiple studies have demonstrated an acute bronchoconstrictive effect induced by inhaled LA in patients with reactive airway disease ${ }^{56.59}$ and not all authors are convinced that intravenous lidocaine is a safe and effective agent under these circumstances, ${ }^{\infty 0}$ the majority of reports in the literature support the beneficial effects of LA on bronchial hyperreactivity. Groeben et al." showed that both intravenous and inhalational administration of lidocaine significantly attenuated bronchial hyperreactivity; both were equally effective, but inhaled lidocaine produced lower plasma concentrations $(0.7 \mathrm{vs} .2 .2 \mu \mathrm{g} / \mathrm{ml})$. However, inhaled lidocaine had the disadvantage of causing transient bronchoconstriction, probably by stimulating irritant receptors within the airways during inhalation. The advantages of inhaled lidocaine, compared with intravenous lidocaine, are lower plasma concentrations and probably a longer-lasting effoct because of prolonged absorption from the airway into the bloodstream. Although lidocaine inhalation initially induced bronchoconstriction in asthmatic patients, it subsequently attenuated responses to challenges with metacholine, hyperosmolar saline, distilled water, or exereise. ${ }^{61}$ A

Intravenous lidocaine (as well as oral mexiletine), in concentrations less than those necessary for cardiac protection against dysrhythmias, was shown not only to prevent histamine-induced bronchoconstriction in Basenji greyhounds (the standard animal model for asthma) ${ }^{65}$ and to block reflex airway hyperresponsiveness in asthmatic subjects, but also to avoid the risk of initial bronchoconstriction induced by the administration of acrosolized lidocaine. ${ }^{66} \mathrm{In}$ a prospective placebo-controlled study, ${ }^{67}$ clinically relevant plasma concentrations of lidocaine and bupivacaine dose-dependently attenuated the hyperreactive response to a inhalational challenge with acetylcholine in human volunteers.

Since beneficial effects of LA in patients with heightened reflex sensitivity resulting from asthma, ${ }^{59,66,68}$, respiratory tract infection, ${ }^{69}$ or cigarette-smoking, ${ }^{70}$ have been clearly demonstrated, the use of LA to prevent bronchial hyperreactivity in these patients is therefore justified.

These findings may be relevant outside of the intensive care setting as well. Patients with severe asthma often require therapy with large doses of glucocorticoids for prolonged periods, and intolerable side effects of exogenous hypercortisolism develop predictably. The use of inhaled glucocorticoids has reduced the requirement for systemically administered glucocorticoids in many patients with severe asthma, but inhaled glucocorticoids do not always control severe bronchial inflammation. For these reasons, physicians responsible for the care of patients with severe asthma are in need of agents with the powerful anti-inflammatory activities of glucocorticoids but without their undesirable side effects. Montelukast, a potent, selective and long lasting leukotriene D4 $\left(\mathrm{LTD}_{4}\right)$ inhibitor, was shown in clinical trials to be well tolerated and to be a significant improvement in chronic asthma irrespective of the presence of inhaled corticosteroids. ${ }^{7}$ In a study with 20 glucocorticoid-dependent asthmatic patients, Hunt et al. ${ }^{66}$ reported that nebulized lidocaine also benefits patients with severe asthma, and possesses significant glucocorticoid sparing activity: 13 patients were able to discontinue oral prednisone treatment.

Remarkably, although the benefit of LA for preventing bronchoconstriction is well established, the mechanisms underlying these effect are not fully understood and sites of action are still debated. Thus, a generally accepted explanation is not available. Here, we will discuss the most likely LA targets in this setting. 
A first possibility is attenuation of bronchial smooth muscle tone. Recently, lidocaine was shown to inhibit muscarinic $\mathrm{ml}$ and $\mathrm{m} 3$ receptors, expressed in Xenopus oocytes, in concentrations 100 to 1000 -fold less than those required for blocking neuronal sodium channels. ${ }^{25,72}$ Both of these receptor types are involved in the efferent neural pathways that regulate airway caliber. M1 muscarinic receptors are found in ganglia within the airway wall and M3 muscarinic receptors are postjunctional in the airway smooth muscle (figure 1).

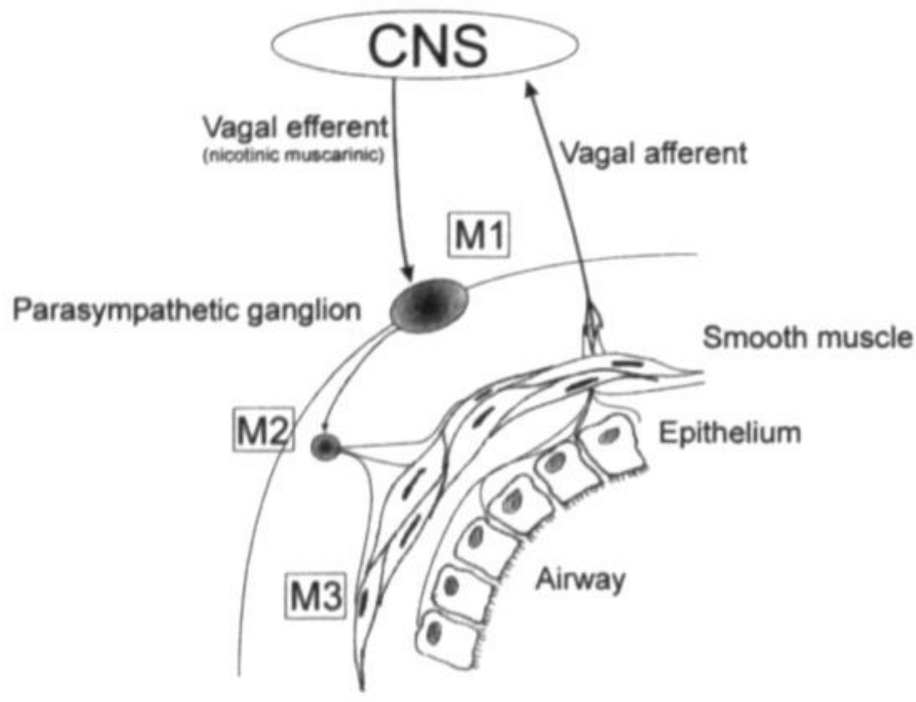

Figure 1: Schematic representation of parasympathetic afferent and efferent neural pathways that affect airway caliber. The afferent fibers arise from the epithelial layer of the airway lumen. CNS = central nervous system; $M 1=M 1$ muscarinic receptors in ganglia within the airway wall; $M 2=$ M2 prejunctional muscarinic receptors; $M 3=M 3$ postjunctional muscarinic receptors in airway smooth muscle.

In contrast, direct depression of smooth muscle contraction by $\mathrm{LA}^{73}$ (due to a decrease in intracellular calcium concentrations ${ }^{74}$ or inhibition of increased calcium sensitivity of the contractile apparatus by affecting the activity of myosin-light- chain kinase (MLCK) ${ }^{75,76}$ were shown only for LA concentrations greater than those obtained in plasma after intravenous or epidural administration. Interestingly, inhibition of MLCK might offer a possible explanation for LA effects on platelet function. Lind and Stossel ${ }^{n}$ reported that platelets contain muscle-like contractile proteins such as actin, myosin, tropomyosin, calmodulin and a MLCK. The myosin light chains in intact platelets are almost completely dephosphorylated when the cells are in a resting state, whereas stimulation with thrombin results in maximal phosphorylation of the myosin light chains. ${ }^{78}$ MLCK is responsible for this phosphorylation, and it is therefore conceivable that attenuation by LA of MLCK activity might lead to the clinically observed alteration of platelet function.

A second potential explanation for LA effects on bronchoconstriction might be their modulatory actions on the inflammatory response. Although it was shown by Kai and Downes ${ }^{74,79}$ that concentrations necessary to achieve this effect were more than 100 times greater than used clinically, more recent reports have demonstrated potent anti-inflammatory effects by LA in clinically relevant concentrations, as described previously. ${ }^{80}$ Lidocaine is thought to act as an inhibitor of eosinophil-active cytokines. ${ }^{81}$ Eosinophils play an important role in the pathogenesis of allergic respiratory diseases, especially bronchial asthma. A number of cytokines, such as IL-3, 
IL-5 and granulocyte-macrophage colony stimulating factor (GM-CSF) augment eosinophil function and enhance their survival. Lidocaine inhibits cosinophil survival and is therefore thought to be an inhibitor of eosinophil-active cytokines.

Third, depression of the central nervous system also suppresses airway responses. Even though there are several effects of LA on CNS, as described above, they do not appear to be clinically important in this case. Moreover, none of the studies in asthmatic subjects demonstrated CNS depression during administration of LA.

Finally, L.A might attenuate nerve conduction and reflex ares involved in the mediation of bronchial hyperreactivity. Intravenous administration of LA has been shown to suppress or even completely block mechanically- and chemically-induced airway reflexes. ${ }^{82,83}$ Most of these reflexes (such as the expiratory reflex, apnea, spasmodic panting, and cough reflexes) are mediated by the vagus nerve. Different sensitivity of these reflexes to inhibition by lidocaine ${ }^{84}$ together with the observation that these reflexes can be induced separately ${ }^{85}$ suggests that separate afferent neuronal pathways may be involved. ${ }^{86}$ The cough reflex is presumably mediated by nerves with endings close to the airway epithelium, affording easier access by L.A than the nerves controlling the Hering-Breuer reflex (the Hering-Breuer or inflation reflex is a mechanism that limits the duration of inspiration. Ventilation with large tidal volumes stretches specific receptors within the lungs. This information is passed via the vagus nerve to the respiratory center of the brain stem, where further inspiration is subsequently inhibited.), which is blocked only by high concentrations of L.A. ${ }^{87}$

In summary, at this time the most favored hypothesis of the mechanisms underlying the beneficial effect of LA on the airways is two-fold. After intravenous administration, inhibition of smooth muscle contraction by LA appears to occur predominantly by blocking neurally mediated reflex bronchoconstriction via the vagus nerve. ${ }^{66}$ After topical (inhalation) application, LA protect against bronchoconstriction by the same mechanism (after absorption of LA into the bloodstream). In addition, since concentrations of LA obtained locally are high, a direct effect on smooth muscle contraction must be considered. ${ }^{59}$ This combined effect might also explain why inhaled lidocaine exerted similar attenuation as did intravenous lidocaine, despite lower plasma concentrations.

Although lidocaine inhibits bronchoconstriction in asthmatic patients, it does not decrease baseline airway resistance in healthy humans. In fact, in one study with healthy human subjects bronchial application of lidocaine in either aqueous or paste form induced increases in airway resistance ${ }^{88}$; larynx and epiglottis were suspected to be the main site of obstruction. This was probably due to collapse of the oropharynx with suppressed dilation of upper airway muscle activity. These muscles (e.g., genioglossus, geniohyoid) are under complex neuronal control which adjusts dilating forces in phase with respiration, in order to maintain upper airway patency. ${ }^{89,90}$ Topical anesthesia of the upper airway depresses upper airway muscle activity by altering this neuronal regulation.

Intravenous lidocaine also worsened histamine-induced bronchoconstriction in dogs without bronchial hyperresponsiveness. ${ }^{91}$ This might be due to a possible sympatholytic effect of lidocaine. Ebert et al. ${ }^{92}$ have reported previously that intravenous lidocaine inhibits sympathetic responses. As the sympathetic innervation of the lung is limited, circulating catecholamines may exert sympathetic effects on airway tone. ${ }^{54}$ This may explain why patients with acute asthma or anaphylactic shock may become dependent on circulating catecholamines. Interestingly, another effect of lidocaine might be also due to its ability to inhibit sympathetic responses. Takakura et al..$^{93}$ performed a study on isoflurane-anesthetized humans. Isoflurane is associated with an increase in sympathetic activity, leading to tachycardia during induction of anesthesia. This tachycardia has been significantly reduced by endotracheal application of lidocaine but not by intravenous lidocaine despite 3-4 fold higher plasma concentrations with the intravenous application. This suggests the existence of a site or sites within the lower airways which are stimulated by isoflurane and inhibited by lidocaine. 


\section{Local anesthetic effects on tinnitus}

Lidocaine is also used for treatment of intractable tinnitus. In a prospective study in 50 patients with intractable tinnitus, intravenous treatment with lidocaine showed favorable results in $76 \%$, especially in patients with bilateral tinnitus. Most relief is obtained when plasma levels are in the range of $1.5-2.5 \mu \mathrm{g} / \mathrm{ml}^{94}$ Treatment of tinnitus with LA is not new. In 1935 Barany ${ }^{95}$ reported relief from tinnitus by procaine when injected into the nasal turbinates. Due to rapid absorption this application is similar to intravenous injection. Gejrot and Engelsson ${ }^{96,97}$ reported on the beneficial effect of intravenous lidocaine on tinnitus in Menière's disease and other causes of tinnitus.

The auditory pathway is a well established reflex are with afferent and efferent fibers conducting a steady discharge in both directions, from the hair cells through the brainstem, thalamus, cortex and back. Damage to the hair cells or the neural pathways alters the pathway such that perception of sound is highly increased, usually for those frequencies at which the damaged hair cells or neural pathways are to receive or transmit sound. The beneficial effect of LA-induced relief of tinnitus is explained by stabilization of the hair cell membrane and cochlear nerve fibers. ${ }^{909}$ Interestingly, intravenous procaine, which is more effective in the control of chronic pain than intravenous lidocaine, is less effective for tinnitus relief, suggesting that lidocaine exerts specific effects at one or more places in the ear and/or CNS to control tinnitus. ${ }^{100}$ In a patient with chronic tinnitus single photon emission computed tomography (SPECT) showed increased perfusion in the auditory cortex. Intravenous injection of lidocaine suppressed tinnitus and concomitantly shifted the enhanced perfusion back to its normal state.

Unfortunately, the beneficial effect of intravenous lidocaine is often only temporary, lasting from minutes to days. Therefore, a single-blinded clinical study using the oral amide of lidocaine, tocainide hydrochloride, was conducted. A dose of $600 \mathrm{mg}$ of this drug was administered to 12 patients, four times a day. Of the 12 patients, 10 showed $80-98 \%$ relief from tinnitus. ${ }^{100}$ However, a double-blind dose ranging study involving 56 patients had to be discontinued because of nausea in $32 \%$ of patients receiving $600 \mathrm{mg}$ four times a day. Nevertheless, follow up on several patients in these studies who experienced the advantages of tocainide hydrochloride, showed a $60-80 \%$ sustained reduction of the tinnitus. ${ }^{100}$

\section{Other therapeutic effects}

Several other interesting alternative effects, which in part may be related to anti-inflammatory action of LA, should be mentioned but will not be discussed in detail. References are provided for the interested reader.

In a prospective randomized clinical study on 65 laboring parturients the addition of subarachnoidal applied bupivacaine $(2.5 \mathrm{mg})$ to fentanyl $(25 \mu \mathrm{g}$, subarachnoidal applied) reduced the incidence of pruritus compared with those who received just fentanyl (except in the facial region) from $95 \%$ to $36.4 \%$. In addition, this combination resulted in a rapid onset and prolonged duration of analgesia compared with either drug alone. ${ }^{102}$ The underlying mechanism may be either a prevention of alteration in neuronal activity at the brainstem level, by inhibition of neuronal transmission in the ventrolateral tracts of the spinal cord, ${ }^{103}$ or direct modulation of opioid receptors. Bupivacaine may inhibit $\mu$-receptor activation and increase the binding of opioids to $\mathrm{k}$ receptors. ${ }^{104}$ Since stimulation of $\mathrm{K}$-receptors has been shown to decrease the incidence of pruritus induced by $\mu$-agonists, ${ }^{105}$ this might at least in part explain decreased truncal pruritus.

Subcutaneous injection of lidocaine ( $1 \%$ ) prior to venous cannulation (18-gauge venous cannula) has been shown to abolish the significant (10-15\% increase in mean arterial pressure (MAP) and rate-pressure product (RPP)) and sustained (for at least $3 \mathrm{~min}$.) pressor response to venous cannulation in $\mathbf{4 0}$ normotensive patients. The authors therefore claimed that subcutaneous LA infiltration before venous cannulation should be a requirement in all patients, especially those in whom the cardiovascular response may have detrimental effects, such as patients with previously compromised coronary or cerebral circulation, or patients with hypertension or increased intracranial pressure. ${ }^{106}$

In fact, intravenous lidocaine has been shown to be as effective as thiopental for rapid reduction 
of intraoperative intracranial hypertension, but with less cardiovascular depression. Thus, lidocaine may be of particular benefit to patients with both intracranial hypertension and marginal circulatory function. ${ }^{10}$ The effects of lidocaine effects on intracranial pressure (ICP) have been addressed in a separate review. ${ }^{100}$

In a prospective case series of 6 patients with headache symptoms highly resistant to a varied and long list of therapeutics, including ketorolac, prochlorperzine, opiates, dihydroergotamine or sumatriptan, pericranial injection therapy (PIT) with LA ( $5 \mathrm{ml}$ of a $50 / 50$ mixture of $2 \%$ lidocaine and $0.25 \%$ bupivacaine) at a single visit provided complete and persistent pain relief in 4 and complete initial relief but recurrence of some minor symptoms in both other patients. In addition, PIT abolished other associated headache symptoms such as nausea, photophobia, visual and auditory changes, without any known complications. Therefore PIT using LA may represent an additional therapeutic option for a subset of patients with severe headache. ${ }^{109}$ Intranasal lidocaine has been shown to be beneficial for patients with certain cluster or migraine headaches. ${ }^{110}$ In a prospective, randomized, double blind, placebo-controlled trial in 81 patients Maizels et al. demonstrated that $4 \%$ lidocaine intranasally caused in $55 \%$ of the patients at least a $50 \%$ reduction of headache within $15 \mathrm{~min}$. and a significant improvement of nausea and photophobia.

Unfortunately, $42 \%$ of the successfully treated patients showed relapse of headache within one hour after treatment." 11 Whether intranasal lidocaine is a reasonable proposition for acute treatment of migraine and if the results suggest that the sphenopalatine ganglion might be involved in migraine headache has to be determined in further studies.

\section{Conclusion}

This chapter has discussed several aspects of local anesthetic action that are considered independent of $\mathrm{Na}$ channel blockade. Local anesthetics provide a modest degree of general anesthetic action, and as such can be usefully employed to 'stretch' an anesthetic (e.g. at the end of a case). They also provide a considerable amount of neuroprotection. In combination with the hemodynamic stability provided, they are therefore of great usefulness in the practice of neuroanesthesia. The ability to reduce bronchial reactiviy is well recognized, even if the underlying mechanism is poorly understood. Finally, these versatile compounds have been employed with success in a variety of other clinical settings, including tinnitus, pruritus and migraine. 


\section{References}

1. Steinbach AB: Alteration by xylocaine (lidocaine) and its derivatives of the time course of the end plate potential. J Gen Physiol 1968; 52:144-61

2. Neher $\mathrm{E}$, Steinbach JH: Local anaesthetics transiently block currents through single acetylcholine-receptor channels. J Physiol 1978; 277:153-76

3. Ruff RL: The kinetics of local anesthetic blockade of end-plate channels. Biophys J 1982; 37:625-31

4. Lu WY, Bieger D: Inhibition of nicotinic cholinoceptor mediated current in vagal motor neurons by local anesthetics. Can J Physiol Pharmacol 1996; 74:1265-9

5. Axelsson K, Nydahl PA, Philipson L, Larsson P: Motor and sensory blockade after epidural injection of mepivacaine, bupivacaine, and etidocaine--a double-blind study. Anesth Analg 1989; 69:739-47

6. Graham JH, Maher JR, Robinson SE: The effect of cocaine and other local anesthetics on central dopaminergic neurotransmission. J Pharmacol Exp Ther 1995; 274:707-17

7. Taverner D, Baine WAL: Intravenous lignocaine as anticonvulsant. Lancet 1958; ii:1145-7

8. Nordmark J, Rydqvist B: Local anaesthetics potentiate GABA-mediated $\mathrm{Cl}$ - currents by inhibiting GABA uptake. Neuroreport 1997; 8:465-8

9. Clark M, Post RM: Lidocaine binds with high affinity to peripheral-type benzodiazepine receptors. Eur J Pharmacol 1990; 179:473-5

10. Olschewski A, Hempelmann G, Vogel W, Safronov BV: Blockade of $\mathrm{Na}+$ and $\mathrm{K}+$ currents by local anesthetics in the dorsal horn neurons of the spinal cord. Anesthesiology 1998; 88:172-9

11. Li YM, Wingrove DE, Too HP, Marnerakis M, Stimson ER, Strichartz GR, Maggio JE: Local anesthetics inhibit substance $\mathrm{P}$ binding and evoked increases in intracellular $\mathrm{Ca} 2+$. Anesthesiology 1995; 82:166-73

12. Bruenger M, Dean-McKinney TA, Sherer TB, Hollmann MW, Tuttle JB, Durieux ME: Mechanisms of anesthetic inhibition of nerve growth factor secretion in stimulated smooth muscle cells. Anesth Analg 2000; 90:S305

13. Schuchardt K, Sherer TB, Dean-McKinney TA, Hollmann MW, Tuttle JB, Durieux ME: Lidocaine decreases nerve growth factor secretion in bladder smooth muscle cells. Anesth Analg 2000; 90:S460

14. Durieux ME, Sherer TB, Dean-McKinney TA, Steers WD, Tuttle JB: Local anesthetic and ketamine inhibit nerve growth factor output from bladder smooth muscle. Soc Neurosci Abstr 1999; 25:1945

15. Hodgson PS, Liu SS, Gras TW: Does epidural anesthesia have general anesthetic effects? A prospective, randomized, double-blind, placebo-controlled trial. Anesthesiology 1999; 91:1687-92 
16. Hirabayashi $\mathrm{Y}$, Shimizu $\mathrm{R}$ : Effect of age on extradural dose requirement in thoracic extradural anaesthesia. Br J Anaesth 1993; 71:445-6

17. Tverskoy M, Shagal M, Finger J, Kissin I: Subarachnoid bupivacaine blockade decreases midazolam and thiopental hypnotic requirements. J Clin Anesth 1994; 6:487-90

18. Tverskoy M, Fleyshman G, Bachrak L, Ben-Shlomo I: Effect of bupivacaine-induced spinal block on the hypnotic requirement of propofol. Anaesthesia 1996; 51:652-3

19. Ben-Shlomo I, Tverskoy M, Fleyshman G, Cherniavsky G: Hypnotic effect of i.v. propofol is enhanced by i.m. administration of either lignocaine or bupivacaine. $\mathrm{Br} \mathrm{J}$ Anaesth 1997; 78:375-7

20. Tverskoy M, Ben-Shlomo I, Vainshtein M, Zohar S, Fleyshman G: Hypnotic effect of i.v. thiopentone is enhanced by i.m. administration of either lignocaine or bupivacaine. $\mathrm{Br}$ J Anaesth 1997; 79:798-800

21. Foster AH, Carlson BM: Myotoxicity of local anesthetics and regeneration of the damaged muscle fibers. Anesth Analg 1980; 59:727-36

22. Eappen S, Kissin I: Effect of subarachnoid bupivacaine block on anesthetic requirements for thiopental in rats. Anesthesiology 1998; 88:1036-42

23. Lanier WL, laizzo PA, Milde JH, Sharbrough FW: The cerebral and systemic effects of movement in response to a noxious stimulus in lightly anesthetized dogs. Possible modulation of cerebral function by muscle afferents. Anesthesiology 1994; 80:392-401

24. Forbes AR, Cohen NH, Eger EI: Pancuronium reduces halothane requirement in man. Anesth Analg 1979; 58:497-9

25. Hollmann MW, Fischer LG, Byford AM, Durieux ME: Local anesthetic inhibition of $\mathrm{m} 1$ muscarinic acetylcholine signaling. Anesthesiolgy 2000; in press

26. Steinhaus JE, Howland DE: Intravenously administered lidocaine as a supplement to nitrous oxide-thiobarbiturate anesthesia. Anesth Analg 1958; 37:40-6

27. Phillips OC, Lyons WB, Harris LC, Nelson AT, Graff TD, Frazier TM: Intravenous lidocaine as an adjunct of general anesthesia: a clinical evaluation. Anesth Analg 1960; 39:31723

28. Himes RSJ, DiFazio CA, Burney RG: Effects of lidocaine on the anesthetic requirements for nitrous oxide and halothane. Anesthesiology 1977; 47:437-40

29. Kissin I, McGee T: Hypnotic effect of thiopental-lidocaine combination in the rat. Anesthesiology 1982; 57:311-3

30. Eriksson M, Englesson S, Horte I, Hartvig P: The anaesthetic potency of propofol in the rat is reduced by simultaneous intravenous administration of lignocaine. Eur J Anaesthesiol $1999 ; 16: 315-9$

31. Hansen AJ: Effect of anoxia on ion distribution in the brain. Physiol Rev 1985; $65: 101-48$

32. Siesjo BK: Mechanisms of ischemic brain damage. Crit Care Med 1988 1988; 16:954-63 
33. Adachi $\mathrm{N}$, Oishi $\mathrm{R}$, Saeki $\mathrm{K}$ : Changes in the metabolism of histamine and monoamines after occlusion of the middle cerebral artery in rats. J Neurochem 1991; 57:61-6

34. Benveniste H, Drejer J, Schousboe A, Diemer NH: Elevation of the extracellular concentrations of glutamate and aspartate in rat hippocampus during transient cerebral ischemia monitored by intracerebral microdialysis. J Neurochem 1984; 43:1369-74

35. Mitani A, Takeyasu S, Yanase $\mathrm{H}$, Nakamura $\mathrm{Y}$, Kataoka $\mathrm{K}$ : Changes in intracellular $\mathrm{Ca} 2+$ and energy levels during in vitro ischemia in the gerbil hippocampal slice. J Neurochem $1994 ; 62: 626-234$

36. Sanchez-Prieto J, Gonzalez P: Occurrence of a large Ca2+-independent release of glutamate during anoxia in isolated nerve terminals (synaptosomes). J Neurochem 1988; 50:1322-4

37. Chen J, Adachi N, Liu K, Nagaro T, Arai T: Improvement of ischemic damage in gerbil hippocampal neurons by procaine. Brain Res 1998; 792:16-23

38. Weber ML, Taylor CP: Damage from oxygen and glucose deprivation in hippocampal slices is prevented by tetrodotoxin, lidocaine and phenytoin without blockade of action potentials. Brain Res 1994; 664:167-77

39. Taylor CP, Burke SP, Weber ML: Hippocampal slices: glutamate overflow and cellular damage from ischemia are reduced by sodium-channel blockade. J Neurosci Methods 1995; 59:121-8

40. Fried E, Amorim P, Chambers G, Cottrell JE, Kass IS: The importance of sodium for anoxic transmission damage in rat hippocampal slices: mechanisms of protection by lidocaine. J Physiol 1995; 489:557-65

41. Lysko PG, Webb CL, Yue TL, Gu JL, Feuerstein G: Neuroprotective effects of tetrodotoxin as a $\mathrm{Na}+$ channel modulator and glutamate release inhibitor in cultured rat cerebellar neurons and in gerbil global brain ischemia. Stroke 1994; $25: 2476-82$

42. Terada H, Ohta S, Nishikawa T, Mizunuma T, Iwasaki Y, Masaki Y: The effect of intravenous or subarachnoid lidocaine on glutamate accumulation during transient forebrain ischemia in rats. Anesth Analg 1999; 89:957-61

43. Liu K, Adachi N, Yanase H, Kataoka K, Arai T: Lidocaine suppresses the anoxic depolarization and reduces the increase in the intracellular $\mathrm{Ca} 2+$ concentration in gerbil hippocampal neurons. Anesthesiology 1997; 87:1470-8

44. Wang D, Wu X, Zhong Y, Zhou Y, Shan G, Hu X, Li J, Liu Y, Qin X, Xia Z: Effect of lidocaine on improving cerebral protection provided by retrograde cerebral perfusion: a neuropathologic study. J Cardiothorac Vasc Anesth 1999; 13:176-80

45. Siemkowicz E: Hyperglycemia in the reperfusion period hampers recovery from cerebral ischemia. Acta Neurol Scand 1981; 64:207-16

46. Sakabe $\mathrm{T}$, Maekawa $\mathrm{T}$, Ishikawa $\mathrm{T}$, Takeshita H: The effects of lidocaine on canine cerebral metabolism and circulation related to the electroencephalogram. Anesthesiology 1974; 40:433-41 
47. Astrup J, Sorensen PM, Sorensen HR: Inhibition of cerebral oxygen and glucose consumption in the dog by hypothermia, pentobarbital, and lidocaine. Anesthesiology 1981; $55: 263$. 8

48. Hall R, Murdoch J: Brain protection: physiological and pharmacological considerations. Part II: The pharmacology of brain protection. Can J Anaesth 1990; 37:762-77

49. Zhou Y, Wang D, Du M, Zhu J, Shan G, Ma D, Xie D, Ma Q, Hu X, Li J: Lidocaine prolongs the safe duration of circulatory arrest during deep hypothermia in dogs. Can J Anaesth $1998 ; 45: 692-8$

50. Muir JK, Lyeth BG, Hamm RJ, Ellis EF: The effect of acute cocaine or lidocaine on behavioral function following fluid percussion brain injury in rats. J Neurotrauma $1995 ; 12: 87-97$

51. Muir JK, Boerschel M, Ellis EF: Continuous monitoring of posttraumatic cerebral blood flow using laser-Doppler flowmetry. J Neurotrauma 1992; 9:355-62

52. Stoelting RK and Dierdorf SE: Anesthesia and Coexisting Disease, New York. Churchill Livingstone, 1993, pp 155-156

53. Bainton CR: Management of the airway, Anesthesia and Perioperative Complications, Benumof J. L. and Saidman LJ. St. Louis, Mosby-Year Book, 1992, pp 10-

54. Gal TJ: Bronchial hyperresponsiveness and anesthesia: physiologic and therapeutic perspectives. Anesth Analg 1994; 78:559-73

55. Brandus V, Joffe S, Benoit CV, Wolff WI: Bronchial spasm during general anaesthesia. Can Anaesth Soc J 1970; 17:269-74

56. McAlpine LG, Thomson NC: Lidocaine-induced bronchoconstriction in asthmatic patients. Relation to histamine airway responsiveness and effect of preservative. CHEST 1989; 96:1012-5

57. Prakash GS, Sharma SK, Pande JN: Effect of $4 \%$ lidocaine inhalation in bronchial asthma. J Asthma 1990; 27:81-5

58. Miller WC, Awe R: Effect of nebulized lidocaine on reactive airways. Am Rev Respir Dis $1975 ; 111: 739-41$

59. Groeben H, Silvanus MT, Beste M, Peters J: Both intravenous and inhaled lidocaine attenuate reflex bronchoconstriction but at different plasma concentrations. Am J Respir Crit Care Med 1999; 159:530-5

60. Zemenick RB: Pretreatment intravenous lidocaine for intubation of the asthmatic patient: more data are needed. Anesthesiology 1999; 91:318-9

61. Weiss EB, Patwardhan AV: The response to lidocaine in bronchial asthma. CHEST 1977; 72:429-38

62. Loehning RW, Waltemath CL, Bergman NA: Lidocaine and increased respiratory resistance produced by ultrasonic aerosols. Anesthesiology 1976; 44:306-10 
63. Makker HK, Holgate ST: The contribution of neurogenic reflexes to hypertonic salineinduced bronchoconstriction in asthma. J Allergy Clin Immunol 1993; 92:82-8

64. Enright PL, McNally JF, Souhrada JF: Effect of lidocaine on the ventilatory and airway responses to exercise in asthmatics. Am Rev Respir Dis 1980; 122:823-8

65. Brown RH, Robbins W, Staats P, Hirshman C: Prevention of bronchoconstriction by an orally active local anesthetic. Am J Respir Crit Care Med 1995; 151:1239-43

66. Groeben H, Foster WM, Brown RH: Intravenous lidocaine and oral mexiletine block reflex bronchoconstriction in asthmatic subjects [see comments]. Am J Respir Crit Care Med $1996 ; 154: 885-8$

67. Groeben H, Schwalen A, Irsfeld S, Stieglitz S, Lipfert P, Hopf HB: Intravenous lidocaine and bupivacaine dose-dependently attenuate bronchial hyperreactivity in awake volunteers. Anesthesiology 1996; 84:533-9

68. Hunt LW, Swedlund HA, Gleich GJ: Effect of nebulized lidocaine on severe glucocorticoiddependent asthma. Mayo Clin Proc 1996; 71:361-8

69. Hall AP, Fox AJ, Raphael JH, Nandwani N, Smith G: Upper airway reactivity and upper respiratory tract infection: effect of nebulized lidocaine. $\mathrm{Br} \mathrm{J}$ Anaesth 1999; 82:857-60

70. Caranza R, Raphael JH, Nandwani N, Langton JA: Effect of nebulised lignocaine on the quality of induction of anaesthesia in cigarette smokers. Anaesthesia 1997; 52:849-52

71. Blake KV: Montelukast: data from clinical trials in the management of asthma. Ann Pharmacother 1999; 33:1299-314

72. Ritter CH, Hollmann MW, Graf BM, Martin E, Durieux ME: Unterschiede in der Lokalanlalsthetika-Sensitivităt zwischen muskarinen $\mathrm{ml}$ - und $\mathrm{m} 3$ - Rezeptoren. Anaesthesiologie \& Intensivmedizin 2000; 41:423

73. Szocik JF, Gardner CA, Webb RC: Inhibitory effects of bupivacaine and lidocaine on adrenergic neuroeffector junctions in rat tail artery. Anesthesiology 1993; 78:911-7

74. Kai T, Nishimura J, Kobayashi S, Takahashi S, Yoshitake J, Kanaide H: Effects of lidocaine on intracellular Ca2+ and tension in airway smooth muscle. Anesthesiology 1993; 78:954-65

75. Tanaka $\mathrm{T}$, Hidaka H: Interaction of local anesthetics with calmodulin. Biochem Biophys Res Commun 1981; 101:447-53

76. Nosaka S, Kamaya H, Ueda I, Wong KC: Smooth muscle contraction and local anesthetics: calmodulin-dependent myosin light-chain kinase. Anesth Analg 1989; 69:504-10

77. Lind SE, Stossel TP: The microfilament network of the platelet. Prog Hemost Thromb 1982; 6:63-84

78. Daniel JL, Molish IR, Holmsen H: Myosin phosphorylation in intact platelets. J Biol Chem $1981 ; 256: 7510-4$ 
79. Downes $\mathrm{H}$, Loehning RW: Local anesthetic contracture and relaxation of airway smooth muscle. Anesthesiology 1977; 47:430-6

80. Hollmann MW, Durieux ME: Local anesthetics and the inflammatory response: a new therapeutic indication? Anesthesiology 2000; in press

81. Ohnishi T, Kita H, Mayeno AN, Okada S, Sur S, Broide DH, Gleich GJ: Lidocaine in bronchoalveolar lavage fluid (BALF) is an inhibitor of eosinophil-active cytokines. Clin Exp Immunol 1996; 104:325-31

82. Bidwai AV, Bidwai VA, Rogers CR, Stanley TH: Blood-pressure and pulse-rate responses to endotracheal extubation with and without prior injection of lidocaine. Anesthesiology $1979 ; 51: 171-3$

83. Yukioka H, Yoshimoto N, Nishimura K, Fujimori M: Intravenous lidocaine as a suppressant of coughing during tracheal intubation. Anesth Analg 1985; 64:1189-92

84. Nishino T, Hiraga K, Sugimori K: Effects of i.v. lignocaine on airway reflexes elicited by irritation of the tracheal mucosa in humans anaesthetized with enflurane. Br J Anaesth $1990 ; 64: 682-7$

85. Eschenbacher WL, Boushey HA, Sheppard D: Alteration in osmolarity of inhaled aerosols cause bronchoconstriction and cough, but absence of a permeant anion causes cough alone. Am Rev Respir Dis 1984; 129:211-5

86. Choudry NB, Fuller RW, Anderson N, Karisson JA: Separation of cough and reflex bronchoconstriction by inhaled local anaesthetics. Eur Respir J 1990; 3:579-83

87. Karlsson JA, Sant, Widdicombe J: Afferent neural pathways in cough and reflex bronchoconstriction. J Appl Physiol 1988; 65:1007-23

88. Beydon L, Lorino AM, Verra F, Labroue M, Catoire P, Lofaso F, Bonnet F: Topical upper airway anaesthesia with lidocaine increases airway resistance by impairing glottic function. Intensive Care Med 1995; 21:920-6

89. Horner RL, Innes JA, Holden HB, Guz A: Afferent pathway(s) for pharyngeal dilator reflex to negative pressure in man: a study using upper airway anaesthesia. J Physiol 1991; 436:31-44

90. White DP, Cadieux RJ, Lombard RM, Bixler EO, Kales A, Zwillich CW: The effects of nasal anesthesia on breathing during sleep. Am Rev Respir Dis 1985; 132:972-5

91. Hirota K, Hashimoto Y, Sato T, Yoshioka H, Kudo T, Ishihara H, Matsuki A: Lv. lidocaine worsens histamine-induced bronchoconstriction in dogs. Br J Anaesth 1999; 82:87-9

92. Ebert TJ, Mohanty PK, Kampine JP: Lidocaine attenuates efferent sympathetic responses to stress in humans. J Cardiothorac Vasc Anesth 1991; 5:437-43

93. Takakura K, Sugiura Y, Takeuchi K, Goto Y: Endotracheal administration of lidocaine inhibits isoflurane-induced tachycardia. Can J Anaesth 1998; 45:1181-5 
94. den HJ, Hilders CG, Schoemaker RC, Hulshof JH, Cohen AF, Vermeij P: Tinnitus suppression by intravenous lidocaine in relation to its plasma concentration. Clin Pharmacol Ther 1993; 54:415-20

95. Baranay R: Die Beeinflussung des Ohrensausens durch intravenoes injizierte Lokalanaesthetika. Acta Otolaryngol 1935; 23:201-3

96. Gejrot $\mathrm{T}$ : Intravenous xylocaine in the treatment of attacks on Meniere's disease. Acta Otolaryngol 1976; 82:301-2

97. Englesson S, Larsson B, Lindquist NG, Lyttkens L, Stahle J: Accumulation of 14C-lidocaine in the inner ear. Preliminary clinical experience utilizing intravenous lidocaine in the treatment of severe tinnitus. Acta Otolaryngol 1976; 82:297-300

98. Sanchez TG, Balbani AP, Bittar RS, Bento RF, Camara J: Lidocaine test in patients with tinnitus: rationale of accomplishment and relation to the treatment with carbamazepine. Auris Nasus Larynx 1999; 26:411-7

99. Haginomori S, Makimoto K, Araki M, Kawakami M, Takahashi H: Effect of lidocaine injection of EOAE in patients with tinnitus. Acta Otolaryngol 1995; 115:488-92

100. Shea JJ, Emmett JR, Orchik DJ, Mays K, Webb W: Medical treatment of tinnitus. Ann Otol Rhinol Laryngol 1981; 90:601-9

101. Staffen W, Biesinger E, Trinka E, Ladurner G: The effect of lidocaine on chronic tinnitus: a quantitative cerebral perfusion study. Audiology 1999; 38:53-7

102. Asokumar B, Newman LM, McCarthy RJ, Ivankovich AD, Tuman KJ: Intrathecal bupivacaine reduces pruritus and prolongs duration of fentanyl analgesia during labor: a prospective, randomized controlled trial. Anesth Analg 1998; 87:1309-15

103. Scott PV, Fischer HB: Spinal opiate analgesia and facial pruritus: a neural theory. Postgrad Med J 1982; 58:531-5

104. Tejwani GA, Rattan AK, McDonald JS: Role of spinal opioid receptors in the antinociceptive interactions between intrathecal morphine and bupivacaine. Anesth Analg 1992; 74:726-34

105. Ackerman WE, Juneja MM, Kaczorowski DM, Colclough GW: A comparison of the incidence of pruritus following epidural opioid administration in the parturient. Can J Anaesth 1989; 36:388-91

106. Langham BT, Harrison DA: The pressor response to venous cannulation: attenuation by prior infiltration with local anaesthetic. Br J Anaesth 1993; 70:519-21

107. Bedford RF, Persing JA, Pobereskin L, Butler A: Lidocaine or thiopental for rapid control of intracranial hypertension? Anesth Analg 1980; 59:435-7

108. Brucia JJ, Owen DC, Rudy EB: The effects of lidocaine on intracranial hypertension. J Neurosci Nurs 1992; 24:205-14

109. Brofeldt BT, Panacek EA: Pericranial injection of local anesthetics for the management of resistant headaches. Acad Emerg Med 1998; 5:1224-9 
110. Mills TM, Scoggin JA: Intranasal lidocaine for migraine and cluster headaches. Ann Pharmacother 1997; 31:914-5

111. Maizels M, Scott B, Cohen W, Chen W: Intranasal lidocaine for treatment of migraine: a randomized, double-blind, controlled trial. JAMA 1996; 276:319-21 
CHAPTER 4

Local anesthetic inhibition of $\mathrm{m} 1$ muscarinic acetylcholine signaling

Markus W. Hollmann

Lars G. Fischer

Anne M. Byford

Marcel E. Durieux

The author is recipient of the second-place award in the American Society of Anesthesiologists Residents' Research Essay Contest in 1999 for a part of the work presented in this article

Published in: Anesthesiology 93 (2):497-509, 2000 


\section{Local anesthetic inhibition of $\mathrm{ml}$ muscarinic acetylcholine signaling}

\section{ABSTRACT}

Background: Local anesthetics inhibit lipid mediator signaling (lysophosphatidate, thrombo-xane) by acting on intracellular domains of the receptor, or on the $\mathrm{G}$ protein. On receptors for polar agonists the ligand binding pocket could form an additional site of interaction, possibly resulting in superadditive inhibition. We therefore investigated the effects of local anesthetics on $\mathrm{ml}$ muscarinic receptor functioning.

Methods: We expressed receptors in isolation using Xenopus oocytes. Using two-electrode voltage clamp, we measured the effects of lidocaine, QX314 (permanently charged) and benzo-caine (permanently uncharged) on $\mathrm{Ca}^{2+}$-activated $\mathrm{Cl}^{\top}$ currents (lcara)), elicited by methylcholine $(\mathrm{MCh})$. We also characterized the interaction of lidocaine with [ $\left.{ }^{3} \mathrm{H}\right] \mathrm{QNB}$ binding to $\mathrm{ml}$-receptors.

Results: Lidocaine inhibited muscarinic signaling with an $\mathrm{IC}_{50}(18 \mathrm{nM}) 140$-fold less than that of extracellularly administered QX314 (IC $\mathrm{IC}_{50} 2.4 \mu \mathrm{M}$ ). Intracellularly injected QX314 (IC $\mathrm{S}_{50} 0.96 \mathrm{mM}$ ) and extracellularly applied benzocaine $\left(\mathrm{IC}_{50} 1.2 \mathrm{mM}\right)$ inhibited at high concentrations only. Inhibition of muscarinic signaling by extracellularly applied QX314 and lidocaine was due to noncompetitive antagonism. Intracellularly injected QX314 and benzocaine inhibited muscarinic and lysophosphatidate signaling at similar concentrations, suggesting an action on the common $G$ protein pathway. Combined administration of intracellularly injected $\left(\mathrm{IC}_{30} 19 \mu \mathrm{M}\right)$ and extracellularly applied QX314 ( $\mathrm{IC}_{50} 49 \mathrm{nM}$ ) exerted superadditive inhibition. Lidocaine did not displace specific [ $\left.{ }^{3} \mathrm{H}\right] \mathrm{QNB}$ binding to $\mathrm{ml}$-receptors.

Conclusions: $\mathrm{ml}$-muscarinic signaling is inhibited by clinically relevant concentrations of lidocaine and by extracellularly administered QX314, suggesting that the major site of action is a extracellular domain of the muscarinic receptor. An additional less potent, but superadditive inhibitory effect on the $\mathrm{G}$ protein is suggested.

\section{INTRODUCTION}

Although the Na channel is usually considered the primary site of action of local anesthetics, several other sites of interaction exist that may be of relevance to local anesthetic effects and side effects. ${ }^{1}$ Previous investigations from our laboratory have shown that local anesthetics inhibit several G protein-coupled receptors. Lysophosphatidate (LPA) signaling is inhibited by lidocaine and bupivacaine. ${ }^{2}$ Clinically relevant concentrations of lidocaine, bupivacaine or ropivacaine inhibit thromboxane $\mathrm{A}_{2}$ receptor functioning. ${ }^{3}$ In contrast, local anesthetics do not affect the angiotensin $\mathrm{II}_{1 \mathrm{~A}}$ receptor, another member of the $\mathrm{G}$ protein-coupled receptor superfamily, which couples, as we demonstrated, to the same intracellular signaling pathway downstream of the $\mathrm{G}$ protein as does the lysophosphatidate receptor. ${ }^{2}$ This suggests that the site of local anesthetic action is the G protein or the receptor itself, rather than the intracellular signaling pathway. These findings were confirmed by experiments demonstrating lack of local anesthetic effect on signaling induced by direct activation of $\mathrm{G}$ proteins or $\mathrm{IP}_{3}$ receptors. ${ }^{2,4}$ On lipid mediator receptors, the main local anesthetic binding site appears to be intracellular, as the permanently charged and therefore membrane impermeant lidocaine analog QX314 inhibited lipid mediator receptor functioning only when injected intracellularly. ${ }^{3,4}$ Together, these findings suggest that local anesthetics act on the intracellular domains of lipid mediator receptors, or on the associated $\mathrm{G}$ proteins. The latter seems more likely, as intracellular QX314 shows a virtually identical concentration-response relationship on lysophosphatidate and thromboxane $\mathrm{A}_{2}$ signaling, ${ }^{4}$ (Hoenemann, unpublished) suggesting the (common) $\mathrm{G}$ protein, rather than the (diverse) receptors as site of action.

However, receptors for more polar compounds have a polar agonist binding pocket, and it is conceivable that local anesthetics would interact with such receptors at this extracellular site as well. In fact, several groups have shown interactions of local anesthetics with muscarinic receptor 
binding. ${ }^{5-10}$ although such interactions usually required high (supraclinical) local anesthetic concentrations. If such receptors contained an extracellular local anesthetic binding domain in addition to the intracellular domain described above, superadditive interaction would be possible. If so, functional inhibition might require much lower concentrations of local anesthetics than those required in the binding studies. To test this hypothesis, we studied the effect of lidocaine on $\mathrm{ml}$ muscarinic receptor signaling.

In addition to providing a suitable model for testing our hypothesis, muscarinic receptors are interesting subjects of anesthetic mechanisms research for several other reasons. First, as mentioned above, local anesthetics have been shown previously to interact with these receptors. However, those studies usually investigated binding, not function. In addition, the specific receptor subtypes involved were rarely determined. Second, we have shown previously that volatile anesthetics ${ }^{n}$ ${ }^{12}$ and ketamine ${ }^{13}{ }^{14}$ interact significantly with muscarinic signaling, and it would be of interest to compare the actions of local and general anesthetics in a similar model. Third, muscarinic signaling has major clinical implications for anesthesiologists. The $\mathrm{m} 1$ receptor is the best defined of all 5 muscarinic acetylcholine receptors. It is primarily found in the brain and linked to phosphatidylinositol metabolism. $\mathrm{ml}$ and $\mathrm{m} 3$ muscarinic receptors are largely responsible for maintenance of airway tone (and local anesthetics are known to be effective in preventing bronchospasm). $\mathrm{m} 2$ muscarinic receptors are primary medatiors of vagal tone in the heart. Muscarinic acetylcholine signaling also plays important roles in the central nervous system (CNS). Level of consciousness is modulated significantly by brainstem muscarinic signaling. ${ }^{5}$ Inhibition of muscarinic signaling (by reducing acetylcholine levels, inhibiting its release, or administration of scopolamine) decreases minimum alveolar concentration of inhaled anesthetics. In contrast, physostigmine administration increases minimum alveolar concentration, ${ }^{16}$ and reverses the action of propofol on the CNS. ${ }^{17}$

Our study was designed to adress the following questions:

- Do clinically relevant concentrations of local anesthetics inhibit $\mathrm{ml}$ muscarinic receptor signaling?

- Is the inhibition competitive or non-competitive?

- Is the site of action located extracellular and/or intracellular?

- How much do interactions with the binding site contribute to the inhibitory effect?

\section{MATERIALS AND METHODS}

\section{Oocyte experiments}

\section{Oocyte Harvesting}

The study protocol was approved by the Animal Research Committee at the University of Virginia.

Female Xenopus laevis toads were obtained from Xenopus I (Ann Arbor, MI, USA), housed in an established frog colony, and fed regular frog brittle twice weekly. Surgery for oocyte harvesting was performed once every two months at most. Animals were killed after six operations. For removal of oocytes a frog was anesthetized by immersion in $0.2 \% 3$-amino-benzoic-methyl-ester until it was unresponsive to a painful stimulus (toe pinching). Surgery was performed while animals were positioned on ice. A 1-cm long incision was made in a lower abdominal quadrant and a lobule of ovarian tissue, containing approximately 200 oocytes, was removed and placed in modified Barth's solution (containing, in mM: $\mathrm{NaCl} 88, \mathrm{KCl} 1, \mathrm{NaHCO}_{3} 2.4, \mathrm{CaCl}_{2} 0.41, \mathrm{MgSO}_{4} 0.82$, $\mathrm{Ca}_{2} \mathrm{NO}_{3} 0.3$, Gentamicin 0.1 and HEPES $15, \mathrm{pH}$ adjusted to 7.6 ). The oocytes were defolliculated by gentle shaking for approximately 2 hours in calcium-free OR2 solution (containing $0.1 \%$ collagenase type la, $82.5 \mathrm{mM} \mathrm{NaCl}, 2 \mathrm{mM} \mathrm{KCl}, 1 \mathrm{mM} \mathrm{MgCl}, 5 \mathrm{mM}$ HEPES, pH adjusted to 7.5). The oocytes were then returned to the modified Barth's solution and microscopic observation confirmed the absence of follicle cells. 
The rat $\mathrm{ml}$ muscarinic acetylcholine receptor complementary DNA (cDNA) was obtained from Dr. T. L. Bonner (National Institute of Mental Health, Bethesda, MD, USA). It consists of a 2.8kilobasepair fragment in a commercial vector (pGEM1; Promega, Madison, WI, USA). The construct was linearized by digestion with the nuclease Hind III and cRNA was prepared by transcription in vitro using the bacteriophage RNA polymerase $T 7$. A capping analog ( ${ }^{\mathrm{m}} \mathrm{mppp}$ ) was included in the reaction to generate capped transcripts, as these are translated more efficiently in the oocyte. The resulting cRNA was quantified by spectometry, and 5 ng cRNA in a $30 \mathrm{nl}$ volume was injected into the oocyte, using an automated microinjector (Nanoject; Drummond Scientific, Broomall, PA, USA). The adequacy of injection was confirmed by a slight increase in cell size during injection. The cells were then cultured in modified Barth's solution for 72 hours at $18^{\circ} \mathrm{C}$ before study.

\section{Electrophysiologic recording}

Experiments were performed at room temperature. A single defolliculated cell was placed in a continous-flow recording chamber $(0.5 \mathrm{ml}$ volume) and superfused with $2 \mathrm{ml} / \mathrm{min}$ Tyrode's solution (containing in mM: $\mathrm{NaCl} 150, \mathrm{KCl} 5, \mathrm{CaCl}_{2} 2, \mathrm{MgSO}_{4} 1$, Dextrose 10 and HEPES 10, pH adjusted to 7.4). The oocyte was positioned close to the inflow tubing, so that complete exposure to test solutions was obtained in $5.3 \pm 0.5 \mathrm{~s}(\mathrm{n}=20)$. Microelectrodes were pulled in one stage from capillary glass (BBL with fiber, World Precision Instruments, Sarasota, FL, USA) on a micropipette puller (model 700C; David Kopf Instruments, Tujunga, CA, USA). Tips were broken to a diameter of approximately $10 \mu \mathrm{m}$. They were filled with $3 \mathrm{M} \mathrm{KCl}$ and tip resistances were usually 1-3 $\mathrm{M} \Omega$. The cell was voltage clamped using a two-microelectrode oocyte voltage clamp amplifier (OC725A; Wamer Corporation, New Haven, CT, USA), connected to a data acquisition and analysis system running on an IBM-compatible personal computer. The acquisition system consisted of a DAS-8A/D conversion board (Keithley-Metrabyte, Taunton, MA, USA) and analysis was performed with a custom-written program (OoClamp software ${ }^{18}$ ). All measurements were performed at a holding potential of $-70 \mathrm{mV}$. Cells that did not show a stable holding current of less than $0.5 \mu$ A during a 5-min equilibration period (less than $5 \%$ of cells tested) were excluded from analysis. Membrane current was sampled at $125 \mathrm{~Hz}$ and recorded for $5 \mathrm{~s}$ before and $45 \mathrm{~s}$ after application of the test compounds. Responses were quantified by integrating the current trace by quadrature and are reported as microCoulombs $(\mu \mathrm{C})$ as described previously. ${ }^{19-21}$

\section{Drug administration}

Acetyl- $\beta$-methylcholine bromide $(\mathrm{MCh})$, used as agonist for the $\mathrm{ml}$ muscarinic receptor, was diluted in Tyrode's solution to the required concentration and was superfused $(2 \mathrm{ml} / \mathrm{min})$ over the oocyte for $10 \mathrm{~s}$. Agonist binding to muscarinic receptors activates one or more heterotrimeric $\mathrm{G}$ proteins (primarily $\mathrm{G}_{4}$ and $\mathrm{G}_{11}{ }^{22}$ ), which in turn activate phospholipase $\mathrm{C}$ (PLC). PLC releases inositoltrisphosphate $\left(\mathrm{IP}_{3}\right)$ and diacylglycerol (DAG) from cell membrane-bound phosphatidylinositolbisphosphate $\left(\mathrm{PIP}_{2}\right) . \mathrm{IP}_{3}$ releases $\mathrm{Ca}^{2+}$ from intracellular stores; diacylglycerol (DAG) activates protein kinase $\mathrm{C}$ (PKC). Intracellular free $\mathrm{Ca}^{2+}$ activates a $\mathrm{Ca}^{2+}$-dependent $\mathrm{Cl}$ channel in the cell membrane of the oocyte, inducing an inward $\mathrm{Ca}^{2+}$-activated $\mathrm{Cl}^{-}$current $\left(\mathrm{I}_{\mathrm{cu}}(\mathrm{Ca})\right.$ ).

Lidocaine was also diluted in Tyrode's solution to various concentrations and superfused (2 $\mathrm{ml} / \mathrm{min}$ ) for $10 \mathrm{~min}$. Benzocaine and QX314 were diluted and administered extracellulary in the same manner as lidocaine.

For intracellular administration of QX314 a third micropipette was inserted into the voltageclamped oocyte. The micropipette was connected to an automated microinjector (Nanoject; Drummond Scientific, Broomall, PA, USA). Under voltage clamp, $50 \mathrm{nl}$ (approximately $10 \%$ of total oocyte volume) of various QX314 concentrations were injected. 


\section{Experimental protocol}

\section{Control response}

After voltage clamping, the oocyte was allowed to stabilize for 5 minutes. During this time the oocyte was superfused continuously with Tyrode's solution. The control response was then determined: $\mathrm{MCh}$ was superfused for $10 \mathrm{~s}$ and membrane current was recorded for $5 \mathrm{~s}$ before and 55 $s$ after the beginning of agonist application. For determination of the concentration-response relationship for $\mathrm{MCh}$ the experiment ended at this point. All other studies continued with measurement of the treatment response in the same oocyte.

\section{Treatment response}

Local anesthetic (or Tyrode's in certain experiments) was administered to the oocyte by superfusion for 10 minutes. Subsequently, the treatment response was induced, in the same oocyte, using the same concentration of $\mathrm{MCh}$ as used for the control response.

\section{Recovery response}

In order to determine if any treatment effect observed could be reversed, the same oocyte was superfused with Tyrode's solution for 10 minutes and the recovery response was measured, using the same MCh concentration as used before.

\section{Intracellular iniections}

Control and treatment experiments with intracellular QX314 injection were performed in different oocytes. In the control oocytes $50 \mathrm{nl}$ of a $150 \mathrm{mM} \mathrm{KCl}$ solution was injected; in the treatment group we injected $50 \mathrm{nl}$ of $\mathrm{KCl}$ solution containing various concentrations of QX314. Injection was followed by superfusion with Tyrode's solution for $10 \mathrm{~min}$, preventing an extracellular effect of any QX314 unintentionally leaked from the cell. I $\mathrm{Cr}_{(\mathrm{C})}$ was then induced by superfusion of $\mathrm{MCh}$ at $\mathrm{EC}_{50}$, as described previously.

\section{Binding experiments \\ Membrane preparation}

CHO cells stably transfected with the muscarinic $\mathrm{ml}$ receptor were homogenized in $10 \mathrm{vol}$ of ice-cold homogenization buffer ( $50 \mathrm{mM}$ Tris, $5 \mathrm{mM} \mathrm{MgCl} 2,5 \mathrm{mM}$ EDTA, $1 \mathrm{mM}$ EGTA, Aprotinin $2 \mu \mathrm{g} / \mathrm{ml}$, pH adjusted to 7.5) with an Overhead stirrer (Wheaton Instruments, Millville, NJ, USA) three times for $15 \mathrm{~s}$ at medium speed. The homogenate was centrifuged for $30 \mathrm{~min}$ at $4^{\circ}$ and $500 \mathrm{x}$ g. The supernatant was adjusted to $107 \mathrm{mM} \mathrm{KCl}$ and $20 \mathrm{mM}$ MOPS (pH 7.4), mixed, incubated for $10 \mathrm{~min}$ on ice, and centrifuged for $60 \mathrm{~min}$ at $160,000 \mathrm{x} \mathrm{g}$ at $4^{\circ}$. The pellet was resuspended in 160 $\mathrm{mM} \mathrm{KCV} / 20 \mathrm{mM}$ Tris (pH 7.4) with a short burst of an Overhead stirrer at medium speed and centrifuged at $160,000 \times \mathrm{g}$ for $45 \mathrm{~min}$ at $4^{\circ}$. The final pellet was resuspended in homogenization buffer and stored in aliquots at $-20^{\circ}$. Protein concentration was determined by the Lowry method using BSA for standards.

\section{Ligand Binding}

Muscarinic $\mathrm{ml}$ receptor density and equilibrium dissociation constants in $\mathrm{CHO}$ cell membranes were determined by specific binding of a muscarinic $\mathrm{ml}$ receptor antagonist, $\left[{ }^{3} \mathrm{H}\right]$ quinuclydinyl benzylate ([ $\left.{ }^{3} \mathrm{H}\right] \mathrm{QNB}, 0.1$ to $\left.16 \mathrm{nM}\right) .100-\mu \mathrm{l}$ aliquots of membrane (15 $\mu \mathrm{g}$ of protein) were incubated with [ $\left.{ }^{3} \mathrm{H}\right] \mathrm{QNB}$ in assay buffer $(20 \mathrm{mM}$ Tris, $100 \mathrm{mM} \mathrm{NaCl}, 0.5 \mathrm{mM}$ EDTA, pH 7.4) for $90 \mathrm{~min}$ at $21^{\circ}$. Membranes were collected onto Whatman GF/C glass fiber filters, which were washed three times for $10 \mathrm{~s}$ with ice-cold buffer ( $10 \mathrm{mM}$ Tris, $5 \mathrm{mM} \mathrm{MgCl}, \mathrm{pH} 7.4)$. Radioactivity trapped on filters was counted using a scintillation counter. All reactions were performed in triplicate. Nonspecific binding was determined by adding $5 \mu \mathrm{M}$ atropine to displace specific binding of $\left[{ }^{3} \mathrm{H}\right] \mathrm{QNB}$. 
Specific binding was fit to a single site-binding model using nonlinear least square curve fitting of the untransformed data to calculate receptor density $\left(\mathbf{B}_{\operatorname{mex}}\right)$ and dissociation constants $\left(\boldsymbol{K}_{\mathbf{d}}\right)$. To determine interaction of lidocaine with specific binding of $\left[{ }^{3} \mathrm{H}\right] \mathrm{QNB}, 100-\mu \mathrm{l}$ aliquots of membrane ( $15 \mu \mathrm{g}$ of protein) were incubated with various concentrations of lidocaine $\left(10^{-2}\right.$ to $10^{-10}$ $\mathrm{M})$ and $\left[{ }^{3} \mathrm{H}\right] \mathrm{QNB}$ (at $\mathrm{K}_{4}$ ) in assay buffer ( $20 \mathrm{mM}$ Tris, $100 \mathrm{mM} \mathrm{NaCl}, 0.5 \mathrm{mM}$ EDTA, pH 7.4) for $90 \mathrm{~min}$ at $21^{\circ}$ and ligand binding was determined as previously described.

\section{Analysis}

Results are reported as mean \pm SEM. Measurements of at least 12 oocytes were averaged to generate each data point. As variability between batches of oocytes is common, responses were at times normalized to control response. Statistical tests employed are indicated in the Results section. $P<0.05$ was considered significant. Concentration-response curves were fit to the following logistic function, derived from the Hill equation: $y=y_{\min }+\left(y_{\max }-y_{\min }\right)\left\{1-x^{n} /\left(x_{90}{ }^{n}+x^{n}\right)\right\}$ where $\mathrm{y}_{\max }$ and $\mathrm{y}_{\min }$ are the maximum and minimum response obtained, $\mathrm{n}$ is the Hill coefficient, and $\mathrm{X}_{s_{0}}$ is the half-maximal effect concentration ( $\mathrm{EC}_{30}$ for agonist) or the half-maximal inhibitory effect concentration ( $\mathrm{IC}_{50}$ for antagonist). To assess if combined administration of intracellularly injected and extracellular QX314 exert superadditive inhibition, we applied the combination in a fixed ratio, based on their IC $\mathrm{IC}_{00}$. The interaction was analyzed by isobolographic analysis. $95 \%$ confidence intervals for the isobologram were calculated from the SEM.

\section{Isobolograms}

Isobolographic analysis is a non-mechanistic method of characterizing the effect resulting from the administration of two compounds, by employing equieffective concentrations of individual drugs and combinations of these. Application of each drug alone is used to determine the isobolar points on the axes, $(a, 0)$ and $(0, b)$. Pure "additivity" is represented by the isobole of additivity, which is based on the equation $x / a+y / b=1$, and results in a straight line connecting the axial points. ${ }^{23.24}$ If the actual measured concentration of the combination of both drugs falls below the isobolar plot of the $95 \%$ confidence interval, super-additivity is suggested.

\section{Materials}

Molecular biology reagents were obtained from Promega (Madison, WI, USA) and other chemicals were obtained from Sigma (St. Louis, MO, USA). CHO cells (CRL-1982), stable transfected with the rat muscarinic $\mathrm{ml}$ receptor, were purchased from ATCC (Manassas, VA, USA). QX314 was a gift from Astra Pharmaceuticals, L.P. (Westborough, MA, USA). 


\section{RESULTS}

\section{Functional expression of $\mathrm{ml}$ muscarinic receptors in Xenopus oocytes}

Whereas uninjected oocytes were unresponsive to $\mathrm{MCh}$, oocytes injected with $\mathrm{ml}$ muscarinic receptor cRNA responded to application of $\mathrm{MCh}\left(10^{-4}-10^{-9} \mathrm{M}\right)$ with a transient $\left.\mathrm{I}_{\mathrm{Cr}} \mathrm{Ca}\right)(\mathrm{e} . \mathrm{g}$. Figure 1).

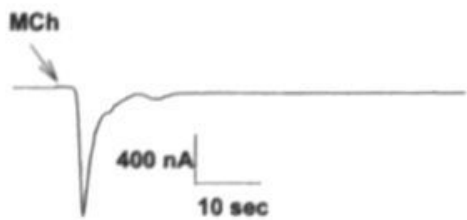

Figure 1: Example of an imward chloride current ( $\left.I_{C I C a l}\right)$ induced by $10 \mathrm{~s}$ administration of MCh (at approximately $E C_{50}\left(5.7 \pm 5.2 \times 1 \sigma^{7} M\right)$ ) in oocytes expressing muscarinic $m /$ receptor.

We have shown previously that this response is mediated by $\mathrm{ml}$ muscarinic receptors, as it is inhibited by atropine and pirenzepine."

We determined the concentration-response relationship for the response. As shown in Figure 2 , the response was concentration-dependent. $\mathrm{EC}_{50}$, calculated from the Hill equation, was $5.7 \pm 5.2 \mathrm{x}$ $10^{-7} \mathrm{M}$. Maximal responses of $14.6 \pm 1.8 \mu \mathrm{C}$ were obtained at a MCh concentration of $0.1 \mathrm{mM}$. Calculated $\mathrm{E}_{\max }$ was $13.8 \pm 2.2 \mu \mathrm{C}$. These findings compare closely with data reported in our previous studies. $11 \cdot 14$

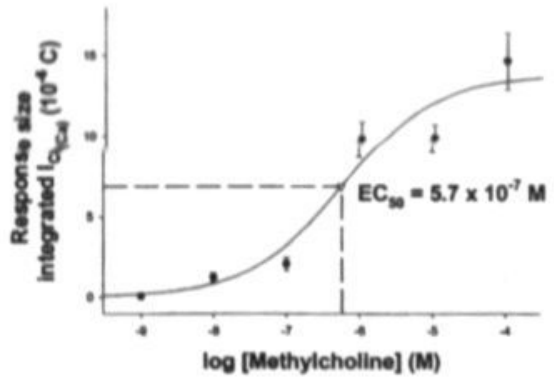

Figure 2: Methylcholine evokes I $\mathrm{Cr}_{\mathrm{Ca}}$ in a concentration-dependent manner. Curve fitting using the Hill equation revealed a half maximal effect concentration $\left(E C_{50}\right)$ of $5.7 \pm 5.2 \times 10^{7} \mathrm{M}$.

To determine if the recombinantly expressed receptors desensitized after repeated agonist administration, we induced three consecutive $\mathrm{I}_{\mathrm{Cr}(\mathrm{C})}$ with $\mathrm{MCh}$ in the same oocyte. Two $\mathrm{MCh}$ concentrations were studied: $10^{-5} \mathrm{M}$ (Figure $3 \mathrm{~A}$ ) and $10^{-6} \mathrm{M}(\mathrm{B})$ ). A recovery time of 10 minutes separated each agonist application (see experimental protocol). Average response sizes for the three applications were $2.5 \pm 0.4,2.2 \pm 0.4$, and $3.2 \pm 0.7$ with $10^{-5} \mathrm{M} \mathrm{MCh}$, and $2.9 \pm 0.6,2.8 \pm 0.5$ and $2.2 \pm 0.4$ with $10^{-6} \mathrm{M} \mathrm{MCh}$. No statistically significant difference between the means of the three response sizes was found ( $\mathrm{p}=0.095$ and 0.308 , repeated measures ANOVA), confirming that the muscarinic receptor does not desensitize. Variability among oocyte batches is common. Figure 3C, obtained from a frog with relatively great response sizes, demonstrates the possibility that receptor desensitization is not dependent on response size. MCh $10^{-5} \mathrm{M}$ was used as agonist. Average response sizes for the three applications were $10.2 \pm 1.0,11.3 \pm 1.1$, and $12.8 \pm 1.8$. No statistically significant difference between the means of the three response sizes was found $(p=0.129$, repeated 
measures ANOVA), confirming that lack of desensitization of the muscarinic receptor is not response size-dependent. Therefore, we used a control-treatment-recovery paradigm in subsequent experiments.
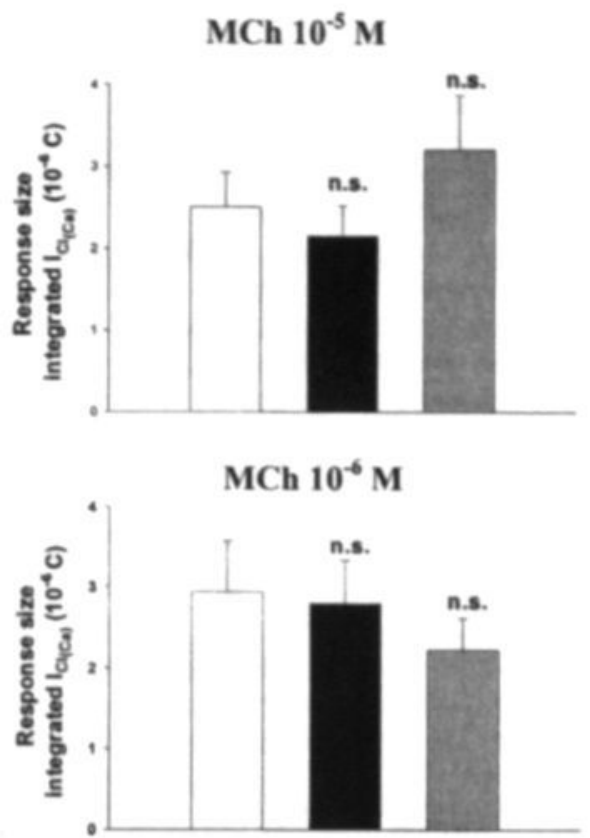

\section{$\operatorname{MCh} 10^{-5} \mathrm{M}$}

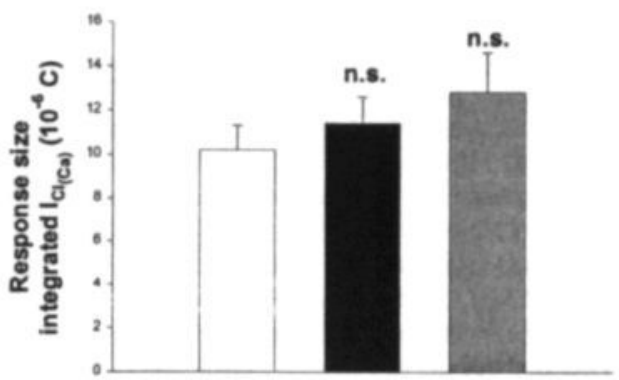

Figure 3A-C: Mean $\pm S E M$ of three consecutive responses in the same oocyte using $10^{5} M(A$ and $C)$ and $10^{6} M(B)$ methylcholine $(n=16)$. Left bar indicates response after the stabilization period, middle bar represents the response 10 minutes later, and right bar is generated 10 minutes after the second response. Response sizes were quantified by integrating the current trace by quadrature and are reported as micro Coulombs $\left(10^{6} \mathrm{C}\right)$. Neither the second nor the third response is statistically different from the first one (n.s.). 


\section{Lidocaine suppresses $\mathbf{M C h}$-induced $\mathbf{I}_{\mathrm{Ca}(\mathrm{Ca})}$ reversibly and concentration-dependently}

To determine if local anesthetics inhibit muscarinic functioning, we chose the most commonly used local anesthetic, lidocaine. Administration for $10 \mathrm{~min}$ of various concentrations of lidocaine resulted in a concentration-dependent inhibition (Figure 4A and B) of muscarinic responses, evoked by stimulation with $\mathrm{MCh}$ at $\mathrm{EC}_{50}(0.57 \mu \mathrm{M})$. Curve fitting revealed a half-maximal inhibitory effect concentration $\left(\mathrm{IC}_{50}\right.$ ) for lidocaine of approximately $1.8 \pm 1.0 \times 10^{-8} \mathrm{M}$, a concentration much lower than that required for blockade of sodium channels, ${ }^{25}$ and also much lower than that reported for interference with muscarinic receptor binding. ${ }^{26}$ Maximal inhibition was obtained with lidocaine 1 $\mathrm{mM}$; at this concentration muscarinic responses were inhibited by $95.4 \%$.
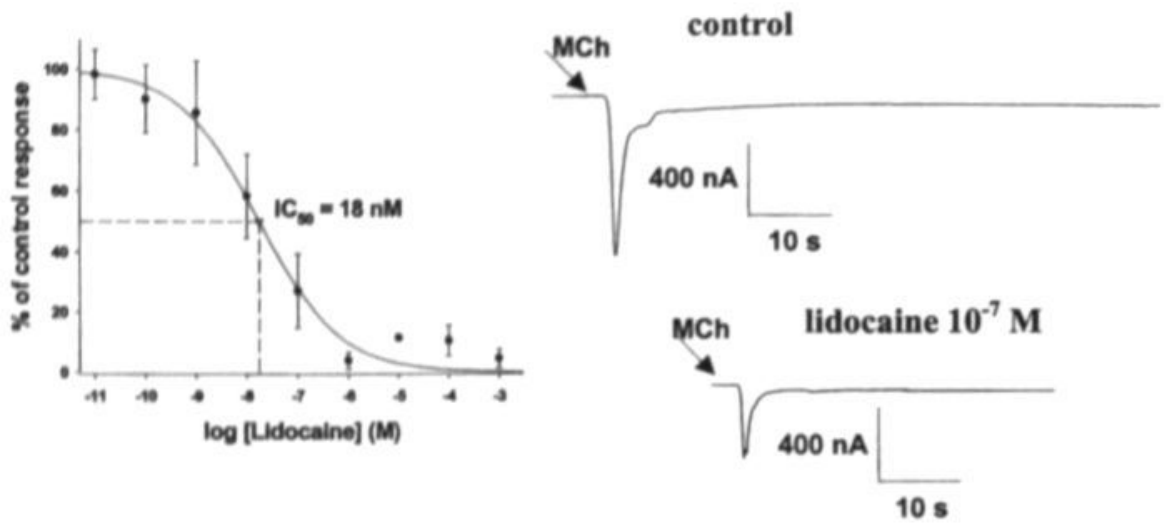

Figure $4 A$ and B: (A) Lidocaine inhibits $M C h\left(E C_{90}\right)$-induced $I_{C_{1}} C_{a j}$ in a concentration-dependent manner. Curve fitting using the Hill equation revealed a half maximal inhibitory concentration $\left(\mathrm{CC}_{30}\right.$ of $1.8 \pm 1.0 \times 10^{\circ} \mathrm{M}$. (B) Example trace of a $\mathrm{MCh}$ (EC $\mathrm{SO}_{\mathrm{s}}$ )-induced control response (top) and $I_{C(C a)}$ after 10 min treatment with lidocaine $\left(I \sigma^{7} M\right)$ on a muscarinic response elicited by $M C h$ (EC sa) stimulation (bottom).

Next we determined the reversibility of the inhibitory effect of lidocaine on $\mathrm{m} 1$ muscarinic ignaling. We used the most efficaceous lidocaine concentration $\left(10^{-3} \mathrm{M}\right)$, as we anticipated it to have a greater likelihood of inducing non-reversible effects. After measurement of the control response, the oocyte was superfused with lidocaine $10^{-3} \mathrm{M}$ for 10 minutes, and the treatment response was obtained. The oocyte was then perfused with Tyrode's solution for 10 minutes and a recovery response was obtained. As shown in Figure 5, the lidocaine effect was reversible. Percent inhibition by lidocaine was similar to that shown in Figure $4 \mathrm{~A}$. Control, treatment and recovery responses to MCh $0.57 \mu \mathrm{M}$ were $8.5 \pm 0.8,0.4 \pm 0.3$, and $6.8 \pm 0.7 \mu \mathrm{C}$, respectively $(n=8)$. There is no statistically significant difference between the control and recovery response $(p=0.149$, paired $t-$ test). The holding current of the oocytes did not change significantly during these experiments. 


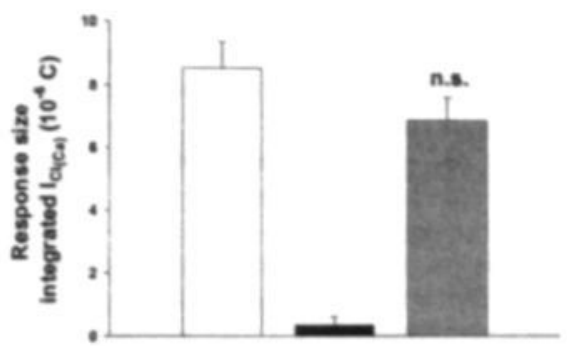

Figure 5: Responses induced by $M C h\left(E C_{90}\right)$ to determine the reversibility of lidocaine $\left(10^{3} M\right)$ inhibition. Three consecutive measurements were made in each oocyte. First bar represents control response $(8.5 \pm 0.8 \mu \mathrm{C})$. The second bar shows the inhibitory effect of lidocaine. I $\mathrm{Crca}_{\mathrm{u}}$ was reduced to $5 \%$ of control response $(0.4 \pm 0.3 \mu \mathrm{C})$. The third bar shows recovery after $10 \mathrm{~min}$ Tyrode's superfusion $(6.8 \pm 0.7 \mu \mathrm{C})$. There is no statistically significant difference between the control and recovery response (n.s.).

\section{Lidocaine acts primarily as an non-competitive antagonist}

To obtain additional information about the site of lidocaine's interaction, we studied the type of antagonism of lidocaine on muscarinic signaling, by determining if lidocaine inhibition could be overcome with greater concentrations of $\mathrm{MCh}$. Responses to various concentrations of $\mathrm{MCh}\left(10^{-9} \mathrm{M}\right.$ to $10^{-3} \mathrm{M}$ were measured under control conditions, or after a 10-minute superfusion with lidocaine at $\mathrm{IC}_{50}(18 \mathrm{nM}, \mathrm{n}=20$ at each MCh concentration, Figure 6$)$. The calculated control EC 50 for $\mathrm{MCh}$ was $4.2 \pm 1.2 \times 10^{-7} \mathrm{M}$; maximal effect $\left(\mathrm{E}_{\max }\right)$ was $7.6 \pm 0.3 \mu \mathrm{C}$. In the presence of lidocaine the concentration-response curve shifted not significantly to the right $\left(\mathrm{EC}_{50} 6.8 \pm 3.1 \times 10^{-7} \mathrm{M}\right.$; $\mathrm{p}=0.445, \mathrm{t}$ test), but $\mathrm{E}_{\max }$ was reduced significantly ( $\mathrm{p}<0.001, \mathrm{t}$ test) to $4.4 \pm 0.4 \mu \mathrm{C}, 43 \%$ inhibition at $\mathrm{E}_{\max }$. These results suggest non-competitive antagonism, as, despite high agonist concentrations, the lidocaine effect is not overcome. These findings suggest that lidocaine does not interact primarily with the ligand binding site.

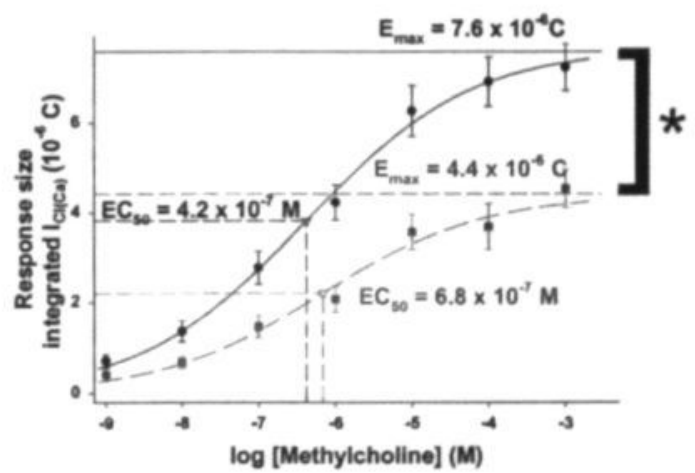

Figure 6: Lidocaine acts primarily as an non-competitive antagonist. Lidocaine did not shift the concentration-response curve for $M C h$ to the right $\left(4.2 \pm 1.2 \times 1 \sigma^{7} M\right.$ to $6.8 \pm 3.1 \times 10^{7} M ; p=0.445$, $t$ test). Maximal effect $\left(E_{\max }\right)$ was significantly reduced after lidocaine administration (7.6 \pm 0.3 to 4.4 $\pm 0.4 \mu C ; p<0.001, t$-test), making an non-competitive antagonism most likely. 
To eliminate oocyte variability, we confirmed the observed non-competitive antagonism in a single oocyte (Figure 7, $\mathrm{n}=20$ ). We performed 4 consecutive measurements: First, the oocyte was stimulated with $1 \mu \mathrm{M} \mathrm{MCh}$ and the corresponding $\mathrm{I}_{\mathrm{C}(\mathrm{C})}$ ) was determined. Average response size was $5.1 \pm 0.5 \mu \mathrm{C}$. Then, the same oocyte was superfused for 10 minutes with lidocaine at approximately $\mathrm{IC}_{\mathrm{s0}}(18 \mathrm{nM})$ and afterwards stimulated with the same concentration of $\mathrm{MCh}$. Lidocaine reduced the average response size to $54 \pm 5.6 \%$ of the control response. A third measurement was performed following another 10-minute superfusion with lidocaine at approximately $\mathrm{IC}_{50}(18 \mathrm{nM})$, this time using a fully efficaceous $\mathrm{MCh}$ concentration of $1 \mathrm{mM}$. Average response size with the higher agonist concentration was similar to that obtained using 1 $\mu \mathrm{M} \mathrm{MCh}(44.2 \pm 3.2 \%$ of the control response, $\mathrm{P}>0.05$, repeated measurements ANOVA, Turkey post hoc test). Although holding current of the oocytes did not change significantly during these experiments, we wished to confirm that the effect obtained was reversible. Thus, we superfused the oocyte with Tyrode's solution for 10 minutes and then stimulated it with $1 \mu \mathrm{M} \mathrm{MCh}$. Mean response size recovered to $89.3 \pm 4.3 \%$ of the control response $(P>0.05$, repeated measurements ANOVA, Turkey post hoc test).

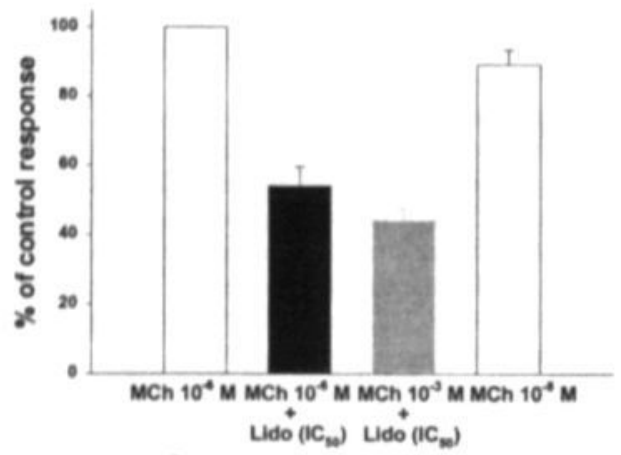

Figure 7: Non-competitive antagonism for lidocaine was confirmed by four consecutive measurements in the same oocyte. First bar represents control response elicited by stimulation of the oocyte using $1 \mu \mathrm{MMCh}(5.1 \pm 0.5 \mu \mathrm{C})$. The second bar shows the inhibitory effect of a 10-minute superfision with lidocaine (at approximately $I C_{s 0}(18 \mathrm{nM})$ ). $1 \mu \mathrm{M} M C$ Ch-induced $I_{C_{C}\left(C_{a}\right)}$ was reduced to $54 \pm 5.6 \%$ of control response. The third bar represents average response, following again a 10 minute superfusion with lidocaine at approximately $I C_{50}(18 \mathrm{nM})$, using $1 \mathrm{mM} M C \mathrm{Ch}$ as agonist. Average response size was reduced to $44.2 \pm 3.2 \%$ of the control response (not significant to stimulation withl $\mu \mathrm{M} M C \mathrm{Ch}, P>0.05$, repeated measurements ANOVA, Turkey post hoc-test). The fourth bar shows recovery after 10 min Tyrode's superfusion. I I ( $\mathrm{Ca}_{\text {a) }}$ was induced by administration of $1 \mu \mathrm{M}$ MCh. Mean response size recovered to $89.3 \pm 4.3 \%$ of the control response (not significant to control response, $P>0.05$, repeated measurements ANOVA, Turkey post hoc-test).

\section{Muscarinic signaling is inhibited by extracellular administered QX314}

To assess lidocaine's site of action on muscarinic signaling, we superfused the oocytes with the permanently charged and therefore membrane impermeant lidocaine analog QX314.

In contrast to our results obtained from experiments with QX314 on lysophosphatidate signaling. where extracellularly administered QX314 was without effect, ${ }^{4}$ extracellular QX314 blocked ml muscarinic signaling. Curve fitting revealed an $\mathrm{IC}_{5_{0}}$ of $2.4 \pm 0.6 \times 10^{-6} \mathrm{M}$ (Figure 8), approximately 2 orders of magnitude less potent than lidocaine. Although, Hill coefficient $(0.39)$ of the inibition curve is not typical for a ligand-gated receptor effect and might be in part due to non-specific action of QX314, muscarinic signaling can be inhibited by local anesthetics acting on an extracellular site. 


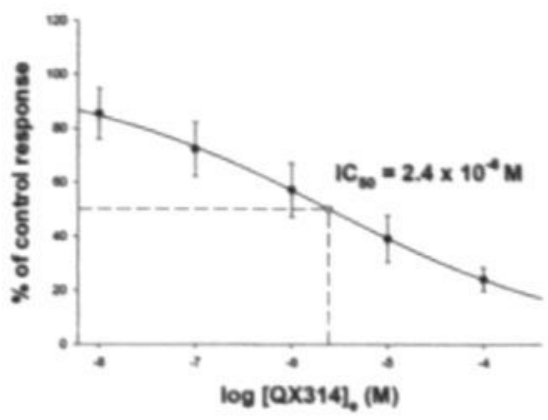

Figure 8: Muscarinic signaling is inhibited by extracellularly administered QX314 in a concentration-dependent manner. Responses were induced by stimulation with MCh at approximately $E C_{90}$. Calculated $I C_{90}$ was $2.4 \pm 0.6 \times 10^{6} \mathrm{M}$.

\section{QX314 administered extracellularly acts as a non-competitive antagonist}

If extracellularly applied QX314, being a charged molecule, acts on the polar, extracellular agonist binding site we would expect competitive antagonism for QX314 on muscarinic signaling. Thus we elicited responses to various concentrations of $\mathrm{MCh}$ before and after administration of QX314 at $\mathrm{IC}_{50}\left(\mathrm{n}>12\right.$ at each MCh concentration). As shown in Figure 9, MCh EC $\mathrm{s0}_{0}$ was $1.8 \pm 0.7 \mathrm{x}$ $10^{-5} \mathrm{M}$ for the control responses and $2.8 \pm 0.5 \times 10^{-5} \mathrm{M}$ for the treatment responses, a difference which did not reach statistical significance $(\mathrm{p}=0.245$, $t$-test $)$. In contrast, calculated $\mathrm{E}_{\max }$ for the control group $(9.1 \pm 0.8 \mu \mathrm{C})$ was significantly different from that of the treatment group $(7.2 \pm 0.3 \mu \mathrm{C}$, $\mathrm{p}=0.048, \mathrm{t}$-test).

Although reduction of $\mathrm{E}_{\max }$ by $\mathrm{QX} 314$ is not $50 \%$ as expected for a theoretical purely noncompetitive effect, these results are in agreement with the results using lidocaine described above, and make competitive antagonism of QX314 on muscarinic functioning unlikely. We therefore suggest that the extracellular inhibitory effect of local anesthetics is mainly exerted by noncompetitive antagonism.

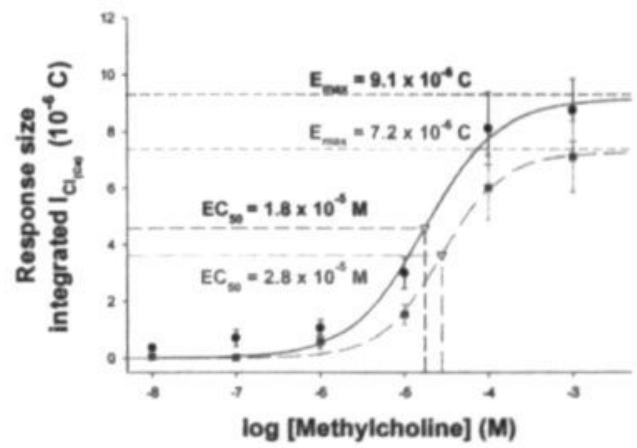

Figure 9: This inhibition is due to a non-competitive antagonism, because QX314 depresses $E_{\max }$ significantly $(9.1 \pm 0.8$ to $7.2 \pm 0.3 \mu \mathrm{C})$, without changing $E C_{50}\left(1.8 \pm 0.7 \times 10^{3}\right.$ to $2.8 \pm 0.5 \times 10^{5} \mathrm{M}$, $(p=0.245))$. 
Benzocaine and intracellular QX314 inhibit muscarinic and lysophosphatidate signaling to similar degrees

After investigating the effect of extracellularly administered QX314, we studied the effect of the permanently uncharged, and therefore membrane permeant, local anesthetic benzocaine.

Benzocaine showed half maximal inhibition at a concentration of $1.2 \pm 0.9 \times 10^{-3} \mathrm{M}$ (Figure 10). Thus, non-polar local anesthetics are not effective muscarinic blockers.

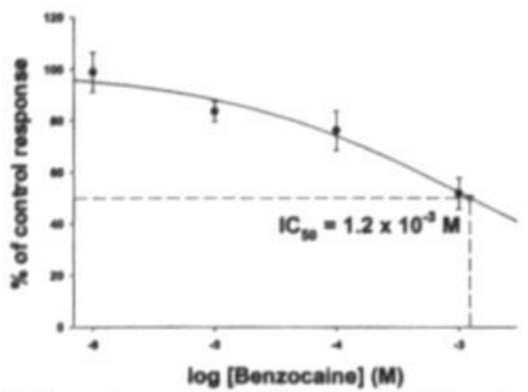

Figure 10: Benzocaine inhibits $\mathrm{ml}$ responses. Calculated half maximal inhibition concentration was $1.2 \pm 0.9 \times 1 \sigma^{3} \mathrm{M}$.

Next we studied the effects of intracellularly injected QX314 on muscarinic signaling. Figure 11 shows the concentration-response relationship for the QX314 effect. Curve fitting to the Hill equation revealed an $\mathrm{IC}_{30}$ of $9.6 \pm 2.0 \times 10^{-4} \mathrm{M}$, approximately 3 orders of magnitude less potent than extracellularly applied $Q \times 314$. Local anesthetics acting intracellularly could interfere at the receptor or $\mathrm{G}$ protein (since we have shown lack of interaction with the distal signaling pathway ${ }^{2}$ ).

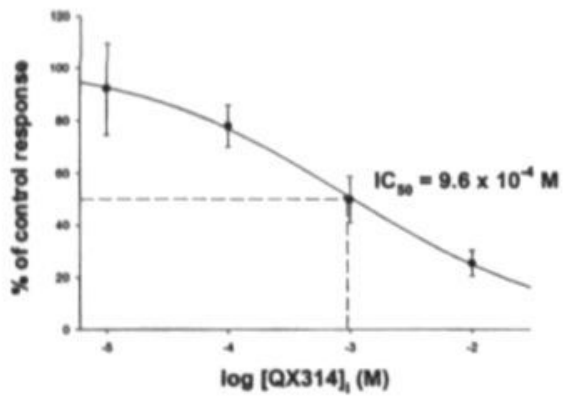

Figure 11: Muscarinic inhibition by intracellularly injected $Q X 314 . I C_{50}$ is $9.6 \pm 2.0 \times 10^{4} \mathrm{M}$.

A differentiation between these sites can be suggested by comparing effects of local anesthetic on two different $\mathrm{G}_{\mathrm{q}}$-coupling receptors expressed in oocytes. In this case the intracellular receptor domains would be divergent, whereas the $\mathrm{G}$ proteins coupled to would be identical. If the local anesthetic acts on the $\mathrm{G}$ protein, similar pharmacologic parameters would be expected to be obtained in both experiments, whereas very different results would be likely when the local anesthetic acts on the receptor. Therefore, we compared the effects of QX314 and benzocaine on $\mathrm{ml}$ receptors with data we obtained previously using LPA receptors. Figure 12A and 12B show the concentration-response relationship for benzocaine and intracellular QX314 on these two receptor systems (lysophosphatidate data from Sullivan et al. ${ }^{4}$ ). For QX314, not only are calculated IC 50 S very similar $\left(9.6 \pm 2.0 \times 10^{-4} \mathrm{M}\right.$ for $\mathrm{MCh}, 7.2 \pm 1.0 \times 10^{-4} \mathrm{M}$ for lysophosphatidate), but maximal degree of inhibition $(74.6 \%$ and $71.6 \%)$ and slope of the inhibition curve $(0.48$ and 0.47$)$ were also 
similar. For benzocaine calculated $\mathrm{IC}_{\mathrm{sos}}$ are close to each other $\left(1.2 \pm 0.8 \times 10^{-3} \mathrm{M}\right.$ for $\mathrm{MCh}, 1.0 \pm 0.6$ $\times 10^{-3} \mathrm{M}$ for lysophosphatidate), whereas slope of the inhibition curve $(0.42$ and 0.68$)$ and maximal degree of inhibition $(62.1 \%$ and $72.2 \%)$ showed slightly more divergence. Nonetheless the similarity of the curves suggest a common site of action on muscarinic and lysophosphatidate signaling by benzocaine and intracellular QX314. This suggests that local anesthetics may inhibit $G$ protein function.
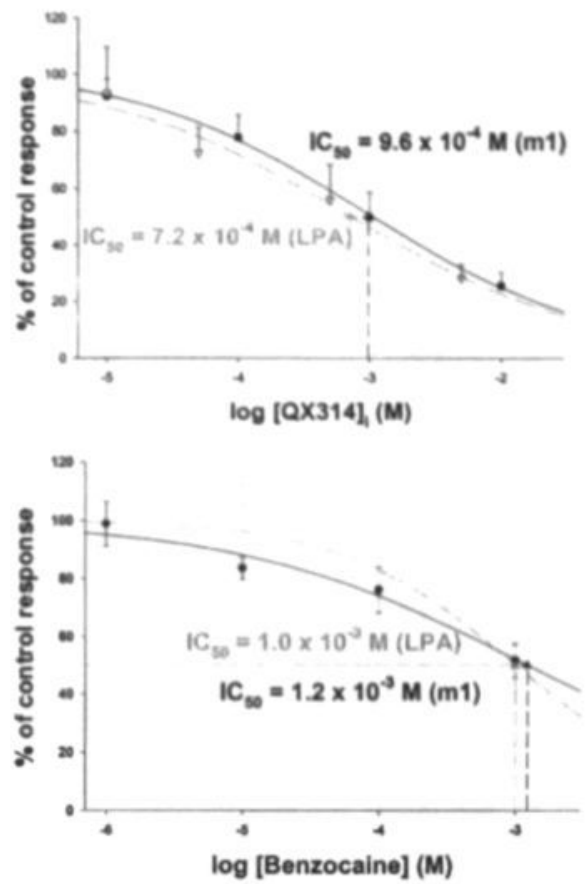

Figure 12: (A) Intracellular injected QX314 inhibits muscarinic mI ( $\bullet-)$ and lysophosphatidate (LPA) (- $\nabla-)$ signaling at similar concentrations (LPA data from Sullivan et al. ${ }^{*}$ ). Curve fitting using the Hill equation revealed an $I C_{s 0}$ of $9.6 \pm 2.0 \times 10^{4} M$ for the $m 1$ muscarinic receptor, and $7.2 \pm 1.0 \times 10^{4} \mathrm{M}$ for the lysophosphatidate receptors. (B) Inhibition by benzocaine of $\mathrm{ml}$

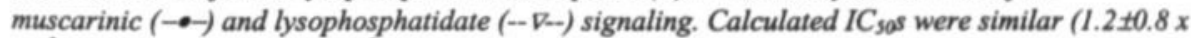
$10^{3} \mathrm{M}$ for $\mathrm{MCh}, 1.0 \pm 0.6 \times 10^{3} \mathrm{M}$ for lysophosphatidate).

\section{Combined administration of intracellularly injected and extracellularly applied QX.314 inhibit in a superadditive manner}

We tested if intracellularly injected and extracellularly administered QX314 act in a superadditive manner. Therefore we measured the effects of various concentrations of intra- $/$ and extracellular QX314 (400:1 concentration ratio) on MCh-elicited responses. Curve fitting using the

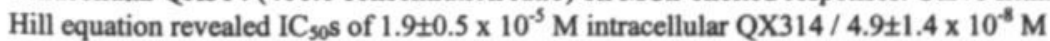
extracellular QX314, approximately 50-fold less than those obtained when the compounds were studied in isolation, and similar to the $\mathrm{IC}_{50}$ obtained with lidocaine. As shown in the isobologram in Figure $13 \mathrm{~A}$, measured $\mathrm{IC}_{50}$ for the combination is outside the $95 \%$ confidence interval (sum of fraction 0.041 ) for purely additive action, supporting our hypothesis of two superadditive sites of 
action: an extracellular site which is not the ligand-binding domain, and an intracellular site which is likely to be the $\mathrm{G}$ protein (Figure 13B). Lidocaine would have access to both sites, which would explain its high potency.
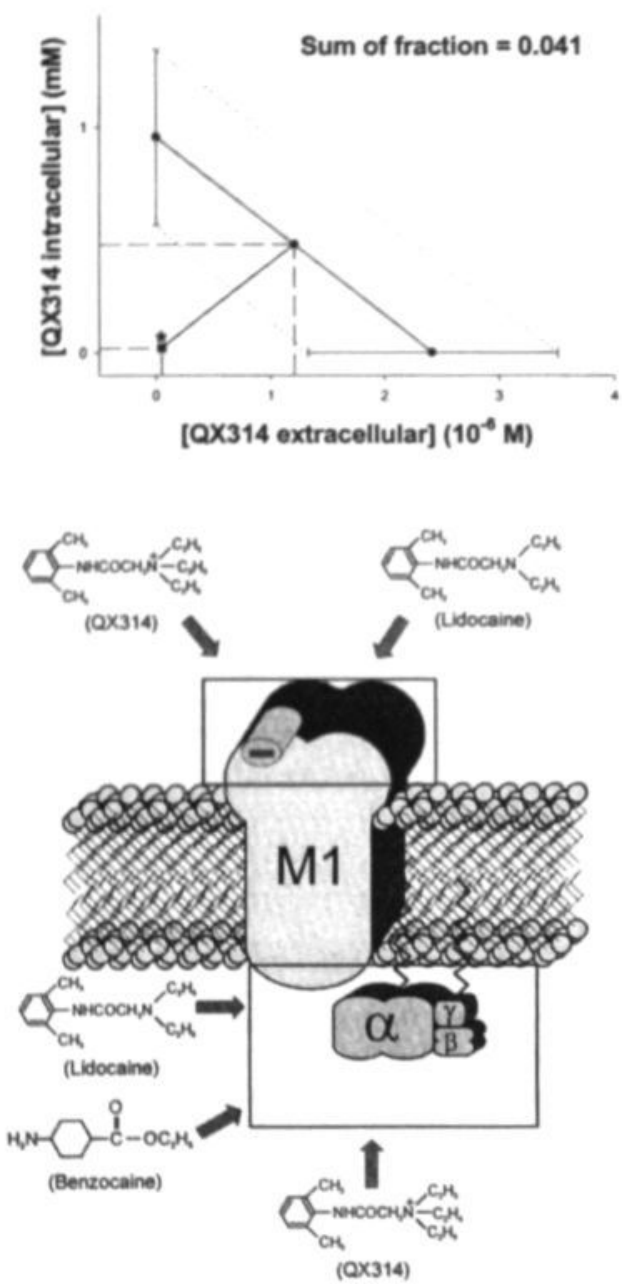

Figure 13: (A) Superadditive inhibition of muscarinic signaling by combined administration of intracellularly injected and extracellularly applied QX314. Measured IC $505\left(1.9 \pm 0.5 \times 10^{5} \mathrm{M}\right.$ intracellular $Q \times 314$ and $4.9 \pm 1.4 \times 10^{8} \mathrm{M}$ extracellular $Q \times 314$ ) for the combination are outside the $95 \%$ confidence interval (sum of fraction 0.041, $p<0.05$ ) for purely additive action, indicating two superadditive sites of action. (B) Hypothesized sites of inhibition for local anesthetics on muscarinic signaling. Main inhibitory action is on an extracellular hydrophilic, polar, non-competitive site on the muscarinic receptor molecule. A second (superadditive) inhibitory effect is obtained by intracellular action, probably on the coupled $G$ protein. 
Inhibition of muscarinic $\mathrm{ml}$ receptor signaling by lidocaine is not due to interaction with the ligand binding pocket

We determined that lidocaine acts primarily as an non-competitive antagonist on muscarinic ml receptors. This strongly suggests an action outside the ligand-binding domain. If so, ligand binding should not be affected significantly by concentrations of lidocaine that inhibit signaling. Previous binding studies suggest this, ${ }^{626}$ but to our knowledge, it has not been tested in a system expressing only $\mathrm{ml}$ receptors. Therefore, we studied the effect of lidocaine on [ $\left.{ }^{3} \mathrm{H}\right] \mathrm{QNB}$ binding to $\mathrm{ml}$ muscarinic receptors. We first characterized [ $\left.{ }^{3} \mathrm{H}\right] \mathrm{QNB}$ binding to membranes prepared from $\mathrm{CHO}$ cells, stably transfected with the rat muscarinic ml receptor. Over a range of 0.1 to $16 \mathrm{nM}$ free drug specific binding was saturable and reached a maximum at 1.8-2.4 nM. The saturation curve and Scatchard analysis (Figure 14) conform closely to a single site model with a $\mathrm{K}_{\mathbb{d}}$ of $0.23 \pm 0.01 \mathrm{nM}$ $(\mathrm{n}=3)$ and $\mathrm{B}_{\max }$ of $549 \pm 17 \mathrm{nM}(\mathrm{n}=3)$.

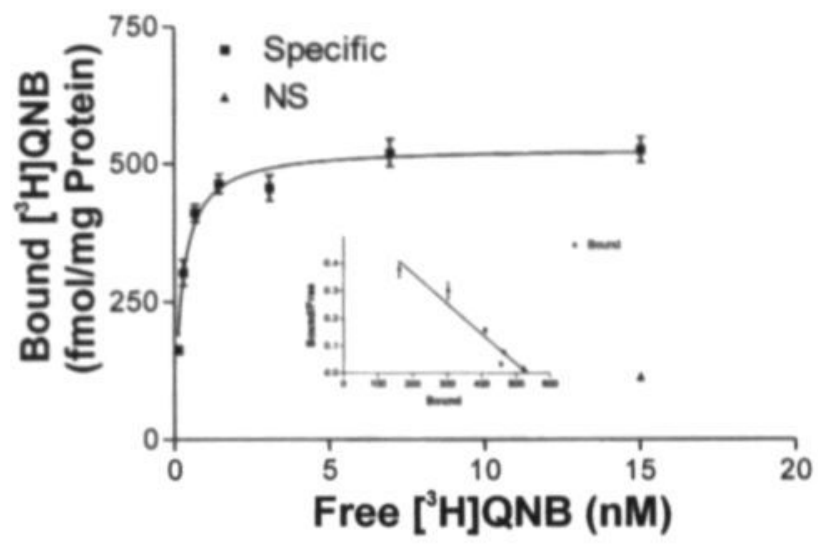

Figure 14: Characterization of $\left.{ }^{3} \mathrm{H}\right] \mathrm{QNB}$ binding to membranes prepared from $\mathrm{CHO}$ cells, stably transfected with the rat muscarinic $m l$ receptor. The saturation curve and Scatchard analysis conform to a single site model with a $K_{d}$ of $0.23 \pm 0.01 n M(n=3)$ and $B_{\max }$ of $549 \pm 17 n M(n=3)$.

The action of lidocaine was tested in concentrations ranging between $10^{-10}$ and $10^{-2} \mathrm{M}$ (Figure 15). Lidocaine, at concentrations that inhibit $\mathrm{ml}$ muscarinic signaling, did not affect specific binding of $\left[{ }^{3} \mathrm{H}\right] \mathrm{QNB}$ to the muscarinic $\mathrm{ml}$ receptor. Lidocaine concentrations of $10^{-3}$ and $10^{-2} \mathrm{M}$ modestly reduced specific binding, but in this concentration range nonspecific effects could not be excluded. Calculated $\mathrm{IC}_{50}$ using the Hill equation was $39 \pm 4 \mathrm{mM}(\mathrm{n}=5)$. These results are in full agreement with the data reported above indicating a primarily non-competitive antagonism of lidocaine on muscarinic $\mathrm{ml}$ receptors. 


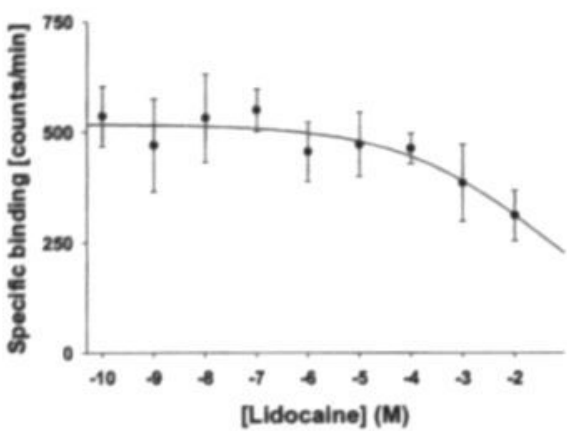

Figure 15: Effects of lidocaine on specific binding of $\left.{ }^{3} H\right] Q N B$ to muscarinic $m /$ receptors. Calculated IC $C_{30}$ using the Hill equation was $39 \pm 4 \mathrm{mM}(n=5)$.

\section{DISCUSSION}

In the present study we investigated the effect of local anesthetics on the functioning of muscarinic receptors of the $\mathrm{ml}$ subtype, the most common subtype in the CNS. We demonstrated that lidocaine inhibits signaling of muscarinic receptors expressed recombinantly in Xenopus oocytes. Its $\mathrm{IC}_{30}(18 \mathrm{nM})$ is significantly less than that required for blocking sodium channels $(60$ to $200 \mu \mathrm{M}$, depending on the state of the $\mathrm{Na}^{+}$-channel). ${ }^{25}$ Clinically relevant blood concentrations during iv infusion or epidural anesthesia are in the range of 1 to $15 \mu \mathrm{M}$, corresponding to a plasma level of 0.3 to $4.5 \mu \mathrm{g} / \mathrm{ml}$. Based on these results we postulate that $\mathrm{ml}$ muscarinic receptors may be a target for local anesthetics in the CNS.

Although best known for their ability to block Na channels, local anesthetics interact with other cellular systems as well, and some of their general anesthetic properties may result from interactions with these other targets. Several studies report that local anesthetics - administered intrathecally, intravenously or intramuscularly - reduce significantly the required concentrations for volatile anesthetics, such as nitrous oxide and halothane, ${ }^{29}$ and for intravenous anesthetics, such as thiopental, midazolam or propofol. ${ }^{28-30}$ Inagaki showed that epidural administration of lidocaine delays awakening from isoflurane anesthesia. ${ }^{31}$ The mechanisms underlying these results have not been not studied in detail; our findings, interpreted in view of the effects of CNS muscarinic blockade on consciousness, ${ }^{32}$ suggest that suppression of muscarinic signaling may be involved.

Part of our present study was designed to compare local anesthetic effects on muscarinic signaling with those on lysophosphatidate signaling, as reported earlier, ${ }^{4}$ and methodology was therefore maintained constant between the two studies. Nonetheless, our findings were quite different. Lysophosphatidate ${ }^{4}$ and thromboxane $\mathrm{A}_{2}{ }^{3}$ receptors are inhibited by local anesthetics, but the primary site of action seemed to be at the intracellular domains of the receptor, or at the $\mathrm{G}$ protein. Extracellular administration of QX314 inhibited neither lysophosphatidate nor thromboxane $\mathrm{A}_{2}$ signaling, but intracellular QX314 inhibits both signaling pathways effectively. Benzocaine inhibits as well, and shows profound superadditive interaction with intracellular QX314 on lysophosphatidate signaling. The signaling pathway downstream of the G protein is not affected by local anesthetics (responses induced by GTPYS injection were not inhibited). Thus, local anesthetics appear to inhibit lysophosphatidate and muscarinic $\mathrm{ml}$ receptor signaling via an action on the intracellular domain of the receptor, the associated $\mathrm{G}$ protein or coupling betqween the two. But since $\mathrm{G}$ protein activation with GTPYS bypasses several critical $\mathrm{G}$ protein functions (e.g. receptor-G protein-coupling and GTPase activity), we could not exclude a direct effect of local anesthetics on the $\mathrm{G}$ protein itself. 
Local anesthetic effects on muscarinic signaling were quite different. The inhibitory potency of lidocaine was several orders of magnitude greater than we observed on lysophosphatidate or thromboxane $A_{2}$ receptors. The effect was non-competitive, and not associated with a decrease in agonist binding. Extracellular QX314 inhibited muscarinic signaling also, although with significantly less potency than lidocaine. Benzocaine and intracellularly injected QX314 inhibited with a potency similar to that observed on lysophophosphatidate and thromboxane $A_{2}$ receptors. Intra- and extracellular QX314 inhibited in a superadditive manner. To explain these findings, we postulate the presence of two interacting local anesthetic binding sites in the early steps of the muscarinic signaling pathway (Figure 13B). The primary site would be a polar, hydrophilic, noncompetitive site on the extracellular receptor domains, the secondary site would be localized on the intracellular receptor domains or on the $\mathrm{G}$ protein. In view of the remarkable similarity of the inhibition curves of intracellular QX314 and benzocaine on muscarinic, lysophosphatidate ${ }^{4}$ and thromboxane $\mathrm{A}_{2}$ (Hoenemann, unpublished) receptors, we hypothesize that this latter site is localized on the (common) $\mathrm{G}$ protein, rather than on the (highly diverse) receptors. Alternatively benzocaine could act on a non-polar extracellular site, but the similar inhibitory effects of benzocaine on different receptors make this explanation less likely. Lidocaine's remarkable potency could be explained because it would have access to both sites, resulting in superadditive interaction.

Several studies have shown inhibition of muscarinic receptor binding by various local anesthetics. In general, the required concentrations were high, and a variety of mechanisms have been invoked to explain the findings. Non-specific alteration of surface charge and fluidity of the cell membrane, ${ }^{33-33}$ resulting in a dislocation of the receptor and effector components, have been proposed. Aguilar et al. suggested that local anesthetics bind not to the receptor site, but to a nearby accessory site, since they found local anesthetics not to provide protection against the deleterious effect of Triton X-100, whereas agonists and antagonists did. ${ }^{26}$ These findings are consistent with our results.

Fairhust et al. investigated the effect of lidocaine on $\left[{ }^{3} \mathrm{H}\right] \mathrm{QNB}$ binding to muscarinic receptors in a rat brain cortex preparation. They found lidocaine to inhibit [ $\left.{ }^{3} \mathrm{H}\right] \mathrm{QNB}$ binding, with inhibitory potency correlating with $\mathrm{pH}$ (i.e. with the amount of the charged form of lidocaine). In their study, competitive inhibition occurred only at higher concentrations ( $\mathrm{IC}_{50}$ for lidocaine $0.13 \mathrm{mM}$ ). The $\mathrm{IC}_{50}$ for lidocaine obtained in our binding assay was two orders of magnitude higher ( $\left.39 \mathrm{mM}\right)$. This discrepancy could be explained by differences in the employed models. Whereas we performed our binding assay as described on membranes prepared from stably transfected $\mathrm{CHO}$ cells, Fairhurst et al. obtained their results from rat brain cortex preparations, probably containing multiple receptor subtypes. QNB is known to interact with accessory sites in addition to the agonist binding region of the muscarinic receptor ${ }^{36,37}$. Therefore it is conceivable that high concentrations of local anesthetics displace $\left[{ }^{3} \mathrm{H}\right] \mathrm{QNB}$ binding by interaction with an accessory receptor region, while having no effect on agonist binding to the receptor. However, the results by Fairhurst et al. fit also partially to a theoretical model indicating that carbachol, $\left[{ }^{3} \mathrm{H}\right] \mathrm{QNB}$ and lidocaine (in higher concentrations) might competitively displace one another at the same agonist binding site.

Other interactions, direct and indirect, between local anesthetics and muscarinic signaling are possible, and were not investigated in our study. In some tissues and brain regions muscarinic receptors might be capable of interacting with sodium channels. Cohen-Armon et al. found that local anesthetics inhibit batrachotoxin-enhanced binding affinity for muscarinic receptor agonists." Recently Horio et al. showed that local anesthetics inhibit mucarinic receptor desensitization in guinea pig ileal longitudinal muscle. ${ }^{10}$ Some local anesthetics exert this effect by competitive antagonism, others act on an non-competitive site. Alteration of the conformation of the ligand binding site followed by modification of ligand receptor interaction were hypothesized to explain these findings. In our model the $\mathrm{ml}$ receptor does not significantly desensitize, so we could not investigate this issue.

One significant limitation of all studies cited is the lack of definition of the muscarinic subtypes investigated. All studies used tissues which may express a variety of receptor subtypes, making interpretation difficult. In brain, all 5 muscarinic receptor subtypes are expressed, ${ }^{38}$ and differences 
between the $\mathrm{m1}-\mathrm{m} 3-\mathrm{m} 5$ and $\mathrm{m} 2-\mathrm{m} 4$ groups in structure and effector coupling are such that results can not be extrapolated easily. (For example, significant $\mathrm{m} 2$ receptor block by local anesthetics would result in tachycardia, which is clearly not one of the common side effects of lidocaine). These problems are overcome by recombinant expression of a single subtype in isolation.

In summary, our present study shows that local anesthetics inhibit muscarinic $\mathrm{ml}$ receptors expressed recombinantly in Xenopus oocytes. Lidocaine inhibits at concentrations significantly less than those required for blocking sodium channels. We suggest that this inhibitory effect is due to superadditive interactions between non-competitive antagonism on an extracellular, polar site on the muscarinic receptor molecule, and an intracellular site probably on the coupled $G$ protein. Whereas the intracellular site appears to be the same on muscarinic, lysophosphatidate and thromboxane $A_{2}$ receptors, the lipid mediator receptors lack the extracellular polar local anesthetic binding domain. 
1. Butterworth JF, Strichartz GR: Molecular mechanisms of local anesthesia: a review. Anesthesiology 1990; 72:711-34

2. Nietgen GW, Chan CK, Durieux ME: Inhibition of lysophosphatidate signaling by lidocaine and bupivacaine. Anesthesiology 1997; 86:1112-9

3. Hoenemann CW, Podranski T, Lo B, Yanovitch M, Durieux ME: Local anesthetic effects on thromboxane A2 signaling. Anesthesiology 1998; 89:A886

4. Sullivan LM, Hoenemann CW, Arledge JAM, Durieux ME: Synergistic inhibition of lysophosphatidic acid signaling by charged and uncharged local anesthetics. Anesth Analg 1999; 88:1117-24

5. Hyvonen PM, Kowolik MJ: Dose-dependent suppression of the neutrophil respiratory burst by lidocaine. Acta Anaesthesiol Scand 1998; 42:565-9

6. Fairhurst AS, Whittaker ML, Ehlert FJ: Interactions of D600 (methoxyverapamil) and local anesthetics with rat brain alpha-adrenergic and muscarinic receptors. Biochem Pharmacol 1980; 29:155-62

7. Schimerlik MI, Searles RP: Ligand interactions with membrane-bound porcine atrial muscarinic receptor(s). Biochemistry 1980; 19:3407-13

8. Nishizawa Y, Gusovsky F, Daly JW: Local anesthetics: comparison of effects on batrachotoxin-elicited sodium flux and phosphoinositide breakdown in guinea pig cerebral cortical synaptoneurosomes. Mol Pharmacol 1988; 34:707-13

9. Cohen-Armon M, Kloog Y, Henis YI, Sokolovsky M: Batrachotoxin changes the properties of the muscarinic receptor in rat brain and heart: possible interaction(s) between muscarinic receptors and sodium channels. Proc Natl Acad Sci U S A 1985; 82:3524-7

10. Horio S, Nagare T, Ishida Y, Moritoki H: Effects of local anesthetics on acetylcholineinduced desensitization of guinea pig ileal longitudinal muscle. J Pharmacol Exp Ther $1998 ; 286: 221-7$

11. Durieux ME: Halothane inhibits signaling through $\mathrm{ml}$ muscarinic receptors expressed in Xenopus oocytes. Anesthesiology 1995; 82:174-82

12. Nietgen GW, Hoenemann CW, Chan CK, Kamatchi GL, Durieux ME: Volatile anaesthetics have differential effects on recombinant $\mathrm{ml}$ and $\mathrm{m} 3$ muscarinic acetylcholine receptor function. Br J Anaesth 1998; 81:569-77

13. Durieux ME: Inhibition by ketamine of muscarinic acetylcholine receptor function. Anesth Analg 1995; 81:57-62

14. Durieux ME, Nietgen GW: Synergistic inhibition of muscarinic signaling by ketamine stereoisomers and the preservative benzethonium chloride. Anesthesiology 1997; $86: 1326-33$

15. Durieux ME: Muscarinic signaling in the central nervous system: Recent developments and anesthetic implications. Anesthesiology 1996; 84:173-89 
16. Zucker J: Central cholinergic depression reduces MAC for isoflurane in rats. Anesth Analg $1991 ; 72: 790-5$

17. Bonhomme V, Meuret P, Backman SB, Plourde G, Fiset P: Cholinergic mechanisms mediating propofol-induced loss of consciousness in man. Can J Anaesth 1998; 45:A52

18. Durieux ME: OoClamp: An IBM-compatible software system for the study of receptors expressed in Xenopus oocytes. Comput Methods Programs Biomed 1993; 41:101-5

19. Durieux ME, Salafranca MN, Lynch KR, Moorman JR: Lysophosphatidic acid induces a pertussis toxin-sensitive $\mathrm{Ca}^{2+}$-activated $\mathrm{Cl}^{2}$ current in Xenopus laevis oocytes. Am J Physiol 1992; 263:C896-C900

20. Durieux ME, Carlisle SJ, Salafranca MN, Lynch KR: Endogenous responses to sphingosine1-phosphate in $X$. laevis oocytes: similarities with lysophosphatidic acid signaling. Am J Physiol 1993; 264:C1360-C1364

21. Fernhout BJH, Dijcks FA, Moolenaar WH, Ruigt GSF: Lysophosphatidic acid induces inward currents in Xenopus laevis oocytes: evidence for an extracellular site of action. Eur J Pharmacol 1992; 213:313-5

22. Shapira H, Amit I, Revach M, Oron Y, Battey JF: G 14 and Gaq mediate the response to trypsin in Xenopus Oocytes. J Biol Chem 1998; 273:19431-6

23. Tallarida RJ, Porreca F, Cowan A: Statistical analysis of drug-drug and site-site interactions with isobolograms. Life Sci 1989; 45:947-61

24. Tallarida RJ: Statistical analysis of drug combinations for synergism. Pain 1992; 49:93-7

25. Scholz A, Kuboyama N, Hempelmann G, Vogel W: Complex blockade of TTX-resistant Na+ currents by lidocaine and bupivacaine reduce firing frequency in DRG neurons. J Neurophysiol 1998; 79:1746-54

26. Aguilar JS, Criado M, De Roberts E: Inhibition by local anesthetics, phentol-amine and propranolol of $[\mathrm{H}]$ Quinyclydinyl benzylate binding to central muscarinic receptors. Eur J Pharmacol 1980; 68:317-26

27. Himes RSJ, DiFazio CA, Burney RG: Effects of lidocaine on the anesthetic requirements for nitrous oxide and halothane. Anesthesiology 1977; 47:437-40

28. Tverskoy M, Ben-Shlomo I, Vainshtein M, Zohar S, Fleyshman G: Hypnotic effect of i.v. thiopentone is enhanced by i.m. administration of either lignocaine or bupivacaine. $\mathrm{Br}$ J Anaesth 1997; 79:798-800

29. Tverskoy M, Fleyshman G, Bachrak L, Ben-Shlomo I: Effect of bupivacaine-induced spinal block on the hypnotic requirement of propofol. Anaesthesia 1997; 51:652-3

30. Tverskoy M, Shagal M, Finger J, Kissin I: Subarachnoid bupivacaine blockade decreases midazolam and thiopental hypnotic requirements. J Clin Anesth 1994; 6:487-90

31. Inagaki Y, Mashimo T, Kuzukawa A, Tsuda Y, Yoshiya I: Epidural lidocaine delays arousal from isoflurane anesthesia. Anesth Analg 1994; 79:368-72 
32. Fibiger HC, Damsma G, Day JC: Behavioral pharmacology and biochemistry of central cholinergic neurotransmission. Adv Exp Med Biol 1991; 295:399-414

33. Richelson E, Prendergast FG, Divinetz-Romero S: Muscarinic receptor-mediated cyclic GMP formation by cultured nerve cells--ionic dependence and effects of local anesthetics. Biochem Pharmacol 1978; 27:2039-48

34. Weber $\mathrm{M}$, Changeux JP: Binding of Naja nigricollis $(3 \mathrm{H})$ alpha-toxin to membrane fragments from Electrophorus and Torpedo electric organs. 3. Effects of local anaesthetics on the binding of the tritiated alpha-neurotoxin. Mol Pharmacol 1974; 10:35-40

35. Sheetz MP, Singer SJ: Biological membranes as bilayer couples. A molecular mechanism of drug-erythrocyte interactions. Proc Natl Acad Sci US A 1974; 71:4457-61

36. Aronstam RS, Abood LG, Baumgold J: Role of phospholipids in muscarinic binding by neural membranes. Biochem Pharmacol 1977; 26:1689-95

37. Ariens EJ, Simonis AM: Cholinergic and anticholinergic drugs, do they act on common receptors?. Ann N Y Acad Sci 1967; 144:842-69

38. Brann MR, Ellis J, Jorgensen H, Hill-Eubanks D, Jones SVP: Muscarinic acetylcholine receptor subtypes: localization and structure/function. Prog Brain Res 1993; 98:121-7 
CHAPTER 5

Inhibition of $\mathrm{m} 3$ muscarinic acetylcholine receptors by local anesthetics

\author{
Markus W. Hollmann \\ Carsten H. Ritter \\ Philipp Henle \\ Manuela de Klaver \\ Ganesan L. Kamatchi \\ Marcel E. Durieux
}

The author is recipient of the second-place award in the American Society of Anesthesiologists

Residents' Research Essay Contest in 2001 for a part of the work presented in this article

Published in: British Journal of Pharmacology 133: 207-216, 2001 


\section{Inhibition of $\mathrm{m} 3$ muscarinic acetylcholine receptors by local anesthetics}

\section{SUMMARY}

1. Muscarinic $\mathrm{ml}$ receptors are inhibited by local anesthetics (LA) at $\mathrm{nM}$ concentrations. To elucidate in more detail the site(s) of LA interaction, we compared these findings with LA effects on $\mathrm{m} 3$ muscarinic receptors.

2. We expressed receptors in Xenopus oocytes. Using two-electrode voltage clamp, we measured the effects of lidocaine, QX314 (permanently charged) and benzocaine (permanently uncharged) on $\mathrm{Ca}^{2+}$-activated $\mathrm{Cr}$-currents ( $\left.\mathrm{I}_{\mathrm{c}} \mathrm{Ca}\right)$, elicited by acetyl- $\beta$-methylcholine bromide $(\mathrm{MCh})$. We also characterized the interaction of lidocaine with $\left[{ }^{3} \mathrm{H}\right]$ quinuclydinyl benzylate ( $\left.{ }^{3} \mathrm{H}\right] \mathrm{QNB}$ ) binding to $\mathrm{m} 3$ receptors. Antisense-injection was used to determine the role of specific $G$ protein $\alpha$ subunits in mediating the inhibitory effects of LA. Using chimeric receptor constructs we investigated which domains of the muscarinic receptors contribute to the binding site for LA.

3. Lidocaine inhibited $\mathbf{m} 3$-signaling in a concentration-dependent, reversible, non-competitive manner with an $\mathrm{IC}_{30}$ of $370 \mathrm{nM}$, approximately 21 -fold higher than the $\mathrm{IC}_{50}(18 \mathrm{nM})$ reported for $\mathrm{ml}$ receptors. Intracellular inhibition of both signaling pathways by L.A was similar, and dependent on the $\mathrm{G}_{\mathrm{q}}$ - protein $\alpha$ subunit. In contrast to results reported for the $\mathrm{ml}$ receptor, the $\mathrm{m} 3$ receptor lacks the major extracellular binding site for charged L.A. The $\mathrm{N}$-terminus and third extracellular loop of the $\mathrm{ml}$ muscarinic receptor molecule were identified as requirements to obtain extracellular inhibition by charged L.A.

\section{INTRODUCTION}

Muscarinic acetylcholine signaling plays important roles in several organ functions of great relevance to anesthesiologists. It is involved in modulation of the level of consciousness in the brainstem. Inhibition of muscarinic signaling (by reducing acetylcholine levels, inhibiting its release, or administration of scopolamine) decreases the minimum alveolar concentration (MAC) of inhaled anesthetics. In contrast, physostigmine administration increases MAC, and reverses the action of propofol on the $\mathrm{CNS}^{1}$. In addition, $\mathrm{ml}$ and $\mathrm{m} 3$ muscarinic receptors are largely responsible for maintenance of airway tone.

$\mathrm{ml}$ Muscarinic acetylcholine receptors have been shown to be highly sensitive to local anesthetics (LA) $)^{2}$. Half-maximal inhibitory concentration for lidocaine on recombinantly expressed $\mathrm{ml}$ muscarinic receptors was $18 \mathrm{nM}$, approximately 500-fold less than that required to block neuronal sodium channels. This sensitivity can be explained by a superadditive interaction between two sites, one located extracellularly on the receptor (separate from the ligand binding domain), and one located intracellularly, on receptor or coupled $\mathrm{G}$ protein.

In an effort to define more precisely these interaction sites, we determined effects of LA on a related receptor, the $\mathrm{m} 3$ muscarinic receptor. Since $\mathrm{ml}$ and $\mathrm{m} 3$ receptors are very similar in sequence ${ }^{3}$, any differences in local anesthetic effect can be used to determine the site of action within the molecule. Our findings indicate the presence of several, molecularly well defined interaction sites for LA on the $\mathrm{m} 3$ muscarinic receptor and coupled $\mathrm{G}$ protein.

\section{MATERIALS AND METHODS}

\section{Oocyte experiments}

\section{Oocyte Expression}

The study protocol was approved by the Animal Care and Use Committee at the University of Virginia. Our methodology for oocyte harvesting and expression has been described previously'. 
Briefly, oocytes were obtained from Xenopus laevis frogs, defolliculated with collagenase, and injected with complementary RNA (cRNA). $\mathrm{Ca}^{2+}$-activated $\mathrm{Cl}$-currents, induced by $\mathrm{IP}_{3}$-mediated intracellular $\mathrm{Ca}^{2+}$-release, were measured using 2-electrode voltage clamp.

\section{cRNA synthesis and injection}

The rat $\mathrm{m} 3$ muscarinic acetylcholine receptor complementary DNA (cDNA) was obtained from Dr. T. L. Bonner (National Institute of Mental Health, Bethesda, MD, USA). It consists of a 2.8kilobasepair fragment in a commercial vector (pGEM1; Promega, Madison, WI, USA). The construct was linearized by digestion with the nuclease Hind III and complementary RNA (cRNA) was prepared by transcription in vitro using the bacteriophage RNA polymerase $\mathrm{T} 7$ (Ambion $\mathrm{T} 7$ mMessage mMachine Kit, Austin, TX, USA). A capping analog ( ${ }^{\mathrm{m}} \mathrm{m}$ GppG) was included in the reaction to generate capped transcripts, as these are translated more efficiently in the oocyte. The resulting cRNA was quantified by spectometry, and $5 \mathrm{ng} c \mathrm{RNA}$ in a $30 \mathrm{nl}$ volume was injected into the oocyte, using an automated microinjector (Nanoject; Drummond Scientific, Broomall, PA, USA). The adequacy of injection was confirmed by a slight increase in cell size during injection. The cells were then cultured in modified Barth's $(88 \mathrm{mM} \mathrm{NaCl}, 1 \mathrm{mM} \mathrm{KCl}, 2.4 \mathrm{mM} \mathrm{NaHCO}$, 15 $\mathrm{mM} \mathrm{N}$-[2-Hydroxyethyl]piperazine-N'-[2-ethanesulphonic acid] (Hepes), $0.3 \mathrm{mM} \mathrm{CaNO}_{3} \bullet 4 \mathrm{H}_{2} 0$, $0.41 \mathrm{mM} \mathrm{CaCl}_{2} \bullet 6 \mathrm{H}_{2} 0,0.82 \mathrm{mM} \mathrm{MgSO}_{4} \bullet 7 \mathrm{H}_{2} 0,10 \mu \mathrm{g} \mathrm{ml} 1 \mathrm{Gentamicin}$ ) solution for 72 hours at 18 ${ }^{\circ} \mathrm{C}$ before study.

\section{Drug administration}

Acetyl- $\beta$-methylcholin bromide $(\mathrm{MCh})$, used as agonist for the $\mathrm{m} 3$ muscarinic receptor, was diluted in Tyrode's ( $150 \mathrm{mM} \mathrm{NaCl}, 5 \mathrm{mM} \mathrm{KCl}, 1 \mathrm{mM} \mathrm{MgCl} \mathrm{M}_{2} \bullet 6 \mathrm{H}_{2} 0,2 \mathrm{mM} \mathrm{CaCl}{ }_{2} \bullet 2 \mathrm{H}_{2} \mathrm{O}, 10 \mathrm{mM}$ Dextrose, $10 \mathrm{mM}$ Hepes) solution to the required concentration and was superfused $\left(3 \mathrm{ml} \mathrm{min}^{-1}\right)$ over the oocyte for $10 \mathrm{~s}$. The oocyte was positioned close to the inflow tubing, so that complete exposure to test solutions was obtained in $4.8 \pm 0.4 \mathrm{~s}(\mathrm{n}=20)$. Lidocaine also was diluted in Tyrode's solution to various concentrations and superfused $\left(3 \mathrm{ml} \mathrm{min}^{-1}\right)$ for $10 \mathrm{~min}$. Benzocaine and QX314 were diluted and administered extracellulary in the same manner as lidocaine.

For intracellular administration of QX314 or lidocaine a third micropipette was inserted into the voltage-clamped oocyte. The micropipette was connected to an automated microinjector (Nanoject; Drummond Scientific, Broomall, PA, USA). Under voltage clamp, $50 \mathrm{nl}$ (approximately $10 \%$ of total oocyte volume) of a $150 \mathrm{mM} \mathrm{KCl}$ solution was injected for determination of the control response; in the treatment group we injected $50 \mathrm{nl}$ of $\mathrm{KCl}$ solution containing various concentrations of QX314 or lidocaine. Injection was followed by superfusion with Tyrode's solution for $10 \mathrm{~min}$, preventing an extracellular effect of any QX314 or lidocaine leaked from the puncture site or through the membrane. $I_{\mathrm{Cl}(\mathrm{Ca})}$ was then induced by superfusion of $\mathrm{MCh}$, as described previously.

Control, treatment and at times recovery responses were obtained from different oocytes to prevent the effects of receptor desensitization from obscuring the results.

\section{Oligonucleotide injection}

Phosphorothioate oligonucleotides were synthesized by the University of Virginia Biomolecular Research Facility. The antisense sequences are complementary to specific 20-base segments showing less than $50 \%$ homology with other types of Xenopus laevis $\mathrm{G}_{\mathrm{a}}$ proteins ${ }^{4}$. Sense oligonucleotides were used as control. Oocytes injected $24 \mathrm{~h}$ prior with cRNA encoding the $\mathrm{m} 3$ receptor were injected with $50 \mathrm{nl}$ sterile water containing $50 \mathrm{ng} /$ cell antisense or sense oligonucleotides. Control cells were injected with the same amount of sterile water. 24 and 48 hours after oligonucleotide injection the cells were tested as described below. 
Chinese Hamster Ovary (CHO) cells stably transfected with the muscarinic $\mathrm{m} 3$ receptor were homogenized in $10 \mathrm{vol}$ of ice-cold homogenization buffer $(50 \mathrm{mM}$ 2-amino-2-

hydroxymethylpropan-1,3-diol (Tris), $5 \mathrm{mM} \mathrm{MgCl}, 5 \mathrm{mM}$ ethylene diamine tetraacetic acid (EDTA), $1 \mathrm{mM}$ ethylene glycol-bis (b-amino ethyl ether) tetraacetic acid (EGTA), aprotinin $2 \mu \mathrm{g}$ $\mathrm{ml}^{-1}, \mathrm{pH}$ adjusted to 7.5) with an Overhead stirrer (Wheaton Instruments, Millville, NJ, USA) three times for $15 \mathrm{~s}$ at medium speed. The homogenate was centrifuged for $30 \mathrm{~min}$ at $4{ }^{\circ} \mathrm{C}$ and $500 \times \mathrm{g}$. The supernatant was adjusted to $107 \mathrm{mM} \mathrm{KCl}$ and $20 \mathrm{mM}$ 3-[N-Morpholino]propanesulphonic acid (MOPS) ( $\mathrm{pH} 7.4$ ), mixed, incubated for $10 \mathrm{~min}$ on ice, and centrifuged for $60 \mathrm{~min}$ at $160,000 \times \mathrm{g}$ at $4{ }^{\circ} \mathrm{C}$. The pellet was resuspended in $160 \mathrm{mM} \mathrm{KCl}$ and $20 \mathrm{mM}$ Tris (pH 7.4) with a short burst of an overhead stirrer at medium speed, and centrifuged at $160,000 \times \mathrm{g}$ for 45 min at $4^{\circ} \mathrm{C}$. The final pellet was resuspended in homogenization buffer and stored in aliquots at $-20^{\circ} \mathrm{C}$. Protein concentration was determined by the Lowry method using bovine serum albumin (BSA) for standards.

\section{Ligand binding}

Muscarinic $\mathrm{m} 3$ receptor density and equilibrium dissociation constants in $\mathrm{CHO}$ cell membranes were determined by specific binding of a muscarinic $\mathrm{ml}$ receptor antagonist, [ $\left.{ }^{3} \mathrm{H}\right]$ quinuclydinyl

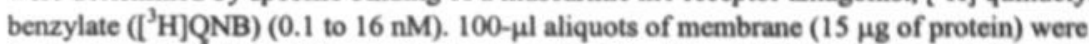
incubated with [ $\mathrm{H}$ ] QNB in assay buffer $(20 \mathrm{mM}$ Tris, $100 \mathrm{mM} \mathrm{NaCl}, 0.5 \mathrm{mM}$ EDTA, pH 7.4) for $90 \mathrm{~min}$ at $21^{\circ} \mathrm{C}$. Membranes were collected onto Whatman GF/C glass fiber filters, which were washed three times for $10 \mathrm{~s}$ with ice-cold buffer (10 mM Tris, $5 \mathrm{mM} \mathrm{MgCl}, \mathrm{pH} 7.4)$. Radioactivity trapped on filters was counted using a scintillation counter. All reactions were performed in triplicate. Nonspecific binding was determined by adding $5 \mu \mathrm{M}$ atropine to displace specific binding of $\left[{ }^{3} \mathrm{H}\right] \mathrm{QNB}$.

Specific binding was fit to a single site binding model using nonlinear least square curve fitting of the untransformed data to calculate receptor density $\left(\mathbf{B}_{\max }\right)$ and dissociation constants $\left(\mathrm{K}_{4}\right)$. To determine interaction of lidocaine with specific binding of $\left[{ }^{3} \mathrm{H}\right] \mathrm{QNB}, 100 \mu \mathrm{l}$ aliquots of membrane (15 $\mu \mathrm{g}$ of protein) were incubated with various concentrations of lidocaine $\left(10^{-2}\right.$ to $\left.10^{-10} \mathrm{M}\right)$ and [ ${ }^{3} \mathrm{H}$ ]QNB (at $\mathrm{K}_{\mathrm{d}}$ ) in assay buffer $(20 \mathrm{mM}$ Tris, $100 \mathrm{mM} \mathrm{NaCl}, 0.5 \mathrm{mM}$ EDTA, pH 7.4) for $90 \mathrm{~min}$ at $21^{\circ} \mathrm{C}$ and ligand binding was determined as previously described.

In order to determine whether lidocaine acts as a competitive or non-competive antagonist, we performed binding in the presence and absence of lidocaine. $100 \mu \mathrm{l}$ aliquots of membrane ( $15 \mu \mathrm{g}$ of protein) and various concentrations of $\left[{ }^{3} \mathrm{H}\right] \mathrm{QNB}$ were incubated with $100 \mu \mathrm{l}$ of assay buffer either with or without $10^{-3} \mathrm{M}$ lidocaine (final concentration of $5 \times 10^{-4} \mathrm{M}$ ). This concentration corresponds approximately to an $\mathrm{IC}_{20}$ (Concentration of antagonist that reduces the response to a submaximal concentration of agonist by $80 \%$ ) for lidocaine in the binding assay. After an incubation period of $90 \mathrm{~min}$ at $21^{\circ} \mathrm{C}$ (to obtain equilibrium between the membrane protein, [ $\left.{ }^{3} \mathrm{H}\right] \mathrm{QNB}$ and lidocaine) membranes were collected, radioactivity was counted and the data were analysed as described previously. Again all reactions were done in triplicate $(n=3)$. Absence of ligand depletion in these studies was assured by determining the ratio of bound to total counts at high ligand concentration. This ratio was $37 \%$, well below the $50 \%$ usually accepted as a cutoff. Also, the binding curve did not show an upward angle at higher $\left[{ }^{3} \mathrm{H}\right] \mathrm{QNB}$ concentrations, again indicating no significant depletion took place.

\section{Chimera constructs}

The chimeras between muscarinic $\mathrm{ml}$ and $\mathrm{m} 3$ receptors were constructed using routine molecular biology techniques. Briefly, all cDNA fragments necessary for the construction of chimeras were obtained from PCR reactions using $\mathrm{ml}$ and $\mathrm{m} 3$ receptor cDNA as templates. These PCR products carrying restriction enzyme sites at their $5^{\prime}$ and $3^{\circ}$ ends were gel purified and digested with the respective restriction enzymes. The matching fragments of $\mathrm{cDNA}$ for the 
respective chimeras were subcloned in peDNA 3.1 (Invitrogen, Carlsbad, CA, USA) by transformation in DHS $\alpha$ cells (Gibco BRL, Gaithersburg, MD, USA) employing the protocols recommended by the suppliers. The transformants with the proper cDNA insert were chosen, sequenced (Biomolecular Research Facility, University of Virginia, VA, USA) and their homology with the parent cDNA was confirmed. These plasmid DNA were linearized and cRNA synthesized in vitro as described above.

\section{Analysis}

Results are reported as mean \pm s.d. Measurements of at least 12 oocytes were averaged to generate each data point. As variability between batches of oocytes is common, responses were at times normalized to control response. Statistical tests employed are indicated in the Results section. $P<0.05$ was considered significant. Concentration-response curves were fit to the following logistic function, derived from the Hill equation: $y=y_{\min }+\left(y_{\max }-y_{\min }\right)\left\{1-x^{n} /\left(x_{90}{ }^{n}+x^{n}\right)\right\}$ where $y_{\max }$ and $\mathrm{y}_{\min }$ are the maximum and minimum response obtained, $\mathrm{n}$ is the Hill coefficient, and $\mathrm{X}_{\mathbf{s}_{0}}$ is the halfmaximal effect concentration ( $\mathrm{EC}_{\mathbf{S}_{0}}$ for agonist) or the half-maximal inhibitory effect concentration (IC so $_{0}$ for antagonist).

\section{Materials}

Molecular biology reagents were obtained from Promega (Madison, WI, USA) and other chemicals were obtained from Sigma (St. Louis, MO, USA). CHO cells (CRL-1982), stably transfected with the rat muscarinic $\mathrm{m} 3$ receptor, were purchased from ATCC (Manassas, VA, USA). QX314 was a gift from Astra Pharmaceuticals, L.P. (Westborough, MA, USA).

\section{RESULTS}

Functional expression of $m 3$ muscarinic receptors in Xenopus oocytes

Whereas uninjected oocytes were unresponsive to $\mathrm{MCh}$, oocytes injected with $\mathrm{m} 3$ muscarinic receptor cRNA responded to application of $\mathrm{MCh}\left(10^{-4}-10^{-9} \mathrm{M}\right)$ with a transient $I_{\mathrm{Cr}}$ (a) $(\mathrm{e} . \mathrm{g}$. Fig 1).

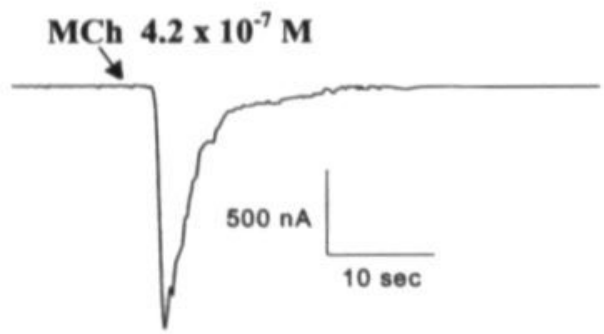

Figure 1: Sample trace of a Ca-activated $\mathrm{Cl}$ current $\left(I_{\mathrm{Cr}} \mathrm{Ca}\right)$ induced by $10 \mathrm{~s}$ administration of $\mathrm{MCh}$ at approximately $\mathrm{EC}_{50}\left(4.2 \times 10^{7} \mathrm{M}\right)$ in an oocyte expressing the muscarinic $\mathrm{m} 3$ receptor. Peak current is $1.12 \mu \mathrm{A}$.

We have shown previously that this response is mediated by $\mathrm{m} 3$ muscarinic receptors, as it is inhibited by atropine and the selective $\mathrm{m} 3$ antagonist 4-Diphenylacetoxy- $\mathrm{N}$-methylpiperidine (4DAMP) ${ }^{5}$. As shown in Fig 2, the response was concentration-dependent. $\mathrm{EC}_{50}$, calculated from the Hill equation, was $4.2 \pm 0.4 \times 10^{-7} \mathrm{M}\left(\mathrm{n}_{\mathrm{H}}=0.6\right)$. Maximal responses of $1.9 \pm 0.2 \mu \mathrm{A}$ were obtained at a MCh concentration of $0.1 \mathrm{mM}$. Calculated maximal response size $\left(\mathrm{E}_{\max }\right)$ was $2.0 \pm 0.4 \mu \mathrm{A}$. These findings compare closely with data reported in our previous study ${ }^{5}$. 


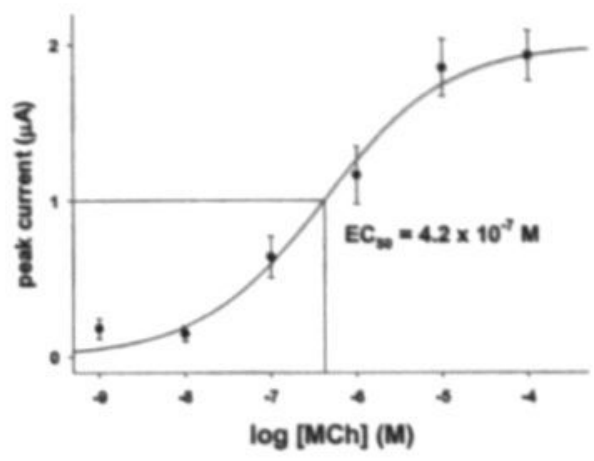

Figure 2: MCh evokes $I_{C a c a v}$ in a concentration-dependent manner. $E C_{30}$ is $4.2 \pm 0.4 \times 1 \sigma^{7} M, E_{\max }$ is $2.0 \pm 0.4 \mu 4$.

\section{Lidocaine inhibits $m 3$ signaling}

Administration for $10 \mathrm{~min}$ of various concentrations of lidocaine resulted in a concentrationdependent inhibition (Fig 3A) of muscarinic responses, evoked by stimulation with $\mathrm{MCh}$ at $\mathrm{EC}_{50}$ $(0.42 \mu \mathrm{M})$. Half-maximal inhibitory effect concentration $\left(\mathrm{IC}_{50}\right)$ for lidocaine was $3.7 \pm 0.8 \times 10^{-7} \mathrm{M}$ (Fig 3B, Fig 1) $\left(n_{H}=0.5\right)$. Although much lower than that required for blockade of sodium channels 6 , this concentration is approximately 21 -fold greater than that reported for inhibition of muscarinic $\mathrm{ml}$ signaling ${ }^{2}$. Maximal inhibition was obtained with lidocaine $100 \mu \mathrm{M}$; at this concentration muscarinic responses were inhibited by $84 \%$.
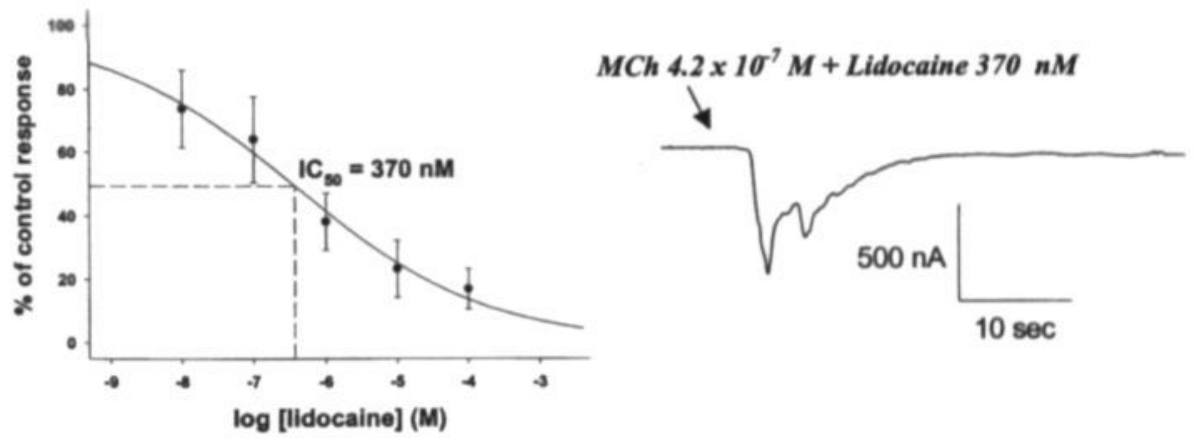

Figure 3: (A) Lidocaine inhibits $M C h$ (at $E C_{50}$ )-induced $I_{C\left(C_{a}\right)}$ in a concentration-dependent manner. $I C_{50}$ is $3.7 \pm 0.8 \times 10^{7} \mathrm{M}$. (B) Sample trace of a $\mathrm{m} 3$ response elicited by stimulation with $M C h$ (at EC $C_{50}$ in the presence of lidocaine at IC $C_{90}$. Peak current is $0.48 \mu \mathrm{A}$. Cf. Fig 1. 
As shown in Fig 4, the lidocaine effect was reversible. Percent inhibition by lidcaine $\left(10^{-4} \mathrm{M}\right)$ was similar to that shown in Fig 3A. Control, treatment and recovery responses to $1 \mathrm{Ch} 0.42 \mu \mathrm{M}$ were $2.6 \pm 0.3,0.4 \pm 0.1$, and $3.1 \pm 0.6 \mu \mathrm{A}$, respectively $(n=16)$. The holding current of the oocytes did not change significantly during these experiments.

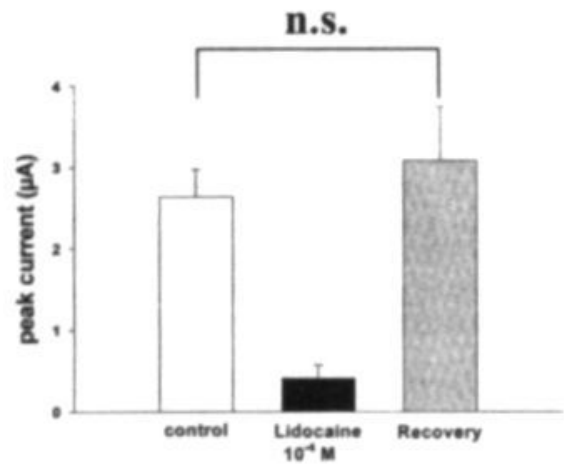

Figure 4: Mean $\pm S D$ of $m 3$ responses elicited with $M C h$ (at $E C_{50}$ ). Left bar indicate the control response, middle bar represents the response after $10 \mathrm{~min}$ incubation in $10^{-4} \mathrm{M}$ lidoeine, and right bar represents the response after a 10 min incubation in $10^{-4}$ M lidocaine and anothr 10 minute wash with Tyrode's solution. The third response is not significantly different in size jom the first one, indicating reversibility of lidocaine inhibition.

The effect of lidocaine was non-competitive. Responses to various concentrations $\mathrm{MCh}^{-10} 0^{-10}$ $\mathrm{M}$ to $10^{-5} \mathrm{M}$ ) were measured under control conditions, or after a 10-minute superfusin with

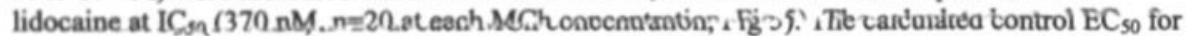
MCh was $7.8 \pm 2.3 \times 10^{-8} \mathrm{M}\left(\mathrm{n}_{\mathrm{H}}=0.8\right)$; $\mathrm{E}_{\max }$ was $4.5 \pm 0.4 \mu \mathrm{A}$. In the presence of lidocaine the $\mathrm{EC}_{50}$ did not change significantly $\left(1.2 \pm 0.3 \times 10^{-7} \mathrm{M} ; \mathrm{n}_{\mathrm{H}}=0.7 ; P=0.293, \mathrm{t}\right.$ test $)$, but $\mathrm{E}_{\max }$ was reduced significantly to $2.9 \pm 0.2 \mu \mathrm{A}(36 \%$ inhibition, $P=0.005$, t test $)$.

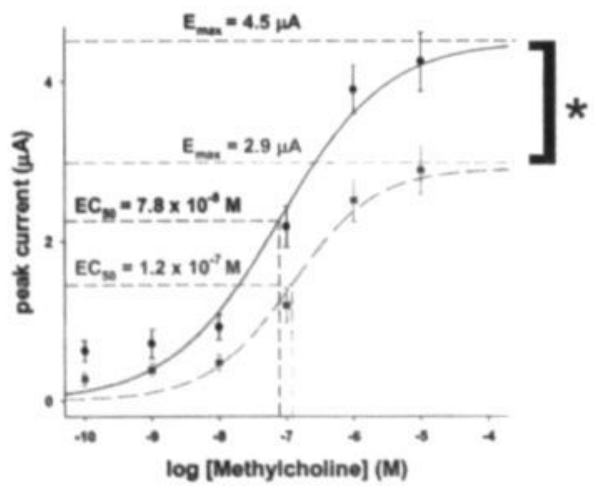

Figure 5: Concentration-response curve for $M C h$ on $m 3$ receptors in the presence or absence of lidocaine (at IC $\mathrm{s}_{\mathrm{s}}$ ). Lidocaine inhibition can not be overcome with maximal agonist concentrations ( $E_{\max }$ remains inhibited by $36 \%$ ) suggesting a primarily non-competitive antagonism. 
This non-competitive antagonism suggests that lidocaine does not interact primarily with the ligand binding site. To confirm this, we studied the effect of lidocaine on $\left.{ }^{3} \mathrm{H}\right] \mathrm{QNB}$ binding to $\mathrm{m} 3$ muscarinic receptors. We first characterized $\left[{ }^{3} \mathrm{H}\right] \mathrm{QNB}$ binding to membranes prepared from $\mathrm{CHO}$ cells, stably transfected with the rat muscarinic $\mathrm{m} 3$ receptor. Over a range of 0.1 to $16 \mathrm{nM}$ free drug specific binding was saturable and reached a maximum at $2.8-4.2 \mathrm{nM}$. The saturation curve and Scatchard analysis (Fig 6) conform closely to a single site model with a $K_{4}$ of $0.15 \pm 0.03 \mathrm{nM}(\mathrm{n}=5)$ and $B_{\max }$ of $3517 \pm 154 \mathrm{fmol} \mathrm{mg}^{-1}$ protein $(n=5)$.

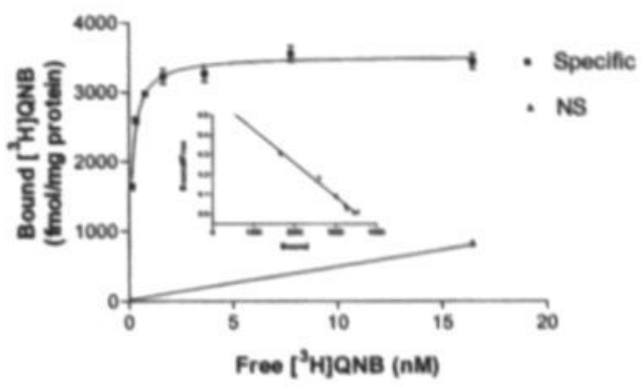

Figure 6: Characterization of $\left.{ }^{3} \mathrm{H}\right] \mathrm{QNB}$ binding to membranes prepared from $\mathrm{CHO}$ cells, stably transfected with the rat muscarinic m3 receptor. The saturation curve and Scatchard analysis conform to a single site model with a $K_{d}$ of $0.15 \pm 0.03 \mathrm{nM}(n=5)$ and $B_{\max }$ of $3517 \pm 154 \mathrm{fmol} / \mathrm{mg}$ protein $(n=5)$.

The action of lidocaine was tested in concentrations ranging between $10^{-10}$ and $10^{-2} \mathrm{M}$ (Fig 7). Lidocaine, at concentrations that inhibit $\mathrm{m} 3$ muscarinic signaling, did not affect specific binding of [ $\left.{ }^{3} \mathrm{H}\right] \mathrm{QNB}$ to the muscarinic $\mathrm{m} 3$ receptor. Lidocaine concentrations of $10^{-3}$ and $10^{-2} \mathrm{M}$ modestly reduced binding, but in this concentration range nonspecific effects could not be excluded.

Calculated $\mathrm{IC}_{5_{0}}$ using the Hill equation was $78 \pm 9 \mathrm{mM}(\mathrm{n}=5)$.

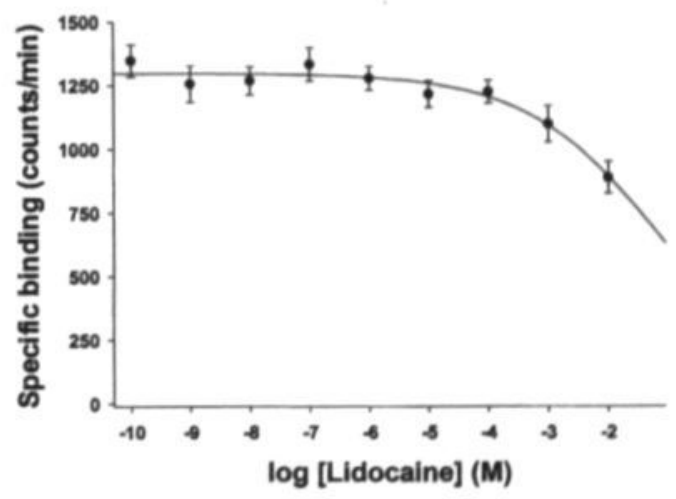

Figure 7: Effects of lidocaine on specific binding of $\left.l^{3} \mathrm{H}\right] \mathrm{QNB}$ to muscarinic m3 receptors. $I C_{s 0}$ is $78 \pm 9 \mathrm{mM}(n=5)$. Lidocaine at functionally determined $I C_{50}\left(3.7 \times 1 \sigma^{7} \mathrm{M}\right)$ does not affect agonist binding. 
We then performed $\left[{ }^{3} \mathrm{H}\right] \mathrm{QNB}$ binding in the presence and absence of lidocaine at $\mathrm{IC}_{20}\left(5 \times 10^{-4}\right.$ $\mathrm{M}$, Fig 8$)$. The binding curve was not shifted significantly by lidocaine ( $P=0.39$, unpaired $t$-test): $\mathrm{K}_{4}$ was $0.57 \pm 0.01 \mathrm{nM}$ in the absence and $0.48 \pm 0.04 \mathrm{nM}$ in the presence of lidocaine. Lidocaine inhibition on $\left[{ }^{3} \mathrm{H}\right] \mathrm{QNB}$-binding could not be overcome with higher concentrations of $\left[{ }^{3} \mathrm{H}\right] \mathrm{QNB}$. $B_{\max }$ for $\left[{ }^{3} \mathrm{H}\right] \mathrm{QNB}$-binding to muscarine $\mathrm{m} 3$ receptors decreased in the presence of lidocaine by $33 \pm 4 \%$ of control binding, from $1482.1 \pm 88$ to $984.3 \pm 45.5 \mathrm{fmol} \mathrm{mg}^{-1}$ protein $(P<0.001, \mathrm{t}$-test). Those results confirm that lidocaine acts as a non-competitive antagonist on muscarinic $\mathrm{m} 3$ receptors.

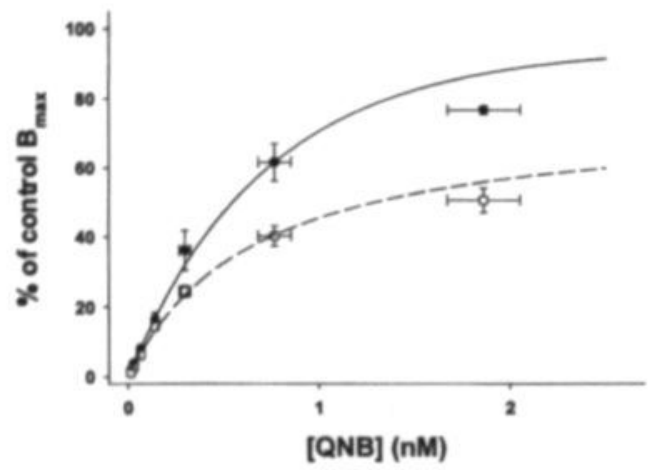

Figure 8: Binding curves for $\left[{ }^{3} H\right] Q N B$ to $m 3$ receptors in the absence and presence of lidocaine at $I C_{20}$ for binding effect $\left(5 \times 10^{4} M\right)$. Whereas $K_{d}$ is not significantly shifted $(0.57 \pm 0.01 \mathrm{nM}$ in the absence and $0.48 \pm 0.04 n M$ in the presence of lidocaine), $B_{\max }$ decreases in the presence of lidocaine by $33.5 \pm 3.8 \%$ of control, from $1482.1 \pm 88$ to $984.3 \pm 45.5 \mathrm{fmol} / \mathrm{mg}$ protein.

Muscarinic $m 3$ signaling is not inhibited by extracellular administered $Q \times 314$

We then proceeded to determine the cause for the 21 -fold difference in lidocaine sensitivity between $\mathrm{m} 1$ and $\mathrm{m} 3$ receptors. At the $\mathrm{m} 1$ receptor, a major part of the inhibition is due to an extracellularly charged interaction site ${ }^{2}$. To determine if the same is true for the $\mathrm{m} 3$ receptor, we used extracellularly administered QX314, a permanently charged and therefore membrane impermeant lidocaine analog. In contrast to our results obtained using $\mathrm{ml}$ signaling $\left(\mathrm{IC}_{50} 2.4 \times 10^{-6}\right.$ $\mathrm{M}^{2}, \mathrm{QX} 314$ in relevant concentrations was without effect on $\mathrm{m} 3$ signaling (Fig 9). Only $10^{-3} \mathrm{M}$ or $10^{-2} \mathrm{M}$ QX314 inhibited partially (to $78 \pm 9$ and $55 \pm 5 \%$ of control response, respectively), but at these concentrations nonspecific effects are likely. Thus, the absence on the $\mathrm{m} 3$ receptor of an extracellular interaction site for charged LA may explain in part its lower sensitivity to these compounds as compared with the $\mathrm{ml}$ receptor. 


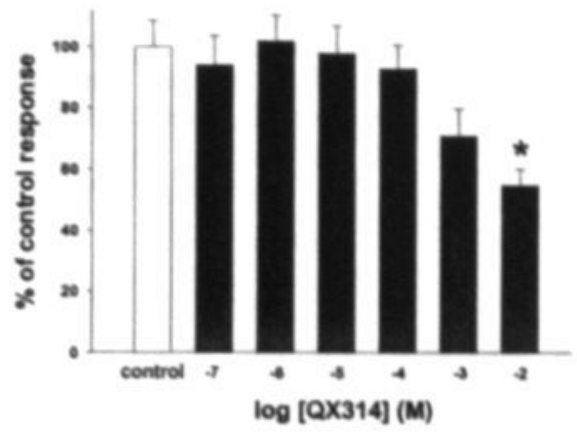

Figure 9: $m 3$ muscarinic signaling induced by $M C h\left(4.2 \times 10^{7} M\right)$ is not affected by relevant concentrations of $Q X 314$. Only concentrations of $10^{3} \mathrm{M}\left(78 \pm 8.7 \%\right.$ of control response) and $10^{2} \mathrm{M}$ (55 $\pm 5.1 \%$ of control response) inhibit partially.

Extracellular inhibition of $\mathrm{ml}$ receptors by $Q X 314$ and lidocaine depends on $\mathrm{N}$-terminus and thind extracellular loop

The $\mathrm{m} 1$ and $\mathrm{m} 3$ receptors are highly similar structurally, with the major differences located in the $\mathrm{N}$-terminus and the third intracellular loop. To localize further the extracellular site of local anesthetic interaction on the $\mathrm{m} 1$ receptor, we used chimeric $\mathrm{ml} / \mathrm{m} 3$ receptors (Fig 10). EC ${ }_{30}$ for MCh on each chimera was between $10^{-7} \mathrm{M}$ and $10^{-6} \mathrm{M}$, similar therefore to that of the parent $\mathrm{ml}$ and $\mathrm{m} 3$ receptors.
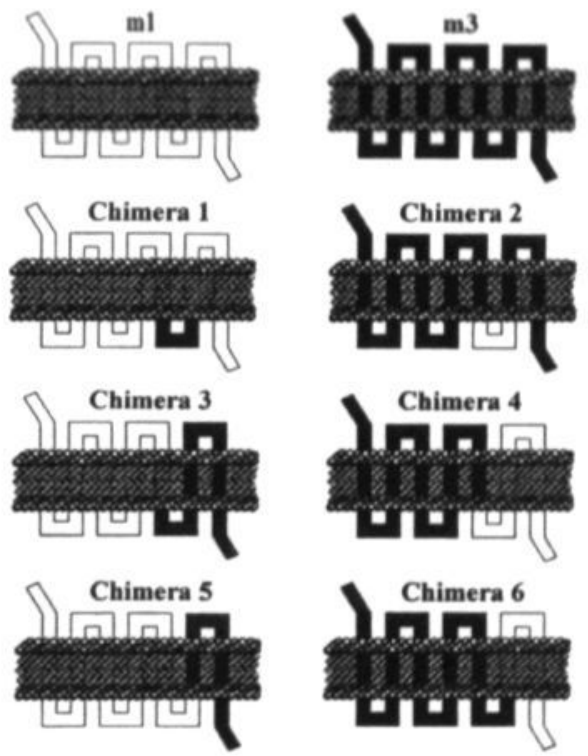

Figure 10: Schematic illustration of the chimeras employed 
We then tested the effect of 10 min incubation in QX314 $\left(10^{-3} \mathrm{M}\right)$ on each of the six chimeras. Chimeras were stimulated with their corresponding $\mathrm{EC}_{\mathbf{s}_{0}}$ of $\mathrm{MCh}$. Only chimera 1, containing both the $\mathrm{N}$-terminus and the third extracellular loop of the $\mathrm{ml}$ receptor, was inhibited by QX314 in a manner similar to that obtained with the $\mathrm{ml}$ receptor $\left(\mathrm{IC}_{50} 1.8 \pm 0.6 \times 10^{-6} \mathrm{M}\left(\mathrm{n}_{\mathrm{H}}=0.5\right)\right.$, as compared with $2.4 \times 10^{-6} \mathrm{M}$ for the $\mathrm{ml}$ receptor (Fig 11) ${ }^{2}$.

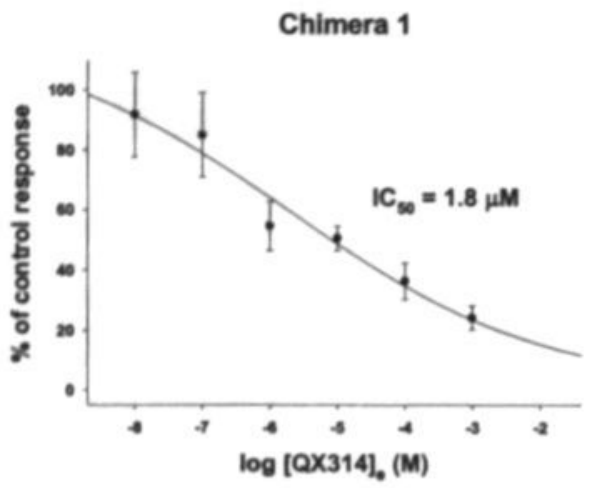

Figure 11: Concentration-response curve for effect of extracellularly applied QX314 on chimera 1. $I C_{s 0}$ is $1.8 \pm 0.6 \mu \mathrm{M}$. Mean control response was $4.9 \pm 0.4 \mu \mathrm{A}$.

Chimeras 3 (Fig 12A) and 5 (Fig 12B), containing the $\mathrm{N}$-terminus, but not the third extracellular loop of $\mathrm{ml}$ were also significantly $(\mathrm{P}<0.05$, One Way ANOVA, Dunnett correction) inhibited at QX314 concentrations higher than $10^{-6} \mathrm{M}$ (for chimera 3) or $10^{-8} \mathrm{M}$ (for chimera 5), but only partially. Calculated $I_{50}$ sere beyond the greatest concentration tested $\left(10^{-3} \mathrm{M}\right)$.

\section{Chimera 3}

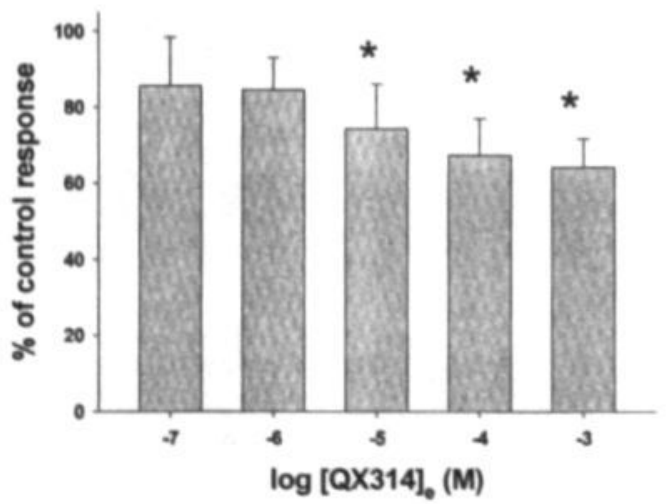




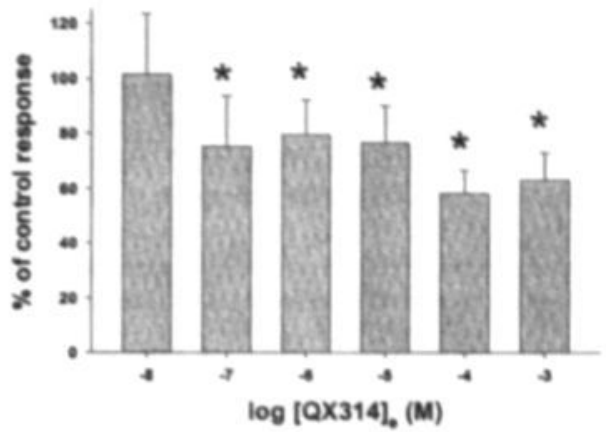

Figure 12: Effects of various concentrations of extracellularly administered QX314 on chimera 3 (A) and chimera 5 (B). Modest inhibition was observed in both cases (* indicates significant differences vs. control). Maximal inhibition is obtained using $10^{3} \mathrm{M}$ QX314 on chimera 3 (64.2 27.5 $\%$ of control response $(1.9 \pm 0.2 \mu \mathrm{u})$ ) and using $10^{-4} \mathrm{M}$ QX314 on chimera 5 (58.2 $18.5 \%$ of control response $(1.5 \pm 0.2 \mu \mathrm{u}))$.

Chimeras 2, 4 and 6 (Fig 13), containing the $\mathrm{N}$-terminus of the $\mathrm{m} 3$ receptor, were not inhibited. Thus, effective inhibition by extracellularly applied QX314 requires the $\mathrm{N}$-terminus and the third extracellular loop of the $\mathrm{ml}$ receptor. The $\mathrm{ml} \mathrm{N}$-terminal domain is necessary, but not fully sufficient for inhibition to take place.

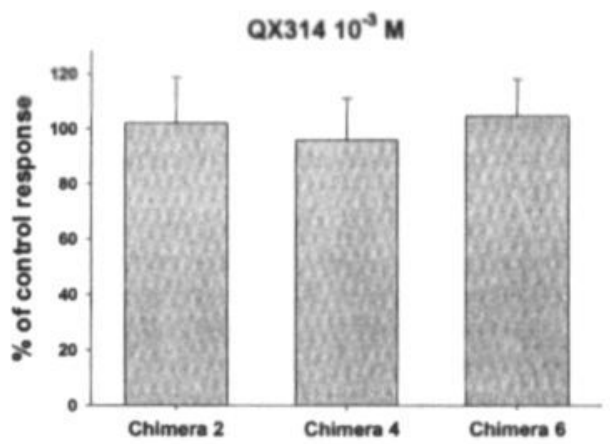

Figure 13: Extracellularly applied $Q X 314\left(10^{3} M\right)$ does not inhibit chimera 2, 4 or 6. Mean response sizes are $102.1 \pm 8.5 \%, 96.2 \pm 15 \%$ and $104.8 \pm 13.5 \%$ of control response for chimera 2,4 and 6 , respectively.

We repeated these experiments with lidocaine itself, at pH 5, when it is almost completely charged, and obtained similar results. Only chimera 1 was inhibited, with a calculated $\mathrm{IC}_{50}$ of $4.0 \pm 0.8 \times 10^{-6} \mathrm{M}$ (data not shown). Partial but significant inhibition was observed for chimeras 3 and 5, whereas chimeras 2, 4 and 6 were not inhibited (data not shown). 
Benzocaine, intracellular QX314 and intracellular lidocaine inhibit m3 muscarinic signaling

We next investigated the effects of intracellularly injected QX314 on m3 signaling. QX314 inhibited concentration-dependently (Fig 14). $\mathrm{IC}_{50}$ was $445 \pm 226 \times 10^{-6} \mathrm{M}\left(\mathrm{n}_{\mathrm{H}}=0.6\right)$, approximately 3 orders of magnitude less potent than lidocaine, and comparable to the $\mathrm{IC}_{50}$ of $962 \pm 204 \times 10^{-6} \mathrm{M}$ obtained on the $\mathrm{ml}$ receptor ${ }^{2}$. Thus, the more potent inhibitory effect of lidocaine as compared with intracellular QX314 cannot be explained solely by an intracellular charged site of action.

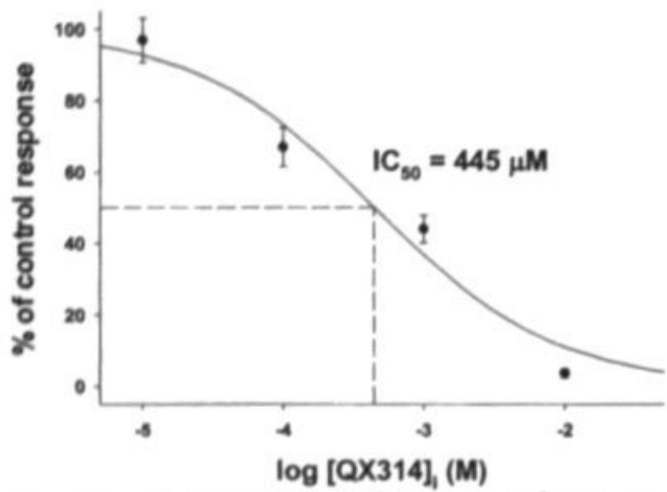

Figure 14: Concentration-dependent inhibition of $\mathrm{MCh}\left(4.2 \times 10^{7} \mathrm{M}\right)$-induced I $\mathrm{I}_{\mathrm{C}} \mathrm{Cas}_{4}$ in oocytes expressing $\mathrm{m} 3$ muscarinic receptors by intracellularly injected QX314 (IC $50445 \pm 226 \mu \mathrm{M})$.

To determine if an additional uncharged site of action may play a role, we studied the effect of the permanently uncharged and therefore membrane permeant local anesthetic benzocaine.

Benzocaine, extracellularly applied, inhibited with an $I_{50}$ of $259 \pm 182 \times 10^{-6} \mathrm{M}\left(\mathrm{n}_{\mathrm{H}}=0.4\right.$; Fig 15). That benzocaine alone is also not able to mimick $\mathrm{m} 3$ receptor inhibition with lidocaine suggests that two separate binding sites contribute to lidocaine inhibition: a charged intracellular site, and an uncharged site which could be located either intra- or extracellularly.

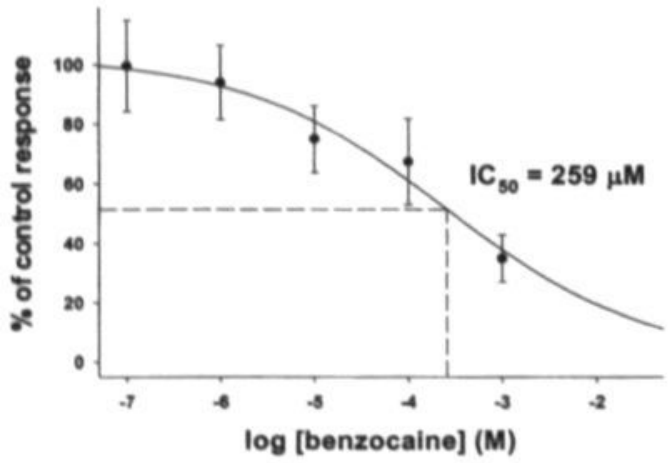

Figure 15: Concentration-dependent inhibition of MCh $\left(4.2 \times 10^{7} \mathrm{M}\right)$-induced I I $\mathrm{CrCa}_{\mathrm{a}}$ in oocytes expressing $m 3$ muscarinic receptors by extracellularly administered benzocaine $\left(I C_{50} 258 \pm 182\right.$ $\mu M)$. 
To determine the location of this uncharged LA site we injected lidocaine into the oocyte and prevented any extracellular effect by continuous copious superfusion of the cell with Tyrode's solution. If the uncharged site of action is located intracellularly we would expect intracellular lidocaine to show an $\mathrm{IC}_{50}$ similar to that obtained when administered extracellularly (since it would have access to both charged and uncharged sites). Conversely, if the uncharged binding site is located on the extracellular domain of the $\mathrm{m} 3$ receptor, we would expect lidocaine, intracellularly injected, to inhibit at similar concentrations as did intracellularly injected QX314 (since it would only have access to the charged site). As shown in figure 16, lidocaine inhibited $\mathrm{m} 3$ responses to a similar degree as did QX314. Calculated $I_{90}$ was $341 \pm 33 \times 10^{-6} \mathrm{M}\left(\mathrm{n}_{\mathrm{H}}=0.8\right)$. We therefore hypothesize that $\mathrm{m} 3$ receptor inhibition by lidocaine is due to interactions at two sites, where the uncharged form acts on the extracellular receptor domain and the charged one acts intracellularly.

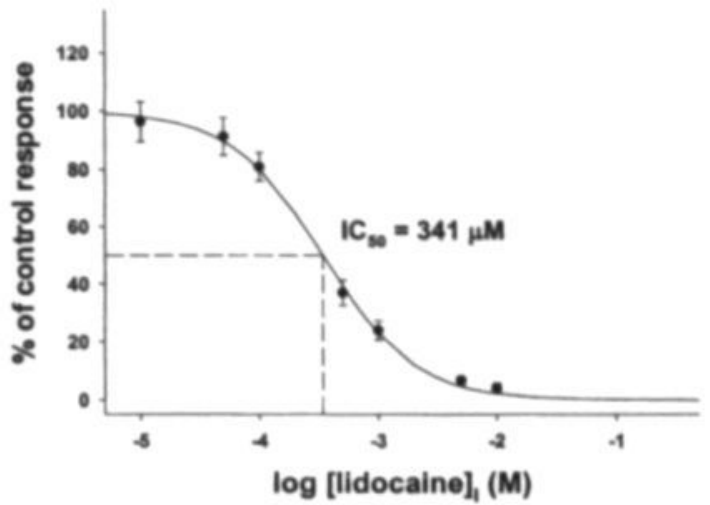

Figure 16: Concentration-dependent inhibition of $M C h\left(4.2 \times 1 \sigma^{7} M\right)$-induced I arcas in oocytes expressing m3 muscarinic receptors by intracellularly applied lidocaine $\left(I C_{50} 34 I \pm 33 \mu M\right)$.

\section{Inhibition of $m 3$ signaling by intracellular $Q \times 314$ depends on $G \alpha_{0}$}

We studied in more detail the location of the intracellular site of action of QX314. The concentration-response curve of intracellular QX314 on $\mathrm{m} 3$ receptor signaling is highly similar to that obtained on lysophosphatidic acid (LPA) receptors and $\mathrm{ml}$ receptors ${ }^{2}$. Since LPA and muscarinic receptors show very little sequence similarity, this suggests that the local anesthetic acts at a common coupled $\mathrm{G}$ protein, rather than at the receptors (effects downstream of the $\mathrm{G}$ protein have been ruled out ${ }^{7}$ ). We have shown previously that $\mathrm{ml}$ muscarinic receptors couple selectively to $\mathrm{G} \alpha_{4}$ and $\mathrm{G} \alpha_{11}$, whereas LPA receptors couple to $\mathrm{G} \alpha_{q}$ and $G \alpha_{0}{ }^{8}$ suggesting $\mathrm{G}_{q}$ as the site of action. Using antisense constructs directed against $G$ protein $\alpha$ subunits, we investigated the $G$ protein-coupling of $\mathrm{m} 3$ muscarinic receptors. Experiments were performed 48 hours after antisense injection. Injection of anti-G $\alpha_{q}\left(49 \pm 6 \%\right.$ of control response) or anti-G $\alpha_{11}(65.4 \pm 6.8 \%$ of control response) affected $\mathrm{MCh}$-induced responses significantly $(P<0.05$, One Way ANOVA, Dunnett correction), whereas anti-G $\alpha_{0}-\left(111 \pm 14 \%\right.$ of control response) or anti-G $\alpha_{14}-(113 \pm 13 \%$ of control response) injected oocytes showed responses not significantly different from those observed in control cells ( $P>0.05$, One Way ANOVA, Dunnett correction) (Fig 17). Similar to our findings for muscarinic $\mathrm{ml}$ signaling ${ }^{2}, \mathrm{~m} 3$ signaling is mainly mediated by $\mathrm{G} \alpha_{q}$ and $\mathrm{G} \alpha_{11}$. 


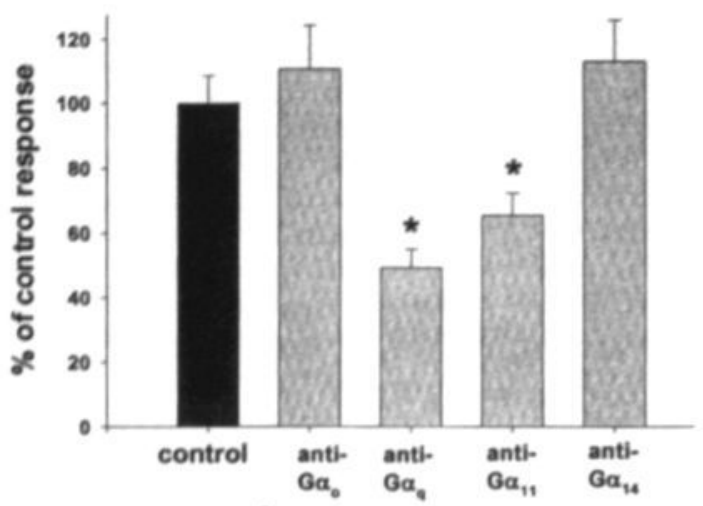

Figure 17: Responses to MCh $\left(4.2 \times 1 \sigma^{7} M\right)$ after selective $G$ protein $\alpha$-subunit knockdown using oligonucleotides directed against $G \alpha_{0} G \alpha_{\phi} G \alpha_{\mid 1}$ or $G \alpha_{14}$ as compared with control responses. Data were collected 48 hours after antisense injection. Knockdown of $G \alpha_{0}(49.3 \pm 5.7 \%$ of control) or $G \alpha_{11}(65.4 \pm 6.8 \%$ of control) significantly affected $M C h$-induced responses $(p<0.05)$, whereas

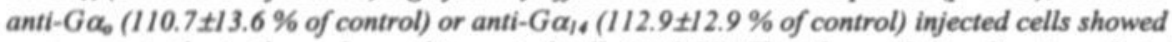
responses similar to those observed in control cells $(p>0.05)$. Therefore, $m 3$ signaling is mediated primarily by $G_{q}$ and $G_{11}$.

These findings suggest that $\mathrm{Ga}_{4}$ may be the target for intracellular charged LA. We therefore determined the ability of intracellular QX314 to inhibit $\mathrm{m} 3$ muscarinic signaling in cells in which $\mathrm{Ga}_{4}$ had been depleted by prior injection of antisense constructs. We chose an $\mathrm{MCh}$ concentration somewhat less than $\mathrm{EC}_{50}$, because injection of $150 \mathrm{nM} \mathrm{KCl}(50 \mathrm{nl})$ used in control cells and in treatment cells as buffer for QX314 caused substantially increased response sizes as a result of the increased intracellular $\mathrm{Cl}^{-}$-load. The inhibitory effect of intracellularly injected QX314 at $\mathrm{IC}_{50}$ (445 $\mathrm{x} 10^{-6} \mathrm{M}$ ) was studied in oocytes injected 48 hours prior with solvent, anti-G $\alpha_{4}$ or anti-G $\alpha_{11}$, which, as shown above, mediate the $\mathrm{m} 3$ response. Oocytes were stimulated with $0.1 \mu \mathrm{M} \mathrm{MCh}$. As shown in Fig 18, intracellularly injected QX314 at $\mathrm{IC}_{30}\left(445 \times 10^{-6} \mathrm{M}\right)$ reduced the responses to $0.1 \mu \mathrm{M}$ $\mathrm{MCh}$ to $44.4 \pm 3.2 \%(1.51 \pm 0.11 \mu \mathrm{A})$ of control response. In addition, significant inhibition of $\mathrm{m} 3$ responses by intracellularly injected QX314 was obtained only in anti-G $\alpha_{11}$ injected cells $(0.5 \pm 0.1$ $\mu \mathrm{A}$ versus $1.4 \pm 0.2 \mu \mathrm{A}, P<0.001, t-t e s t)$. In contrast, in anti-G $\alpha_{4}$ injected cells $\mathrm{QX} 314$ had no significant inhibitory effect $(1.4 \pm 0.2 \mu \mathrm{A}$ versus $1.6 \pm 0.1 \mu \mathrm{A}, P=0.724$, t-test). These findings indicate that QX314 inhibits only when functional $G \alpha_{Q}$ is present, suggesting that it mediates its inhibitory effect by acting on this $\mathrm{G}$ protein subunit. 


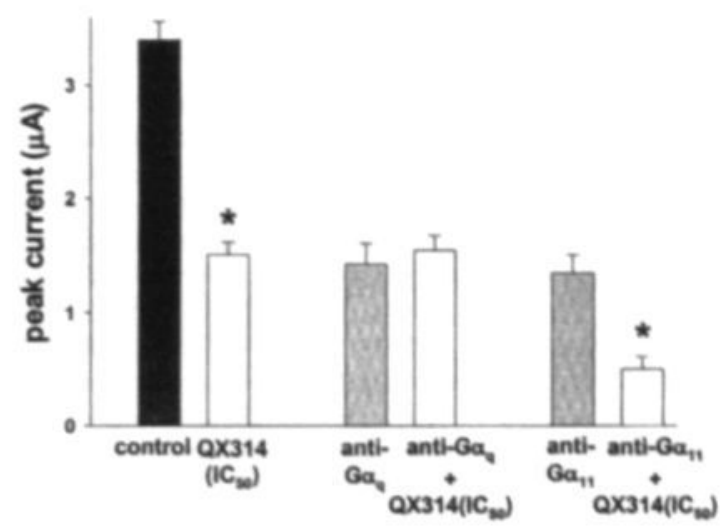

Figure 18: Mean $\pm S D$ of $I_{\text {CrCan }}$ elicited by $M C h\left(10^{7} M\right)$ in oocytes expressing $m 3$ muscarinic receptors, injected with $50 \mathrm{nl}$ of $150 \mathrm{mM} \mathrm{KCl}$ (control, $3.4 \pm 0.16 \mu \mathrm{4}$, black bar): QX314 (445 x $10^{-6}$ $M$ ) reduced $m 3$ responses to $44 \pm 3 \%$ of the control response $(1.51 \pm 0.11 \mu 4$, white bar) $150 \mathrm{mM} \mathrm{KCl}$

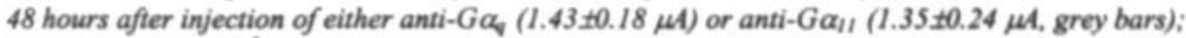

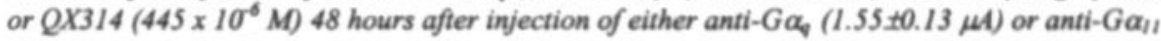
$\left(0.5 \pm 0.11 \mu \mathrm{A}\right.$, white bars). Lack of effect of the local anesthetic after $G_{q}$ knockdown indicates that inhibition requires this $G$ proteins subunit.

\section{DISCUSSION}

In the present study we investigated the effect of LA on the functioning of muscarinic $\mathrm{m} 3$ receptors. We demonstrated that lidocaine reversibly inhibits signaling of $\mathrm{m} 3$ receptors recombinantly expressed in Xenopus oocytes. The calculated $\mathrm{IC}_{50}(370 \mathrm{nM})$ is significantly less than that required for blocking sodium channels $\left(60\right.$ to $200 \mu \mathrm{M}$, depending on the state of the $\mathrm{Na}^{+}$channel) ${ }^{6}$. (For comparison, clinically relevant blood concentrations during IV infusion or epidural anesthesia are in the range of 1 to $15 \mu \mathrm{M}$, corresponding to a plasma level of 0.3 to $4.5 \mu \mathrm{g} \mathrm{ml}^{-1}$.) However, compared with inhibition of $\mathrm{ml}$ muscarinic signaling $\left(\mathrm{IC}_{50} 18 \mathrm{nM}\right)^{2}, \mathrm{~m} 3$ signaling is approximately 21 -fold less sensitive to lidocaine. This discrepancy is explained most parsimoniously by absence on the $\mathrm{m} 3$ receptor of the major extracellular binding site for charged LA that is present on the $\mathrm{ml}$ receptor. The $\mathrm{N}$-terminus and third extracellular loop of the $\mathrm{ml}$ receptor molecule were identified as requirements for this extracellular binding site for charged LA. In contrast, intracellular inhibition of both receptors was quite similar. As determined for $\mathrm{ml}$ signaling ${ }^{8}, \mathrm{~m} 3$ signaling is primarily mediated by $\mathrm{G}_{\mathrm{q}}$ and $\mathrm{G}_{11}$; of these, $\mathrm{G}_{\mathrm{q}}$ was shown to be a likely target for intracellular inhibition by LA.

It is of interest that, despite their sequence similarity except for the amino-terminus and the third intracellular loop ${ }^{3}$, the $\mathrm{m} 3$ receptor lacks the extracellular binding site for charged LA present on the $\mathrm{ml}$ receptor ${ }^{2}$. Since the greatest variety in amino acid sequence extracellularly between both receptors is attributable to their N-terminus, we built chimeric constructs to identify domains of the muscarinic receptor molecule required for this extracellular binding site for charged LA. Our results suggest that the $\mathrm{N}$-terminal as well as the third extracellular loop of the $\mathrm{ml}$ receptor molecule are required to form the binding pocket for charged LA. The amino terminus is quite divergent between $\mathrm{ml}$ and $\mathrm{m} 3$ receptors, and significant additional work will be required to delineate the amino acids involved in the binding site. However, since in the third extracellular loop only five amino acids are different between the $\mathrm{ml}$ and $\mathrm{m} 3$ receptors, further investigations might be able to exactly 
characterize the amino acid residues involved in this part of the binding site for LA on muscarinic receptors.

In contrast to the difference in extracellular actions, intracellular injection of lidocaine or QX314, a permanently charged and therefore membrane impermeant lidocaine analog, inhibited $\mathrm{m} 3$ signaling quite similarly to their effect on lysophosphatidate (LPA) and $\mathrm{m} 1$ muscarinic signaling ${ }^{2}$, suggesting a common intracellular site of action for LA. Similar to $\mathrm{ml}$ signaling, we found $\mathrm{m} 3$ signaling primarily mediated by $\mathrm{G \alpha}_{2}$ and $\mathrm{G} \alpha_{11}$. This is in agreement with findings by Stehno-Bittel et al. ${ }^{9}$. Employing the Xenopus oocyte expression system, they showed that antisense oligonucleotides and antibodies to $\mathrm{G} \alpha_{9}$ and $\mathrm{G} \alpha_{11}$ blocked $\mathrm{m} 3$-mediated signal transduction by inhibiting interaction of the muscarinic receptor with the $\mathrm{G}$ protein. Interestingly, agents that specifically bound free $G \beta \gamma$ also inhibited acetylcholine-induced activation of phospholipase C- $\beta$ (PLC- $\beta$ ). Conversely, direct injection of G $\beta \gamma$ subunits into oocytes induced release of intracellular $\mathrm{Ca}^{2+}$, suggesting that receptor coupling is determined by $\mathrm{G}_{4}$ but that $\mathrm{G} \beta \gamma$ is the predominant signaling molecule activating oocyte PLC $-\beta^{9}$. These findings are not specific to the oocyte. Morel et al. studied coupling of $\mathrm{G}$ protein subunits involved in acetylcholine-induced $\mathrm{Ca}^{2+}$ release in mouse duodenal myocytes. Intracellular dialysis with a patch pipette solution containing anti-Ga $\alpha_{0 / 11}$ antibodies inhibited acetylcholine-induced $\mathrm{Ca}^{2+}$ release, and antisense oligonucleotide studies showed that only $\mathrm{Ga}_{4}$ was involved ${ }^{10}$.

Further studies should elucidate the exact mechanism by which $\mathrm{LA}$ inhibit $\mathrm{G}_{\mathrm{q}}$ functioning. Several possible explanations exist. First, LA might interfere selectively with the coupling of the $\mathrm{G}_{q}$ protein to the muscarinic receptor. Either decreasing the affinity of $\mathrm{Ga}_{4}$ for the receptor (preventing activation of the $G$ protein), but also stabilization of the receptor- $G$ protein complex (preventing uncoupling of the $\mathrm{G}$ protein from the receptor), as suggested for volatile anesthetics ${ }^{11}$, could be underlying mechanisms. Second, LA might stabilize the $G \alpha_{\alpha}-\beta \gamma$ complex, thus reducing free $G \beta \gamma$ and preventing PLC activation. A maybe less likely possibility would be LA-enhanced guanosinetriphosphatase (GTPase) activity, due to more effective GTPase-activating protein (GAP) activity of a regulator of $\mathrm{G}$ protein signaling (RGS) protein. This would lead to faster reassembly of the heterotrimeric complex. Since the Guanosindiphosphate (GDP)/Guanosintriphosphate (GTP) binding site is highly conserved among all G $\alpha$-subunits, it seems unlikely that LA interact selectively with the nucleotide binding site on $\mathrm{Ga}_{\mathrm{a}}$. Whatever the underlying mechanism, it will have to account for the ability of local anesthetic to differentiate between $G_{4}$ and $G_{11}$, two very closely related $\mathrm{G}$ protein $\alpha$ subunits.

However, the profound sensitivity of $\mathrm{m} 3$ receptor signaling to extracellularly applied lidocaine can not be solely explained by a single intracellular site of action. Our findings using benzocaine and intracellularly injected lidocaine suggest that inhibition of $\mathrm{m} 3$ signaling by lidocaine is most likely due to a combined effect on an intracellular charged site on $\mathrm{G}_{\mathrm{q}}$ and an extracellular uncharged site on the $\mathrm{m} 3$ receptor molecule, as illustrated in Fig 5C. Interaction of two separate binding sites explaining LA inhibition of $\mathrm{G}$ protein-coupled receptors ( $\mathrm{ml}$ muscarinic and LPA receptors) were demonstrated in previous studies from our group ${ }^{2}$. 


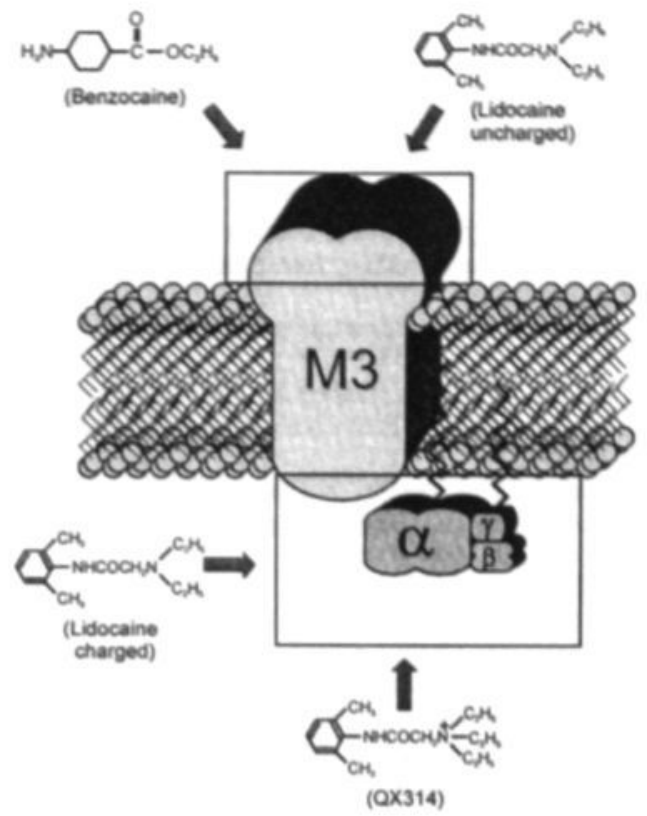

Figure 19: Schematic summary of hypothesized sites of action on m3 muscarinic signaling for the local anesthetics studied.

In summary, our present study adds to previous findings that LA at clinically relevant concentrations can inhibit $\mathrm{G}$ protein-coupled receptors. The interactions between the anesthetics and the receptor pathways are complex, and involve multiple sites of action, on receptor as well as coupled $\mathrm{G}$ protein. In view of the important roles of $\mathrm{ml}$ and $\mathrm{m} 3$ muscarinic signaling in the brain and peripheral tissues, LA inhibition of these receptors is likely to be of relevance. The clinical implications remain to be addressed. 


\section{References}

1. Bonhomme V, Meuret P, Backman SB, Plourde G, Fiset P: Cholinergic mechanisms mediating propofol-induced loss of consciousness in man. Can J Anaesth 1998; 45:A52

2. Hollmann MW, Fischer LG, Byford AM, Durieux ME: Local anesthetic inhibition of $\mathrm{ml}$ muscarinic acetylcholine signaling. Anesthesiolgy 2000; 93:497-509

3. Bonner TI: The molecular basis of muscarinic receptor diversity. TINS $1989 ; 12: 148-51$

4. Shapira H, Amit I, Revach M, Oron Y, Battey JF: $\mathrm{Ga}_{14}$ and $\mathrm{Ga}_{4}$ mediate the response to trypsin in Xenopus oocytes. J Biol Chem 1998; 273:19431-6

5. Nietgen GW, Hoenemann CW, Chan CK, Kamatchi GL, Durieux ME: Volatile anaesthetics have differential effects on recombinant $\mathrm{m} 1$ and $\mathrm{m} 3$ muscarinic acetylcholine receptor function. Br J Anaesth 1998; 81:569-77

6. Scholz A, Kuboyama N, Hempelmann G, Vogel W: Complex blockade of TTX-resistant Na+ currents by lidocaine and bupivacaine reduce firing frequency in DRG neurons. J Neurophysiol 1998; 79:1746-54

7. Sullivan LM, Hoenemann CW, Arledge JAM, Durieux ME: Synergistic inhibition of lysophosphatidic acid signaling by charged and uncharged local anesthetics. Anesth Analg 1999; 88:1117-24

8. Hollmann MW, Berger A, Fischer LG, Durieux ME: Lysophosphatidate and muscarinic ml receptor signaling is mediated by different $G$ protein alpha subunits. Anesth Analg 2000; $90:$ S426

9. Stehno-Bittel L, Krapivinsky G, Krapivinsky L, Perez-Terzic C, Clapham DE: The G protein beta gamma subunit transduces the muscarinic receptor signal for $\mathrm{Ca} 2+$ release in Xenopus oocytes. J Biol Chem 1995; 270:30068-74

10. Morel JL, Macrez N, Mironneau J: Specific Gq protein involvement in muscarinic M3 receptor-induced phosphatidylinositol hydrolysis and $\mathrm{Ca}_{2}+$ release in mouse duodenal myocytes. Br J Pharmacol 1997; 121:451-8

11. Aronstam RS, Dennison RL: Anesthetic effects on muscarinic signal tranduction. Int Anesthesiol Clin 1989; 27:265-72 
CHAPTER 6

\section{Local anesthetic inhibition of $\mathbf{G}$ protein-coupled receptor signaling by interference with $\mathbf{G} \alpha_{4}$ protein function}

Markus W. Hollmann

Kathrin S. Wieczorek

Andreas Berger

Marcel E. Durieux

The author is recipient of the third-place award in the American Society of Anesthesiologists Residents' Research Essay Contest in 2000 and the BenCovino award 2000 from the International Anesthesia Research Society for the work presented in this article.

Published in: Molecular Pharmacology: 59:294-301, 2001 


\section{Local anesthetic inhibition of $\mathbf{G}$ protein-coupled receptor signaling by}

interference with $\mathrm{Ga}_{\mathrm{q}}$ protein function

\section{ABSTRACT}

Although local anesthetics are considered primarily Na channel blockers, previous studies suggest a common intracellular site of action on different $\mathrm{G}$ protein-coupled receptors. In the present study, we characterized this site for the LPA, $\mathrm{ml}$ muscarinic and trypsin receptor. Xenopus oocytes expressing endogenous LPA and trypsin or recombinant $\mathrm{ml}$ receptors were two-electrode voltage clamped. We studied LPA inhibition in the presence of ropivacaine stereoisomers to determine whether LA act on a protein site. Ropivacaine irhibited LPA signaling in a stereoselective and non-competitive manner, suggesting a protein interaction. Antisense injection was used to characterize G protein $\alpha$-subunits involved in mediation of LPA, ml, trypsin and angiotensin $_{1 \mathrm{~A}}$ receptor signaling. Lidocaine and its analogae QX314 were injected into oocytes expressing these receptors to examine a potential role for specific $G$ protein $\alpha$-subunits as targets for LA. $\mathrm{Ga}_{4}$ was shown to be among the primary $\mathrm{G}$ proteir subunits mediating the LPA, $\mathrm{ml}$ and trypsin receptor signaling, all of which were inhibited to a similar degree by intracellular injected QX314 $\left(424 \times 10^{-6} \mathrm{M}\right)$. Since the angiotensin $\sin _{1 \mathrm{~A}}$ receptor, previously shown not to be affected by $\mathrm{LA}$, was found not to signal via $\mathrm{G \alpha}_{4}$, but via $\mathrm{G} \alpha_{0}$ and $\mathrm{G} \alpha_{14}$, the intracellular effect of LA most likely takes place at the $\mathrm{G \alpha}_{\mathrm{q}}$-subunit.

\section{INTRODUCTION}

Although blockade of $\mathrm{Na}$ channels is the primary mode of local anesthetic action, in the past decade alternative actions of LA have increasingly become a topic of investigation, and may lead to new clinical uses for these compounds (such as anti-inflamnatory indications). We have previously reported inhibitory effects of $\mathrm{LA}$ on several $\mathrm{G}$ protein-coupled receptors, such as thromboxane $\mathrm{A}_{2}$, $\mathrm{ml}$ muscarinic acetylcholine ${ }^{2}$, and in particular LPA receptors ${ }^{3}$. LPA is likely to be a wound healing mediator, making such investigations particularly relevant, since LA are used frequently for injection around surgical wounds. We have shown that lidocaine or bupivacaine inhibit LPA, but not angiotensin, signaling. QX314 (a permanentify charged and hence membrane impermeant lidocaine analogue) inhibited LPA signaling only when injected intracellularly, and benzocaine (permanently uncharged LA) inhibited with a similar half-maximal inhibitory concentration (IC $\mathrm{C}_{50}$ ). Combined administration of both compounds exerted superadditive effects, suggesting the presence of two different binding sites for LA, one of which is intracellular ${ }^{4}$. Downstream signaling induced by $\mathrm{IP}_{3}$ or GTP $\gamma \mathrm{S}^{4}$ was not affected by LA ${ }^{3}$, suggesting that the action of LA is on the receptor or coupled $\mathrm{G}$ protein. However, non-specific membrane actions of LA are possible, and we did not directly confirm a protein site of action in our previous studies. Comparison of the effects of intracellular QX314 on m1 muscarinic and LPA receptors showed not only very similar calculated $\mathrm{IC}_{50} \mathrm{~s}$, but maximal degree of inhibition and slope of the inhibition curve were also similar ${ }^{2}$, suggesting a common site of action. No similarity exists between the receptors, but since they couple to similar G proteins, we hypothesized that LA may inhibit G protein function.

In the present study we tested this hypothesis. Specifically, we (1) determined stereoselectivity of LA effect to investigate whether LA act on a protein site; (2) determined the G protein subtypes coupling to LPA, ml muscarinic, trypsin and angiotensin $\sin _{1 \mathrm{~A}}$ receptors; and (3) determined if specific $\mathrm{G}$ protein $\alpha$ subunits are involved in the LA effect. 


\section{MATERIALS AND METHODS}

The studies were performed in Xenopus oocytes. These cells express endogenous LPA and trypsin receptors; other $\mathrm{G}$ protein-coupled receptors can be expressed conveniently. Intracellular $\mathrm{Ca}$ release as a response to receptor stimulation is easily assessed as $\mathrm{Ca}$-activated $\mathrm{Cl}$ currents. The size of the cells makes intracellular injection straightforward. In addition, using oocytes allowed comparison with our previous results obtained in this model. The study protocol was approved by the Animal Research Committee at the University of Virginia.

\section{Materials}

Molecular biology reagents were obtained from Promega (Madison, WI) and other chemicals were obtained from Sigma (St. Louis, MO). QX314 and the stereoisomers of ropivacaine were a gift from Astra Pharmaceuticals, L.P. (Westborough, MA).

Oocyte harvesting, receptor expression, electrophysiologic recording and intracellular injections were performed as described previously $5,4,4,67$

\section{Oligonucleotide injection}

Phosphorothioate oligonucleotides were synthesized by the University of Virginia Research Facility. The antisense sequences, shown in figure 2A, are complementary to specific 20-base segments with less than $50 \%$ homology with other types of $X$. laevis $\mathrm{G}_{\mathrm{a}}$ proteins ". Sense oligonucleotides were used as control. Uninjected oocytes (for experiments on the LPA or endogenous protease receptor) or those injected $24 \mathrm{~h}$ prior with cRNA encoding the $\mathrm{m} /$ or AT/A receptor were injected with $50 \mathrm{nl}$ sterile water containing $50 \mathrm{ng} /$ cell antisense or sense oligonucleotides. Control cells were injected with the same amount of sterile water. 24 and 48 hours after oligonucleotide injection the cells were tested as described below.

\section{Analysis}

Results are reported as mean \pm SEM. At least 12 oocytes were used to determine each data point unless noted otherwise. As variability between batches of oocytes is common, responses were at times normalized to control response. Statistical tests employed are indicated in the Results section. $P<0.05$ was considered significant. Concentration-response curves were fit to the following logistic function, derived from the Hill equation: $y=y_{\min }+\left(y_{\max }-y_{\min }\right)\left\{1-x^{n} /\left(x_{50}{ }^{n}+x^{n}\right)\right\}$ where $\mathrm{y}_{\max }$ and $\mathrm{y}_{\min }$ are the maximum and minimum response obtained, $\mathrm{n}$ is the Hill coefficient, and $\mathrm{X}_{90}$ is the half-maximal effect concentration ( $\mathrm{EC}_{50}$ for agonist) or the half-maximal inhibitory effect concentration ( $\mathrm{IC}_{50}$ for antagonist).

\section{RESULTS}

\section{LPA responses in Xenopus oocytes}

In order to provide baseline measurements, and to assure that our model behaved similar to our previous studies, we determined the concentration-response relationship for LPA. LPA induced inward currents as described previously by us ${ }^{6,9,10}$ and others ${ }^{11,12-15}$ (Figure 1). 


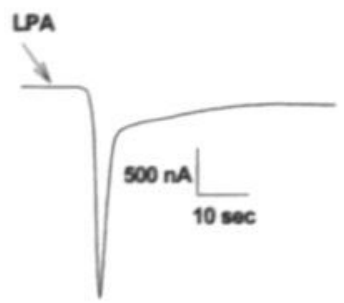

Figure 1: Example of inward chloride current $\left.I_{\mathrm{C}_{(} \mathrm{Ca}}\right)$ induced by LPA $(0.6 \mu \mathrm{M})$ in oocytes expressing endogenous $L P A$ receptors.

As shown in Figure 2, the response to LPA was concentration-dependent. Half-maximal effect concentration $\left(\mathrm{EC}_{50}\right.$ ) was $6.0 \pm 3.3 \times 10^{-7} \mathrm{M}$. Maximal responses of $4.3 \pm 0.5 \mu \mathrm{C}$ were obtained at a LPA concentration of $10 \mu \mathrm{M}$. Calculated $\mathrm{E}_{\max }$ was $5.1 \pm 0.5 \mu \mathrm{C}$ and Hill coefficient was $0.57 \pm 0.08$. These findings compare closely with data reported in our previous studies ${ }^{3,16-18}$

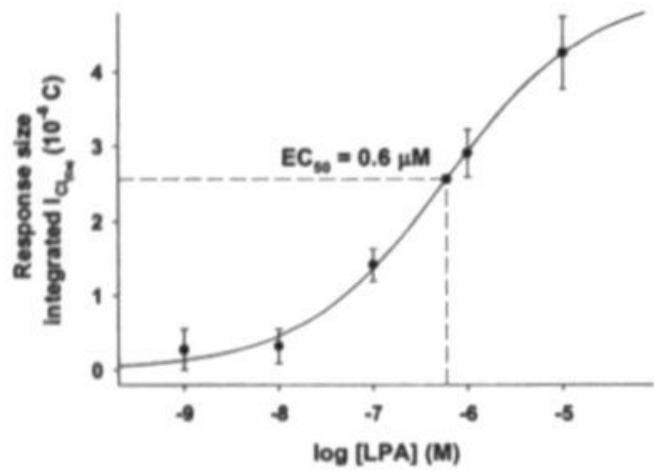

Figure 2: LPA evokes I arcai $_{\text {in }}$ a concentration-dependent manner. Curve fitting using Hill equation revealed an $E C_{50}$ of $6.0 \pm 3.3 \times 10^{7} \mathrm{M}$. Maximal responses of $4.3 \pm 0.5 \mu \mathrm{C}$ were obtained with $10 \mu \mathrm{M}$ LPA. Calculated $E_{\max }$ was $5.1 \pm 0.5 \mu C$.

\section{Ropivacaine stereoselectively inhibits LPA receptor function}

In order to determine if LA inhibition of LPA signaling takes place at a protein site, we studied stereoselectivity of LA action. We selected S(-) and $\mathrm{R}(+)$-ropivacaine for these experiments. Both stereoisomers concentration-dependently inhibited functioning of LPA receptors (e.g. Figure 3A) activated by LPA at $\mathrm{EC}_{50}\left(6.0 \times 10^{-7} \mathrm{M}\right)$ (Figure $\left.3 \mathrm{~B}\right)$. Calculated $\mathrm{IC}_{50}$ for the clinically relevant $\mathrm{S}(-)-$ enantiomer of ropivacaine was $23.8 \pm 3.3 \times 10^{-3} \mathrm{M}$. R(+)-ropivacaine showed an approximately 5fold greater inhibitory potency than did $\mathrm{S}(-)$-ropivacaine $\left(\mathrm{IC}_{50} 4.8 \pm 0.2 \times 10^{-3} \mathrm{M}\right)$; the difference in $\mathrm{IC}_{90}$ between $\mathrm{S}(-)$ and $\mathrm{R}(+)$ was significant $(\mathrm{p}=0.001$, t-test), but we observed no statistically significant difference in Hill-coefficients of both curves $(1.2 \pm 0.3$ for $\mathrm{R}(+)$ vs $2.1 \pm 0.4$ for $\mathrm{S}(-)$, $\mathrm{p}=0.102, \mathrm{t}$-test). 

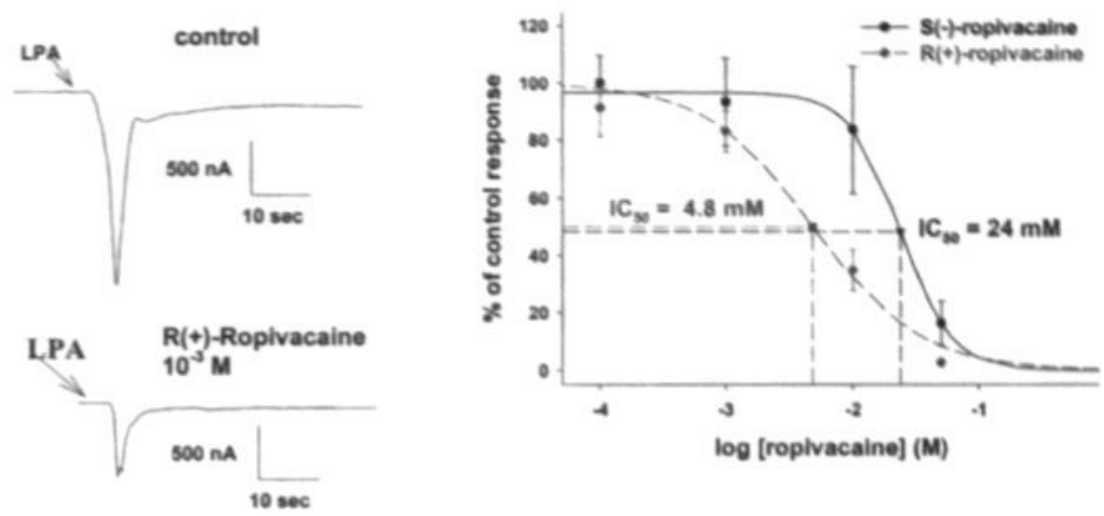

Figure 3: (A) Example trace of LPA $(0.6 \mu \mathrm{M})$-induced I $\mathrm{Caca}$, under control conditions (top) and after 10 min incubation in $R(+)$-ropivacaine $\left(10^{3} \mathrm{M}\right)$ (bottom). (B) Both ropivacaine stereoisomers concentration-dependently inhibit functioning of $L P A$ receptors, activated by $L P A$ at $E C_{50}(0.6 \mu M)$, but with different half-maximal inhibition concentrations $\left(I C_{90}\right)$. Calculated $I C_{90}$ was $23.8 \pm 3.3 \times 10$ ${ }^{3} M$ for $S(-)$ ropivacaine and $4.8 \pm 0.2 \times 10^{3} M$ for $R(+)$-ropinacaine. Mean $\pm S E M$ of control responses were $1.1 \pm 0.3 \mu \mathrm{A}$ for $S(-)$-ropivacaine and $2.3 \pm 0.4 \mu \mathrm{A}$ for $R(+)$-ropivacaine.

These results demonstrate that LPA signaling is inhibited by ropivacaine enantiomers in a stereoselective manner. Although an action on an organized (and hence stereoselective) lipid membrane can not be ruled out by these experiments, the data are compatible with a protein interaction for ropivacaine, as suggested for other LA in our previous studies ${ }^{3}$.

Our data show that S(-)-ropivacaine, the clinically relevant enantiomer, is approximately 6 -fold less potent than bupivacaine and 4-fold less potent than lidocaine in blocking LPA signaling ${ }^{3}$. Like bupivacaine, $\mathrm{S}(-)$ ropivacaine inhibited in a non-competitive manner (Figure 1E). EC so $_{0}$ for LPA in the presence of $\mathrm{S}(-)$ ropivacaine at $\mathrm{IC}_{50}\left(23.8 \times 10^{-3} \mathrm{M}\right)$ was $1.7 \pm 0.9 \times 10^{-7} \mathrm{M}$; this was not significantly different from the $\mathrm{EC}_{50}$ of $1.6 \pm 0.2 \times 10^{-7} \mathrm{M}$ obtained under control conditions $\left(\mathrm{p}=0.744, \mathrm{t}\right.$-test). In contrast, $\mathrm{E}_{\max }$ was reduced by the presence of $\mathrm{S}(-)$ ropivacaine from $1.1 \pm 0.1 \mu \mathrm{A}$ to $0.6 \pm 0.03 \mu \mathrm{A}(\mathrm{p}<0.001, \mathrm{t}$ test $)$.

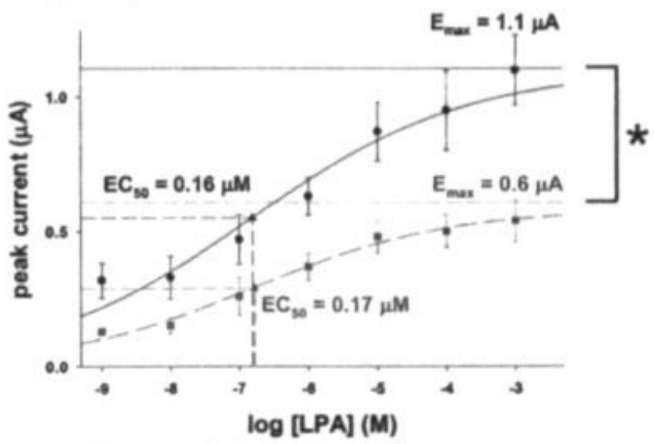

Figure 4: S(-)-ropivacaine does not shift the LPA concentration-response curve to the right (- $\rightarrow$ - : control, EC $C_{50} 1.7 \pm 0.9 \times 10^{7} \mathrm{M} ;-\cdots-;$ in the presence of ropivacaine $24 \mathrm{mM}, E C_{50} 1.6 \pm 0.2 \times 10^{7}$ $M)$. Maximal effect concentration ( $E_{\max }$ ) was significantly reduced after $S(-)$-ropivacaine administration (1.1 $\pm 0.1 \mu \mathrm{A}$ to $0.6 \pm 0.03 \mu \mathrm{A})$, making a non-competitive antagonism most likely. 
Functional degradation of $\mathbf{G}$ protein $\alpha$-subunits by injection of antisense oligonucleotides.

Stereoselectivity of ropivacaine block is compatible with our hypothesis that $\mathrm{G}$ proteins are a target site in the inhibitory effect of LA on LPA signaling. We therefore determined if receptors inhibited by LA share a common coupled G $\alpha$ subunit, by selectively depleting $\mathrm{G} \alpha$ proteins using antisense oligonucleotides directed against the $\mathrm{G}$ protein subunits. To verify that this system functioned appropriately in our hands, we determined the $G$ protein $\alpha$ subunits coupling to (1) endogenous protease receptors and (2) recombinantly expressed $\mathrm{ml}$ muscarinic receptors in Xenopus oocytes. We studied these receptor systems previously ${ }^{2}$, and the $\mathrm{G}$ protein $\alpha$ subunits coupling to these receptors have been determined previously by others allowing verification of the technique ${ }^{8}$. Since the receptors of interest induce intracellular $\mathrm{Ca}$ release, we used antisense oligonucleotides directed against $\mathrm{G} \alpha_{4}, \mathrm{G} \alpha_{11}, \mathrm{G} \alpha_{14}$, and $\mathrm{G} \alpha_{0}$ (Figure 5). Oocytes injected with vehicle served as control.

\section{Antisense-oligonucleotide-sequence}

anti-G ${ }_{a q}:$ 5'-ATTCTCAAAAGAGGCGACC-3';

anti-G ${ }_{\alpha / 1}:$ 5'-CTGTTCAAAGGTACATACT-3';

anti-G ${ }_{\alpha 14}:$ 5'-GTTTCCTTTCAAGACTGGAT-3';

anti-G ${ }_{a 0}$ : 5'-GCGCTCAGTCTGCAGCCCAT-3';

Figure 5: Antisense oligonucleotide sequence used."

First, we determined the $\mathrm{G}$ protein $\alpha$ subunits coupling to the endogenous protease receptor. We reported previously that the protease trypsin induces $\mathrm{Ca}$-activated $\mathrm{Cl}$ current in oocytes ${ }^{7}$. The site of action of trypsin was extracellular, the response desensitized completely, and the suggested mechanism was the presence of a protease receptor on the oocyte. As in our previous study, trypsin ( $1 \mu \mathrm{g} / \mathrm{ml}$ ) induced responses in oocytes similar to those induced by LPA (data not shown). As shown in Figure 6, responses elicited by trypsin $(1 \mu \mathrm{g} / \mathrm{ml}) 24$ hours after injection of antisense oligonucleotides were not affected by anti-Ga $(90 \pm 19 \%$ of control response, $p>0.05)$, (unless otherwise stated, all determinations of $\mathrm{G}$ protein $\alpha$ subunits were compared by One Way ANOVA with Dunnett correction) or anti-G $\alpha_{11}(81.3 \pm 16.6 \%$ of control response, $p>0.05)$. In contrast, oocytes injected 24 hours before measurement with anti-G $\alpha_{4}(32.4 \pm 6.2 \%$ of control response, $p<$

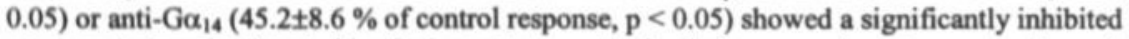
response to trypsin. Nearly identical results were obtained when experiments were performed 48 hours after antisense injection (data not shown). These results indicate that the response evoked by trypsin is mediated by $\mathrm{G} \alpha_{4}$ and $\mathrm{G} \alpha_{14}$, suggesting strongly that the trypsin response is mediated by a $\mathrm{G}$ protein-coupled receptor system. 


\section{Trypsin -24 h}

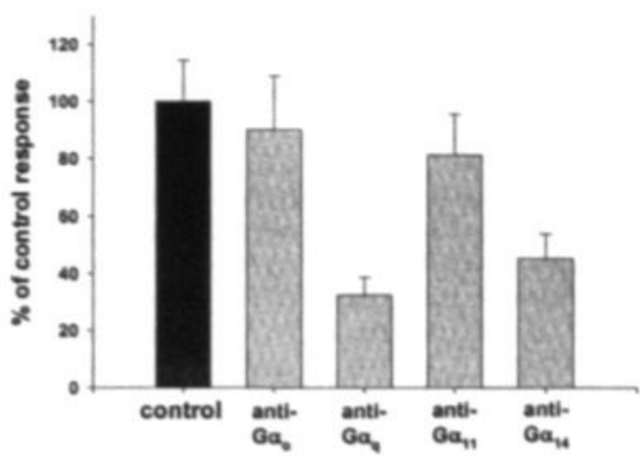

Figure 6: Mean $\pm S E M$ of peak currents of trypsin (I $1 \mathrm{gg} / \mathrm{ml})$-induced I arcas, in control oocytes (black bar) and cells injected with DNA antisense oligonucleotides (50 ng/oocyte) targeted against specific Ga-subunits, 24 hours prior to experiments. Mean $\pm S E M$ of control currents were $1.4 \pm 0.3$ $\mu 1$ Each data point includes at least 24 oocytes.

Next we investigated the $\mathrm{G}$ protein $\alpha$-subunit coupling of $\mathrm{ml}$ muscarinic responses elicited by stimulation with $\mathrm{MCh}$ at $\mathrm{EC}_{50}\left(5.7 \times 10^{-7} \mathrm{M}\right.$, calculated from our previous investigations $\left.{ }^{2}\right)$ in oocytes injected previously with $\mathrm{ml}$ receptor $\mathrm{cRNA}$. Experiments were performed 48 hours after

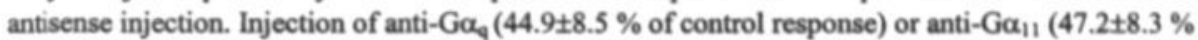

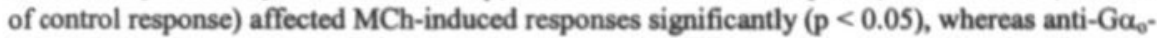
(92.2 $\pm 12.7 \%$ of control response) or anti-G $\alpha_{14^{-}}(98.9 \pm 5.5 \%$ of control response) injected oocytes showed responses not significantly different from those observed in control cells $(p>0.05)$ (Figure 7). Our results show that muscarinic $\mathrm{ml}$ signaling is mainly mediated by $\mathrm{G} \alpha_{4}$ and $\mathrm{G} \alpha_{11}$.

\section{M1 muscarinic $-\mathbf{4 8} \mathrm{h}$}

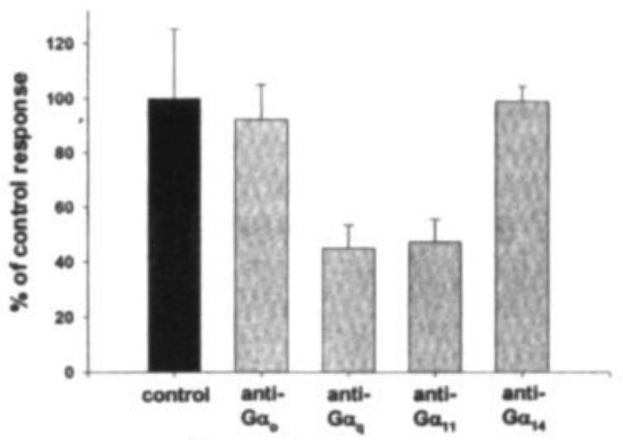

Figure 7: MCh (at EC $50\left(5.7 \pm 5.2 \times 1 \sigma^{7} \mathrm{M}\right)$ )-induced $I_{C_{1}} \mathrm{Ca}_{a}$ in control oocytes (black bar, $0.4 \pm 0.1$ $\mu 4)$ and cells tested 48 hours after injection of antisense constructs. 
The studies using trypsin and muscarinic receptors demonstrate that $\mathrm{G} \alpha$ protein depletion by antisense oligonucleotides functions appropriately in our hands, as results are similar to those obtained by Shapira et al. ${ }^{8}$. These investigators demonstrated in addition that the reduced functional responses are associated with decreased mRNA and protein levels for the respective $G$ proteins. After these confirmatory experiments, we proceeded to determine the Ga proteins mediating the LPA response.

\section{$\mathrm{Ga}_{4}$ and $\mathrm{G} \alpha_{0}$ mediate the response to LPA in Xenopus oocytes}

To exclude the possibility that injection of DNA oligonucleotides per se affects responses to LPA (at EC $50,6.0 \times 10^{-7} \mathrm{M}$ ), we first studied the effects of sense oligonucleotide injection. Neither after 24 (data not shown) nor after 48 hours (Figure 8) did sense-injected oocytes show responses different from those obtained in control oocytes injected with sterile water $(p>0.05)$. Thus, sense oligonucleotides are without effect.

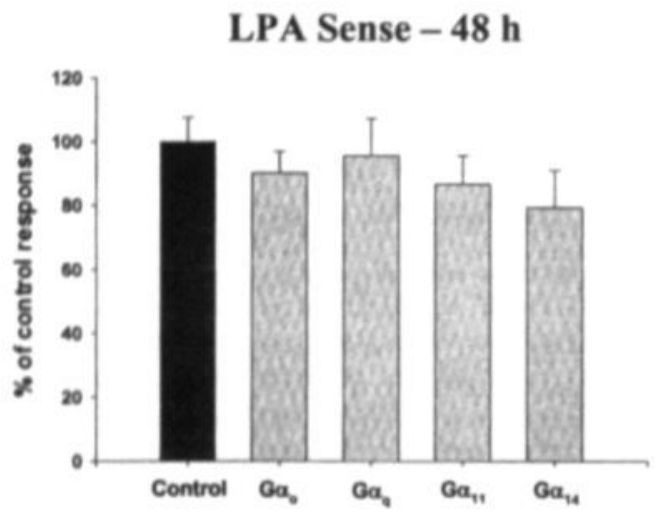

Figure 8: Effects of sense oligomucleotide (see figure 5 for sequences) injection 24 hours prior on LPA signaling, stimulated by LPA at $E C_{50}\left(6.0 \pm 3.3 \times 10^{7} \mathrm{M}\right)$. At neither time point did sense oligonucleotide-injected oocytes show a significant difference in response compared with sterile water-injected control oocytes (1.9 $\pm 0.1 \mu \mathrm{A}$ (24 hours) and $1.5 \pm 0.2 \mu \mathrm{A}$ (48 hours)).

Antisense injection 48 hours (Figure 9) before oocytes were tested caused a significant $(\mathrm{p}<0.05)$ inhibition of peak current when anti-G $\alpha_{0}\left(38.1 \pm 3.9 \%\right.$ of control response) or anti-G $\alpha_{9}(41.7 \pm 4.9 \%$ of control response) were used. In contrast, injection of anti-G $\alpha_{11}(102 \pm 17 \%$ of control response) or anti-G $\alpha_{14}(109 \pm 21 \%$ of control response) was without significant $(p>0.05)$ effect compared with control oocytes $(100 \pm 19.3 \%)$. These findings indicate that LPA signaling is mediated primarily by $\mathrm{G} \alpha_{4}$ and $\mathrm{G} \alpha_{0}$. 


\section{LPA Antisense - $48 \mathrm{~h}$}

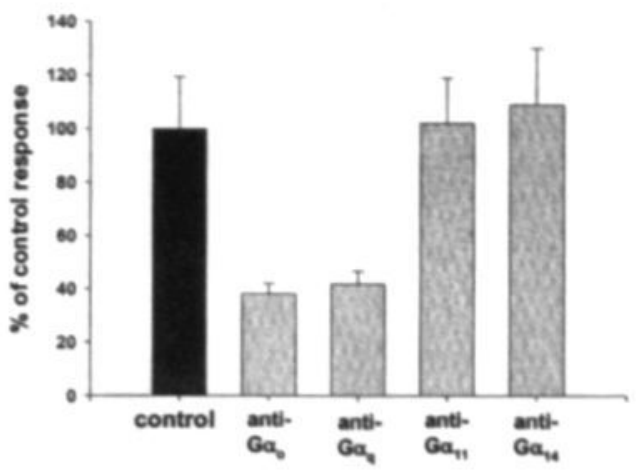

Figure 9: Mean $\pm S E M$ of peak currents of LPA responses induced by $L P A$ at $E C_{30}\left(6.0 \pm 3.3 \times 1 \sigma^{7}\right.$ $M$ ) in control oocytes (black bar, 1.8 $\pm 0.3 \mu \mathrm{A}$ ) and cells injected with the corresponding DNA antisense oligonucleotides (50 ng/oocyte) 48 hours prior. Anti-G $\alpha_{0}$ inhibited responses to $38.1 \pm 3.9$ $\%$ anti-Ga, to $41.7 \pm 4.9 \%$ as compared with control. In contrast, injection of anti-G $\alpha_{11}(102 \pm 17 \%$ of control response) or anti-Ga $\alpha_{14}(109 \pm 21 \%$ of control response) was without significant effect compared with control oocytes.

Since $\mathrm{ml}$ muscarinic and LPA signaling are similarly inhibited by intracellular QX314, our findings suggest that the $\mathrm{G} \alpha_{4}$ protein, common to both signaling pathways, might be the target of the LA. This hypothesis was tested in the next series of experiments.

\section{QX314 inhibition of LPA signaling requires $\mathbf{G a}_{4}$}

We addressed the question if LA inhibit LPA signaling by an action on G protein $\alpha$-subunits. To exclude an extracellular LA effect, we chose the permanently charged and therefore membrane impermeant lidocaine analogue QX314 for our experiments and applied it intracellularly. First, we determined the inhibition curve for intracellularly injected QX314 on LPA responses induced by stimulation with LPA $\left(10^{-7} \mathrm{M}\right)$. We chose an LPA concentration somewhat less than $\mathrm{EC}_{50}$, because injection of $150 \mathrm{nM} \mathrm{KCl}(50 \mathrm{nl})$ used in control cells and in treatment cells as buffer for QX314 caused substantially increased response sizes as a result of the increased intracellular $\mathrm{Cl}$ load.

Figure 10 presents the results. Fitting to the Hill equation revealed a calculated $\mathrm{IC}_{50}$ of $424 \pm 70 \times 10^{\circ}$

${ }^{6} \mathrm{M}$, which is close to the value reported by Sullivan et al. ${ }^{4}$. Mean size of the control response was $3.6 \pm 0.3 \mu \mathrm{A}$. 


\section{LPA}

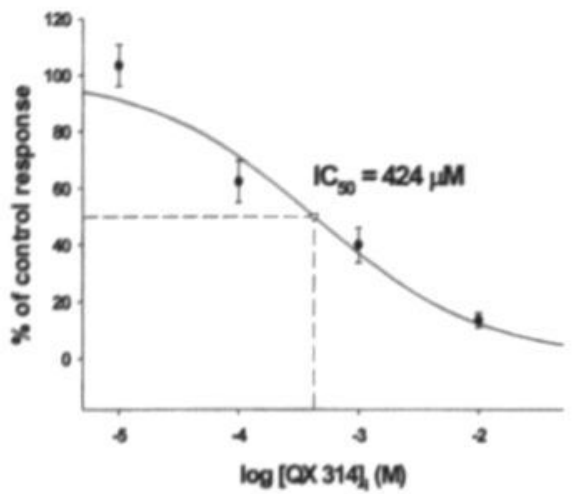

Figure 10: Concentration-inhibition relationship for inhibition of LPA $\left(10^{7} M\right) I_{C \text { Cal }}$ by intracellularly injected $Q X 314$. Curve fitting using Hill equation revealed an $I C_{30}$ of $424 \pm 70 \times 10^{6}$ $M$. Mean control response was $3.6 \pm 0.3 \mu$.

To assure that QX314 effect is not dependent on response size, we also studied its action on responses elicited by a low concentration of LPA ( $1 \mathrm{nM})$. In control cells mean peak current was $1.1 \pm 0.2 \mu \mathrm{A}$ (Figure 11). Injection of QX314 at $\mathrm{IC}_{50}\left(424 \times 10^{-6} \mathrm{M}\right)$ caused an inhibition to approximately $38 \%(0.4 \pm 0.1 \mu \mathrm{A})$, showing that the effect of the compound is independent of LPA response size.

\section{LPA}

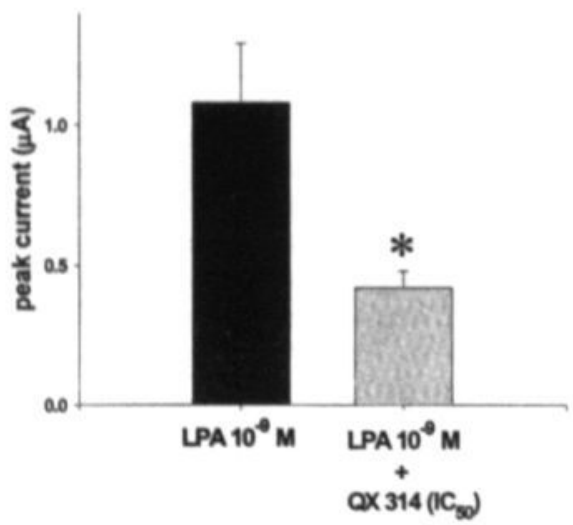

Figure 11: Mean $\pm S E M$ of peak I arca induced by stimulation with LPA $\left(10^{9} \mathrm{M}\right)$ in either $\mathrm{KCl}(50$ $\mathrm{nl}$ of $150 \mathrm{mM} \mathrm{KCl)-injected} \mathrm{control} \mathrm{oocytes} \mathrm{(black} \mathrm{bar,} 1.1 \pm 0.2 \mu \mathrm{A})$ or cells injected with QX314 (at IC 5 sa $42470 \times 10^{-6} \mathrm{M}$ ) (grey bar, $\left.0.4 \pm 0.1 \mu 4\right)$. 
We then tested the inhibitory effect of intracellularly injected QX314 at $\mathrm{IC}_{50}\left(424 \times 10^{-6} \mathrm{M}\right)$ on oocytes injected 48 hours prior with anti-Ga $\alpha_{4}$ or anti-Ga $\mathrm{G}_{0}$, which, as shown above, mediate the LPA response. Oocytes were stimulated with $0.1 \mu \mathrm{M}$ LPA. As shown in Figure 12, significant inhibition of LPA responses by intracellularly injected QX 314 was obtained only in anti-G $\alpha_{0}$ injected cells

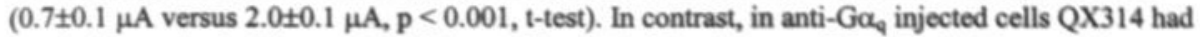
no significant $(p=0.574, t$-test) inhibitory effect $(1.6 \pm 0.2 \mu \mathrm{A}$ versus $1.7 \pm 0.2 \mu \mathrm{A})$. These findings indicate that $\mathrm{QX} 314$ inhibits only when functional $\mathrm{Ga}_{4}$ is present, suggesting that it mediates its inhibitory effect by acting on this $\mathrm{G}$ protein subunit.

\section{LPA}

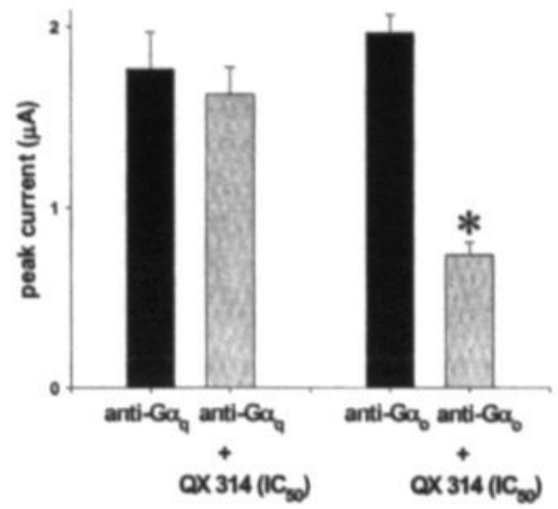

Figure 12: Mean \pm SEM of peak I carcai for LPA responses, elicited by LPA $\left(1 \sigma^{7} M\right)$ in oocytes injected with either anti-Ga or anti-Ga, Black bars represent mean peak currents of control oocytes injected with $50 \mathrm{nl}$ of $150 \mathrm{mM} \mathrm{KCl}$, whereas grey bars show mean peak currents of $\mathrm{QX314}$ (at IC so, $424 \pm 70 \times 10^{-6} \mathrm{M}$ )-injected cells.

In contrast to our findings, Noh et al. reported involvement of $G \alpha_{11}$ in mediation of LPA responses in Xenopus oocytes ". If so, LA inhibition of LPA signaling might also take place at this $\mathrm{G}$ protein. We therefore investigated the effect of intracellularly injected QX314 on either water (control) or anti-G $\alpha_{11}$ injected oocytes (Figure 13). Oocytes, injected 48 hours prior with water (control), showed an average peak current of $1.95 \pm 0.15 \mu \mathrm{A}$ after stimulation with LPA $\left(10^{-7} \mathrm{M}\right)$. Injection of QX314 at approximately $\mathrm{IC}_{50}\left(424 \times 10^{-6} \mathrm{M}\right)$ inhibited peak current of control oocytes to $63.1 \pm 6.2 \%$ of control response. Anti-G $\alpha_{11}$ injection changed neither the response to LPA ( $10^{-7}$

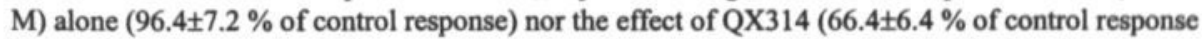
in anti-G $\alpha_{11}$ injected oocytes) compared with control cells. Thus, in our hands at least, $G \alpha_{11}$ seems not to be involved in mediation of the LPA response, and knockdown of $\mathrm{G}_{11}$ did not affect inhibition of the LPA response by QX314.

These results indicate that intracellularly injected QX314 acts by interference with $\mathrm{G}$ protein functioning, and that its main target is the $G \alpha_{q}$-subunit, rather than $G \alpha_{0}$ or $G \alpha_{11}$. 


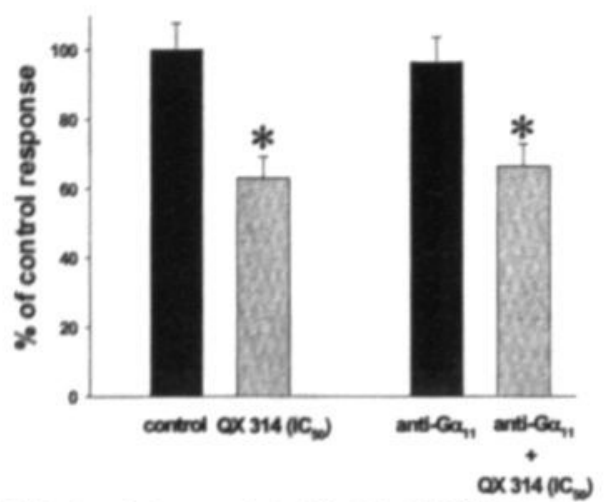

Figure 13: Mean \pm SEM of peak I Carcab, elicited by LPA $\left(10^{7} \mathrm{M}\right)$ in oocytes injected with either sterile water or anti-Ga $\alpha_{11}$ (black bars, $1.95 \pm 0.15 \mu \mathrm{A}$ and 1.88 $\pm 0.14 \mu \mathrm{A}$, respectively). Grey bars represent mean peak I arca of sterile water or anti-Ga $\alpha_{I 1}$-injected cells treated with QX314 (at IC 5 . $424 \pm 70 \times 10^{6} \mathrm{M}$ ) intracellularly.

\section{QX314 inhibition of $\mathbf{m 1}$ muscarinic signaling also requires $\mathbf{G} \alpha_{4}$}

If intracellular $\mathrm{QX} 314$ acts selectively on $\mathrm{Ga}_{4}$, the $\mathrm{ml}$ muscarinic receptor, which couples to this $G$ protein, should be inhibited also by this LA. Since we determined that $G \alpha_{4}$ and $G \alpha_{11}$ are the primary $\mathrm{G}$ protein subunits coupling to the $\mathrm{ml}$ muscarinic receptor, we studied the effect of intracellularly injected QX314 in oocytes expressing the m1 muscarinic receptor, 48 hours after injection of antisense oligonucleotides directed against $\mathrm{G} \alpha_{4}$ or $G \alpha_{11}$. As shown above, injection of anti-G $\alpha_{4}$ or anti-G $\alpha_{11}$ alone reduced the control response (3.25 $\left.\pm 0.19 \mu \mathrm{A}\right)$ (Figure 14), elicited by stimulation of the $\mathrm{ml}$ receptor with $\mathrm{MCh}\left(10^{-7} \mathrm{M}\right)$, to $44 \%(1.44 \pm 0.16 \mu \mathrm{A})$ and $48 \%(1.56 \pm 0.24$ $\mu \mathrm{A})$ respectively. If $\mathrm{QX} 314$ acts on $\mathrm{G} \alpha_{\mathrm{q}}$, its half-maximal inhibition concentration should be independent of the receptor studied. We therefore used QX314 at $\mathrm{IC}_{50}$ as determined for LPA signaling. Intracellularly injected QX314 $\left(424 \times 10^{-6} \mathrm{M}\right)$ had no significant $(\mathrm{p}=0.719, \mathrm{t}-\mathrm{test}, \mathrm{n}=20)$ effect in $\mathrm{G} \alpha_{\mathrm{q}}$-degraded oocytes $(1.35 \pm 0.19 \mu \mathrm{A}, 94 \%)$, whereas 48 hours after anti-G $\alpha_{11}$ injection it inhibited responses to $\mathrm{MCh}(0.87 \pm 0.15 \mu \mathrm{A})$ by the appropriate percentage $(55 \%, \mathrm{p}=0.02, \mathrm{t}$-test, $\mathrm{n}=20$ ). Thus, $\mathrm{QX} 314$ inhibition is dependent on the presence of $\mathrm{G} \alpha_{\alpha}$, and the compound differentiates between two very similar $G$ protein $\alpha$ subunits: $G \alpha_{4}$ and $G \alpha_{11}$. 


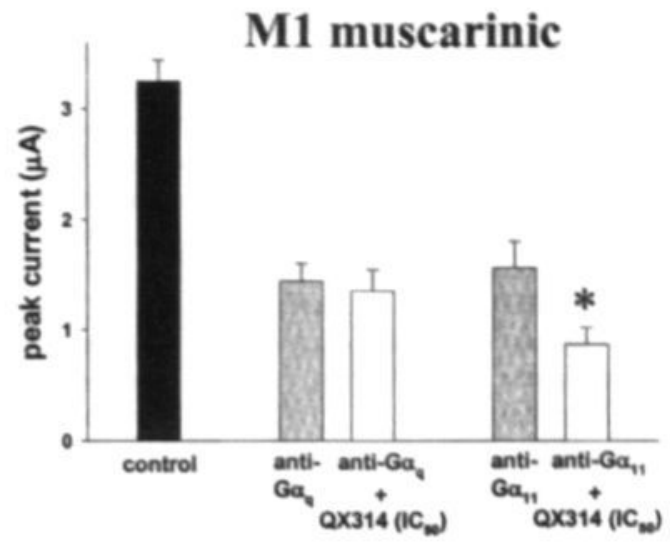

Figure 14: Mean $\pm S E M$ of I arcap, elicited by $M C h\left(1 \sigma^{7} M\right)$ in oocytes, expressing $m I$ muscarinic receptors, injected with $50 \mathrm{nl}$ of $150 \mathrm{mM} \mathrm{KCl}$ alone (control, black bar, 3.25 $10.19 \mu \mathrm{A}$ ), $50 \mathrm{nl}$ of 150

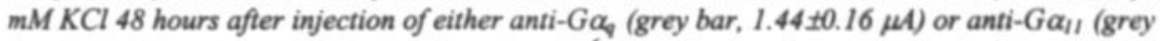
bar, $1.56 \pm 0.24 \mu \mathrm{A})$, or QX314 (at IC sa. $\left.424 \times 10^{6} \mathrm{M}\right) 48$ hours after injection of either anti-Ga, $(1.35 \pm 0.19 \mu \mathrm{A})$ or anti-G$\alpha_{11}(0.87 \pm 0.15 \mu \mathrm{A})$.

\section{Trypsin signaling is inhibited by intracellularly injected QX314 and lidocaine}

To confirm that the $\mathrm{Ga}_{\mathrm{q}}$-subunit is an intracellular target site for LA, we studied the effect of intracellularly injected QX314 on responses induced by trypsin. Again, we used the IC 50 for QX314 as determined for LPA signaling. Responses of the endogenous protease receptor, elicited by extracellular application of trypsin $(1 \mu \mathrm{g} / \mathrm{ml})$ to oocytes revealed a mean response size of $4.34 \pm 0.46$ $\mu \mathrm{A}$ (Figure 15). $10 \mathrm{~min}$. after injection of QX314 $\left(424 \times 10^{-6} \mathrm{M}\right)$, mean response size was significantly $(\mathrm{p}=0.004, \mathrm{t}$-test, $\mathrm{n}=20)$ reduced by $39 \%$ to $2.66 \pm 0.3 \mu \mathrm{A}$. This finding indicates that another receptor coupled to $\mathrm{G \alpha}_{Q}$ is inhibited by intracellularly injected $\mathrm{QX} 314$, with similar potency as that observed at the LPA receptor. This supports our hypothesis that the $\mathrm{G \alpha}_{\mathrm{q}}$-subunit is likely to be an intracellular target site for LA.

\section{Trypsin}

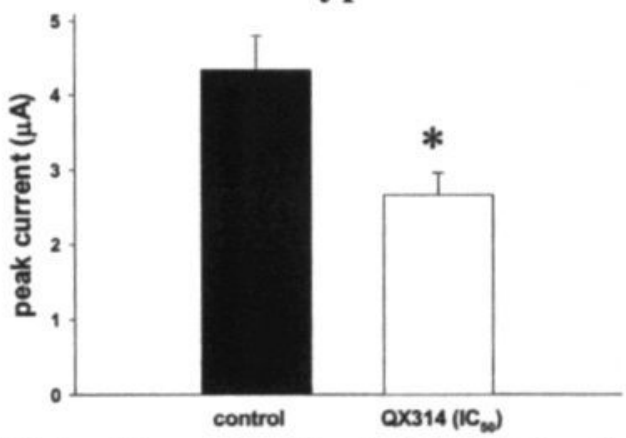

Figure 15: Mean $\pm S E M$ of peak $I_{C(C a)}$ induced by stimulation with trypsin $(1 \mathrm{\mu g} / \mathrm{ml})$ for either $\mathrm{KCl}$ $(50 \mathrm{nl}$ of $150 \mathrm{mM} \mathrm{KCl}$ )-injected control oocytes (black bar, $4.34 \pm 0.46 \mu \mathrm{A})$ or cells injected with QX314 (at IC $50.424 \times 10^{-6} \mathrm{M}$ ) (white bar, $2.66 \pm 0.3 \mu \mathrm{A}$ ). 
To confirm that our findings determined for the quaternary lidocaine analogue QX314 also hold for tertiary amide LA such as lidocaine, we next determined if intracellularly injected lidocaine is able to inhibit trypsin-induced responses in the absence of $\mathrm{Ga}_{4}$ or $\mathrm{Ga}_{14}$, both of which were previously determined to be required for this signaling pathway. To prevent possible extracellular effects by lidocaine leaking to the outside, oocytes were superfused with Tyrode's solution at high flow rates ( $10 \mathrm{ml} / \mathrm{min})$. As shown in Figure 16, 48 hours after injection of anti-G $\alpha_{4}$ or anti-G $\alpha_{14}$ mean control response $(3.49 \pm 0.42 \mu \mathrm{A}$, elicited by extracellular application of trypsin $(1 \mu \mathrm{g} / \mathrm{ml})$ to oocytes expressing the endogenous protease receptor, was reduced to $33 \%(1.16 \pm 0.27 \mu \mathrm{A})$ and $42 \%$ $(1.46 \pm 0.27 \mu \mathrm{A})$ respectively. Intracellularly injected lidocaine $\left(445 \times 10^{-6} \mathrm{M}\right.$, approximate $\mathrm{IC}_{50}$ as determined from pilot studies) had no significant ( $\mathrm{p}=0.294, \mathrm{t}$-test, $\mathrm{n}=24$ ) effect on $\mathrm{G} \alpha_{\mathrm{q}}$-degraded oocytes ( $1.58 \pm 0.29 \mu \mathrm{A}, 136 \%)$, whereas 48 hours after anti-G $\alpha_{14}$ injection it inhibited responses to trypsin $(0.42 \pm 0.09 \mu \mathrm{A})$ by $71 \%, \mathrm{p}=0.001, \mathrm{t}$-test, $\mathrm{n}=22)$. Thus, inhibition by intracellular lidocaine is also dependent on the presence of $\mathrm{Ga}_{\mathbf{q}}$.

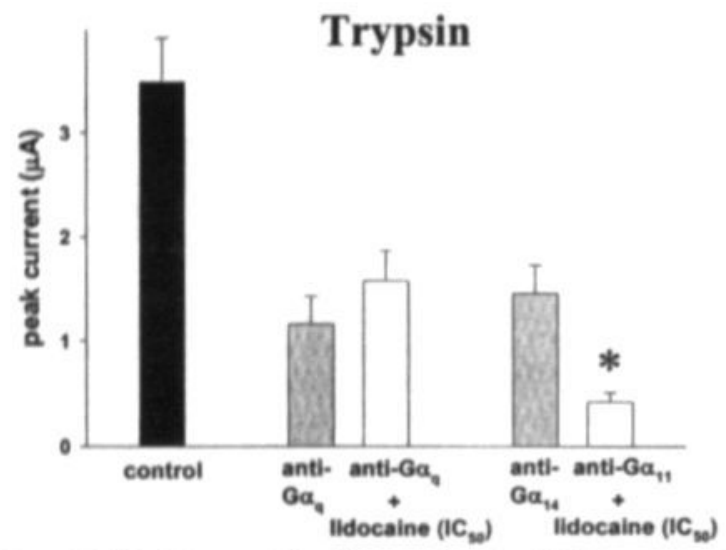

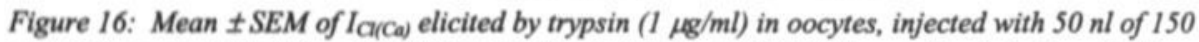
$\mathrm{mM} \mathrm{KCl}$ (control, black bar, $3.49 \pm 0.42 \mu \mathrm{A}), 50 \mathrm{nl}$ of $150 \mathrm{mM} \mathrm{KCl} 48$ hours after injection of either

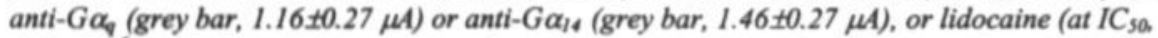
$\left.445 \times 10^{6} \mathrm{M}\right) 48$ hours after injection of either anti-G $\alpha_{q}(1.58 \pm 0.29 \mu \mathrm{A})$ or anti-G $\alpha_{14}(0.42 \pm 0.09$ H4).

\section{AT $T_{1 A}$ signaling is primarily mediated by $\mathbf{G} \alpha_{0}$ and $\mathbf{G a}_{14}$}

We showed previously ${ }^{3}$ that $\mathrm{AT}_{1 \mathrm{~A}}$ signaling is not inhibited by LA. If intracellular inhibition of $\mathrm{G}$ protein-coupled receptors by $\mathrm{LA}$ is due to action on the $\mathrm{G \alpha}_{\mathrm{q}}$-subunit, we would predict that $\mathrm{AT}_{1 \mathrm{~A}}$ signaling is not primarily mediated by $\mathrm{G \alpha}_{4}$ in our model. To test our hypothesis, we determined the $\mathrm{G}$ protein $\alpha$ subunits coupling to the $\mathrm{AT}_{1 \mathrm{~A}}$ receptor (Figure 17). In oocytes recombinantly expressing the $\mathrm{AT}_{1 \mathrm{~A}}$ receptor, angiotensin II $\left(10^{-6} \mathrm{M}\right)$ induced an $\mathrm{I}_{\mathrm{C}(\mathrm{Ca})}$ with an average peak current of $2.72 \pm 0.29 \mu \mathrm{A}$, comparable with our previous data ${ }^{3} .48$ hours after antisense injection,

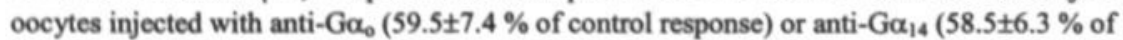
control response) showed a significant $(\mathrm{p}<0.05)$ reduction in peak current. In contrast, injection of anti-G $\alpha_{4}(78.2 \pm 6.4 \%$ of control response, $p>0.05)$ or anti-G $\alpha_{11}(105.9 \pm 11.4 \%$ of control response, $p>0.05$ ) did not significantly affect responses elicited by stimulation with angiotensin II $\left(10^{-6} \mathrm{M}\right)$.

Thus, although a slight contribution of $\mathrm{G}_{4}$ cannot be ruled out, $\mathrm{AT}_{1 \mathrm{~A}}$ receptor signaling is mediated primarily by $\mathrm{G} \alpha_{0}$ and $\mathrm{G \alpha}_{14}$. Lack of LA effect on this receptor is therefore compatible 
with our hypothesis that intracellular inhibition of several $\mathrm{G}$ protein-coupled receptors by LA is due to interaction with the $\mathrm{G} \alpha_{-}$-subunit.

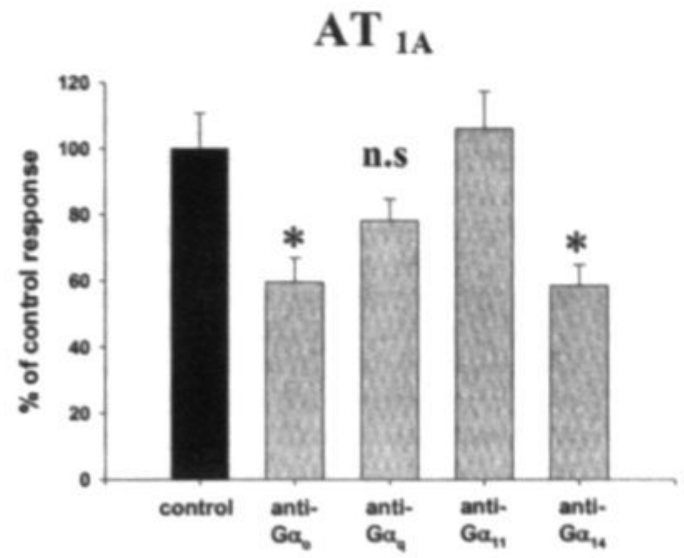

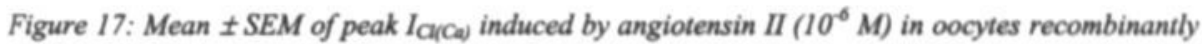
expressing the $A T_{L A}$ receptor. Average response in control oocytes (black bar) was $2.72 \pm 0.29 \mu \mathrm{A}$. Cells injected with the corresponding DNA antisense oligomucleotides (50 ng/oocyte) 48 hours prior revealed inhibition of peak current to $59.5 \pm 7.4$ of control response by anti-G $\alpha_{0}$ and $58.5 \pm 6.3 \%$ of control response by anti-Ga $\alpha_{16}$ whereas injection of anti-Ga $378.2 \pm 6.4 \%$ of control response) or anti-Ga $\alpha_{11}(105.9 \pm 11.4 \%$ of control response) was without significant effect compared with control oocytes.

\section{DISCUSSION}

In the present study we have shown that LPA signaling is inhibited by ropivacaine stereoisomers in a concentration-dependent and stereoselective manner, strongly suggesting a protein site of action for ropivacaine. This inhibition is primarily due to a non-competitive antagonism. We also found that LPA signaling is mediated primarily by $G \alpha_{q}$ and $G \alpha_{0} . G \alpha_{q}$ couples to both LPA, muscarinic $\mathrm{ml}$, and trypsin receptors, and is a main target for intracellular LA inhibition of G protein-coupled receptors.

As in our previous studies, we used the Xenopus oocyte model. Several potential problems with the technique should be considered when interpreting the data. Using Xenopus oocytes requires performing experiments at room temperature, which raises the question if the Xenopus LPA receptor and $\mathrm{G}$ proteins might behave differently from their mammalian orthologs. However, LPAinduced Ca-signaling in oocytes and in mammalian cells has been shown to be similar. ${ }^{10,9,19} \mathrm{We}$ have only studied a single form of LPA signaling ( $\mathrm{Cl}$ currents induced by intracellular $\mathrm{Ca}$ release), whereas several intracellular signaling cascades are activated by LPA (e.g. decreases in cAMP, activation of $\mathrm{Rho}$ and ras). It is possible that these other actions might be affected differently by $\mathrm{LA}$; indeed, this appears likely, as they involve different $\mathrm{G} \alpha$ subunits in their signaling pathways (e.g. $\mathrm{G}_{\mathrm{i}}$ mediates LPA-induced decreases in cAMP) ${ }^{20}$. Therefore, our data should not be extrapolated to LPA signaling in general. The $\mathrm{ml}$ muscarinic and the $\mathrm{AT}_{1 \mathrm{~A}}$ angiotensin receptor derive from rat and therefore were expressed at a lower temperature than they normally function in, but this has not been shown to affect their signaling properties appreciably. Although LPA and ml muscarinic receptors have been shown to couple to $\mathrm{G}_{\mathrm{q}}$ in mammalian cells, it is important to emphasize that the specificity of $\mathrm{G}$ protein-coupling may depend on the cell type and species. 
However, $90 \%$ homology between mammalian and frog $\mathrm{G}$ proteins and lack of any evidence for differences in the physiological activity of species homologues of those $\mathrm{G}$ protein subunits, make significant difference unlikely ${ }^{21}$. Despite these caveats, the oocyte model provides great advantages for studies of this kind. Particularly useful in the current context is the ability to study intracellular actions by microinjection of different compounds.

We supported our previous findings, which suggested that LA affect LPA signaling at either the $\mathrm{G}$ protein or the receptor itself ${ }^{3 / A}$ by showing stereoselectivity for ropivacaine inhibition of LPA signaling. This makes an interaction with a protein most likely. It should be realized, however, that phospholipids also contain a chiral carbon, and that organized lipid membranes can show significant stereoselectivity ${ }^{22}$. Interaction of LA with the compound LPA itself is unlikely since we demonstrated inhibition by intracellular QX314, whereas LPA acts extracellularly at its receptor ${ }^{4}$. Our studies using ropivacaine revealed an additional finding with potential clinical relevance. We found (S-)-ropivacaine to be 6-fold less potent than bupivacaine and 4-fold less potent than lidocaine in inhibiting LPA signaling. Since LPA is likely to play a role in wound healing, LA, when injected around surgical wounds, may impair wound healing by inhibiting LPA signaling. If so, ropivacaine might have advantages over bupivacaine. Moreover, our findings with ropivacaine suggest that the LPA-inhibitory properties of racemic bupivacaine may largely reside in the clinically irrelevant stereoisomer dextrobupivacaine, suggesting that levobupivacaine would have fewer deterimental effects on wounds than the racemic preparation.

We found LPA signaling to be mediated mainly by $\mathrm{Ga}_{0}$ and $\mathrm{G \alpha}_{\mathrm{q}}$. In contrast, Noh et al. reported involvement of $\mathrm{G \alpha}_{4}$ and $\mathrm{G} \alpha_{11}$ in mediation of the LPA response in Xenopus oocytes "T. This inconsistency might be explained by the different antisense oligonucleotides employed. Crossdegradation of other $\mathrm{G}$ protein $\boldsymbol{\alpha}$-subunits was not evaluated in Noh's study, whereas our experiments were performed with antisense sequences for which cross reactions with other G protein $\alpha$-subunits has been determined on the mRNA and protein level ${ }^{8}$. In other words, whereas Noh et al. can not exclude that the reduction of LPA peak currents after injection of anti-G $\alpha_{11}$ is in fact caused by degradation of (highly similar ${ }^{23}$ ) $\mathrm{G \alpha}_{2}$, we can rule out that anti-G $\alpha_{11}$ and anti-G $\alpha_{14}$ had effects on the other $G$ protein $\alpha$-subunits. In addition, it is not surprising that they did not observe involvement of $\mathrm{G} \alpha_{0}$ in the LPA signaling pathway, since it was not, or only in small amounts, present in their oocytes.

Antisense results should not be overinterpreted in a quantitative manner. Specifically, although adding the percent inhibition obtained by anti-G $\alpha_{0}$ and anti-G $\alpha_{9}$ suggests complete inhibition of the LPA response when both $\mathrm{G}$ proteins are knocked-down, involvement of other $\mathrm{G}$ proteins can not be ruled out. For example, data from Shapira et al. would predict that combined $\mathrm{G} \alpha_{9}$ and $\mathrm{G} \alpha_{14}$ depletion would inhibit trypsin signaling by $140 \%\left(69 \%\right.$ by anti-G $\alpha_{4}$ and $68 \%$ by anti-G $\left.\alpha_{14}\right)$. In reality, when both antisense oligonucleotides were injected in combination, a $7 \%$ response to trypsin remained ${ }^{8}$. The underlying mechanisms may be several. Degradation of the $\mathrm{G}$ protein subunit may be incomplete, and the percentage $G$ protein $\alpha$-subunit degradation may not necessarily correlate with the percentage of response inhibition. As stated by Shapira et al., it cannot be excluded that even residual amounts of any $\mathrm{G}$ protein can mediate a full response ${ }^{8}$. In addition, other $\mathrm{G}$ protein $\alpha$-subunits, like $\mathrm{G} \alpha_{11}$ and/or $\mathrm{G} \alpha_{14}$, which are usually not involved in the mediation of the LPA response when $G \alpha_{4}$ and/or $G \alpha_{0}$ are present, may be recruited when $G \alpha_{4}$ and $G \alpha_{0}$ are depleted. We attempted to determine the effect of combined injection of anti-G $\alpha_{4}$ and anti-G $\alpha_{0}$, but most cells died and most surviving oocytes did not show a stable holding potential of less than 0.5 $\mu$ A. Shapira et al. reported similar difficulties ${ }^{8}$.

Our previous studies ${ }^{2,4}$ suggest that intracellular LA affect several G protein-coupled receptors with different structure (muscarinic $\mathrm{ml}$ and LPA receptors) in a similar manner, making the G protein as a target most likely (since we have shown lack of interaction with the distal signaling pathway ${ }^{3,4}$ ). Our results in the present study confirm this hypothesis. The significant inhibitory effect of intracellular QX314 on $\mathrm{G \alpha}_{0}$ - (LPA signaling) and $\mathrm{G \alpha}_{11^{-}}$(ml muscarinic signaling) depleted cells, and of intracellularly applied lidocaine in $\mathrm{G}_{14^{-}}$(trypsin signaling) depleted cells, 
contrasted with lack of LA effect on $\mathrm{G} \alpha_{4}$-degraded cells, suggests that LAs might act intracellularly by inhibiting $\mathrm{Ga}_{4}$ signaling. This is consistent with our findings that all three LA-sensitive receptors (muscarinic ml, LPA and trypsin receptors) couple to $\mathrm{G \alpha}_{4}$ and that those structurally completely different receptors are inhibited to a similar degree by intracellularly injected QX314. In contrast, the angiotensin $1_{A}$ receptor, which is not inhibited by LA, was found not to couple to $G \alpha_{4}$ to an appreciable degree.

Our results are consistent with findings by Xiong et al. who investigated LA inhibition of G protein-mediated modulation of potassium and calcium currents in anterior pituitary cells from rats. They demonstrated that licocaine acts between agonist binding and $\mathrm{G}$ protein activation and concluded that such inhibition of $\mathrm{G}$ protein pathways might be an important component of the general action of $\mathrm{LA}^{24}$.

In conclusion, our study suggests that $G$ protein-coupled receptors may be common targets for local anesthetics. The concentrations used in this study are routinely attained after local injection of these compounds. Inhibition of G protein-coupled receptors by LA results in part from an intracellular action, which can be largely explained by selective interference with $G \alpha_{4}$ function. 
1. Hoenemann CW, Podranski T, Lo B, Yanovitch M, Durieux ME: Local anesthetic effects on thromboxane A2 signaling. Anesthesiology 1998; 89:A886

2. Hollmann MW, Fischer LG, Durieux ME: Lidocaine inhibits muscarinic $\mathrm{ml}$ receptor signaling in Xenopus oocytes. Br J Anaesth 1999; 82 Suppl 1:A.385

3. Nietgen GW, Chan CK, Durieux ME: Inhibition of lysophosphatidate signaling by lidocaine and bupivacaine. Anesthesiology 1997; 86:1112-9

4. Sullivan LM, Hoenemann CW, Arledge JAM, Durieux ME: Synergistic inhibition of lysophosphatidic acid signaling by charged and uncharged local anesthetics. Anesth Analg 1999; 88:1117-24

5. Durieux ME, Carlisle SJ, Salafranca MN, Lynch KR: Endogenous responses to sphingosine1-phosphate in $X$. laevis oocytes: similarities with lysophosphatidic acid signaling. Am J Physiol 1993; 264:C1360-C1364

6. Chan CK, Durieux ME: Effects of halothane and isoflurane on lysophosphatidate signaling. Anesthesiology 1997; 86:660-9

7. Durieux ME, Salafranca MN, Lynch KR: Trypsin induces $\mathrm{Ca}(2+)$-activated $\mathrm{Cl}$ - currents in $\mathrm{X}$. laevis oocytes. FEBS Lett 1994; 337:235-8

8. Shapira $\mathrm{H}$, Amit I, Revach $\mathrm{M}$, Oron $\mathrm{Y}$, Battey JF: $\mathrm{G} \alpha_{\mathrm{U}}$ and $\mathrm{G \alpha}_{4}$ mediate the response to trypsin in Xenopus oocytes. J Biol Chem 1998; 273:19431-6

9. Durieux ME, Salafranca MN, Lynch KR, Moorman JR: Lysophosphatidic acid induces a pertussis toxin-sensitive $\mathrm{Ca}^{2+}$-activated $\mathrm{Cl}^{\top}$ current in Xenopus laevis oocytes. Am J Physiol 1992; 263:C896-C900

10. Durieux ME, Lynch KR: Signalling properties of lysophosphatidic acid. Trends Pharmacol Sci $1993 ; 14: 249-54$

11. Noh SJ, Kim MJ, Shim S, Han JK: Different signaling pathway between sphingosine-1phosphate and lysophosphatidic acid in Xenopus oocytes: functional coupling of the sphingosine-1-phosphate receptor to PLC-xbeta in Xenopus oocytes. J Cell Physiol $1998 ; 176: 412-23$

12. Kakizawa K, Nomura H, Yoshida A, Ueda H: Signaling of lysophosphatidic acid-evoked chloride current: calcium release from inositol trisphosphate-sensitive store. Brain Res Mol Brain Res 1998; 61:232-7

13. Fernhout BJH, Dijcks FA, Moolenaar WH, Ruigt GSF: Lysophosphatidic acid induces inward currents in Xenopus laevis oocytes: evidence for an extracellular site of action. Eur J Pharmacol 1992; 213:313-5

14. Liliom K, Murakami-Murofushi K, Kobayashi S, Murofushi H, Tigyi G: Xenopus oocytes express multiple receptors for LPA-like lipid mediators. American Journal of Physiology 1996; 270:C772-C777 
15. Guo Z, Liliom K, Fischer DJ, Bathurst IC, Tomei LD, Kiefer MC, Tigyi G: Molecular cloning of a high-affinity receptor for the growth factor-like lipid mediator lysophospahtidic acid from Xenopus oocytes. Proceedings of the National Academy of Sciences of the USA 1996; $93: 14367-72$

16. Nietgen GW, Hoenemann CW, Chan CK, Kamatchi GL, Durieux ME: Volatile anaesthetics have differential effects on recombinant $\mathrm{ml}$ and $\mathrm{m} 3$ muscarinic acetylcholine receptor function. Br J Anaesth 1998; 81:569-77

17. Durieux ME: Inhibition by ketamine of muscarinic acetylcholine receptor function. Anesth Analg 1995; 81:57-62

18. Durieux ME, Nietgen GW: Synergistic inhibition of muscarinic signaling by ketamine stereoisomers and the preservative benzethonium chloride. Anesthesiology 1997; 86:1326-33

19. Moolenaar WH: Lysophosphatidic acid signalling. Curr Opin Cell Biol 1995; 7:203-10

20. Corven EJv, Groenink A, Jalink K, Eichholtz T, Moolenaar WH: Lysophosphatidate-induced cell proliferation: identification and dissection of signaling pathways mediated by $\mathrm{G}$ proteins. Cell 1989; 59:45-54

21. Filtz TM, Paterson A, Harden TK: Purification and G protein subunit regulation of a phospholipase C-beta from Xenopus laevis oocytes. J Biol Chem 1996; 271:31121-6

22. Dickinson R, Franks NP, Lieb WR: Can the stereoselective effects of the anesthetic isoflurane be accounted for by lipid solubility? Biophys J 1994; 66:2019-23

23. Stehno-Bittel L, Krapivinsky G, Krapivinsky L, Perez-Terzic C, Clapham DE: The G protein beta gamma subunit transduces the muscarinic receptor signal for $\mathrm{Ca} 2+$ release in Xenopus oocytes. J Biol Chem 1995; 270:30068-74

24. Xiong Z, Bukusoglu C, Strichartz GR: Local anesthetics inhibit the G protein mediated modulation of $\mathrm{K}+$ and $\mathrm{Ca} 2+$ currents in anterior pituitary cells. Mol Pharmacol 1999; $55: 150-8$ 
CHAPTER 7

Local anesthetics: effects on inflammation, wound healing and coagulation

Markus W. Hollmann

Marcel E. Durieux

Published in: Progress in Anesthesiology: 14 (18):291-304, 2000 


\section{Local anesthetics: effects on inflammation, wound healing and coagulation}

\section{Introduction}

Blockade of voltage-gated sodium channels, leading to inhibition of nerve impulse conduction, is probably the most important effect of local anesthetics (LA) and is the major mechanism underlying their well-known antinociceptive and antiarrhythmic effects. However, LA affect other cellular systems as well. These interactions may contribute to antinociception and antiarrhythmic actions, but could also explain some other LA effects and side effects. Interestingly, several of these alternative target sites, for example muscarinic receptors, ${ }^{1}$ are known to be much more sensitive to LA than are voltage-gated sodium channels.

In this chapter we will highlight some actions of LA that are less well known to most anesthesiologists. First, we will discuss LA effects on inflammatory responses, in vitro as well as in vivo. Second, we address LA effects on wound healing. Third, effects on coagulation by these compounds will be discussed.

\section{Local anesthetic effects on inflammation}

One of the most interesting and best studied alternative effects of LA is their anti-inflammatory action, probably responsible, at least in part, for several important effects of these compounds (e.g., antinociception, as well as antithrombotic and neuroprotective actions).

The response of the host against injurious events such as pathogens or tissue trauma is called inflammation. This reaction is accompanied by the classic inflammatory signs rubor (redness), calor (heat), tumor (swelling) and dolor (pain), caused by the release of inflammatory mediators. These inflammatory mediators induce vasodilation and increased vascular permeability. Their interaction with the sensory system produces pain. Most important for regulation of the inflammatory response at the site of injury is the release of cytokines such as interleukin (IL) 1, IL 8 or tumor necrosis factor (TNF). These cytokines mediate the systemic inflammatory response including fever induction, mobilization of polymorphonuclear neutrophils (PMNs) from the bone marrow and lymphocyte proliferation. In addition, some cytokines promote, among other things, the migration of PMNs to the site of inflammation, termed chemotaxis. PMNs and monocytes are crucial for the inflammatory response. After migration to the site of injury, they destroy the injurious agents, largely by phagocytosis. Although the inflammatory response is essential for structural and functional repair of injured tissue, over-stimulation of the pro-inflammatory cascade by products derived from inflammatory cells can aggravate tissue damage, as occur in several disease states.

The inflammatory process can be subdivided into several steps illustrated in figure 1. LA have been shown to interfere with some of these inflammatory stages. The following paragraph will highlight some of those interactions. In some studies high concentrations of LA have been employed. Judging clinical relevance of those reports requires consideration of LA concentrations used in the clinical setting. LA concentrations at specific sites vary widely and depend on method of application. Plasma levels in the range of 0.5 to $5 \mu \mathrm{g} / \mathrm{ml}(2-20 \mu \mathrm{M}$, for lidocaine) are required for systemic effects of LA. Such concentrations are commonly obtained after intravenous ${ }^{2-4}$ or epidural $^{5}$ administration. Plasma concentrations above $10 \mu \mathrm{g} / \mathrm{ml}$ (for lidocaine) tend to produce adverse effects. ${ }^{6}$ In contrast, after topical application or tissue infiltration of LA, tissue concentrations in the millimolar range are usually obtained. 


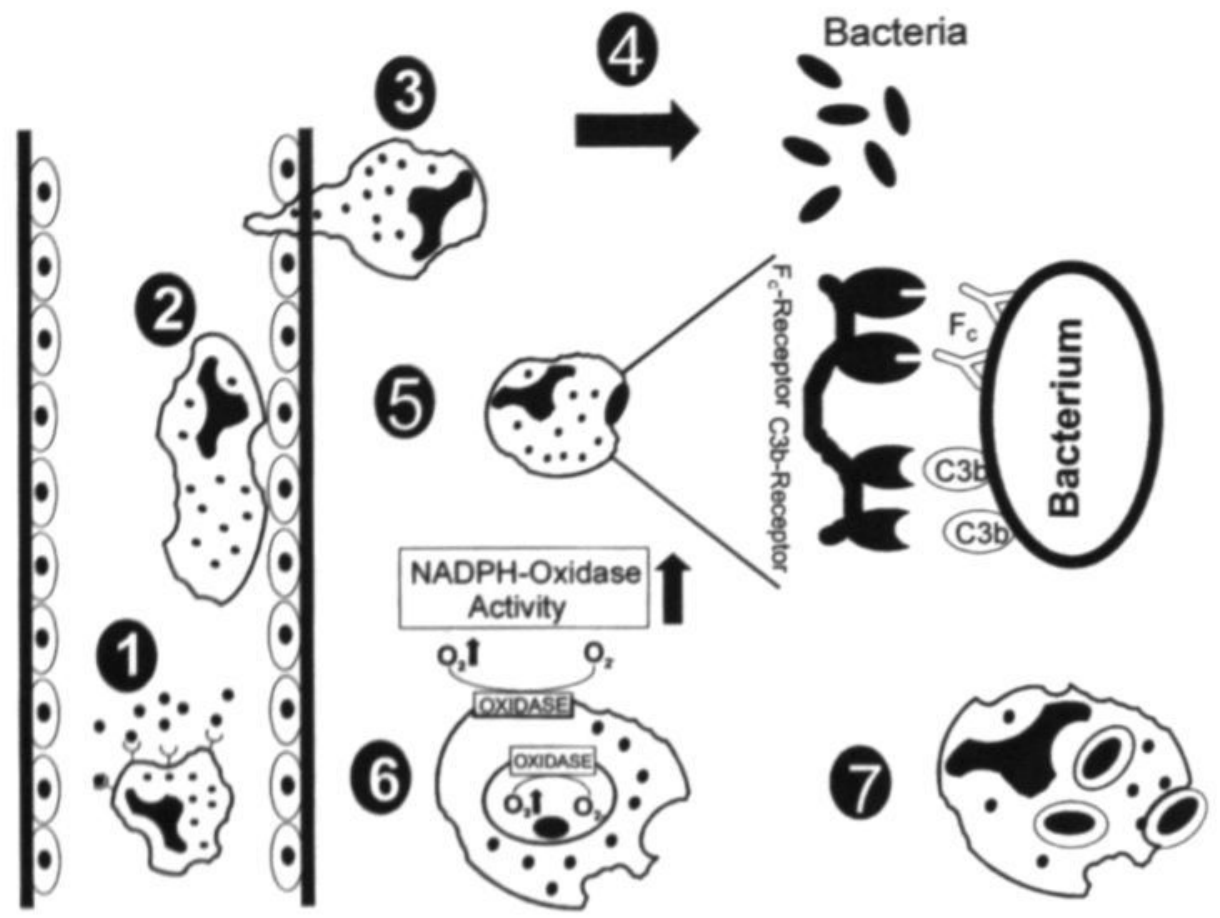

Figure 1: Stages of the inflammatory response:

(- Sensing of chemoattractants by PMN; 2 Margination/Adhesion; 0 Diapedesis;

(- Chemotaxis; 9 Opsonization; 6 Generation of reactive oxygen metabolites;

(2) Phagocytosis 
(- At the site of infection, substances produced by bacteria, complement activation or cytokines are sensed by PMNs. This process is defined as chemoattraction. Leukotrienes, in particular leukotriene $\mathbf{B}_{4}$ (LTB $)_{4}$, but also IL-1 a play important roles in this early phase of inflammation.' Both have high chemotactic potency for PMNs in vitro and in vivo. Therefore, blocking the release of these inflammatory mediators causes an anti-inflammatory effect, since recruitment of PMNs to the site of inflammation is inhibited. In vitro, preincubation of hPMNs or monocytes with different concentrations of lidocaine or bupivacaine (2-20 mM lidocaine and $0.4-4.4 \mathrm{mM}$ bupivacaine) was shown to block release of these mediators concentration-dependently. ${ }^{8}$

Histamine, complement factors such as $\mathrm{C} 5 \mathrm{a}$ or $\mathrm{C} 3 \mathrm{a}, \mathrm{IL}-1, \mathrm{IL}-8$, TNF and platelet activating factor (PAF) are responsible for PMN rolling onto and attaching to endothelial cells, a process termed margination and adhesion. Excessive adhesion of PMNs to endothelium mediated by several adhesion molecules may induce endothelial injury. One of the most important adhesion molecules for firm adhesion of PMNs to endothelium is CD11/CD18. Monoclonal antibodies against this adhesion molecule prevent endothelial cell injury in vitro. ${ }^{9}$ LA also decrease the ability of PMNs to adhere to surfaces. As a result a significant reduction of PMN accumulation at the site of inflammation can be expected. Indeed, ropivacaine or lidocaine $(100-300 \mu \mathrm{M})$ treatment significantly reduces the upregulation of CD11/CD18. ${ }^{10}$ Consequently, lidocaine has been shown to reduce granulocyte adherence in vitro, ${ }^{11-14}$ where significant effects were obtained in concentrations higher than $100 \mu \mathrm{M}$, and in vivo. ${ }^{15}$ In the latter study peritonitis was induced in rabbits, accompanied by a profound increase in PMN adherence. Lidocaine treatment $(1.5 \mathrm{mg} / \mathrm{kg}$ bolus, followed by $0.3 \mathrm{mg} \cdot \mathrm{kg}^{-1} \cdot \mathrm{min}^{-1}$ inhibited inflammation 10-fold more $(6 \mathrm{~h}$ after induction of peritonitis and initiation of lidocaine infusion) than did methylprednisolone (2-3 kg rabbits were given $15 \mathrm{mg}$ doses of the depot form subcutaneously. twice at 7-day intervals, and 1-3 days after the second dose sterile peritonitis was induced). ${ }^{15}$

3 Diapedesis describes PMNs squeezing through gaps between adjacent endothelial cells.

PMNs migrate up the chemoattractant gradient to the site of injury (chemotaxis). Migration and accumulation of PMNs are key events during the inflammatory response. Using both in vitro and in vivo models, ${ }^{15-19}$ LA inhibitory effects on PMN migration and accumulation have been reported. Scott et al., ${ }^{17}$ for example, found that lidocaine, at $\mu \mathrm{M}$ concentrations, impairs accumulation of PMNs at the site of inflammation in an in vivo canine model. Decrease in PMN accumulation at the site of injury by LA is most likely due to their inhibition of PMN migration and by interference with the critical steps of adhesion.

5 Pathogens are coated (opsonized) with specific serum proteins and PMNs are primed. Priming refers to a process whereby the response of PMNs to a subsequent activating stimulus is potentiated. Release of oxygen metabolites is markedly enhanced when activated PMNs have been primed previously. ${ }^{20}$ Importantly, the priming process has been shown to be a critical component of PMNmediated tissue injury both in vitro and in vivo. ${ }^{20}$

LA has been shown to block the priming of PMNs by lysophosphatidic acid (LPA) and PAF with half-maximal inhibition concentrations $\left(\mathrm{IC}_{50}\right)$ of approximately $1 \mu \mathrm{M}^{21,22} \mathrm{NADPH}$-oxidase activity, $\mathrm{Ca}^{2+}$ and $\mathrm{PKC}$, all likely to be involved in the priming process, ${ }^{20}$ have also been described to be inhibited by several LA. ${ }^{23-26}$ It is conceivable that inhibition of priming contributes to the antiinflammatory action of LA, and in particular suppresses the deleterious effects of the uncontrolled, overactive response of inflammatory cells to a stimulating agent. This may also explain, as pointed out later in this section, why LA are able to decrease tissue damage without impairment of host defense. 
(-) Using NADPH-oxidase or myeloperoxidase enzyme complexes, PMNs produce reactive oxygen species such as $\mathrm{O}_{2}, \mathrm{H}_{2} \mathrm{O}_{2}, \mathrm{OH}$, and $\mathrm{HOCl}$. In vitro, lidocaine and bupivacaine have been shown to inhibit free radical generation concentration-dependently ( $\mathrm{IC}_{5_{0}} 4-5 \mathrm{mM}$ for lidocaine and 1.4-2 mM for bupivacaine). ${ }^{8,29}$ Contradictory effects have been reported for lower LA concentrations. Some investigators reported no or only a slightly impairment of free radical generation by LA in vitro. ${ }^{28-30}$ In contrast, Hattori et al. ${ }^{31}$ demonstrated in vitro suppression of PMN free radical generation by 8 different LA in a concentration-dependent manner $(0.1$ and $10 \mathrm{mM})$. Since neither tetrodotoxin (TTX), nor veratridine (VTD) and amiloride hydrochloride showed any inhibitory effects on free radical generation of human PMN, the underlying mechanism of LA action is unlikely to be $\mathrm{Na}^{+}$ influx blockade. ${ }^{31}$ Cederholm et al. ${ }^{32}$ reported in vitro a small but statistically significant decrease in production of oxygen metabolites in human PMN by ropivacaine, bupivacaine, lidocaine, mepivacaine and prilocaine $(0.5-200 \mu \mathrm{M})$. Studies on surgical wounds in rats confirmed the effects of LA on free radical release in vivo. ${ }^{15}$ This LA effect is more likely due to inhibition of PMNinduced produce of reactive oxygen species, rather than scavenge generated free radicals. ${ }^{33}$

Pathogens are killed by those free radicals delivered and generated by PMNs and mononuclear phagocytes (termed phagocytosis).

\section{Effects of local anesthetics on inflammatory processes}

This section will describe some actions of LA on inflammatory processes relevant to anesthesiologists: inflammatory lung injury, increased microvascular permeability, myocardial ischemia-reperfusion injury and inflammatory bowel disease. Finally, we refer to an issue of considerable importance: the possibility that LA, because of their anti-inflammatory properties, might increase the risk of infection in certain settings.

\section{Local anesthetic effects on lung injury and microvascular permeability}

Inflammatory cells and mediators such as cytokines, macrophages and PMNs play important roles in the pathogenesis of inflammatory lung injury. Beneficial effects of LA have been reported for three different types of inflammatory lung injury, namely hydrochloric acid ( $\mathrm{HCl}$ ), endotoxinand hyperoxia-induced lung injury. In rabbits, pre- or early post-treatment with lidocaine (plasma concentrations of $1.2-2.5 \mu \mathrm{g} / \mathrm{ml}$ ) attenuates the late phase of acid installation-induced lung injury. Not only PMN accumulation, free radical production, pulmonary edema and cytokine levels in bronchoalveolar fluid were reduced, but also lung function was improved, indicated by an increase in $\mathrm{P}_{2} \mathrm{O}_{2}$ and attenuation of both decreased compliance and increased resistance. ${ }^{34}$ In a rat model of sepsis, pretreatment with lidocaine (plasma concentrations of $1.4-2.5 \mu \mathrm{g} / \mathrm{ml}$ ) blocked the endotoxin-induced increase in PMN activation, adherence and migration to the site of inflammation. In addition, free radical generation by PMNs was inhibited in the lidocaine-treated rats. Lidocaineinduced changes in venular wall shear rate were shown not to be the underlying mechanism for the observed anti-inflammatory action. ${ }^{35}$ Nearly similar results were reported by Mikawa et al.. ${ }^{36}$ Long term exposure to high concentrations of oxygen can induce adult respiratory distress syndrome (ARDS). Since antioxidants have been shown to protect the lung under these circumstances, an underlying inflammatory mechanism in this syndrome is most likely. Therefore, it was not surprising that LA exerted a protective effect on inflammatory responses and pulmonary function in a rabbit model of hyperoxia-induced lung injury. ${ }^{37}$ Systemically relevant concentrations of lidocaine $(1.4-2.5 \mu \mathrm{g} / \mathrm{ml})$ decreased chemotactic factors such as $\mathrm{C} 3 \mathrm{a}, \mathrm{C} 5 \mathrm{a}, \mathrm{TNF}-\alpha$ or IL-1 $\beta$ in bronchoalveolar fluid, leading to less PMN accumulation, reduced free radical production and attenuation of the extent of lung edema, indicated by a decrease in albumin extravasation and improved wet/dry ratio of the lung. In addition, rabbits treated with lidocaine demonstrated less histopathological changes of lung damage. ${ }^{37}$

Summarized, most likely due to their anti-inflammatory action, LA have been shown to be beneficial for treatment of several types of inflammatory lung injury in various animal models. 
In addition to the previously mentioned beneficial effects of LA on microvascular permeability in lung injury, protective effects for LA have been shown also for sepsis, burns and peritonitis associated increase in microvascular permeability. ${ }^{10.38 .39}$ Cassuto et al., ${ }^{40}$ for example, reported greatly reduced plasma exudation in skin burns in rats after topical and systemic administration (plasma concentrations lower than the toxic level) of several amide LA.

\section{Local anesthetic effects on gastro-intestinal inflammatony disonders}

In the pathogenesis of several bowel diseases such as ulcerative colitis and proctitis, inflammatory processes play a crucial role. Ropivacaine has been shown to be protective in a rat colitis model. ${ }^{10,41}$ In clinical studies LA improved severe mucosal inflammation of these diseases. ${ }^{42,43}$ Patients treated with ropivacaine $200 \mathrm{mg}$ twice daily for two weeks (plasma concentrations $1.0-1.4 \mu \mathrm{g} / \mathrm{ml}$ ) did not only show attenuation of inflammation, but also improvement in clinical symptoms. ${ }^{44}$ LA (lidocaine $100 \mathrm{mg}$ bolus intravenous $+3 \mathrm{mg} / \mathrm{min}$ continuous intravenous infusion or bupivacaine $2 \mathrm{mg} / \mathrm{kg}$ intra-abdominal installation) also shortened the duration of postoperative ileus in patients undergoing major abdominal surgery. ${ }^{45,46}$ In this era of evidence based medicine, where measurable improvements in patient outcome becomes ever more the yardstick by which therapeutic interventions are measured, the study by Groudine et al. is of great importance. These authors demonstrated that in patients undergoing radical retropubic prostatectomy, systemic lidocaine administration during and shortly after the procedure (plasma concentration between 1.3-3.7 $\mu \mathrm{g} / \mathrm{ml}$ ) induces an earlier return of bowel function, reduces postoperative pain and, most impressively, decreases hospital stay. ${ }^{47}$ The return to normal bowel function in this regard might be explained in part by a direct excitatory effect on intestinal smooth muscle as a result of a blockade of inhibitory reflexes from the myenteric plexus. ${ }^{45}$ However, the effect on bowel function persists for 36 hours after the infusion was discontinued. Since anti-inflammatory effects of amide anesthetics are prolonged and remain measurable even after serum levels have decreased ${ }^{45}$ this might be a more likely underlying mechanism for the observed effect, consistent with the observation that non-steroidal antiinflammatory drugs are similar effective. ${ }^{48}$

\section{Local anesthetic effects on myocardial infarction and reperfusion iniury}

Interactions between PMNs and endothelium as well as free radicals generated by PMNs are responsible for the excessive inflammatory response during myocardial infarction and in particular reperfusion injury. ${ }^{49}$ As expected, inhibition of PMN function or suppression of PMN accumulation in the myocardium has been reported to reduce myocardial ischemia-reperfusion injury. ${ }^{50,51}$ Consequently, PMN depletion during reperfusion leads to decreased endothelial reperfusion injury. ${ }^{32}$ Contradictory effects for LA on these types of inflammatory processes have been reported, most likely due to different models employed (e.g., differences in duration of occlusion). Whereas some studies demonstrated protective effects on the ischemic myocardium and reductions in infarct size by lidocaine in various animal models, ${ }^{53,54}$ others found neither significant attenuation of PMN accumulation in the myocardium nor reduction in infarct size by lidocaine (plasma concentration approximately $4 \mu \mathrm{g} / \mathrm{ml})$. 55

\section{Local anesthetics and increased risk of infection}

Since LA impair PMN presence and function, concerns arose that LA might increase the susceptibility to infections. ${ }^{56}$ This is supported by a single study, in which 5 of 6 lidocaine-treated rats died within $\mathbf{4 8}$ hours of Staphylococcus aureus inoculation, compared to just one in a not lidocaine treated control group. 37

Although in theory an increased risk of infection might be expected, several investigations suggest that the remaining PMN function is sufficient to minimize the risk. ${ }^{27}$ Nonetheless, LA should be employed with caution in settings of gross bacterial contamination. However, their use in sterile inflammation appears to be beneficial. Antibacterial actions by LA reported in vitro ${ }^{58,59}$ and in vivo ${ }^{60}$ are obtained only at millimolar concentrations. 
One of the hallmarks of the findings described above is that these compounds can modulate excessive inflammatory responses without significant impairment of host defenses. For the interested reader this topic has also been addressed in detail in a recent review article. ${ }^{61}$

\section{Local anesthetic effects on wound healing}

It is well known that infiltration of a wound with LA can reduce postoperative pain to various degrees and allows performance of minor surgery. But how does infiltration of LA around wounds affect the healing process? The literature is contradictory on this issue. Most experimental studies in vitro reported negative effects on wound healing, based presumptively on observed reductions in the synthesis of mucopolysaccharides and collagen. ${ }^{62,63}$

Several other LA effects might theoretically influence wound healing. LA inhibit signaling of LPA, a compound probably involved in wound healing. ${ }^{64}$ LA interfere with leukocyte oxygen metabolism (important for local tissue repair in a mouse model ${ }^{65}$ ), and tetracaine $(0.001-0.25 \%$ ) induces a concentration- and time-dependent reduction in viability of cultured human keratocytes. ${ }^{66}$ These findings underscore the concern that LA might affect stromal wound healing. However, most in vivo and clinical studies have shown, at most, histopathological changes ${ }^{67}$ or retardation of wound healing. ${ }^{68}$ without substantially altering outcome. No differences in tensile strength of the wound were observed. ${ }^{67}$ Verma et al. reported no difference in epithelial closure, and therefore no effect on corneal wound healing, in 44 patients receiving either tetracaine $1 \%$ or placebo for keratectomy. ${ }^{69}$ Similar results were reported for ropivacaine $(300-375 \mathrm{mg})$ infiltration in men undergoing inguinal hernia repair, ${ }^{70}$ or after EMLA cream application $(8 \mathrm{~h})$ to burn injuries in volunteers." Indeed, enhanced wound healing has been described when EMLA cream was used in skin grafting. ${ }^{n}$

In summary, while in vitro data suggest that use of LA around surgical wounds might theoretically be detrimental to wound healing, in vivo data would suggest that this issue is, at most, of minor importance.

\section{Local anesthetics and antithrombotic activity}

A number of studies have shown that epidural anesthesia reduces the incidence of thrombotic events, ${ }^{7 \cdot 73}$ significantly inhibits platelet aggregation, ${ }^{76}$ and is associated with beneficial effects on

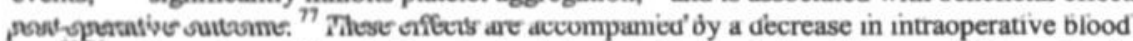
loss, ${ }^{73-75}$ and may be attributed either to physiological changes induced by neuraxial anesthesia (e.g., sympathetic blockade with increased blood flow), or to pharmacological effects of LA on the coagulation system. Odoom et al. studied the effect of epidural administration of bupivacaine on platelet aggregation in seven patients undergoing transurethral resection of prostate. The authors reported a significant correlation between plasma bupivacaine levels after epidural administration and inhibition of platelet aggregation for all platelet aggregation parameters, except maximum ADP-induced aggregation, ${ }^{8}$ leading to the suggestion that the observed effect is likely to be caused by the LA itself.

In 1977 Cooke et al. ${ }^{79}$ reported that intravenous lidocaine (bolus and continuous infusion for 6 postoperative days leading to plasma levels between $1-5 \mu \mathrm{g} / \mathrm{ml}$ ) prevents deep venous thrombosis (DVT) after elective hip surgery. Diagnosis of DVT was made by thermographic scanning of the legs pre- and postoperatively daily until discharge, and in case of positive thermographic scan by additional percutaneous ascending functional phlebography. Eleven of 14 patients $(78 \%)$ in the untreated control group suffered from DVT within 6 days postoperatively, compared with $14 \%$ in the lidocaine-treated group. Significantly, between postoperative day 7 and 14 (after stopping the lidocaine infusion) 9 of 22 patients $(41 \%)$, who where free of thrombosis during the therapy, developed DVT. Blood loss and transfusion requirements were similar in both groups, indicating that lidocaine is able to reduce the risk of thrombosis without increasing bleeding. Unfortunately no follow up was performed to assess differences in clinical outcome.

In a hamster cheek pouch model, topical application of lidocaine $(60 \mu \mathrm{g})$ prevented thrombus formation when applied $3 \mathrm{~min}$. before laser-induced microvascular injury in all animals. In contrast, 
bupivacaine $(15 \mu \mathrm{g})$ was almost without effect, and protected in only 1 of 14 animals. In addition, when administered $15 \mathrm{~min}$ after thrombus formation, lidocaine promoted the restoration of blood flow in all animals (12 of 12), whereas bupivacaine did so in only 3 of 14 experiments. The ability of the lidocaine metabolite mono-ethyl-glycinexylidide (MEGX) and tocainide (both at $60 \mu \mathrm{g}$ ) to prevent or inhibit thrombus formation ranged between that obtained for lidocaine and bupivacaine. ${ }^{80}$ The profound difference between lidocaine and bupivacaine was attributed to different penetration properties or a bupivacaine-induced increase in epinephrine concentration ${ }^{81}$ leading to increased plasminogen activator release. ${ }^{76}$ Thus, lidocaine seems to be the most effective anti-aggregating LA. ${ }^{2}$

The mechanisms responsible for the observed antithrombotic effect by LA have been studied, but details remain unclear. Most in vitro studies have found that LA are able to inhibit platelet aggregation $^{22: 83,84}$ but only in concentrations 10 to 100 -fold greater than those commonly obtained in plasma after intravenous or epidural administration. Bupivacaine, in clinically relevant concentrations $(2.7 \mu \mathrm{g} / \mathrm{ml})$ showed no or only slight effects on TEG variables. ${ }^{85}$ These findings are in agreement with the observation by Cooke et al. ${ }^{79}$ that lidocaine had no effect on the level of coagulant factors, on platelets, on the quantity of circulating antithrombin III, or on fibrinolysis. The authors explained the clinically observed LA effect by inhibition of white cell activity (endothelial adhesion and transendothelial migration), preventing endothelial damage and thereby decreasing the incidence of thrombosis.

Several caveats must be considered before rejecting platelet effects as the primary explanation of LA antithrombotic activity. First, to our knowledge all in vitro experiments were performed using incubation times of 2 to $60 \mathrm{~min}$, compared with an LA exposure time of hours or days in the clinical setting (epidural anesthesia). Time-dependent inhibition by LA has been shown not only for coagulation-associated pathways like thromboxane $\mathrm{A}_{2}$ signaling ${ }^{86.87}$ but also for platelet rich plasma ${ }^{82}$ Exposure to low concentrations of bupivacaine $(1-10 \mu \mathrm{M})$ for $2 \mathrm{~h}$ resulted in significant changes in TEG parameters. ${ }^{88}$ Second, blood samples for in vitro experiments were drawn from healthy human donors. It is conceivable that the antithrombotic effect of LA is based on their ability to reverse the hypercoagulable postoperative state, which is most likely responsible for the increased incidence in thrombosis. Thus, one would not necessarily expect a significant effect on blood from donors with a normal coagulation status. This hypothesis is supported by the observation that LA do not increase bleeding. Finally, it might be possible that the LA effect is achieved by several actions on diverse sites. If so, studying a single potential target, as usually done in in vitro studies, is unlikely to show significant effects.

Whether the antithrombotic effect of LA is attributable to their anti-inflammatory action, as suggested by Cooke et al., ${ }^{79}$ or whether it is an interaction of various effects, remains to be determined. In addition, the question of how long these compounds have to be administered to obtain maximal benefit needs to be addressed. However, LA are likely to be of significant benefit for patients at risk of thrombotic complications. Lack of effect on clinical bleeding makes them unique in this regard, and LA infusion should be considered in the perioperative setting for patients at risk for thrombosis who are not candidates for regional anesthesia. For example, for patients who decline epidural anesthesia for major orthopedic or urologic surgery, or in whom placement of an epidural catheter is unsuccessful, we routinely consider IV lidocaine $(1.5 \mathrm{mg} / \mathrm{kg}$ bolus, followed by $2 \mathrm{mg} / \mathrm{min}$ ) administered during the procedure and for $1 \mathrm{~h}$ in the PACU. This technique will not only provide a degree of thromboprophylaxis, but in addition stabilize hemodynamics and reduce postoperative analgesic requirements. At these dosages, side effects are very rare.

\section{Conclusion}

In this chapter we have summarized several interesting and potentially important "alternative" effects of LA, not explained by their well-known antinociceptive and antiarrhythmic actions. The most remarkable observation is that LA are able to prevent pathological changes such as hypercoagulability or excessive stimulation of the inflammatory system, without inducing increased bleeding or impairment of host defense. This sets them apart from drugs currently in use for 
treatment of such disorders, and points the way to potential therapeutic application. Indeed, we use intravenous LA infusions in patients who would benefit from epidural anesthesia/analgesia but are not candidates for the technique. We hope that this chapter will urge some readers to investigate these effects in more detail, because much more research is needed on basic mechanisms. What does seem clear is that $\mathrm{Na}^{+}$channel blockade plays only a limited, if any, role in these effects.

Further research should determine which molecular determinants of the LA structure exert these effects and where the corresponding site of action is. This might eventually lead to development of new drugs, selective for treatment of these disorders, but without the "side effect" of $\mathrm{Na}^{+}$channel blockade. 
1. Hollmann MW, Fischer LG, Byford AM, Durieux ME: Local anesthetic inhibition of $\mathrm{ml}$ muscarinic acetylcholine signaling. Anesthesiolgy 2000; 93:497-509

2. Collinsworth KA, Kalman SM, Harrison DC: The clinical pharmacology of lidocaine as an antiarrhythymic drug. Circulation 1974; 50:1217-30

3. Wiklund L: Human hepatic blood flow and its relation to systemic circulation during intravenous infusion of lidocaine. Acta Anaesthesiol Scand 1977; 21:148-60

4. Tsai PS, Buerkle H, Huang LT, Lee TC, Yang LC, Lee JH: Lidocaine concentrations in plasma and cerebrospinal fluid after systemic bolus administration in humans. Anesth Analg 1998; 87:601-4

5. Mayumi T, Dohi S, Takahashi T: Plasma concentrations of lidocaine associated with cervical, thoracic, and lumbar epidural anesthesia. Anesth Analg 1983; 62:578-80

6. Fink BR: Acute and chronic toxicity of local anaesthetics. Can Anaesth Soc J 1973; 20:5-16

7. Samuelsson B, Dahlen SE, Lindgren JA, Rouzer CA, Serhan CN: Leukotrienes and lipoxins: structures, biosynthesis, and biological effects. Science 1987; 237:1171-6

8. Sinclair R, Eriksson AS, Gretzer C, Cassuto J, Thomsen P: Inhibitory effects of amide local anaesthetics on stimulus-induced human leukocyte metabolic activation, LTB4 release and IL-1 secretion in vitro. Acta Anaesthesiol Scand 1993; 37:159-65

9. Fujita H, Morita I, Murota S: A possible mechanism for vascular endothelial cell injury elicited by activated leukocytes: a significant involvement of adhesion molecules, CD11/CD18, and ICAM-1. Arch Biochem Biophys 1994; 309:62-9

10. Martinsson T, Oda T, Fernvik E, Roempke K, Dalsgaard CJ, Svensjo E: Ropivacaine inhibits leukocyte rolling, adhesion and CD11b/CD18 expression. J Pharmacol Exp Ther 1997; 283:59-65

11. Goldstein IM, Lind S, Hoffstein S, Weissmann G: Influence of local anesthetics upon human polymorphonuclear leukocyte function in vitro. Reduction of lysosomal enzyme release and superoxide anion production. J Exp Med 1977; 146:483-94

12. Hoidal JR, White JG, Repine JE: Influence of cationic local anesthetics on the metabolism and ultrastructure of human alveolar macrophages. J Lab Clin Med 1979; 93:857-66

13. Cullen BF, Haschke RH: Local anesthetic inhibition of phagocytosis and metabolism of human leukocytes. Anesthesiology 1974; 40:142-6

14. Nicolson GL, Smith JR, Poste G: Effects of local anesthetics on cell morphology and membrane-associated cytoskeletal organization in BALB/3T3 cells. J Cell Biol 1976; 68:395-402

15. MacGregor RR, Thorner RE, Wright DM: Lidocaine inhibits granulocyte adherence and prevents granulocyte delivery to inflammatory sites. Blood 1980; 56:203-9 
16. Hammer R, Dahlgren C, Stendahl O: Inhibition of human leukocyte metabolism and random mobility by local anaesthesia. Acta Anaesthesiol Scand 1985; 29:520-3

17. Scott BD, Shasby DM, Tomanek RJ, Kieso RA, Seabold JE, Ponto JA, Kerber RE: Lidocaine and dextran sulfate inhibit leukocyte accumulation but not postischemic contractile dysfunction in a canine model. Am Heart J 1993; 125:1002-11

18. Schreiner A, Hopen G: Adhesion and locomotion of human leukocytes in vitro; importance of protein coating; effect of lidocain, ethanol and endotoxin. Acta Pathol Microbiol Scand [C] $1979 ; 87: 333-40$

19. Eriksson AS, Sinclair R, Cassuto J, Thomsen P: Influence of lidocaine on leukocyte function in the surgical wound. Anesthesiology 1992; 77:74-8

20. Condliffe AM, Kitchen E, Chilvers ER: Neutrophil priming: pathophysiological consequences and underlying mechanisms. Clin Sci 1998; 94:461-71

21. Fischer LG, Conrad B, Krumm B, Hollmann MW, Durieux ME: Time-dependent attenuation by lidocaine of respiratory burst in human neutrophils primed with lysophosphatic acid. Anesth Analg 2000; 90:S405

22. Jelacin N, Hollmann MW, Gross A, Durieux ME: Local anesthetics inhibit neutrophil priming. Anesthesiology 2000; 93:Abstract in press

23. Irita K, Fujita I, Takeshige K, Minakami S, Yoshitake J: Cinchocaine and amethocaine inhibit activation and activity of superoxide production in human neutrophils. $\mathrm{Br} \mathrm{J}$ Anaesth $1986 ; 58: 639-45$

24. Haines KA, Reibman J, Callegari PE, Abramson SB, Philips MR, Weissmann G: Cocaine and its derivatives blunt neutrophil functions without influencing phosphorylation of a 47 . kilodalton component of the reduced nicotinamide-adenine dinucleotide phosphate oxidase. $J$ immunol 1990; 144:4757-64

25. Kai T, Nishimura J, Kobayashi S, Takahashi S, Yoshitake J, Kanaide H: Effects of lidocaine on intracellular $\mathrm{Ca}+$ and tension in airway smooth muscle. Anesthesiology 1993; 78:954-65

26. Tomoda MK, Tsuchiya M, Ueda W, Hirakawa M, Utsumi K: Lidocaine inhibits stimulationcoupled responses of neutrophils and protein kinase $\mathrm{C}$ activity. Physiol Chem Phys Med NMR 1990; 22:199-210

27. Peck SL, Johnston RB, Jr., Horwitz LD: Reduced neutrophil superoxide anion release after prolonged infusions of lidocaine. J Pharmacol Exp Ther 1985; 235:418-22

28. Siminiak T, Wysocki H, Veit A, Maurer HR: The effect of selected antiarrhythmic drugs on neutrophil free oxygen radicals production measured by chemiluminescence. Basic Res Cardiol 1991; 86:355-62

29. White IW, Gelb AW, Wexler HR, Stiller CR, Keown PA: The effects of intravenous anaesthetic agents on human neutrophil chemiluminescence. Can Anaesth Soc J 1983; 30:506-11 
30. Hyvonen PM, Kowolik MJ: Dose-dependent suppression of the neutrophil respiratory burst by lidocaine. Acta Anaesthesiol Scand 1998; 42:565-9

31. Hattori M, Dohi S, Nozaki M, Niwa M, Shimonaka H: The inhibitory effects of local anesthetics on superoxide generation of neutrophils correlate with their partition coefficients. Anesth Analg 1997; 84:405-12

32. Cederholm I, Briheim G, Rutberg H, Dahlgren C: Effects of five amino-amide local anaesthetic agents on human polymorphonuclear leukocytes measured by chemiluminescence. Acta Anaesthesiol Scand 1994; 38:704-10

33. Mikawa K, Akamatsu H, Nishina K, Shiga M, Maekawa N, Obara H, Niwa Y: Inhibitory effect of local anaesthetics on reactive oxygen species production by human neutrophils. Acta Anaesthesiol Scand 1997; 41:524-8

34. Nishina K, Mikawa K, Takao Y, Shiga M, Naekawa N, Obara H: Intravenous lidocaine attenuates acute lung injury induced by hydrochloric acid aspiration in rabbits. Anesthesiology 1998; 88:1300-9

35. Schmidt W, Schmidt H, Bauer H, Gebhard MM, Martin E: Influence of lidocaine on endotoxin-induced leukocyte-endothelial cell adhesion and macromolecular leakage in vivo. Anesthesiology 1997; 87:617-24

36. Mikawa K, Maekawa N, Nishina K, Takao Y, Yaku H, Obara H: Effect of lidocaine pretreatment on endotoxin-induced lung injury in rabbits. Anesthesiology 1994; 81:689-99

37. Takao Y, Mikawa K, Nishina K, Maekawa N, Obara H: Lidocaine attenuates hyperoxic lung injury in rabbits. Acta Anaesthesiol Scand 1996; 40:318-25

38. Rimbăck G, Cassuto J, Wallin G, Westlander G: Inhibition of peritonitis by amide local anesthetics. Anesthesiology 1988; 69:881-6

39. Nellgard P, Jonsson A, Bojo L, Tarnow P, Cassuto J: Small-bowel obstruction and the effects of lidocaine, atropine and hexamethonium on inflammation and fluid losses. Acta Anaesthesiol Scand 1996; 40:287-92

40. Cassuto J, Nellgard P, Stage L, Jonsson A: Amide local anesthetics reduce albumin extravasation in burn injuries. Anesthesiology 1990; 72:302-7

41. Martinsson T: Ropivacaine inhibits serum-induced proliferation of colon adenocarcinoma cells in vitro. J Pharmacol Exp Ther 1999; 288:660-4

42. Asklin B, Cassuto J: Intravesical lidocaine in severe interstitial cystitis. Case report. Scand J Urol Nephrol 1989; 23:311-2

43. Bjorck S, Dahlstrom A, Ahlman H: Topical treatment of ulcerative proctitis with lidocaine. Scand J Gastroenterol 1989; 24:1061-72

44. Arlander E, Ost A, Stahlberg D, Lofberg R: Ropivacaine gel in active distal ulcerative colitis and proctitis -- a pharmacokinetic and exploratory clinical study. Aliment Pharmacol Ther 1996; 10:73-81 
45. Rimback G, Cassuto J, Tollesson PO: Treatment of postoperative paralytic ileus by intravenous lidocaine infusion. Anesth Analg 1990; 70:414-9

46. Rimback G, Cassuto J, Faxen A, Hogstrom S, Wallin G, Tollesson PO: Effect of intraabdominal bupivacaine instillation on postoperative colonic motility. Gut 1986; 27:170-5

47. Groudine SB, Fisher HAG, Kaufman RP, Patel MJ, Wilkins LJ, Mehta SA, Lumb PD: Intravenous lidocaine speeds the return of bowel function, decreases postoperative pain, and shortens hospital stay in patients undergoing radical retropubic prostatectomy. Anesth Analg 1998; 86:235-9

48. Cheng G, Cassissi C, Drexler PG, Vogel SB, Sninsky CA, Hocking MP: Salsalate, morphine, and postoperative ileus. Am J Surg 1996; 171:85-8 (discussion 88-89)

49. Simpson PJ, Lucchesi BR: Free radicals and myocardial ischemia and reperfusion injury. J Lab Clin Med 1987 1987; 110:13-30

50. Mullane KM, Read N, Salmon JA, Moncada S: Role of leukocytes in acute myocardial infarction in anesthetized dogs: relationship to myocardial salvage by antiinflammatory drugs. J Pharmacol Exp Ther 1984; 228:510-22

51. Gumina RJ, el Schultz J, Yao Z, Kenny D, Warltier DC, Newman PJ, Gross GJ: Antibody to platelet/endothelial cell adhesion molecule-1 reduces myocardial infarct size in a rat model of ischemia-reperfusion injury. Circulation 1996; 94:3327-33

52. Schmidt FEJ, MacDonald MJ, Murphy CO, Brown WM, Gott JP, Guyton RA: Leukocyte depletion of blood cardioplegia attenuates reperfusion injury. Ann Thorac Surg 1996; 62:1691-6

53. Lee R, Nitta T, Schmid RA, Schuessler RB, Harris KM, Gay WAJ: Retrograde infusion of lidocaine or $\mathrm{L}$-arginine before reperfusion reduces myocardial infaret size. Ann Thorac Surg 1998; 65:1353-9

54. Lesnefsky EJ, VanBenthuysen KM, McMurtry IF, Shikes RH, Johnston RB, Horwitz LD: Lidocaine reduces canine infarct size and decreases release of a lipid peroxidation product. J Cardiovasc Pharmacol 1989; 13:895-901

55. de Lorgeril M, Rousseau G, Basmadjian A, Latour JG: Lignocaine in experimental myocardial infarction: failure to prevent neutrophil accumulation and ventricular fibrillation and to reduce infarct size. Cardiovasc Res 1988; 22:439-46

56. Drage M: Caution in the use of lidocaine infusion in the surgical patient. Anesth Analg 1998; $87: 1213$

57. Di Rosa M, Giroud JP, Willoughby DA: Studies on the mediators of the acute inflammatory response induced in rats in different sites by carrageenan and turpentine. J Pathol $1971 ; 104: 15-29$

58. Ravin CE, Latimer JM, Matsen JM: In vitro effects of lidocaine on anaerobic respiratory pathogens and strains of Hemophilus influenzae. CHEST 1977; 72:439-41 
59. Rosenberg PH, Renkonen OV: Antimicrobial activity of bupivacaine and morphine. Anesthesiology 1985; 62:178-9

60. Conte BA, Laforet EG: The role of the topical anesthetic solutions on bronchial secretions during bronchoscopy. N Engl J Med 1962; 267:957-9

61. Hollmann MW, Durieux ME: Local anesthetics and the inflammatory response: a new therapeutic indication? Anesthesiology 2000; in press

62. Morris T, Tracey J: Lignocaine: its effect on wound healing. Br J Surg 1977; 64:902-3

63. Chvapil M, Hameroff SP, O'Dea K, Peacock EE: Local Anesthetics and Wound Healing. J Surg Res 1979; 27:367-71

64. Nietgen GW, Chan CK, Durieux ME: Inhibition of lysophosphatidate signaling by lidocaine and bupivacaine. Anesthesiology 1997; 86:1112-9

65. Eriksson AS, Sinclair R: Leukocyte hydrogen peroxide production in a surgical wound in mice. The effects of an amide local anaesthetic. Inflammation 1996; 20:569-79

66. Moreira LB, Kasetsuwan N, Sanchez D, Shah SS, LaBree L, McDonnell PJ: Toxicity of topical anesthetic agents to human keratocytes in vivo. J Cataract Refract Surg 1999; 25:975-80

67. Drucker M, Cardenas E, Arizti P, Valenzuela A, Gamboa A: Experimental studies on the effect of lidocaine on wound healing. World J Surg 1998; 22:394-7

68. Morris T, Appbly R: Retardation of wound healing by procaine. Br J Surg 1980; 67:391-2

69. Verma S, Corbett MC, Marshall J: A prospective, randomized, double-masked trial to evaluate the role of topical anesthetics in controlling pain after photorefractive keratectomy. Ophthalmology 1995; 102:1918-24

70. Pettersson N, Emanuelsson BM, Reventlid H, Hahn RG: High-dose ropivacaine wound infiltration for pain relief after inguinal hernia repair: a clinical and pharmacokinetic evaluation. Reg Anesth Pain Med 1998; 23:189-96

71. Pedersen JL, Callesen T, Moiniche S, Kehlet H: Analgesic and anti-inflammatory effects of lignocaine-prilocaine (EMLA) cream in human burn injury. Br J Anaesth 1996; 76:806-10

72. Bondville J: Pain-free harvesting of skin grafts with EMLA. Plast Surg Nurs 1994; 14:231-4

73. Modig J, Borg T, Bagge L, Saldeen T: Role of extradural and of general anaesthesia in fibrinolysis and coagulation after total hip replacement. $\mathrm{Br} \mathrm{J}$ Anaesth 1983; 55:625-9

74. Modig J, Borg T, Karlstrom G, Maripuu E, Sahlstedt B: Thromboembolism after total hip replacement: role of epidural and general anesthesia. Anesth Analg 1983; 62:174-80

75. Modig J, Hjelmstedt A, Sahlstedt B, Maripuu E: Comparative influences of epidural and general anaesthesia on deep venous thrombosis and pulmonary embolism after total hip replacement. Acta Chir Scand 1981; 147:125-30 
76. Henny CP, Odoom JA, TenCate JW, TenCate RJF, Osterhoff NF, Dabhoiwala NF, Sih IL: Effects of extradural bupivacaine on the hemostatic system. Br J Anaesth 1986; $58: 301-5$

77. Tuman KJ, McCarthy RJ, March RJ, DeLaria GA, Patel RV, Ivankovich AD: Effects of epidural anesthesia and analgesia on coagulation and outcome after major vascular surgery. Anesth Analg 1991; 73:696-704

78. Odoom JA, Dokter PWC, Sturk A, Ten Cate JW, Sih IL, Bovill JG: The influence of epidural analgesia on platelet function and correlation with plasma bupivacaine concentrations. Eur.J.Anaesth. 1988; 5:305-12

79. Cooke ED, Bowcock SA, Lloyd MJ, Pilcher MF: Intravenous lignocaine in prevention of deep venous thrombosis after elective hip surgery. Lancet 1977; 2:797-9

80. Luostarinen V, Evers H, Lyytikainen MT, Scheinin, Wahlen A: Antithrombotic effects of lidocaine and related compounds on laser-induced microvascular injury. Acta Anaesthesiol Scand 1981; 25:9-11

81. Hasselstrom LJ, Mogensen T, Kehlet H, Christensen NJ: Effects of intravenous bupivacaine on cardiovascular function and plasma catecholamine levels in humans. Anesth Analg $1984 ; 63: 1053-8$

82. Borg T, Modig J: Potential anti-thrombotic effects of local anesthetics due to their inhibition of platelet aggregation. Acta Anaesth.Scand. 1985; 29:739-42

83. Grant GJ, Ramanathan S, Patel N, Turndorf H: The effects of local anesthetics on maternal and neonatal platelet function. Acta Anaesthesiol Scand 1989; 33:409-12

84. Feinstein MG, Fiekers J, Fraser C: An analysis of the mechanism of local anesthetic inhibition of platelet aggregation and secretion. Journal of Pharmacology \& Experimental Therapeutics 1976; 197:215-28

85. Gibbs NM, Sear JW: Effect of ketorolac, bupivacaine, and low-dose heparin on thrombelastographic variables in vitro. British Journal of Anaesthesia 1995; 75:27-30

86. Hoenemann CW, Podranski T, Lo B, Yanovitch M, Durieux ME: Local anesthetic effects on thromboxane A2 signaling. Anesthesiology 1998; 89:A886

87. Hoenemann CW, Podranski T, Sertel S, Durieux ME: Zeitabhăngiger inhibitorischer Effekt von Bupivacain auf die Signalabertragung rekombinanter Thromboxan $\mathrm{A}_{2}$-Rezeptoren in Xenopus Oozyten. Anaesthesiologie \& Intensivmedizin 2000; 41:423

88. Kohrs R, Hoenemann CW, Feirer N, Durieux ME: Bupivacaine inhibits whole blood coagulation in vitro. Reg Anesth Pain Med 1999; 24:326-30 


\title{
CHAPTER 8
}

\section{Local anesthetic effects on priming and activation of human neutrophils}

\author{
Markus W. Hollmann \\ Ariane Gross \\ Niko Jelacin \\ Marcel E. Durieux
}

Published in: Anesthesiology 95: 113-22, 2001 


\section{ABSTRACT}

Introduction: Local anesthetics (LA) have been shown to inhibit human polymorphonuclear neutrophil (hPMN) functions in vitro, but mechanisms are poorly understood. In this study we determined how LA affect superoxide anion production of hPMNs primed with platelet-activating factor (PAF). We studied which pharmacological properties of LA are important for this action and assessed the LA site of action within the PAF signaling pathway.

Materials and Methods: Metabolic activity of primed and/or activated hPMNs were measured using the cytochrome-c assay. hPMNs were incubated with several LA for $1 \mathrm{~h}$ to assess interference with PAF signaling. Using protein kinase $\mathrm{C}(\mathrm{PKC})$ inhibitors, the $\mathrm{PKC}$ activator phorbol myristate acetate (PMA) and the phospholipase C (PLC) antagonist U-73122, we studied involvement of PKC and $\mathrm{PLC}$ in the priming process. Pertussis toxin (PTX) was used to characterize the G proteins mediating this pathway. Combined administration of lidocaine with PMA or PTX was used to determine the LA site of action within the priming pathway.

Results: PAF effectively primed hPMNs. Ester-LA (tetracaine and benzocaine) exerted the most profound inhibitory effect on PAF-primed hPMNs, whereas inhibitory potency of amide-LA increased with decreased charged fraction. The major PAF-induced priming pathway is PLC- and PKC-dependent and mainly $\mathrm{G}_{\mathrm{q}}$-mediated. The main target site for LA in this pathway is located upstream of PKC.

Conclusions: LA in clinically relevant concentrations inhibit superoxide anion production of PAF-primed hPMNs. Effects on priming by these compounds might explain at least in part the previously unexplained difference between concentrations of LA required for their antiinflammatory action in vitro and in vivo. This study suggests a target site for $\mathrm{LA}_{\text {within }}$ a $\mathrm{G}_{\mathrm{q}}$ coupled signaling pathway.

\section{INTRODUCTION}

Local anesthetics (LA) have a variety of actions in addition to $\mathrm{Na}$ channel blockade. Of particular interest are reports indicating that these compounds modulate the inflammatory response. In vivo they prevent or reduce inflammatory disorders like reperfusion injury in heart, lung and brain, as well as endotoxin- or hypoxia-induced pulmonary injury. In vitro LA inhibit signaling actions of macrophages and granulocytes, which mediate early steps of the inflammatory response (for review see').

Unfortunately, the mechanisms behind these potentially beneficial effects of LA are largely unknown. It is clear, however, that these actions do not result primarily from $\mathrm{Na}$ channel blockade. The anti-inflammatory effects of LA observed in vitro can not easily explain those found in the clinical setting, since concentrations required to achieve inhibition of inflammatory cells in vitro are approximately 3 orders of magnitude greater than plasma concentrations obtained after iv or epidural administration of LA. ${ }^{2}$ LA inhibit signaling through several G protein-coupled receptors. Since many inflammatory mediators signal through such receptors, LA may modulate inflammatory responses by inhibiting inflammatory mediator signaling. Recently, we have shown that clinically relevant concentrations of LA inhibit several actions of the phospholipid mediator lysophosphatidate (LPA) on human polymorphonuclear neutrophils (hPMNs). ${ }^{3,4}$

hPMNs are of great importance in host defense, as they move actively to the site of inflammation (chemotaxis), where a multicomponent enzyme complex, Nicotinamide Adenine Dinucleotide phosphate (NADPH) oxidase, generates toxic oxygen metabolites $\left(\mathrm{O}_{2}{ }_{2}^{*}, \mathrm{H}_{2} \mathrm{O}_{2}, \mathrm{HOCl}\right.$, and $\left.\mathrm{OH}\right)$. hPMNs exist in one of three states: quiescent, primed or active. Priming refers to a process whereby the response of hPMNs to a subsequent activating stimulus is potentiated. Release of oxygen metabolites is markedly enhanced when hPMNs have previously been primed. ${ }^{5}$ The priming 
process has been shown to be a critical component of hPMN-mediated tissue injury both in vitro and in vivo. ${ }^{5}$

In this study we investigated the effects of LA on hPMN priming by platelet-activating factor (PAF), a representative inflammatory mediator. PAF is an established mediator in early ARDS, ${ }^{6}$ a typical postoperative inflammatory disorder. It plays a pivotal role in lipopolysaccharide (LPS)induced lung-injury ${ }^{7-10}$ and alveolar PAF levels are increased in ARDS." PAF inhibition reduces endotoxin-induced lung dysfunction ${ }^{12}$ and pulmonary injury after cardiopulmonary bypass. ${ }^{13}$

Our findings indicate that LA inhibit PAF-mediated priming. The priming pathway is phospholipase C (PLC)- and protein kinase C (PKC)-dependent and the main site of LA action is upstream from PKC.

\section{MATERIALS AND METHODS}

The study protocol was approved by the University of Virginia Institutional Review Board.

\section{Preparation of hPMNs}

Human venous blood was obtained from healthy donors who had not used any medication for at least two weeks. Blood was heparinized $(10 \mathrm{U} / \mathrm{ml})$ and $\mathrm{hPMNs}$ were isolated by a one-step separation procedure. Following 40 minutes of centrifugation at $500 \times \mathrm{g}, \mathrm{hPMNs}$ were washed three times with Hank's Balanced Salt Solution (HBSS, containing $10 \mathrm{U} / \mathrm{ml}$ heparin), and centrifuged after each washing step at $350 \times \mathrm{g}$ ( $20 \mathrm{~min}$ after first wash, $10 \mathrm{~min}$ after second and third wash). hPMNs were then resuspended in $5 \mathrm{ml}$ HBSS, and counted using a hemocytometer. Unopette (Becton Dickinson, Franklin Lakes, NJ) in vitro Diagnostic System was used for the enumeration of hPMNs in the suspension, which was then diluted with HBSS to obtain a final neutrophil suspension of $5 \times 10^{6}$ cells/ml. Purity of our hPMN suspension, assessed by morphology, exceeded $98 \%$. The viability of neutrophils was checked by Trypan blue exclusion and always found to be greater than $94 \%$. All preparation and assays were performed at room temperature.

\section{Superoxide anion $\left(\mathrm{O}_{2}\right)$ generation}

\section{Cytochrome c-reduction assay:}

We used the cytochrome c-reduction assay to measure extracellular $\mathrm{O}_{2}{ }^{-}$-production by activated hPMNs as described previously. ${ }^{14,15} \mathrm{O}_{2}$ generation was measured spectrophotometrically as the SOD-inhibitable reduction of cytochrome $\mathrm{c}$.

Superoxide anion production was measured over time by the absorbance of cytochrome $\mathrm{c}$ at 550 $\mathrm{nm}$. The reaction was performed in a spectrophotometer (Genesys 5, Spectronic Instruments, Rochester, NY). The reaction mixture was prepared by placing $700 \mu$ buffer (HBSS + BSA $0.1 \%$ ), $200 \mu \mathrm{l}$ of hPMN suspension (final concentration $10^{6} \mathrm{cells} / \mathrm{ml}$ ) and $100 \mu \mathrm{l}$ cytochrome c (from horse

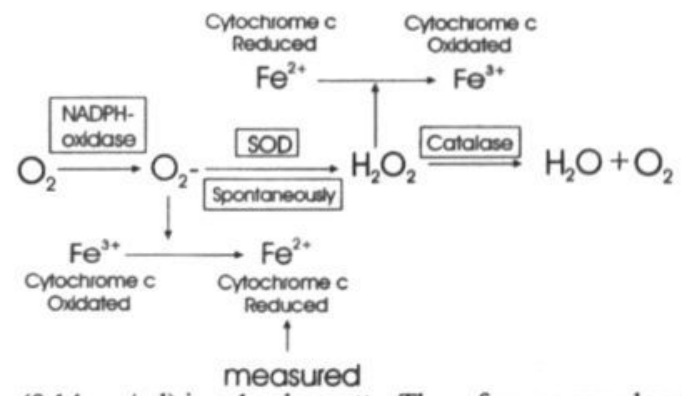

heart, $3.7 \mathrm{mg} / \mathrm{ml})$ with catalase $(0.14 \mathrm{mg} / \mathrm{ml})$ in a $1-\mathrm{ml}$ cuvette. The reference sample was prepared the same way, but in addition $10 \mu \mathrm{l}$ of superoxide dismutase (SOD, $10^{-2} \mathrm{M}$ ) was added to the mixture. Many electron donors besides $\mathrm{O}_{2}{ }^{-}$can reduce cytochrome c, but only $\mathrm{O}_{2}{ }^{-}$is destroyed by 
SOD, by catalyzing its conversion to $\mathrm{H}_{2} \mathrm{O}_{2}$. By subtracting the absorbance of the $\mathrm{SOD}$ reaction (representing cytochrome $\mathrm{c}$ reduction due to other radical oxygen metabolites), the selective contribution of $\mathrm{O}_{2}{ }_{2}$ can be determined. Catalase was used to degrade $\mathrm{H}_{2} \mathrm{O}_{2}$ into $\mathrm{H}_{2} \mathrm{O}$ and $\mathrm{O}_{2}$, preventing $\mathrm{H}_{2} \mathrm{O}_{2}$ from reoxidizing the reduced cytochrome $c$. Such $\mathrm{H}_{2} \mathrm{O}_{2}$-dependent oxidation of reduced cytochrome $\mathrm{c}$ would give inaccurate, falsely low results.

The reaction was activated by either adding $\mathrm{N}$-formylmethionine-leucyl-phenylalanine (AMLP) or PMA, and the change in absorbance at $550 \mathrm{~nm}$ was followed over time. The reference sample was measured immediately after, and $\mathrm{O}_{2}{ }^{-}$-dependent cytochrome $\mathrm{c}$ reduction was determined by subtracting the reference value from the study sample value. To test LA effects on either priming or activation, hPMNs were incubated for $60 \mathrm{~min}$ at $37^{\circ} \mathrm{C}$ in various concentrations of different LA prior to hPMN activation with MMLP. When PAF was employed as priming agent, $\mathrm{hPMNs}$ were incubated for 5 min prior to activation with AMLP or PMA, since priming effect by PAF has been shown to be maximal after $5 \mathrm{~min}{ }^{16}$ Using fMLP for activation, $\mathrm{O}_{2}$ generation at time points 0,5 , $10,14,16$, and $18 \mathrm{~min}$ was measured, because we determined in a prior study maximal activation after 16 min. ${ }^{3 / 4}$ PMA-induced superoxide anion production was determined at time points 0 to 50 min every five minutes. $\mathrm{O}_{2}$ production was calculated using as conversion factor $47.4 \mu \mathrm{mol}(1 / 21.1$ $\mathrm{mM}^{-1}$ difference of extinction coefficient between oxidized and reduced cytochrome $\mathrm{c}$ at $550 \mathrm{~nm}$ ) $\mathrm{O}_{2}$ per unit change in absorbance.

We measured extracellular (rather than total) PMN-mediated release of $\mathrm{O}_{2}{ }^{\circ}$ since it is the release of oxygen metabolites into the extracellular milieu that may directly damage cells in the surrounding microenvironment. Extracellular $\mathrm{O}_{2}{ }^{\prime}$ release can be monitored by either end-point or kinetic assays. In spectrophotometric end-point assays, the total amount of $\mathrm{O}_{2}^{-}$that is released into the extracellular environment by a fixed number of PMNs is quantitated after a given incubation time. A kinetic assay determines both the total amount of $\mathrm{O}_{2}-$ produced and the rate of $\mathrm{O}_{2}{ }_{2}$ release over time. We used a kinetic assay because the kinetics of $\mathrm{PMN} \mathrm{O}_{2}{ }^{-}$-release are non-linear and vary with different priming and activating stimuli.

\section{Reagents}

HBSS (without phenol red, with $\mathrm{Ca}^{2+} / \mathrm{Mg}^{2+}$ ) was bought from Whittaker Bioproducts (Walkersville, MD), superoxide dismutase (SOD, from bovine liver), AMLP, cytochrome C (from horse heart), catalase (from bovine liver), PMA, U73122, BIM, CT, PTX were obtained from Sigma Chemicals Co.(St. Louis, MO). Ficoll-Hypaque and BSA (protease free bovine albumin fraction / fatty acid free) were from ICN Biomedicals, Inc. (Aurora, OH). Polymorph (Westbury, NY), Neutrophil isolation medium (NIM) was from Cardinal Associates (Santa Fe, NM). PAF (1-alkyl-2acetoyl-sn-glycero-3-phosphocholine) were obtained from Avanti polar lipids (Alabaster, AL). Lidocaine and QX 314 were a gift from Astra Pharmaceuticals, L.P. (Westborough, MA).

\section{Statistical analysis}

Data are reported as mean \pm SD. Leukocyte metabolic activity is reported either as superoxide anion production or as percentage change from control. Blood from at least 8 donors $(\mathrm{n}=8)$ was used for each datapoint. Groups were compared using either paired Student's t-test or one-way repeated measurement ANOVA, followed by Dunnett or Student Newman Keuls correction (as described in the Result section), if necessary. $\mathrm{P}<0.05$ was considered significant. SigmaStat 2.0 (Jandel Scientific Corporation, San Rafael, CA) was used for all statistical analyses. 


\section{RESULTS}

Since hPMNs were to be incubated in LA for significant duration prior to the activation assay, we determined, in pilot experiments, the effect of incubation in buffer $\left(37^{\circ} \mathrm{C}, 0-60 \mathrm{~min}\right)$ as well as the effect of movement (by a shaking waterbath) on $\mathrm{O}_{2}{ }^{-}$production. Neither affected $\mathrm{O}_{2}^{*}$-production as compared with untreated control hPMNs (data not shown). We also determined any interference of PAF with the cytochrome $c$ assay. PAF did not have any significant effect on absorbance in a neutrophil-free solution as compared with control (data not shown).

\section{PAF primes, but does not activate hPMNs}

After these control experiments, we determined PAF's ability to activate and/or prime hPMNs. hPMNs were added to the assay solution, and baseline activity was measured to exclude activating effects of the isolation process itself. Activator was then added to the samples and absorbance was measured for the next $20 \mathrm{~min}$. PAF in concentrations between $10^{-4}$ and $10^{-8} \mathrm{M}$ induced virtually no activation. In contrast, fMLP $\left(10^{-6} \mathrm{M}\right.$, a concentration selected as it gave optimal responses in our previous studies ${ }^{3,4}$ ) induced superoxide anion production of approximately $1.9 \pm 0.6 \mathrm{nmol} / 10^{6}$ cells, confirming the functionality of the assay (Figure 1).

\section{Activation by fMLP or PAF}

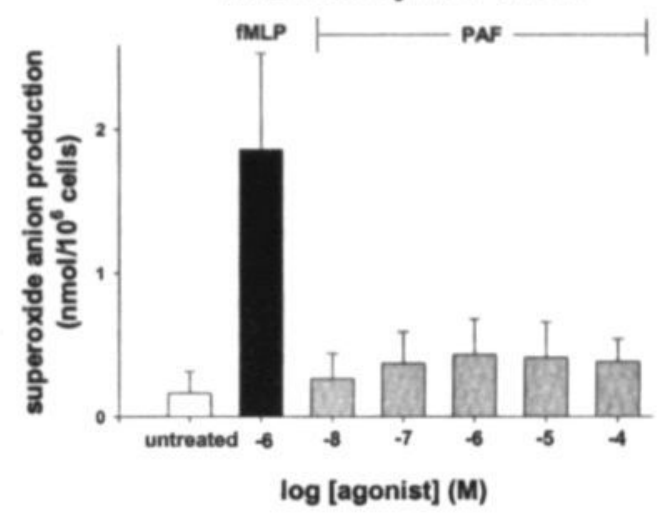

Figure 1: $f M L P$ - and PAF-induced $h P M N$ activation. Whereas $f M L P\left(10^{6} M\right.$, black bar $)$ induces superoxide anion production, $P A F$ has virtually no activating properties (grey bars). Untreated: Baseline superoxide anion production by untreated hPMNs (white bar).

When pretreated for $5 \mathrm{~min}$ with various PAF concentrations $\left(10^{-5}-10^{-8} \mathrm{M}\right)$, responses to AMLP were increased significantly (Figure 2), indicating that hPMNs could be primed appropriately by PAF, as described previously. ${ }^{16,17}$ Maximal priming effect $\left(11.1 \pm 3.9 \mathrm{nmol} / 10^{6}\right.$ cells, and almost 6fold increase) was obtained with $10^{-6} \mathrm{M}$ PAF. Therefore, this concentration was used for the remainder of the study. 


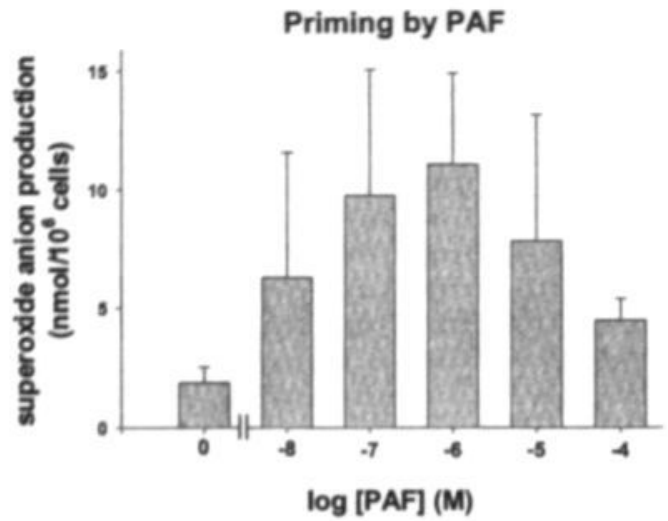

Figure 2: Superoxide anion production by $h P M N$ s activated by $P M L P\left(1 \sigma^{6} M\right.$, left bar, data from Fig I), or after priming for 5 min with $P A F\left(1 \sigma^{4}-10^{s} M\right)$. Optimal priming effect is achieved with a PAF concentration of $10^{6} \mathrm{M}$.

\section{PAF priming is mediated by a PTX-insensitive G protein}

We studied the intracellular signaling pathways involved in PAF-induced priming. Since both PAF and MLLP act through $G$ protein-coupled receptors, we determined the effects of pertussis toxin (PTX) on PAF-primed/fMLP-activated $\mathrm{O}_{2}$ production. Preincubation with PTX $(0.3 \mu \mathrm{g} / \mathrm{ml})$ for 90 min caused a modest but significant $(\mathrm{P}=0.001$, $t$-test $)$ reduction in superoxide anion production to $73.4 \pm 9.6 \%$ of control response $\left(13.4 \pm 3.1 \mathrm{nmol} / 10^{6}\right.$ cells, figure 3$)$. This suggests that $\mathrm{G}_{\mathrm{a}}$ and/or $\mathrm{G}_{\mathrm{o}}$ proteins are involved, but are not the only $\mathrm{G}$ protein subtypes mediating $\mathrm{O}_{2}{ }^{*}$ production.

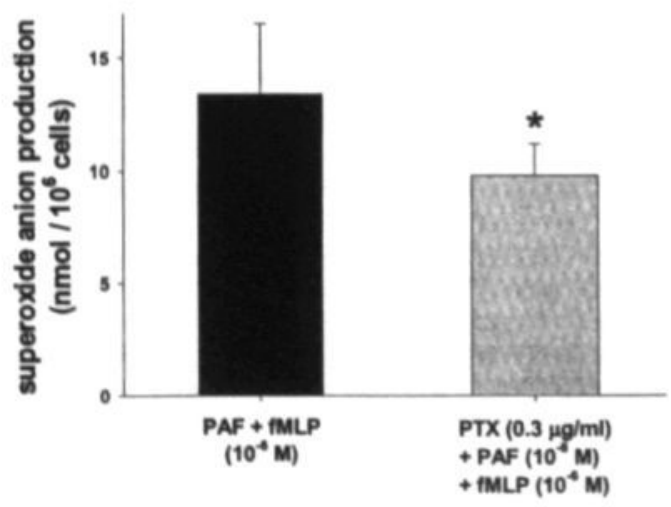

Figure 3: $90 \mathrm{~min}$ preincubation of hPMNs with PTX $(0.3 \mathrm{\mu g} / \mathrm{ml}$, grey bar $)$ inhibits superoxide anion production of PAF $\left(10^{6} \mathrm{M}\right)$-primed/AMLP $\left(10^{6}{ }_{M}\right.$ )-activated hPMNs to $73.4 \pm 9.6 \%$ of control response. ': significant difference compared with $P A F$-primed/fMLP-activated control response. 
We also investigated the effect of PTX on $\mathrm{O}_{2}$ production of $\mathrm{hPMNs}$ primed with PAF $\left(10^{-6} \mathrm{M}\right)$ and activated with the PKC agonist phorbol myristate acetate (PMA), bypassing the G protein step of the activation pathway. As illustrated in figure $4, \mathrm{O}_{2}$ production in response to $1 \mathrm{nM}$ PMA $\left(4.7 \pm 1.1 \mathrm{nmol} / 10^{6}\right.$ cells) increased significantly after incubation with PAF for $5 \mathrm{~min}(14.4 \pm 2.8$ nmol/10 cells).

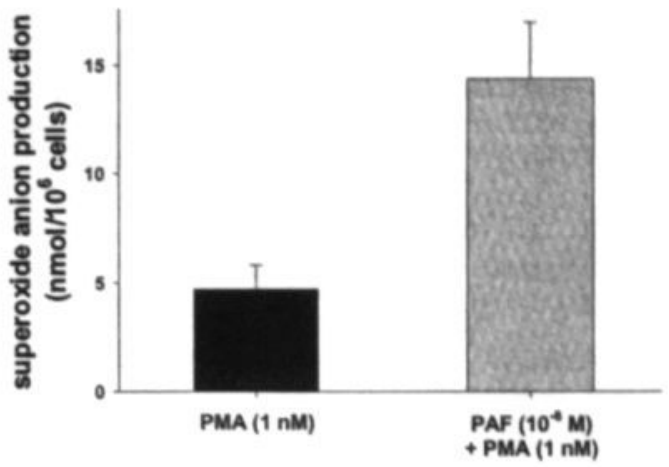

Figure 4: PAF $\left(10^{6} \mathrm{M}\right)$ increases superaxide anion production in $h P M N$ s induced by $1 \mathrm{nM} P \mathrm{PMA}$.

In contrast to our findings using PMLP as activator, we observed no significant effect of PTX on PAF-primed/PMA-activated $\mathrm{O}_{2}$ production (PTX $14.1 \pm 0.4 \mathrm{nmol} / 10^{6}$ cells; control $13.9 \pm 0.4$ $\mathrm{nmol} / 10^{6}$ cells, $(\mathrm{n}=19) \mathrm{p}=0.105$, $\mathrm{t}$-test; figure 5$)$. Based on these experiments we conclude that activation is partially PTX sensitive, but only PTX-insensitive G proteins are required for the priming process.

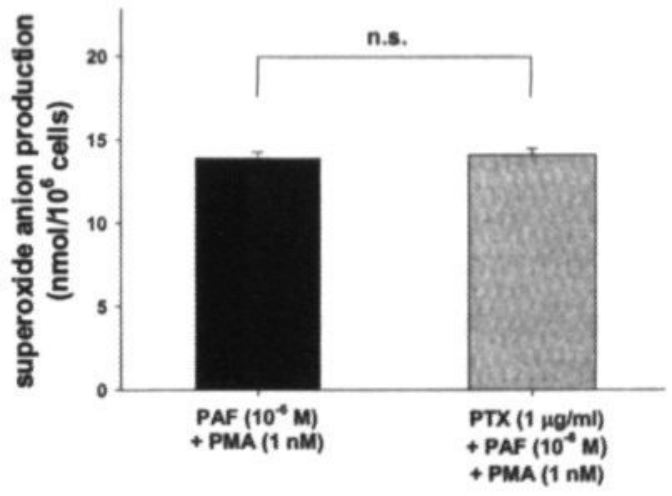

Figure 5: PTX (1 $\mu \mathrm{g} / \mathrm{ml})$ has no significant effect on PAF $\left(10^{6} \mathrm{M}\right)$-primed/PMA (1 nM)-activated superoxide anion production (grey bar) compared with PAF $\left(10^{6} \mathrm{M}\right)$-primed/PMA (I nM)activated control hPMNs (black bar). 


\section{U-73122 abolishes PAF priming of PMA-induced superoxide anion production}

Since we determined that PAF priming is mediated through PTX-insensitive G proteins (presumably $\mathrm{G}_{4 / 1}$ ), we studied if priming depends on activation of phospholipase $\mathrm{C}$ (PLC), the main effector activated by these $G$ proteins.

We primed hPMNs with PAF and measured superoxide anion production after agonist stimulation, in the absence and presence of the putative PLC antagonist 1-(6-[([17beta]-3methoxyestra-1,3,5[10]-trien-17-yl)amino]hexyl)-1H-pyrrole-2,5-dione (U-73122). Since the activation pathway may also in part involve $\mathrm{PLC}^{15}$, we used PMA as the activating stimulus. The priming effect of PAF was abolished completely $\left(5.0 \pm 1.9 \mathrm{nmol} / 10^{6}\right.$ cells) when hPMNs were preincubated for $60 \mathrm{~min}$ in U-73122 $\left(10^{-6} \mathrm{M}\right.$ ) (figure 6), indicating that PLC mediates PAF priming.

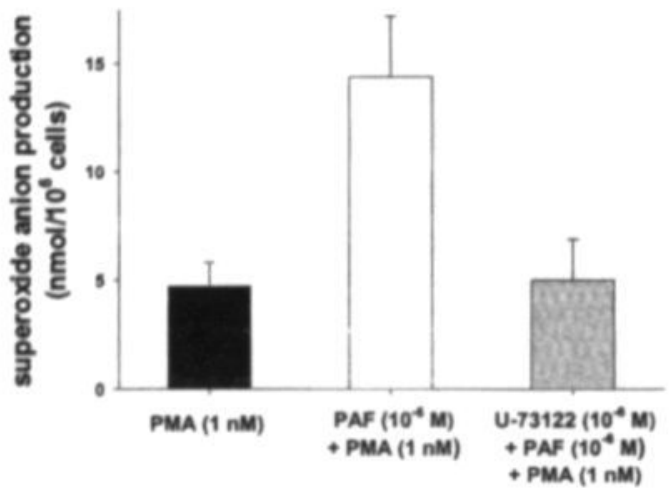

Figure 6: PAF $\left(10^{6} \mathrm{M}\right)$ increases superoxide anion production in hPMNs induced by $1 \mathrm{nM} P M A$ (data form fig. ID). U-73122 (10 $M$ M), a PLC-antagonist completely abolishes the priming effect of PAF (grey bar).

\section{PKC inhibitors abolish the priming effect of PAF}

Diacylglycerol, generated by the action of PLC on phosphatidylinositolbisphosphate $\left(\mathrm{PIP}_{2}\right)$, is the endogenous activator of PKC. Since PAF priming is mediated through a PLC mechanism, we hypothesized that PKC activation plays a role in this pathway. We therefore investigated if PKC inhibitors block PAF priming. 60 min pretreatment of hPMNs with one of two different PKC inhibitors completely abolished the priming effect by PAF and reduced response sizes to those obtained with fMLP alone ( $9.5 \pm 4.8 \%$ of primed response, Figure 7 ). Bisindolylmaleimide (BIM, $10^{-6} \mathrm{M}$ ) reduced superoxide anion production to $12.9 \pm 3.6 \%$ of control response and chelerythrine $\left(\mathrm{CT}, 10^{-5} \mathrm{M}\right.$ ) inhibited $\mathrm{O}_{2}$ production to $5.9 \pm 3.1 \%$ of control response. No significant difference ( $\mathrm{P}>0.05$, one way ANOVA, Dunnett correction) between $\mathrm{MLP}$-induced responses and those elicited after priming/activation in the presence of BIM or CT was obtained. This finding suggests that, in contrast to the activation process, ${ }^{14}$ priming through PAF is critically dependent on PKC. 


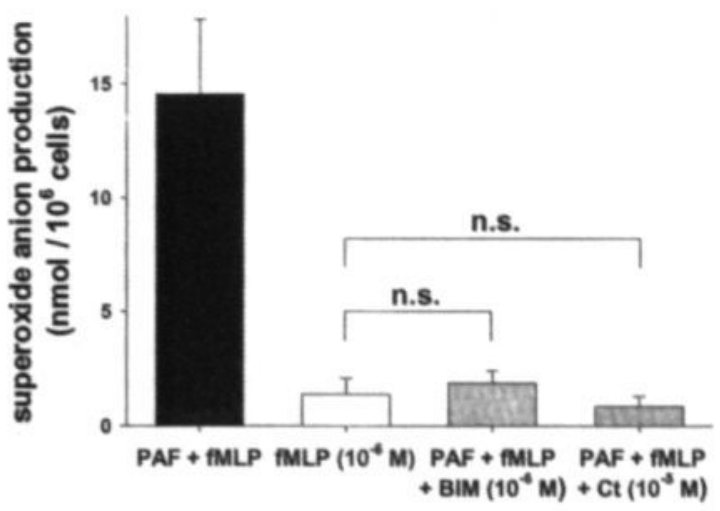

Figure 7: PAF $\left(10^{6} \mathrm{M}\right)$-primed/fMLP $\left(10^{6} \mathrm{M}\right)$-activated $\mathrm{O}_{2}$ production by hPMNs (black bar) is inhibited after $60 \mathrm{~min}$ pretreatment with bisindolylmaleimide $\left(B I M, 10^{6} \mathrm{M}\right.$, grey bar) or chelerythrine $\left(\mathrm{CC}, 10^{5} \mathrm{M}\right.$, grey bar) to a level not significantly different from that obtained with fMLP $\left(10^{6} \mathrm{M}\right)$ activation alone (white bar).

\section{PMA both activates and primes}

If priming is dependent on PKC, one should be able to induce priming by direct PKC activation. At the same time, PMA is able to induce superoxide anion production (although it has been shown that PKC is not required for activation of hPMNs ${ }^{14}$ ). Therefore, it seems likely that PMA treatment of hPMNs would both prime and activate the cells. To determine the maximal priming/activating dose of PMA we performed a concentration-response study. After adding PMA to hPMNs, superoxide anion production was measured 40 minutes (since pilot experiments determined this as sufficient time for $\mathrm{O}_{2}{ }^{-}$production to plateau after PMA stimulation, data not shown). As indicated in Fig 8, maximal superoxide anion production was induced by $100 \mathrm{nM}$ PMA $\left(23.6 \pm 4.5 \mathrm{nmol} / 10^{6}\right.$ cells).

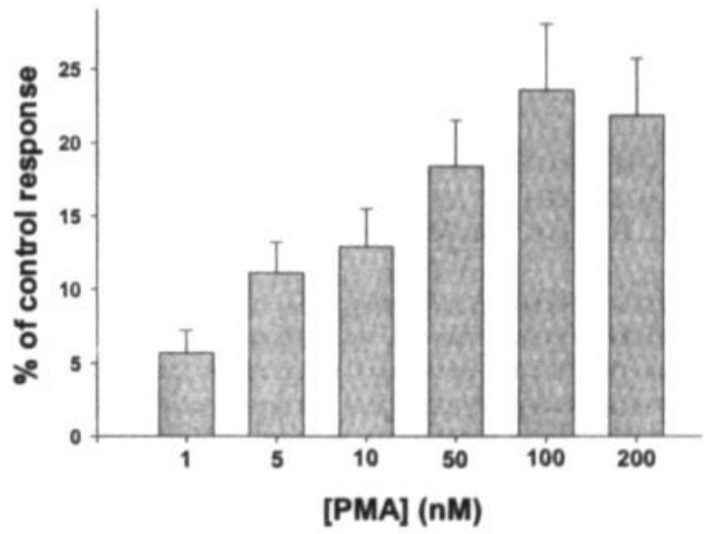

Figure 8: Concentration-response relationship for superoxide anion production induced by various concentrations of PMA (1-200 nM), measured 40 minutes after adding PMA to hPMNs. 
Using this PMA concentration to provide maximal stimulation, we next tested our hypothesis that PMA treatment of hPMNs would both prime and activate the cells. We determined first the time course of $\mathrm{O}_{2}{ }^{-}$production after stimulation with PMA $(100 \mathrm{nM})$, and compared it with that obtained after PAF/fMLP treatment. As shown in figure 9, PMA induced a slower respiratory burst than did PAF/PMLP. 30 min after PMA administration superoxide anion production reached the maximal level. At this time point measured $\mathrm{O}_{2}{ }^{*}$ production was $174.6 \pm 16.6 \%$ of the response (13.6 $\pm 1.6 \mathrm{nmol} / 10^{6}$ cells) obtained after stimulation with fully priming and activating concentrations of PAF and AMLP. The slow time course suggests that priming may be taking place at the same time as activation.

If PMA indeed acts as a full priming agent, PAF priming of PMA responses might accelerate the onset of priming, but should not increase the maximal response. Therefore, we tested the ability of PAF $\left(10^{-6} \mathrm{M}\right)$ to prime PMA $(100 \mathrm{nM})$-induced $\mathrm{O}_{2}^{-}$production. Although PAF accelerated the time course of superoxide production by PMA (cf Fig 4), after 30 min no significant difference between $\mathrm{O}_{2}{ }^{*}$ production induced by PMA with or without PAF-pretreatment was present (figure 9). These finding suggests that after 30 min superoxide anion production by PMA results from a combined priming/activating effect, most likely due to a dual action of PKC on the priming and activation pathways.

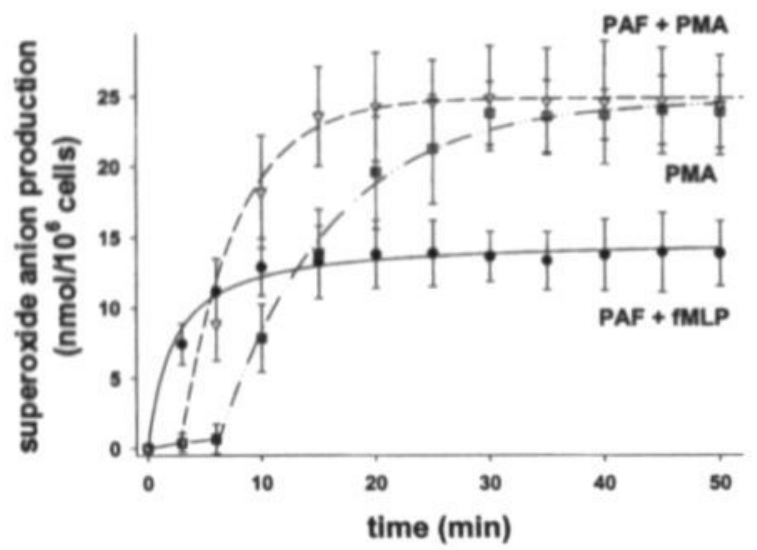

Figure 9: Time-course of superoxide anion production induced by either $f M L P\left(10^{-6} M\right)$ activation and prior incubation with PAF $\left(10^{6} \mathrm{M}\right)$ for $5 \mathrm{~min}, \mathrm{PMA}(100 \mathrm{nM})$ alone or PMA (100 nM) and 5 min preincubation with PAF $\left(10^{-6} \mathrm{M}\right)$.

\section{Lidocaine and tetracaine inhibit hPMN priming}

After mapping the PAF priming pathway, we studied the effects of LA on priming. We confirmed the findings from our previous study, (Durieux ME, unpublished observation) showing that LA (lidocaine, tetracaine and the permanent charged lidocaine analog QX314) do not affect the activation process of hPMNs (data not shown). We then investigated the effect of the most commonly used amide LA, lidocaine (Fig 10A), and the ester LA tetracaine (Figure 10B) on hPMN priming by PAF. hPMNs were incubated for $60 \mathrm{~min}$ in various concentrations $\left(10^{-4}-10^{-6} \mathrm{M}\right)$ of the LA, prior to priming with PAF. Both LA inhibited superoxide anion production, in a modestly concentration-dependent manner over the range tested. Even at an LA concentration $\left(10^{-6} \mathrm{M}\right)$ commonly attained in plasma after epidural or intravenous administration ${ }^{18-21}, \mathrm{O}_{2}$ - production was attenuated significantly (to $73.5 \pm 6.7 \%$ of control response for lidocaine and $68 \pm 12.1 \%$ of control response for tetracaine, $\mathrm{p}<0.05$, one way repeated measurement ANOVA, Dunnett correction), as compared with the PAF $\left(10^{-6} \mathrm{M}\right)$-primed/fMLP $\left(10^{-6} \mathrm{M}\right)$-activated control response $(11.8 \pm 2.5$ 
$\mathrm{nmol} / 10^{6}$ cells for lidocaine and $14.2 \pm 7.3 \mathrm{nmol} / 10^{6}$ cells for tetracaine experiments). At the highest concentration tested $\left(10^{-4} \mathrm{M}\right)$, tetracaine $\left(42.8 \pm 13 \%\right.$ of control response) was found to inhibit $\mathrm{O}_{2}{ }^{*}$ production more effectively $(\mathrm{p}=0.001$, unpaired $\mathrm{t}$-test $)$ than lidocaine $(62.8 \pm 5.1 \%$ of control response).
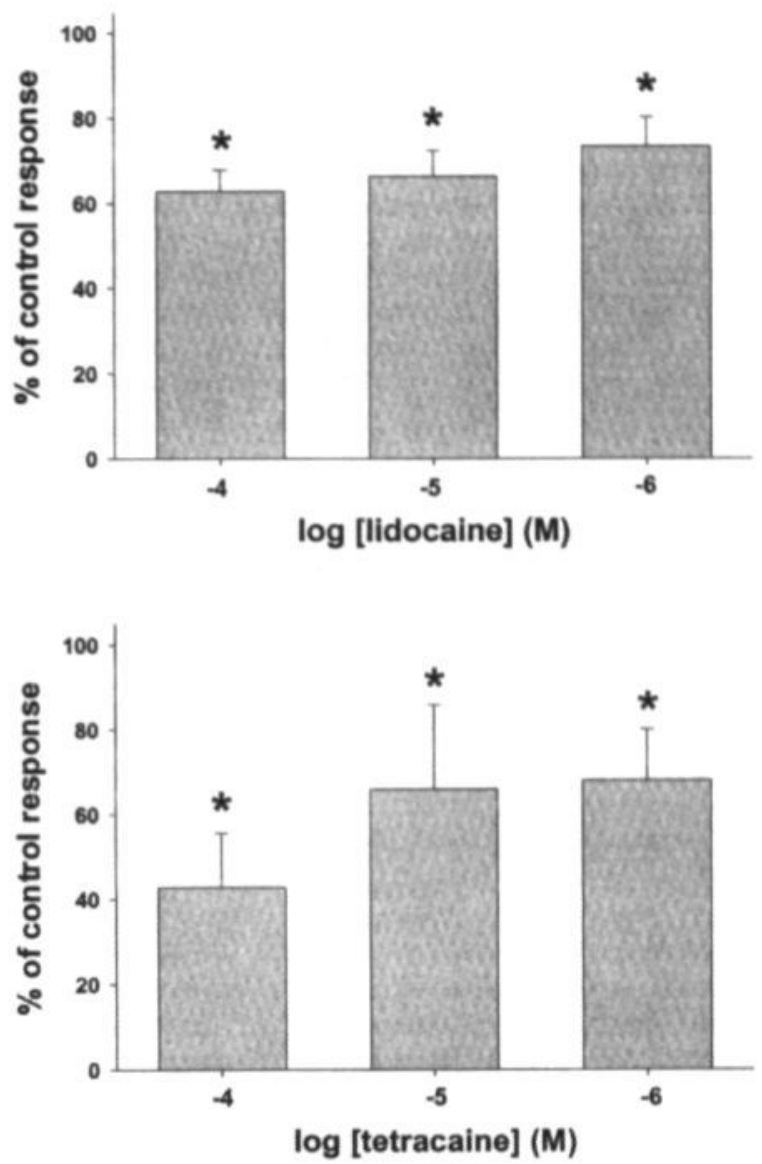

Figure 10: Concentration-dependent inhibition of superoxide anion production in hPMNs after 60 min incubation in lidocaine $(A)$ or tetracaine $(B)\left(10^{4}-10^{6} M\right)$ prior to priming with $P A F\left(10^{6} M\right)$ and activation with $F M L P\left(10^{-6} \mathrm{M}\right)$. 


\section{Ropivacaine and bupivacaine are less potent inhibitors of hPMN priming}

Since the amide LA ropivacaine has received significant interest as an inflammatory modulator, and has undergone clinical studies of its use in inflammatory bowel disease ${ }^{22}$, we determined its action on PAF $\left(10^{-6} \mathrm{M}\right)$-primed/fMLP $\left(10^{-6} \mathrm{M}\right)$-activated hPMNs. Both stereoisomers of ropivacaine $\left(10^{-4} \mathrm{M}\right)$ inhibited PAF priming, with a modest but significant $(\mathrm{p}<0.05$, one way repeated measurement ANOVA, Student Newman Keuls correction) difference between S(-)ropivacaine (78.8 $3.6 \%$ of control response) and the $\mathrm{R}(+)$-isomer $(67 \pm 5.1 \%$ of control response, Figure 11).

In addition, we tested the inhibitory potency of bupivacaine, which is structurally similar to ropivacaine, but is much more lipophilic. At a concentration of $10^{-4} \mathrm{M}$, bupivacaine showed a weak ( $81.4 \pm 4.3 \%$ of control response), but nonetheless significant $(p<0.05$, paired $t$-test) inhibition of superoxide anion production, compared with PAF $\left(10^{-6} \mathrm{M}\right)$-primed/fMLP $\left(10^{-6} \mathrm{M}\right)$-activated control cells (13.2 $\pm 4.2 \mathrm{nmol} / 10^{6}$ cells, Figure 11). Ropivacaine and bupivacaine were similar in their inhibitory effect $(\mathrm{p}=0.06,(\mathrm{n}=18), \mathrm{t}$-test). Both compounds showed a lower inhibitory potency on priming than did lidocaine or tetracaine, and their effect appears not to depend on lipophilicity.

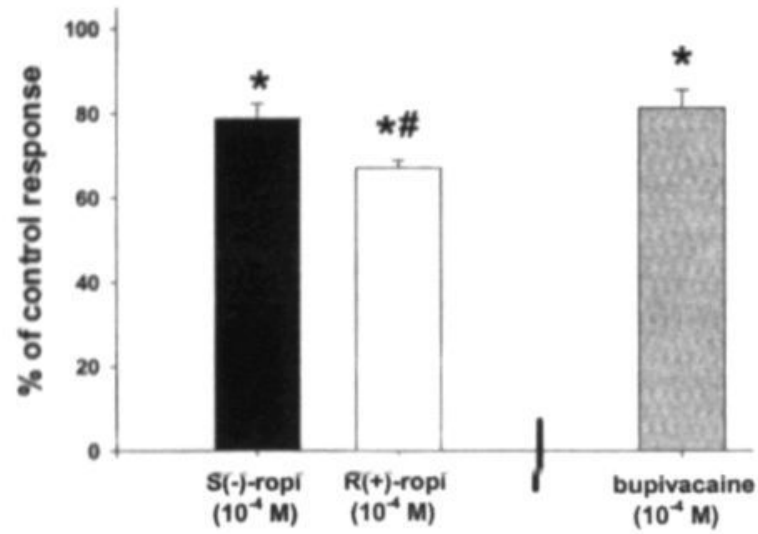

Figure 11: Effects of 60 min preincubation with ropivacaine isomers $\left(10^{-4} \mathrm{M}\right)$ or bupivacaine $\left(10^{-4}\right.$ $M)$ on PAF $\left(10^{6} M\right)$-primed/fMLP $\left(10^{6} M\right)$-activated hPMNs. ": significant difference between ropivacaine stereoisomers. ": significant difference from PAF-primed/fMLP-activatred control.

\section{Priming of hPMNs by PAF or LPA is inhibited more profoundly by uncharged LA}

To obtain additional information about the site of LA action on PAF-induced priming, we tested the effects of the permanently charged and therefore membrane impermeant lidocaine analog QX314, and the permanently uncharged, membrane permeant LA benzocaine. We compared both with lidocaine's effect on PAF $\left(10^{-6} \mathrm{M}\right)$-primed/fMLP $\left(10^{-6} \mathrm{M}\right)$-activated hPMNs (Figure 12). Benzocaine $\left(10^{-4} \mathrm{M}\right)$ inhibited priming profoundly (to $33.2 \pm 4.5 \%$ of control response) whereas QX314 $\left(10^{-4} \mathrm{M}\right)$ had a modest effect $(86.4 \pm 6.7 \%$ of control response). Lidocaine, as a partially charged compound, was intermediate in effect and inhibited to $59.3 \pm 5.9 \%$ of control response.

For comparative purposes, we also determined the effects of QX 314 and benzocaine on LPA $\left(10^{-4} \mathrm{M}\right.$ ) priming in neutrophils (Fig 12). The findings were very similar to those obtained using PAF. Benzocaine $\left(10^{-4} \mathrm{M}\right)$ inhibited primed responses to $39.6 \pm 4.8 \%$ of control response, whereas QX314 was without effect ( $101 \pm 13.6 \%$ of control response). The latter finding is in agreement with our previous observation showing that LPA signaling in Xenopus oocytes is not affected by extracellularly applied QX314. ${ }^{23}$ Lidocaine inhibited to $69 \pm 5.6 \%$ of control.

These findings suggest that LPA and PAF signaling in hPMNs are affected similarly by local anesthetics. There appears to be, at best, a limited role for extracellular block by charged 
compounds. The major site of action therefore is either an uncharged extracellular domain or an intracellular site, which may be charged or uncharged.

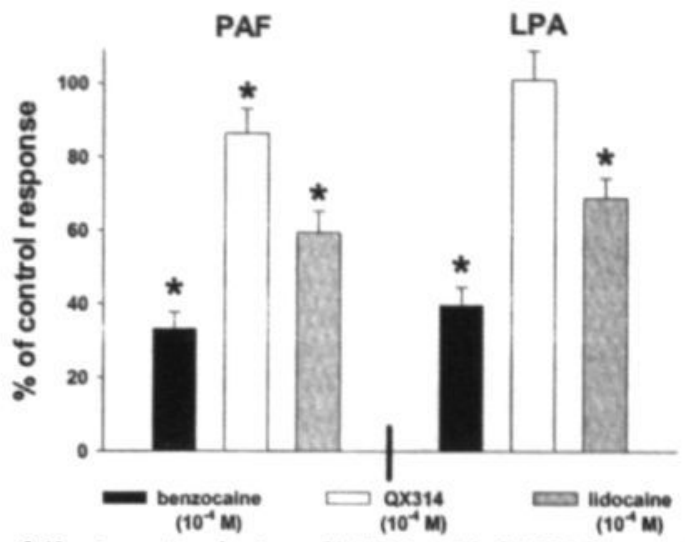

Figure 12: Effects of 60 min preincubation of $h P M N s$ with QX314, benzocaine, or lidocaine (all at $\left.10^{4} \mathrm{M}\right)$ on LPA $\left(10^{-4} \mathrm{M}\right)$ or PAF $\left(10^{6} \mathrm{M}\right)$-primed and fMLP $\left(10^{-6} \mathrm{M}\right)$-activated hPMNs. * indicates significant difference compared to with PAF-primed and fMLP-activated control response; black dividers on the $x$-axis indicates different experiments with different control responses.

Lidocaine's site of action is located upstream of PKC, and does not involve $G_{v_{0}}$

To determine the site of action of lidocaine $\left(10^{-4} \mathrm{M}\right)$ in more detail, we studied its effect on hPMNs primed and activated by PMA. We studied the effects $30 \mathrm{~min}$ after PMA application, at which time both priming and activation are complete (cf. Fig 8). As shown in figure 13, lidocaine was without effect when cell were stimulated with PMA $100 \mathrm{nM}$ (lidocaine $21.7 \pm 0.5 \mathrm{nmol} / 10^{6}$ cells, control $22 \pm 0.8 \mathrm{nmol} / 10^{6}$ cells, $(\mathrm{n}=17), \mathrm{p}=0.2, \mathrm{t}$-test) or PMA $10 \mathrm{nM}$ (lidocaine $13.1 \pm 0.4$ $\mathrm{nmol} / 10^{6}$ cells, control $13.3 \pm 0.4 \mathrm{nmol} / 10^{6}$ cells, $(\mathrm{n}=20), \mathrm{p}=0.122$, $\mathrm{t}$-test). Thus, lidocaine did not affect PMA-induced $\mathrm{O}_{2}{ }^{-}$production, suggesting that neither in activation nor priming pathway is its target site located downstream of PKC.

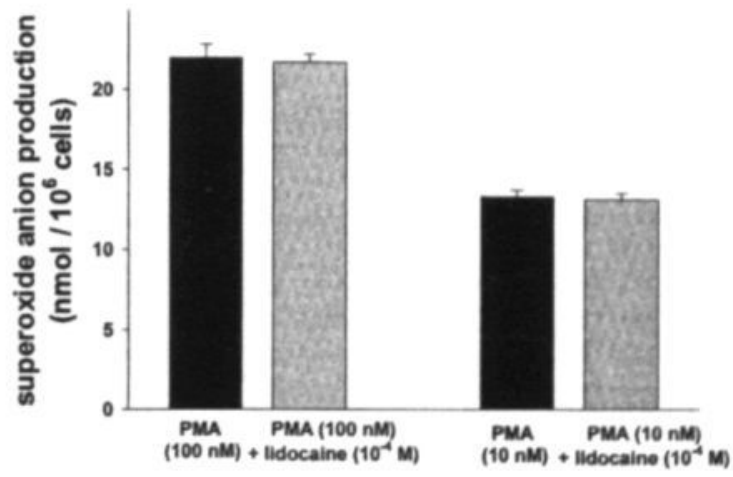

Figure 13: Lidocaine $\left(10^{-4} \mathrm{M}\right)$, when incubated for $60 \mathrm{~min}$ prior to $\mathrm{hPMN}$ activation with PMA (100 $n M$ or $10 \mathrm{nM}$ ) does not affect superoxide anion production (after $30 \mathrm{~min}$ ) significantly. 
Finally, we determined if inhibition of $\mathrm{G} / \mathrm{G}_{0}$ may play a role in the effects of lidocaine. We preincubated hPMNs in PTX $(0.3 \mu \mathrm{g} / \mathrm{ml})$ and lidocaine $\left(10^{-4} \mathrm{M}\right)$. As demonstrated in figure 14 , superoxide anion production was reduced to $31.4 \pm 7.9 \%$ of control response. Lidocaine still exerted an approximately $40 \%$ inhibition of PAF $\left(10^{-6} \mathrm{M}\right)$-primed/fMLP $\left(10^{-6} \mathrm{M}\right)$-activated $\mathrm{hPMNs}$, in addition to the $31 \%$ inhibition by PTX. This is similar to its effect in the absence of PTX (cf. Fig 10A). Taking this finding together with the previously described lack of lidocaine inhibition on fMLP-induced activation, the main target site for lidocaine is likely to be different from $\mathrm{G}_{\mathbf{v}}$.

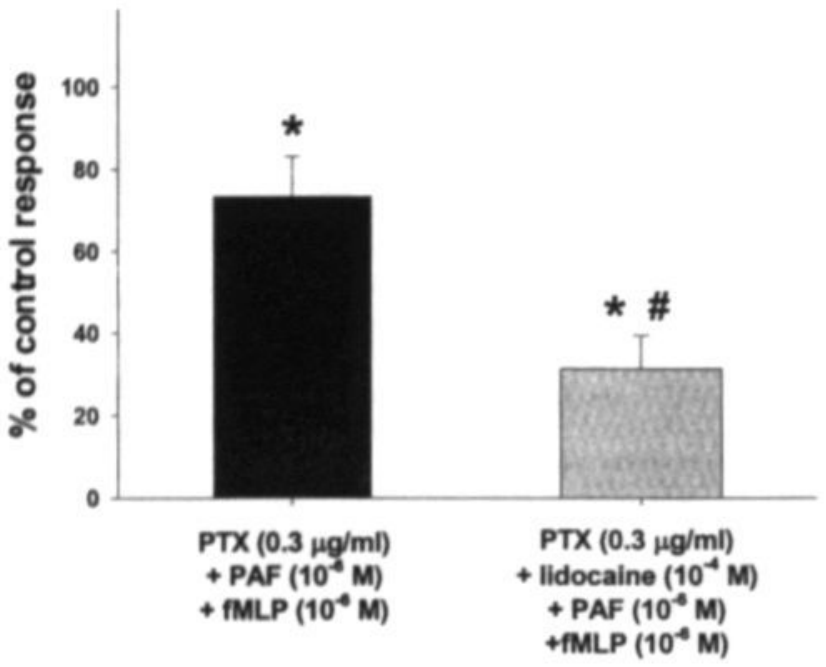

Figure 14: $90 \mathrm{~min}$ preincubation of $\mathrm{hPMNs}$ with PTX $(0.3 \mathrm{\mu g} / \mathrm{ml})$ inhibits superaxide anion production only partially, whereas combined pretreatment with lidocaine $\left(1 \sigma^{4} M\right)$ and PTX $(0.3$ $\mu \mathrm{gg} / \mathrm{ml}$, grey bar) reduces $\mathrm{O}_{2}{ }^{-}$-production to $31.4 \pm 7.9 \%$ of control response.

\section{DISCUSSION}

In the present study we have shown that PAF primes neutrophils through a pathway dependent on PTX-insensitive G proteins, PLC and PKC. PKC activation is both necessary and sufficient for this process. In addition, we show that clinically relevant concentrations of local anesthetics selectively inhibit priming, but not fMLP-induced activation. Ester-LA exerted the most profound inhibitory effect, whereas inhibitory potency of amide-LA increased with increased uncharged fraction. The main target site for LA in the PAF priming pathway is located upstream of PKC.

The concentrations at which these effects take place are much less than those required to block $\mathrm{Na}$ channels. Lidocaine showed significant inhibitory effects on priming even at concentrations commonly obtained in plasma of patients after epidural or intravenous administration (approximately 0.5 to $5 \mu \mathrm{g} / \mathrm{ml}$, corresponding to 2 to $20 \mu \mathrm{M}$ ) $;^{18}$ for example, IV administration of lidocaine at $2-4 \mathrm{mg} / \mathrm{min}$ leads to plasma concentrations of $1-3 \mu \mathrm{g} / \mathrm{ml}(4-12 \mu \mathrm{M})$ after $150 \mathrm{~min}{ }^{19} \mathrm{~A} 2$ $\mathrm{mg} / \mathrm{kg} \mathrm{IV}$ bolus of lidocaine results in peak plasma levels of $1.5-1.9 \mu \mathrm{g} / \mathrm{ml}(6-8 \mu \mathrm{M})$ after $15 \mathrm{~min}^{20}$ Similar plasma concentrations are obtained after epidural administration. ${ }^{21} \mathrm{LA}$ effects on priming of hPMNs might be one explanation for the discrepancy between concentrations required to achieve anti-inflammatory effects of LA in vitro and in vivo. Virtually all in vitro studies of LA effects on hPMNs investigated activation. To our knowledge LA effects on priming have not been reported before, although this state of hPMNs should be more representative for in vivo inflammatory 
processes. Primed hPMNs have been identified in the peripheral blood of patients after blunt trauma, ${ }^{24} \mathrm{ARDS}^{25}$ and bacterial or fungal infections. ${ }^{26} \mathrm{hPMN}$ priming has been shown to be critical for the induction of endothelial injury ${ }^{29}$ and lung damage ${ }^{28}$ in vivo. Since LA, in reasonable concentrations, did not block unprimed neutrophil metabolic activity, this might explain why antiinflammatory LA concentrations required to block activation in vitro are generally much greater than those required to block inflammatory responses in vivo. ${ }^{1,2}$ Another factor may be that duration of LA incubation ( $60 \mathrm{~min}$ ) is longer in our study than in most other studies. We feel that this mimics the clinical setting more closely.

We used different LA in order to determine which chemical properties might enhance or reduce their inhibitory potency. Since tetracaine and benzocaine (ester-LA) showed inhibition comparable to or even more profound than that obtained with amide-LA, the inhibitory effect appears independent of the linkage type within the LA molecule, consistent with our findings on LPAprimed hPMNs (Durieux ME, unpublished observation). For the amide-LA lidocaine (ropivacaine, bupivacaine and QX314) we observed an increase in inhibitory potency with increased uncharged fraction. Lidocaine, a representative mostly uncharged amide-LA at physiologic pH, exerted the most profound inhibition within the group of amide compounds, whereas bupivacaine (highly lipophilic and highly charged at pH 7.4) and QX314 (permanently charged) showed the least inhibitory effect. Obviously, these findings may reflect a need for the compound to traverse the cell membrane to reach its site of action. Ropivacaine, which is structurally quite similar to bupivacaine, but similar in lipophilicity to lidocaine, showed no significant difference in inhibitory potency as compared with bupivacaine, suggesting that the inhibitory effect is independent of lipophilicity of the compound.

The site of local anesthetic action is of obvious interest. Interaction with $\mathrm{Na}$ channels is unlikely, as these are not present in $\mathrm{hPMNS},{ }^{29}$ and concentrations used are less than those required to block $\mathrm{Na}$ channels. Lidocaine failed to inhibit PMA-induced superoxide anion production, indicating that lidocaine's major site of action has to be located upstream of PKC in the PAF priming pathway. LA effects on the activation process were excluded in this and also in our previous study (Durieux ME, unpublished observation). The site of action is therefore likely to be located between receptor and PKC. In Xenopus oocytes we have shown previously that local anesthetics do not interfere with the PLC-inositol-trisphosphate $\left(\mathrm{IP}_{3}\right)$-Ca pathway. ${ }^{23}$ If these findings can be extrapolated to hPMNs, the PAF receptor or $G$ protein(s) itself seem to be the most likely target. QX314 was virtually without effect when applied extracellularly, excluding a charged extracellular site as the main target. However, an uncharged extracellular site can not be ruled out. In oocytes, we have shown intracellular QX314 to inhibit $\mathrm{G}_{\mathrm{q}}$ proteins selectively. ${ }^{30}$ Since we determined that PAF priming is mediated through a PTX-insensitive $\mathrm{G}$ protein, we hypothesize that $\mathrm{G}_{\mathrm{q}}$ is a likely LA target in inhibiting PAF priming. This is in agreement with the finding that lidocaine still exerted its inhibitory action in the presence of PTX, and with previous findings from our group showing that neither $\mathrm{G}_{\mathrm{i}}$ (Durieux ME, unpublished observation) nor $\mathrm{G}_{0}{ }^{30}$ signaling is inhibited by relevant LA concentrations. Although $\mathrm{G}_{\mathrm{s}}$-mediated signaling is PTX insensitive, it is unlikely to be involved because increases in cAMP levels, resulting from $\mathrm{G}_{3}$ activation, inhibit neutrophil functions. ${ }^{31-33}$

PKC activation with PMA is able to both prime and activate hPMNs. PMA concentrationdependently induces respiratory burst. We determined that PMA-induced superoxide anion production could be primed effectively with PAF after $15 \mathrm{~min}$. However, maximal PMA-induced $\mathrm{O}_{2}{ }^{-}$production obtained after $30 \mathrm{~min}$ is most likely due to a combined priming and activation effect, as PAF is no longer able to increase $\mathrm{O}_{2}{ }^{-}$production further. Lack of priming effect on PMAstimulated superoxide anion production by PAF after 30 min can not be attributed to loss of PAF action, because its priming effect on fMLP-induced $\mathrm{O}_{2}{ }^{\circ}$ production did not change over a 50 min time course.

Using different PKC inhibitors (including the broad range PKC-inhibitor BIM) we demonstrated that PAF-priming is inhibited completely by $\mathrm{PKC}$ blockade, indicating that the priming process is critically dependent on PKC. This is in contrast to activation by fMLP: Pongracz et al. showed that several PKC-inhibitors were not able to affect fMLP-induced superoxide anion production. ${ }^{14}$ 
PTX partially inhibited superoxide anion production in PAF-primed, AMLP-activated hPMNs, but not in PAF-primed, PMA-activated cells. hPMNs were incubated in PTX for 90 min prior to their activation, as reported by Christiansen et al.. ${ }^{15}$ We used a PTX concentration of $0.3 \mu \mathrm{g} / \mathrm{ml}$ when studying $\mathrm{MLP}$ activation, as this concentration has been shown to inhibit MLP-induced superoxide anion production by approximately $50 \% .{ }^{15}$ Higher concentrations would have abolished AMLP activation completely, and were therefore used only when studying PAF-primed/PMAactivated cells. Despite the greater concentration, PTX was without effect on PAF primed, PMAactivated hPMNs. The most likely explanation is that PTX partially inhibited AMLP-induced activation, but was without effect on priming. In fact, several authors reported that fMLP-induced signaling in $\mathrm{hPMNs}$ is mediated by PTX sensitive G proteins. ${ }^{34-36}$ Our hypothesis of the signaling pathways involved in superoxide anion production of PAF-primed and AMLP-activated hPMNs is illustrated in figure 15.

In short, our data provide new insights into the mechanism of hPMN priming, and in addition suggest a mechanism by which LA may exert some of their anti-inflammatory actions. 


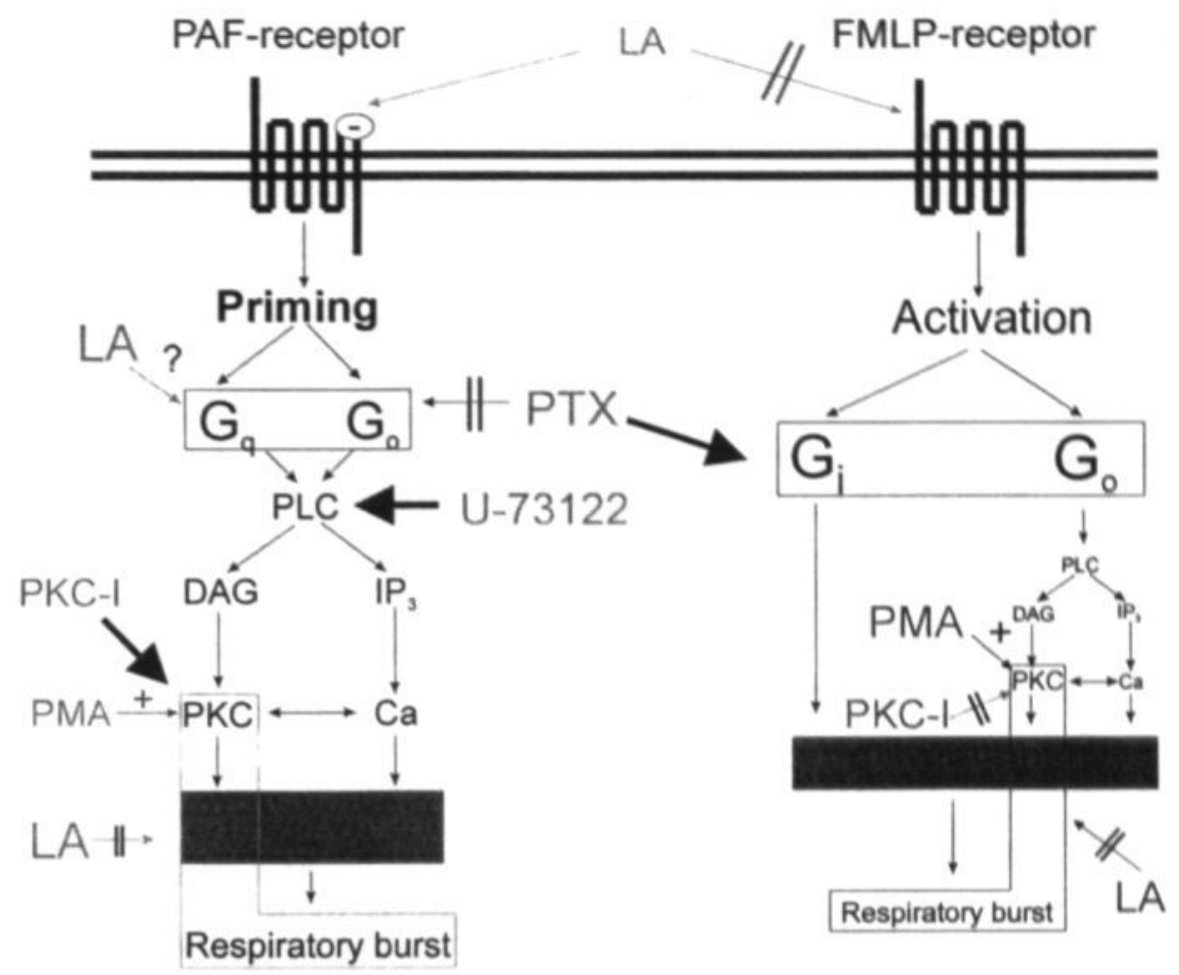

Figure 15: Schematic overview of our hypothesis of signaling pathways involved in PAF priming and $M M L P$ activation of $h P M N$ respiratory burst (superoxide anion production). Bold arrows indicate inhibition by the specified compound; crossed arrows indicate no effect of the compound. Whereas $f M L P$ activation is not affected by $L A$, the PAF receptor may be partially inhibited at a charged extracellular domain. Stimulation of the fMLP receptor leads to activation of a $G$ protein dependent pathway. Since PTX is able to completely abolish fMLP-induced activation, coupling to either $G_{i}$ or $G_{o}$ is most likely. Several PKC-inhibitors failed to inhibit superoxide anion production after $f M L P$ stimulation, suggesting that PKC-independent signaling pathways are able to mediate full $f M L P$-induced $\mathrm{O}_{2}$-production. However, a secondary, PLC-dependent pathway may exist. PAFinduced priming is mediated through a PLC-PKC dependent pathway, since PKC-inhibitors and the $P L C$-inhibitor U-73122 completely abrogate the priming effect by PAF. PTX was not able to affect

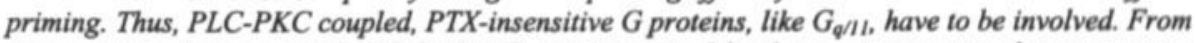
our experiments it seems to be likely that $G_{0}$ is not required for the priming process, but we can not rule out that signaling through a $G_{o}$-coupled pathway also induces priming (similar to PKC involvement in $f L M P$-induced activation). Although $G$, mediated signaling is PTX-insensitive, it is unlikely to be involved because increases in CAMP levels inhibit many hPMN functions. The LA site of action has to be located upstream of $P K C$, because $P M A$-induced $\mathrm{O}_{2}{ }^{-}$-production was not affected by lidocaine. 


\section{References}

1. Hollmann MW, Durieux ME: Local anesthetics and the inflammatory response: a new therapeutic indication? Anesthesiology 2000; 93:858-75

2. Sasagawa S: Inhibitory effects of local anesthetics on migration, extracellular release of lysosomal enzyme, and superoxide anion production in human polymorphonuclear leukocytes. Immunopharmacol Immunotoxicol 1991; 13:607-22

3. Fischer LG, Conrad B, Krumm B, Hollmann MW, Durieux ME: Time-dependent attenuation by lidocaine of respiratory burst in human neutrophils primed with lysophosphatic acid. Anesth Analg 2000; 90:S405

4. Fischer LG, Krumm B, Conrad B, Hollmann MW, Durieux ME: Lysophosphatidic acid has a priming but no activating effect in human neutrophils. Anesth Analg 2000; 90:S406

5. Condliffe AM, Kitchen E, Chilvers ER: Neutrophil priming: pathophysiological consequences and underlying mechanisms. Clin Sci 1998; 94:461-71

6. Nakos G, Pneumatikos J, Tsangaris I, Tellis C, Lekka M: Proteins and phospholipids in BAL from patients with hydrostatic pulmonary edema. Am J Respir Crit Care Med 1997; 155:945-51

7. Rabinovici R, Bugelski PJ, Esser KM, Hillegass LM, Vernick J, Feuerstein G: ARDS-like lung injury produced by endotoxin in platelet-activating factor-primed rats. J Appl Physiol 1993; 74:1791-802

8. Rabinovici R, Yeh CG, Hillegass LM, Griswold DE, DiMartino MJ, Vernick J, Fong KL, Feuerstein G: Role of complement in endotoxin/platelet-activating factor-induced lung injury. J Immunol 1992; 149:1744-50

9. Fink A, Geva D, Zung A, Konichezky S, Eliraz A, Bentwich Z: Adult respiratory distress syndrome: roles of leukotriene C4 and platelet activating factor. Crit Care Med 1990; 18:905-10

10. Goldsmith JA, Kavanagh BP, Pearl RG: Plasma potentiates the priming effects of endotoxin on platelet activating factor-induced pulmonary hypertension in the rabbit lung. Anesth Analg 1996; 83:242-6

11. Matsumoto $\mathrm{K}$, Taki F, Kondoh $\mathrm{Y}$, Taniguchi H, Takagi K: Platelet-activating factor in bronchoalveolar lavage fluid of patients with adult respiratory distress syndrome. Clin Exp Pharmacol Physiol 1992; 19:509-15

12. Christman BW, Lefferts PL, Blair IA, Snapper JR: Effect of platelet-activating factor receptor antagonism on endotoxin-induced lung dysfunction in awake sheep. Am Rev Respir Dis 1990; 142:1272-8

13. Zehr KJ, Poston RS, Lee PC, Uthoff K, Kumar P, Cho PW, Gillinov AM, Redmond JM, Winkelstein JA, Herskowitz A: Platelet activating factor inhibition reduces lung injury after cardiopulmonary bypass. Ann Thorac Surg 1995; 59:328-35 
14. Pongracz J, Lord JM: Superoxide production in human neutrophils: evidence for signal redundancy and the involvement of more than one PKC isoenzyme class. Biochem Biophys Res Commun 1998; 247:624-9

15. Christiansen NO: Pertussis toxin inhibits the FMLP-induced membrane association of protein kinase C in human neutrophils. J Leukoc Biol 1990; 47:60-3

16. Koenderman L, Yazdanbakhsh M, Roos D, Verhoeven AJ: Dual mechanisms in priming of the chemoattractant-induced respiratory burst in human granulocytes. A Ca2+dependent and a Ca2+-independent route. J Immunol 1989; 142:623-8

17. Simchowitz L, Spilberg I: Generation of superoxide radicals by human peripheral neutrophils activated by chemotactic factor. Evidence for the role of calcium. J Lab Clin Med $1979 ; 93: 583-93$

18. Collinsworth KA, Kalman SM, Harrison DC: The clinical pharmacology of lidocaine as an antiarrhythymic drug. Circulation 1974; 50:1217-30

19. Wiklund L: Human hepatic blood flow and its relation to systemic circulation during intravenous infusion of lidocaine. Acta Anaesthesiol Scand 1977; 21:148-60

20. Tsai PS, Buerkle H, Huang LT, Lee TC, Yang LC, Lee JH: Lidocaine concentrations in plasma and cerebrospinal fluid after systemic bolus administration in humans. Anesth Analg 1998; 87:601-4

21. Mayumi T, Dohi S, Takahashi T: Plasma concentrations of lidocaine associated with cervical, thoracic, and lumbar epidural anesthesia. Anesth Analg 1983; 62:578-80

22. Arlander E, Ost A, Stahlberg D, Lofberg R: Ropivacaine gel in active distal ulcerative colitis and proctitis - a pharmacokinetic and exploratory clinical study. Aliment Pharmacol Ther 1996; 10:73-81

23. Sullivan LM, Hoenemann CW, Arledge JAM, Durieux ME: Synergistic inhibition of lysophosphatidic acid signaling by charged and uncharged local anesthetics. Anesth Analg 1999; 88:1117-24

24. Krause PJ, Maderazo EG, Bannon P, Kosciol K, Malech HM: Neutrophil heterogeneity in patients with blunt trauma. J Lab Clin Med 1988; 112:208-15

25. Chollet-Martin S, Montravers P, Gibert C, Elbim C, Desmonts JM, Fagon JY, GougerotPocidalo MA: Subpopulation of hyperresponsive polymorphonuclear neutrophils in patients with adult respiratory distress syndrome. Role of cytokine production. Am Rev Respir Dis 1992; 146:990-6

26. Bass DA, Olbrantz P, Szejda P, Seeds MC, McCall CE: Subpopulations of neutrophils with increased oxidative product formation in blood of patients with infection. J Immunol $1986 ; 136: 860-6$

27. Smedly LA, Tonnesen MG, Sandhaus RA, Haslett C, Guthrie LA, Johnston RBJ, Henson PM, Worthen GS: Neutrophil-mediated injury to endothelial cells. Enhancement by endotoxin and essential role of neutrophil elastase. J Clin Invest. 1986; 77:1233-43 
28. Worthen GS, Haslett C, Rees AJ, Gumbay RS, Henson JE, Henson PM: Neutrophil-mediated pulmonary vascular injury. Synergistic effect of trace amounts of lipopolysaccharide and neutrophil stimuli on vascular permeability and neutrophil sequestration in the lung. Am Rev Respir Dis 1987; 136:19-28

29. Krause $\mathrm{KH}$, Demaurex N, Jaconi M, Lew DP: Ion channels and receptor-mediated Ca2+ influx in neutrophil granulocytes. Blood Cells 1993; 19:165-73

30. Hollmann MW, Wieczorek KS, Berger A, Durieux ME: Local anesthetic inhibition of lysophosphatidate signaling is mediated by interference with $\mathrm{G}$-alpha-q protein function. Mol Pharmacol 2000; in press

31. Richter J: Effect of adenosine analogues and cAMP-raising agents on TNF-, GM-CSF-, and chemotactic peptide-induced degranulation in single adherent neutrophils. J Leukoc Biol 1992; 51:270-5

32. Agwu DE, McCall CE, McPhail LC: Regulation of phospholipase D-induced hydrolysis of choline-containing phosphoglycerides by cyclic AMP in human neutrophils. J Immunol 1991; 146:3895-903

33. Tyagi SR, Olson SC, Burnham DN, Lambeth JD: Cyclic AMP-elevating agents block chemoattractant activation of diradylglycerol generation by inhibiting phospholipase D activation. J Biol Chem 1991; 266:3498-504

34. Rabet L, Coffer PJ, Wolthuis RM, Zwartkruis F, Koenderman L, Bos JL: Differential fMetLeu-Phe- and platelet-activating factor-induced signaling toward Ral activation in primary human neutrophils. J Biol Chem 1999; 274:21847-52

35. Goldsmith P, Gierschik P, Milligan G, Unson CG, Vinitsky R, Malech HL, Spiegel AM: Antibodies directed against synthetic peptides distinguish between GTP-binding proteins in neutrophil and brain. J Biol Chem 1987; 262:14683-8

36. Uhing RJ, Polakis PG, Snyderman R: Isolation of GTP-binding proteins from myeloid HL-60 cells. Identification of two pertussis toxin substrates. J Biol Chem 1987; 262:15575-9 
CHAPTER 9

Epidural anesthesia prevents hypercoagulation in patients undergoing major orthopedic surgery

Markus W. Hollmann

Kathrin S. Wieczorek

Mary Smart

Marcel E. Durieux

Published in: Regional Anesthesia \& Pain Medicine 26: 215-22, 2001 


\section{Epidural anesthesia prevents hypercoagulation in patients undergoing major orthopedic surgery}

\section{ABSTRACT}

Background and Objectives: Epidural anesthesia (EA) is well known to reduce postoperative thromboembolic complications, but mechanisms are poorly understood. In this study, we tested the hypothesis that local anesthetics (LA) prevent postoperative hypercoagulability without affecting physiologic aggregation and coagulation processes.

Methods: Clot signature analysis (CSA) was used to assess platelet and clotting function. Venous blood samples were collected pre- and postoperatively from 41 patients undergoing major orthopedic surgery. The effect of surgery on three CSA parameters (platelet-mediated hemostasis time (PHT), clotting time (CT) and collagen-induced thrombus formation (CITF)) was determined in patients receiving EA $(n=20)$ and those receiving general anesthesia $(G A)(n=21)$.

Results: In the GA group, orthopedic surgery induced a hypercoagulable state: PHT was reduced by $39 \pm 8.6 \%(p<0.001)$, CT by $21 \pm 3.3 \%(p<0.001)$, CITF by $10.3 \pm 5.9 \%(p=0.06)$ compared with respective baseline values. In the EA group, by contrast, no parameter was altered significantly, but PHT showed a tendency towards prolongation by $33.2 \pm 15.4 \%(p=0.25)$. CT changed by $0 \pm 4.4 \%$ ( $\mathrm{p}=0.89)$, CITF by $3.8 \pm 7 \%(\mathrm{p}=0.78)$.

Conclusions: Use of EA prevents postoperative hypercoagulability without affecting physiologic aggregation and coagulation processes. Also, CSA appears useful in predicting hypercoagulability and detecting platelet dysfunction.

\section{INTRODUCTION}

Numerous studies have shown that epidural anesthesia (EA), as compared with general anesthesia (GA), reduces the incidence of thromboembolic complications after surgical operations associated with a high risk of subsequent postoperative deep venous thrombosis. ${ }^{17}$ However, there is no definitive explanation for this effect. It has been attributed either to improved rheologic conditions associated with the sympathetic blockade resulting from neuraxial anesthesia, or to direct inhibition of the coagulation system or platelet aggregation by local anesthetics (LA). However, to induce inhibition of platelet aggregation and coagulation in vitro required concentrations 10 - to 100 - fold greater than those used clinically ${ }^{4-6}$

LA modulate excessive inflammatory responses without significantly impairing host defense. 7 Therefore, by analogy, it is conceivable that LA abolish hypercoagulability induced by surgery without affecting physiologic aggregation and coagulation processes. This hypothesis would explain why in vitro studies (using non-hypercoagulable blood from healthy volunteers) failed to show significant effects on aggregation of LA at clinically relevant concentrations. ${ }^{6,8,9}$ In direct support of this hypothesis is the finding that the use of LA does not lead to an increase in postoperative bleeding as observed with anticoagulants. ${ }^{10-12}$

The aim of the present investigation was therefore (1) to quantitate postoperative hypercoagulability in patients undergoing major orthopedic surgery (total knee or hip replacement), and (2) to determine whether the use of EA as compared with GA would affect the degree of hypercoagulability after surgery. We used clot signature analysis (CSA, using a Clot Signature Analyzer, Xylum corporation, Scarsdale, NY) to study coagulation in a more physiologic environment than do traditional tests such as thrombelastography and aggregometry. 


\section{MATERIALS AND METHODS}

\section{Patients}

Forty-one patients undergoing elective total hip $(n=23)$ or knee $(n=18)$ replacement were studied. The study protocol was approved by the Institutional Review Board of the University of Virginia, and the patients were fully informed about the nature of the study before providing consent. Exclusion criteria were known abnormalities of coagulation, hemostatis or fibrinolysis, or the use of drugs known to influence platelet function. Patients determined the type of anesthesia with their anesthesiologists (who were not among the authors nor aware of the goals of the study). We studied 21 patients receiving GA and 20 patients receiving EA.

Intraoperatively, all patients were monitored with at least electrocardiogram, non-invasive blood pressure and pulse oximetry. Patients in the EA group were treated with 1-2 mg midazolam, depending on their level of anxiety, and were in the sitting position for placement of the epidural catheter. Skin was prepared and draped in a sterile fashion. 1 to $5 \mathrm{ml}$ of $1 \%$ lidocaine was infiltrated subcutaneously. A $17 \mathrm{G}$ Tuohy needle was used to locate the epidural space using the loss of resistance technique (using $\mathrm{NaCl} 0.9 \%$ with an air bubble). The catheter (Arrow international inc., Reading, PA) was threaded and secured. Each patient was given a test dose of 3 $\mathrm{ml} \mathrm{1.5 \%} \mathrm{lidocaine} \mathrm{with} \mathrm{1:200,000} \mathrm{epinephrine,} \mathrm{and} \mathrm{observed} \mathrm{for} \mathrm{signs} \mathrm{of} \mathrm{subarachnoid} \mathrm{and/or}$ intravenous injection. Guided by block level, boluses of 10 to $20 \mathrm{cc}$ of $2 \%$ lidocaine with 1:200,000 epinephrine and $1 \mathrm{ml} 8.4 \%$ bicarbonate per $10 \mathrm{ml}$ lidocaine were then administered through the epidural catheter, with intermittent aspiration for the presence of CSF or blood. A sensory block at T8 was sought. Additional boluses between 5 and $10 \mathrm{cc}$ of the same solution were given as needed throughout the procedure.

Patients in the GA group were denitrogenated with $100 \% \mathrm{O}_{2}$ by face mask. Anesthetic induction was performed with $1.5 \mu \mathrm{g} / \mathrm{kg}$ fentanyl, $1.5 \mathrm{mg} / \mathrm{kg}$ lidocaine, and either $5 \mathrm{mg} / \mathrm{kg}$ sodium thiopental or $3 \mathrm{mg} / \mathrm{kg}$ propofol. An adequate airway was assured prior to the administration of $1 \mathrm{mg} / \mathrm{kg}$ succinylcholine. Direct laryngoscopy was performed with Miller or Macintosh blades, and an appropriately-sized endotracheal tube was placed. Isoflurane, sevoflurane or desflurane were used as anesthetics. Additional narcotic (fentanyl, morphine or both) was administered as needed. Lactated Ringer's solution was used for perioperative fluid replacement.

Lidocaine levels were determined in all patients: in the GA group samples were obtained 45 minutes after induction of anesthesia; in the EA group at the end of surgery.

\section{Coagulation Assays}

Two venous blood samples for determination of coagulation parameters were collected from each patient: preoperatively (approximately one hour prior to induction of anesthesia) and postoperatively (immediately after skin closure). Thus, each patient acted as his/her own control for comparison of post-surgical versus pre-surgical coagulation profiles. After $10 \mathrm{ml}$ of blood was discarded, 2 samples $\left(3 \mathrm{ml}\right.$ each) of venous blood were collected into prewarmed $\left(37^{\circ} \mathrm{C}\right)$ plastic syringes. Within the next 2 minutes, these syringes were inserted into a prewarmed CSA cassette, and CSA was performed. CSA is a methodology that allows separate assessment of the coagulation cascade and platelet function. Non-anticoagulated blood is perfused from the syringes through two separate pathways ("punch" and "collagen"), in each of which the coagulation system is activated in a different manner. Both pathways are contained within the cassette under controlled temperature $\left(37^{\circ} \mathrm{C}\right)$, pressure $(65 \mathrm{mmHg})$, and flow rate $(0.085 \mathrm{ml} / \mathrm{min})$, resulting in a shear rate similar to that found in intermediate-size blood vessels $\left(\sim 300 \mathrm{~s}^{-1}\right)$. In the punch pathway, a needle pierces the wall of the tubing carrying the blood, causing an immediate drop in pressure and producing an increase in shear rate to greater than $10,000 \mathrm{~s}^{-1}$. This, in turn, induces a platelet response, eventually leading to sealing of the injury site and recovery of pressure within the flow pathway. Platelet-mediated hemostasis time (PHT) is calculated as the time between the punch (onset of bleeding) and the formation of the platelet clump (arrest of bleeding, arbitrarily defined as return of the pressure to $90 \%$ of its original value). Activation of the coagulation cascade induces buildup of a fibrin clot in 
the vessel, resulting in a subsequent decrease in pressure (measured behind clot). Clotting time (CT) is calculated when flow ceases (defined as a pressure decrease to $10 \%$ of baseline). In the collagen pathway, blood is perfused over a collagen fiber, leading to platelet activation and formation of a platelet-rich thrombus which occludes the pathway and reduces the pressure behind the clot to zero, the instant of which is assessed as collagen-induced thrombus formation (CITF). These reactions are presented as both numerical values and graphical signatures.

\section{Statistical analysis}

Results are expressed as mean \pm SEM. Significance was assessed using Student's $t$ test. $P<0.05$ was considered significant.

\section{RESULTS}

Of the 41 patients enrolled, 30 were female and 11 were male. Mean age was $63 \pm 11$ years (range 39-83). 23 patients underwent total knee-, 18 patients total hip replacement. Mean operation duration was $94 \pm 23$ minutes (range $60-142$ ). There was no difference in operation length between the EA $(94.7 \pm 44 \mathrm{~min})$ and the GA $(97 \pm 22 \mathrm{~min})$ group $(\mathrm{p}=0.87)$. The preoperative coagulation state was similar between the EA and GA group as determined by PHT $(p=0.122)$, CT $(p=0.337)$ or CITF $(p=0.097$, Table 1)

\section{Table 1:}

Comparison of Clotting Signature Analysis (CSA) parameters between patients receiving general and epidural anesthesia

\begin{tabular}{|c|c|c|c|c|c|c|}
\cline { 2 - 7 } \multicolumn{1}{c|}{} & \multicolumn{3}{c|}{ General anesthesia } & \multicolumn{3}{c|}{ Epidural anesthesia } \\
\cline { 2 - 8 } \multicolumn{1}{c|}{} & pre-op & post-op & $\%$ & pre-op & post-op & $\%$ \\
\hline PHT & $321 \pm 25$ & $169 \pm 21$ & $61 \pm 8.6$ & $264 \pm 26$ & $296 \pm 23$ & $133.2 \pm 15.4$ \\
\hline & \multicolumn{2}{|c|}{$p<0.001$} & & \multicolumn{2}{|c|}{$p=0.25$} & \\
\hline CT & $1573 \pm 48$ & $1234 \pm 55$ & $79.2 \pm 3.3$ & $1507 \pm 48$ & $1489 \pm 61$ & $100 \pm 4.4$ \\
\hline & \multicolumn{2}{|c|}{$p<0.001$} & & \multicolumn{2}{|c|}{$p=0.89$} & \\
\hline CITF & $344 \pm 13$ & $300 \pm 19$ & $89.7 \pm 5.9$ & $302 \pm 21$ & $300 \pm 19$ & $103.8 \pm 7$ \\
\hline & \multicolumn{2}{|c|}{$p=0.06$} & & \multicolumn{2}{|c|}{$p=0.78$} & \\
\hline
\end{tabular}

Data expressed as mean seconds it SEM,

PHT = platelet-mediated bemostasis time; CT - elotting time; CTT = collagen-induced thrombus formation 
Figure 1 shows representative examples of CSA reports from 2 patients, 1 in the EA and 1 in the GA group.

\section{preoperative}

A

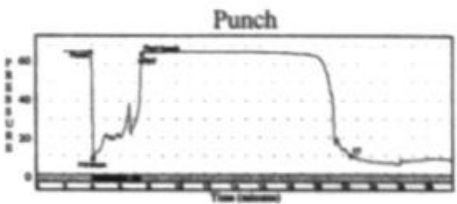

GA

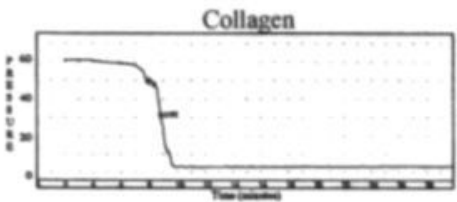

C

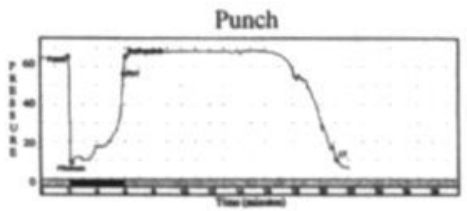

EA

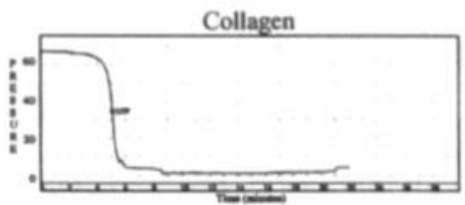

postoperative

B
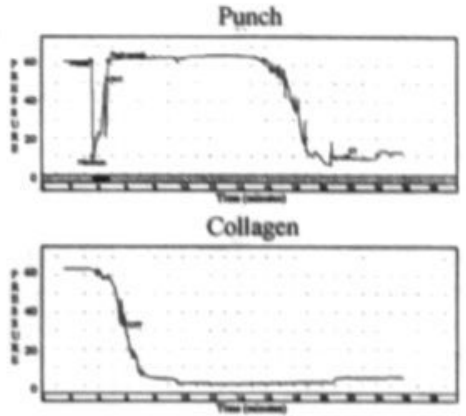

D
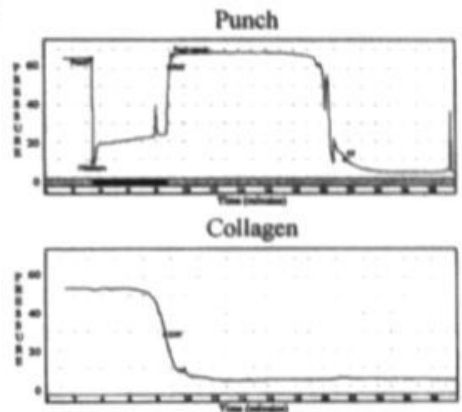

Figure 1: Representative examples for the pre- and postoperative Clot Signature Analysis (CSA) reports: Normal ranges of CSA values are (min:sec) 1:42 - 6:18 for platelet-mediated hemostasis time (PHT), 17:54 - 29:06 for clotting time (CT), 4:24 - 8:12 for collagen- induced thrombus formation (CITF). * denotes value outside established normal range. (A) Patient of the general anesthesia (GA) group preoperatively: $P H T=3: 33, C T=22: 37, C I T F=6: 51$ (B) Patient of the GA group postoperatively: $P H T=1: 08, C T=21: 56, C I T F=4: 18$. All three CSA parameters are reduced after surgery. (C) Patient of the epidural anesthesia (EA) group preoperatively: PHT = 3:56, $C T=21: 12, C I T F=5: 06$ (D) Patient of the EA group postoperatively: $P H T=5: 39, C T=$ $21: 50$, CITF $=7: 13$. 
Aggregate data are shown in Fig 2 and Table 1. In the GA group, PHT ( $<<0.001), C T$ (p<0.001) and CITF $(\mathrm{p}=0.06)$ decreased as compared with preoperative values. In contrast, no significant changes in any parameter were observed in the EA group.
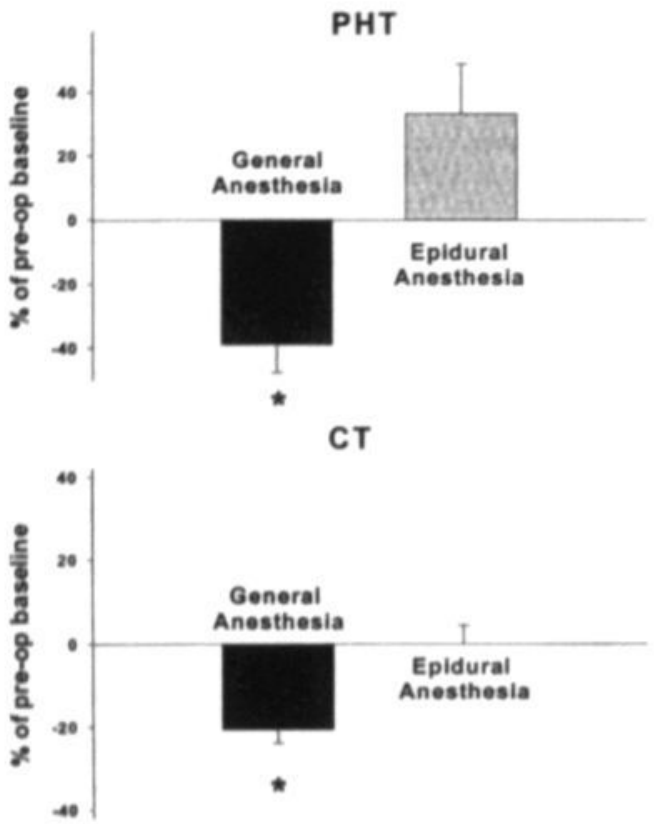

CITF

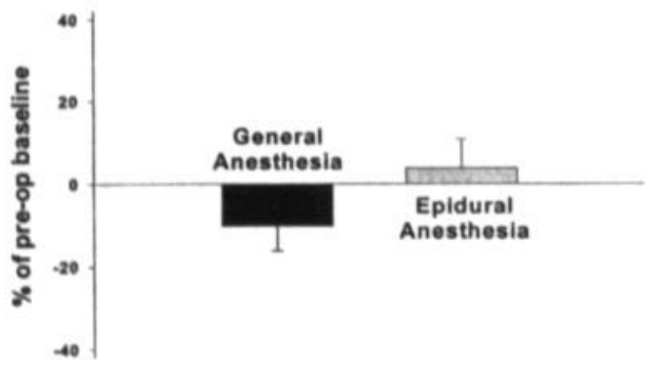

Figure 2: Comparison of Clotting Signature Analysis (CSA) parameters platelet-mediated hemostasis time (PHT), clotting time (CT) and collagen-induced thrombus formation (CITF) between patients receiving general anesthesia (GA, black bar) or epidural anesthesia (EA, grey bar). See table 1 for raw data. (A) Mean \pm SEM PHT, compared with preoperative baseline: in patients receiving $G A$ reduction by $39 \pm 8.6 \%$, in patients receiving $E A$ prolongation by $33.2 \pm$ $15.4 \%$ (not significant, $p=0.25$ ). (B) Mean \pm SEM CT, compared with baseline: in patients of GA group decreased by $20.8 \pm 3.3 \%$, in patients of EA group not altered $(0 \pm 4.4 \%)$. (C) Mean $\pm S E M$ CITF, compared with baseline: in patients receiving $G A$ reduction by $10.3 \pm 5.9 \%$, in patients receiving EA tendency towards prolongation by $3.8 \pm 7 \%$ 
We analyzed pre- and postoperative coagulation parameters separately for patients undergoing hip- or knee-arthroplasty by generating four subgroups: hip-GA $(n=13)$, hip-EA $(n=10)$, knee-GA $(n=10)$ and knee-EA $(n=8$, Fig 3, Table 2). Changes in coagulation parameters were similar in both groups: postoperative PHT and CT were significantly different between GA and EA groups, with values decreasing in the GA group and increasing in the EA group. No significant changes were observed in CITF.

Table 2: Comparison of Coeting Signature Analyais (CSA) parameters between patients patients receiving general and epidural anesthesia, seperately dividad ints patients undergoing tobal bilp and lotal baee arthroplanty

\begin{tabular}{|c|c|c|c|c|c|c|c|}
\hline & \multicolumn{3}{|c|}{ General anesthesia } & \multicolumn{3}{|c|}{ Epidural anesthesia } \\
\hline & & pre-op & post-op & $\%$ & $\%$ & pre-op & post-op \\
\hline \multirow{6}{*}{$\begin{array}{l}\mathbf{H} \\
\mathbf{i} \\
\mathbf{p}\end{array}$} & \multirow[t]{2}{*}{ PHT } & $397 \pm 24$ & $157 \pm 30$ & $43.1 \pm 10.7$ & $146.0+25.2$ & $258 \pm 39$ & $291 \pm 39$ \\
\hline & & & & \multicolumn{2}{|c|}{$\mathrm{p}<0.001$} & & \\
\hline & \multirow[t]{2}{*}{ CT } & $1615 \pm 73$ & $1207 \pm 69$ & $76.2+4.9$ & $101.3+5.0$ & 1549167 & $1545: 65$ \\
\hline & & & & \multicolumn{2}{|c|}{$p=0.002$} & & \\
\hline & \multirow{2}{*}{ CITF } & $330 \pm 16$ & $329+30$ & $100.6+7.9$ & $109.0+9.7$ & $312+30$ & $323+26$ \\
\hline & & & & \multicolumn{2}{|c|}{$p=0.505$} & & \\
\hline \multirow{6}{*}{$\begin{array}{l}\mathbf{K} \\
\mathbf{n} \\
\mathbf{e} \\
\mathbf{e}\end{array}$} & \multirow[t]{2}{*}{ PHT } & $226+30$ & $186+29$ & $83.9 \pm 11.2$ & $113.9+5.8$ & $273 \pm 33$ & $304+30$ \\
\hline & & & & \multicolumn{2}{|c|}{$p=0.043$} & & \\
\hline & \multirow[t]{2}{*}{ CT } & $1522+59$ & $1266 \div 92$ & $82.7 \pm 4.5$ & $104.5 \pm 7.1$ & $1417 \div 64$ & $1476 \pm 104$ \\
\hline & & & & \multicolumn{2}{|c|}{$p=0.016$} & & \\
\hline & \multirow[t]{2}{*}{ CITF } & $361 \pm 23$ & $266 \pm 17$ & $76.6 \pm 7.3$ & $96.0 \pm 10.3$ & $289 \pm 31$ & $266+22$ \\
\hline & & & & \multicolumn{2}{|c|}{$p=0.134$} & & \\
\hline
\end{tabular}

Data expremed as mean socoedstSEM

PUT - platelet-modiatod hemeatasis time, CT = clotting time, CTT = collagen-indweed thrombes formation

Mean lidocaine plasma level in the EA group was $2.1 \pm 0.6 \mu \mathrm{g} / \mathrm{ml}$. Patients in the GA group had no detectable lidocaine plasma levels $(<0.3 \mu \mathrm{g} / \mathrm{ml}) 45$ minutes after administration of lidocaine for intubation. 

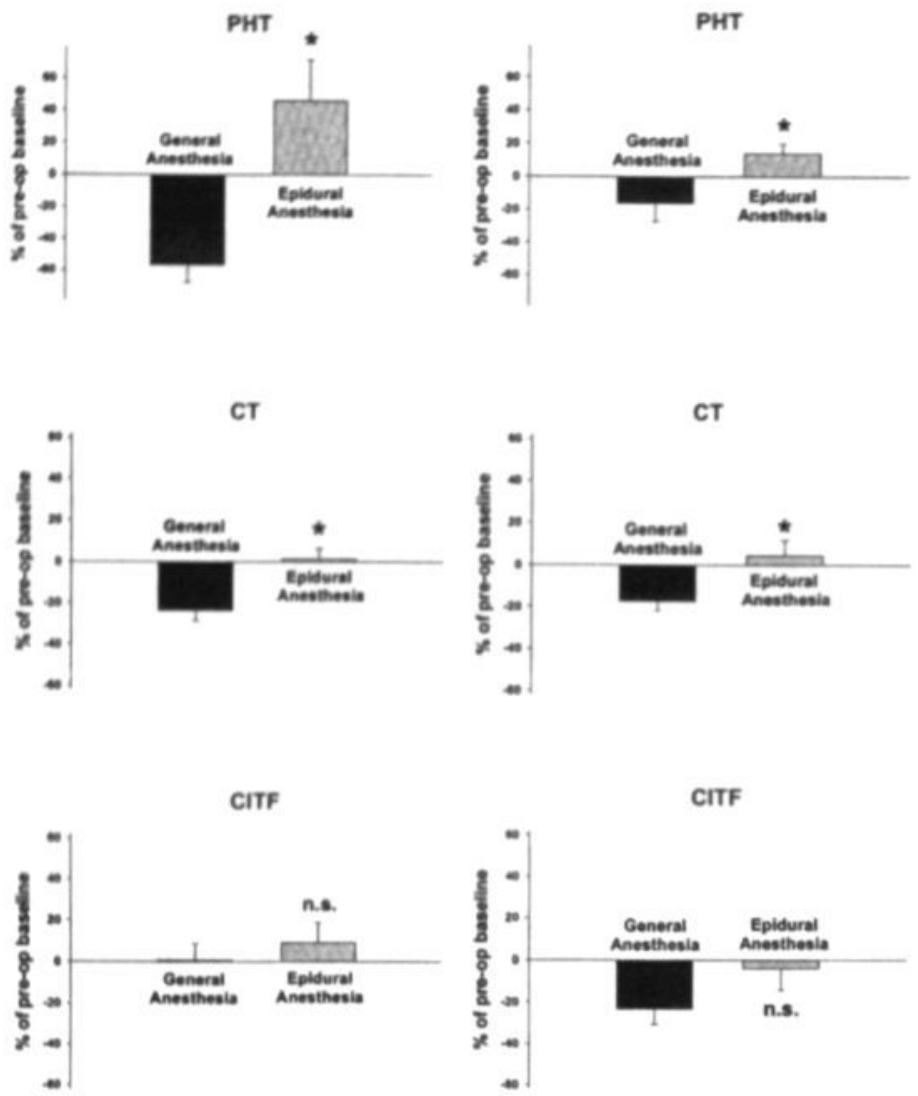

Figure 3: Comparison of Clotting Signature Analysis (CSA) parameters platelet-mediated hemostasis time (PHT), clotting time (CT) and collagen-induced thrombus formation (CITF) between patients receiving general anesthesia (GA, black bars) or epidural anesthesia (EA, grey bars), additionally divided into patients undergoing total hip (left column) and total knee (right column) arthroplasty. See table 2 for raw data. (A) Mean \pm SEM PHT in patients undergoing hip replacement: in GA group reduction by $56.9 \pm 10.7 \%$, compared with a prolongation by $46 \pm 25.2$ in patients of the EA group. (B) Mean \pm SEM PHT in patients undergoing knee replacement: shortening by $16.1 \pm 11.2 \%$ in GA group, prolongation by $13.9 \pm 5.8 \%$ in patients of $E A$ group. (C) Mean $\pm S E M C T$ in patients with hip surgery, in GA group reduced by $23.8 \pm 4.9 \%$ compared with an increase by $1.3 \pm 5 \%$ in EA group. (D) Mean \pm SEM CT in patients with knee surgery: in GA group reduced by $17.3 \pm 4.5 \%$, compared with a prolongation by $4.5 \pm 7.1$ in patients of the $E A$ group. (E) Mean \pm SEM CITF of patients undergoing hip arthroplasy: basically no effect in the GA group (increase by $0.6 \pm 7.9 \%$ ), compared with patients in EA group: prolongation by $9 \pm 9.7 \%$ (F) Mean \pm SEM CITF in patients undergoing total knee replacement: Decrease of CITF by $23.3 \pm$ $7.3 \%$ in patients receiving $G A$, decrease of CITF by $4 \pm 10.3 \%$ in patients receiving EA. * $p<0.05$ compared with $G A$. 


\section{DISCUSSION}

The major findings of this study are twofold. First, the hypercoagulable state induced by major orthopedic surgery, which is not easily demonstrated by routine coagulation tests, is reliably identified by the CSA parameters PHT and CT. The third parameter, CITF, showed a tendency towards shortening; however, this effect was not significant. Second, this hypercoagulability is completely prevented in patients receiving EA. We found no significant differences between knee and hip surgery. It should be realized that we only studied coagulation status at the beginning and end of surgery. Subsequent studies should investigate if the effect is prolonged.

At present, there is no satisfactory clinical test of platelet function (with the debatable exception of bleeding time). A simple screening technique for the detection of hypercoagulability is not available. Thromboplastin time and thrombin time were shown not to be affected by orthopedic surgery. ${ }^{13}$ Bredbacka and Edner ${ }^{14}$ suggested increased soluble fibrin and D-dimer levels as good markers of posttraumatic hypercoagulation in patients with isolated brain trauma. However, to our knowledge those parameters have not been evaluated for patients undergoing orthopedic surgery. Thrombelastography (TEG) is used in monitoring hemostasis during liver transplantation and has been found to be predictive of hemorrhagic risk in cardiac surgery. ${ }^{13,16}$ In a study investigating the effects of EA on coagulation after major vascular surgery, TEG was suggested as a useful marker for accelerated coagulability in high risk patients. However, TEG does not allow differentiation of effects on platelets from those on the clotting cascade, and the test takes a long time to perform. We therefore decided to use CSA to assess information about platelet function (represented by the parameters PHT and CITF) and coagulation processes (CT). CSA has been used previously for determination of clinical clotting disorders ${ }^{17-19}$, but not in the setting of surgery. To our knowledge, our findings represent the first time a coagulation test was able to demonstrate that orthopedic surgery induces hypercoagulability and that the use of EA prevents this effect.

Patients receiving EA are less likely to suffer from thromboembolic complications than patients receiving GA, although the underlying mechanisms remain obscure. Modig et al. ${ }^{11,12,20,21}$ reported beneficial hemodynamic changes in arterial and venous blood pressure, calf blood flow and venous capacity in patients undergoing regional anesthesia. However, sympathetic blockade alone does not seem to be a likely explanation for the observed changes in the coagulation system: Cooke et al. ${ }^{10}$ demonstrated that intravenously administered lidocaine (plasma levels $2-3 \mu \mathrm{g} / \mathrm{ml}$ ) reduced deep vein thrombosis in patients undergoing total hip replacement, indicating that sympathectomy is not required for the effect. Since results of routine coagulation and fibrinolysis studies were normal, it was suggested that LA-induced inhibition of leukocyte activity (endothelial adhesion ${ }^{22}$ and transendothelial migration ${ }^{23}$ ) might prevent endothelial damage and decrease the incidence of thrombosis. However, our data, obtained using an in vitro assay, suggest that the hypercoagulability is an inherent property of the blood itself, and not dependent on an abnormal vascular wall. Niemi et al. ${ }^{24}$ compared hypotensive epidural and spinal anesthesia in patients undergoing total hip arthroplasty and found a decrease in blood loss, a decreased prothrombin time and increased Ddimer concentrations in the epidural group. Since these forms of regional anesthesia both induce sympathectomy but result in different systemic levels of LA (higher in epidural group), these findings are most parsimoniously explained by an effect of LA per se.

However, in vitro studies suggest that LA concentrations as occur in plasma during clinical use are unlikely to effect platelet function. Borg et Modig ${ }^{6}$ reported effects of LA on primary hemostasis. They incubated platelet-rich plasma with lidocaine, bupivacaine or tocainide and determined ADP- or collagen-induced platelet aggregation. They found LA concentrations required to inhibit platelet aggregation to be much higher $(25 \mu \mathrm{g} / \mathrm{ml})$ than the peak concentrations that occur in vivo $(\sim 2 \mu \mathrm{g} / \mathrm{mL})$. This statement was verified by other authors. ${ }^{4,8}$ Several mechanisms may explain this discrepancy between in vivo and in vitro studies: first of all, it is possible that LA affect several parallel steps in the aggregation and coagulation cascade which cannot be mimicked in vitro by studying single parameters. Second, an obvious difference between in vivo and in vitro studies is the exposure time to LA: during EA patients are often exposed $>8 \mathrm{hrs}$, whereas incubation in vitro 
is rarely more than $30 \mathrm{~min}$. Kohrs et al. ${ }^{25}$ studied the effect of bupivacaine on whole blood coagulation as measured by thrombelastography (TEG) and activated clotting time (ACT). Blood samples were incubated for up to two hours (as opposed to previous studies where incubation time never exceeded 45 minutes) and bupivacaine in clinically relevant concentrations $(\sim 2 \mu \mathrm{g} / \mathrm{mL})$ was found to affect TEG and ACT significantly. Borg and Modig ${ }^{6}$ similarly noticed that the inhibitory effect of LA was significantly greater after longer incubation times. In studies using Xenopus oocytes, we observed time-dependent inhibition of recombinantly expressed thromboxane $\mathrm{A}_{2}$ receptors by bupivacaine ${ }^{26}$. After $8 \mathrm{~h}$, agonist (at $1 / 10$ of $\mathrm{EC}_{50}$ )-induced responses were reduced to $40 \%$ of those obtained in control cells. Since under clinical conditions of EA, LA have prolonged contact with blood, it is possible that the discrepancies between in vitro and in vivo findings result from different exposure times. In agreement, although the GA group in our study received a bolus of $1.5 \mathrm{mg} / \mathrm{kg}$ lidocaine for induction of anesthesia, this brief exposure did not prevent changes in CSA parameters. Forty-five minutes after administration plasma lidocaine levels were below detection threshold. This confirmed findings by Tsai et al. ${ }^{27}$ who studied lidocaine concentrations in plasma after systemic bolus administration and found rapidly declining lidocaine plasma levels. Bolus administration of lidocaine therefore does not seem to have a beneficial effect on the coagulation system, although it remains to be tested whether patients receiving GA without prior administration of lidocaine have an even higher risk to suffer from thromboembolic complications.

In our study, we concentrated on a third potential explanation of the difference between in vitro and in vivo findings, suggested by the anti-inflammatory effects of LA. LA prevent only the overstimulation of inflammatory responses, without impairing the physiological host defense. ${ }^{7}$ Therefore it might be conceivable that LA, by analogy, abolish the hypercoagulability induced by surgery without affecting the normal aggregation and coagulation processes. Our findings suggest that such may indeed be the case.

In summary, major orthopedic surgery induces a notable hypercoagulability, which is reliably determined by CSA, and prevented by EA. 


\section{References}

1. Modig J, Hjelmstedt A, Sahlstedt B, Maripuu E: Comparative influences of epidural and general anaesthesia on deep venous thrombosis and pulmonary embolism after total hip replacement. Acta Chir Scand 1981; 147:125-30

2. Modig J, Borg T, Karlstrom G, Maripuu E, Sahlstedt B: Thromboembolism after total hip replacement: role of epidural and general anesthesia. Anesth Analg 1983; 62:174-80

3. Tuman KJ, McCarthy RJ, March RJ, DeLaria GA, Patel RV, Ivankovich AD: Effects of epidural anesthesia and analgesia on coagulation and outcome after major vascular surgery. Anesth Analg 1991; 73:696-704

4. Odoom JA, Dokter PWC, Sturk A, Ten Cate JW, Sih IL, Bovill JG: The influence of epidural analgesia on platelet function and correlation with plasma bupivacaine concentrations. Eur J Anaesthesiol 1988; 5:305-12

5. Tobias MD, Henry C, Augostides YG: Lidocaine and bupivacaine exert differential effects on whole blood coagulation. J Clin Anesth 1999; 11:52-5

6. Borg T, Modig J: Potential anti-thrombotic effects of local anesthetics due to their inhibition of platelet aggregation. Acta Anaesthesiol Scand 1985; 29:739-42

7. Hollmann MW, Durieux ME: Local anesthetics and the inflammatory response: a new therapeutic indication? Anesthesiology 2000; 93:858-75

8. Grant GJ, Ramanathan S, Patel N, Turndorf H: The effects of local anesthetics on maternal and neonatal platelet function. Acta Anaesthesiol Scand 1989; 33:409-12

9. Feinstein MG, Fiekers J, Fraser C: An analysis of the mechanism of local anesthetic inhibition of platelet aggregation and secretion. J Pharmacol Exp Ther 1976; 197:215-28

10. Cooke ED, Bowcock SA, Lloyd MJ, Pilcher MF: Intravenous lignocaine in prevention of deep venous thrombosis after elective hip surgery. Lancet $1977 ; 2: 797-9$

11. Modig J: Regional anaesthesia and blood loss. Acta Anaesthesiol Scand Suppl 1988; 89:44-8

12. Modig J, Karlstrom G: Intra- and post-operative blood loss and haemodynamics in total hip replacement when performed under lumbar epidural versus general anaesthesia. Eur J Anaesthesiol 1987; 4:345-55

13. Hellinger $\mathrm{J}$ : Studies on the action of blood coagulation, fibrinolysis and thrombocyte function following orthopedic surgery. Z Orthop Thre Grenzgeb 1971; 109:487-500

14. Bredbacka S, Edner G: Soluble fibrin and D-dimer as detectors of hypercoagulability in patients with isolated brain trauma. J Neurosurg Anesthesiol 1994; 6:75-82

15. Tuman KJ, Spiess BD, McCarthy RJ, Ivankovich AD: Comparison of viscoelastic measures of coagulation after cardiopulmonary bypass. Anesth Analg 1989; 69:69-75

16. Spiess BD, Tuman KJ, McCarthy RJ, DeLaria GA, Schillo R, Ivankovich AD:

Thromboelastography as an indicator of post-cardiopulmonary bypass coagulopathies.

J Clin Monit Comput 1987; 3:25-30 
17. Li CK, Hoffmann TJ, Hsich PY, Malik S, Watson WC: The Xylum Clot Signature Analyzer: a dynamic flow system that simulates vascular injury. Thromb Res 15-12-1998; 92:6777

18. Igawa T, Kornhauser R, Cilla DD, King JO, Kambayashi J: Evaluation of the Clot Signature Analyzer as a hemostasis test in healthy volunteers exposed to low doses of aspirin. Clin Appl Thromb Hemost 1999; 5:117-21

19. MeKenzie ME, Gurbel PA, Levine DJ, Serebruany VL: Clinical utility of available methods for determining platelet function. Cardiology 1999; 92:240-7

20. Modig J: Beneficial effects on intraoperative and postoperative blood loss in total hip replacement when performed under lumbar epidural anesthesia. An explanatory study. Acta Chir Scand Suppl 1989; 550:95-100

21. Modig J, Malmberg P, Karlstrom G: Effect of epidural versus general anaesthesia on calf blood flow. Acta Anaesthesiol Scand 1980; 24:305-9

22. Giddon DB, Lindhe J: In vivo quantitation of local anesthetic suppression of leukocyte adherence. Am J Pathol 1972; 68:327-38

23. Stewart GJ, Ritchie WG, Lynch PR: Venous endothelial damage produced by massive sticking and emigration of leukocytes. Am J Pathol 1974; 74:507-32

24. Niemi TT, Pitkanen M, Syrjala M, Rosenberg PH: Comparison of hypotensive epidural anaesthesia and spinal anaesthesia on blood loss and coagulation during and after total hip arthroplasty. Acta Anaesthesiol Scand 2000; 44:457-64

25. Kohrs R, Hoenemann CW, Feirer N, Durieux ME: Bupivacaine inhibits whole blood coagulation in vitro. Reg Anesth Pain Med 1999; 24:326-30

26. Hollmann MW, Berger A, Hoenemann CW, Durieux ME: Time-dependent inhibition of lysophosphatidate and thromboxane signaling by local anesthetics. Anesthesiology 2000; 93:A828

27. Tsai PS, Buerkle H, Huang LT, Lee TC, Yang LC, Lee JH: Lidocaine concentrations in plasma and cerebrospinal fluid after systemic bolus administration in humans. Anesth Analg 1998; 87:601-4 
CHAPTER 10

Summary and conclusions / Samenvatting en conclusies

Markus W. Hollmann 


\section{Summary and conclusions / Samenvatting en conclusies}

This thesis reports the interaction of local anesthetics with various signaling pathways of $\mathrm{G}$ protein- coupled receptors. Although local anesthetics interact primarily with the sodium channel, from which interaction derive their analgesic and antiaarhythmic effects, not all actions of these compounds can be explained by sodium channel blockade. Their interaction with GPCR signaling pathways may explain some of the "alternative" effects of local anesthetics, (e.g. antithrombotic and antiinflammatory properties).

As reviewed in chapter 2, recent experimental results have modified profoundly our understanding of $\mathrm{G}$ protein-mediated transmembrane signaling. The concept of linear signal transduction pathways, i.e. one receptor coupling to one $\mathrm{G}$ protein that activates one effector, is inadequate to explain recent findings. The majority of seven transmembrane spanning receptors interact with diverse $G$ proteins and elicit multiple intracellular signals. Interaction of a single $G$ protein with a given receptor in a certain cell, however, may be regulated by a high degree of selectivity. G protein-mediated signal transduction can be seen as a complex, highly organized signaling network with diverging and converging transduction steps at the ligand-receptor, receptor$\mathrm{G}$ protein, and $\mathrm{G}$ protein-effector composition. Although the $\alpha$-subunit gained most attention for its important role in interactions with receptor and effector structures, and $G$ proteins are named according to their $\alpha$ subunit, our knowledge of $G \beta \gamma$ 's role in signal transduction has advanced from the assumption that it simply anchored and regulated $\mathrm{G} \alpha$ to the demonstration that the $\beta$-isoform in the $\beta \gamma$ dimer also can determine the specificity of signaling at both effectors and receptors.

Chapter 3 has discussed several aspects of local anesthetic action that are considered independent of $\mathrm{Na}$ channel blockade. Local anesthetics provide a modest degree of general anesthetic action, and as such can be usefully employed to 'stretch' an anesthetic (e.g. at the end of a case). They also provide a considerable amount of neuroprotection. In combination with the hemodynamic stability provided, they are therefore of great usefulness in the practice of neuroanesthesia. The ability to reduce bronchial reactiviy is well recognized, even if the underlying mechanism is poorly understood. Finally, these versatile compounds have been employed with success in a variety of other clinical settings, including tinnitus, pruritus and migraine.

Chapters 4 and 5 described local anesthetic inhibition of muscarinic $\mathrm{ml}$ and $\mathrm{m} 3$ acetylcholine receptors expressed recombinantly in Xenopus oocytes. Their action on these signaling pathways might explain at least in part some of the additional effects of local anesthetics reported in chapter 3.

As detailed in chapter 4 , we found that local anesthetics inhibit muscarinic $\mathrm{m} 1$ receptors expressed recombinantly in Xenopus oocytes. Lidocaine inhibits at concentrations significantly less than those required for blocking sodium channels. We suggest that this inhibitory effect is due to superadditive interactions between an extracellular, polar, non-competitive site on the muscarinic receptor molecule, and an intracellular site probably on the coupled $\mathrm{G}$ protein. Whereas the intracellular site appears to be the same on muscarinic, lysophosphatidate and thromboxane $\mathrm{A}_{2}$ receptors, the lipid mediator receptors lack the extracellular polar local anesthetic binding domain.

Chapter 5 reports our finding that lidocaine reversibly inhibits signaling of $\mathrm{m} 3$ receptors recombinantly expressed in Xenopus oocytes. The calculated $\mathrm{IC}_{50}(370 \mathrm{nM})$ is significantly less than that required for blocking sodium channels. However, compared with inhibition of $\mathrm{ml}$ muscarinic signaling $\left(\mathrm{IC}_{50} 18 \mathrm{nM}\right.$ ), $\mathrm{m} 3$ signaling is approximately 21 -fold less sensitive to lidocaine. This discrepancy is explained most parsimoniously by absence on the $\mathrm{m} 3$ receptor of the major extracellular binding site for charged local anesthetics that is present on the $\mathrm{ml}$ receptor. The $\mathrm{N}$-terminus and third extracellular loop of the $\mathrm{ml}$ receptor molecule were identified as requirements for this extracellular binding site for charged local anesthetics. In contrast, intracellular inhibition of both receptors was quite similar. As determined for $\mathrm{m} 1$ signaling, $\mathrm{m} 3$ signaling is primarily mediated by $\mathrm{G}_{4}$ and $\mathrm{G}_{11}$; of these, $\mathrm{G}_{4}$ was shown to be a likely target for intracellular inhibition by local anesthetics. In summary, this study adds to previous findings that local anesthetics at clinically relevant concentrations can inhibit $\mathrm{G}$ protein-coupled receptors. The interactions between the 
anesthetics and the receptor pathways are complex, and involve multiple sites of action, on receptor as well as coupled $\mathrm{G}$ protein. In view of the important roles of $\mathrm{ml}$ and $\mathrm{m} 3$ muscarinic signaling in the brain and peripheral tissues, local anesthetic inhibition of these receptors is likely to be of relevance. The clinical implications remain to be addressed.

To elucidate in more detail a common intracellular site of action for local anesthetics within the signaling pathway of various $\mathrm{G}$ protein-coupled receptors, we determined the $\mathrm{G}$ protein- $\alpha$-subunits coupling to those receptors using antisense methodology. As described in chapter 6, LPA signaling was shown to be inhibited by ropivacaine stereoisomers in a concentration-dependent and stereoselective manner, strongly suggesting a protein site of action for ropivacaine. This inhibition was primarily due to a non-competitive antagonism. We also found that LPA signaling is mediated primarily by $\mathrm{G} \alpha_{9}$ and $\mathrm{G} \alpha_{0}$. G $\alpha_{4}$ couples to both LPA, muscarinic $\mathrm{ml}$, and trypsin receptors, and is a main target for intracellular LA inhibition of $\mathrm{G}$ protein-coupled receptors.

In conclusion, our studies suggest that $\mathrm{G}$ protein-coupled receptors may be common targets for local anesthetics. The concentrations used in these investigations are routinely attained after local injection of these compounds. Inhibition of $\mathrm{G}$ protein-coupled receptors by LA results in part from an intracellular action, which can be largely explained by selective interference with $\mathrm{Ga}_{4}$ protein function.

Chapter 7 reviewed the effects of local anesthetics on inflammation, coagulation and wound healing. In this chapter we have summarized several interesting and potentially important "alternative" effects of L.A, not explained by their well-known antinociceptive and antiarrhythmic actions. The most remarkable observation is that LA are able to prevent pathological changes such as hypercoagulability or excessive stimulation of the inflammatory system, without inducing increased bleeding or impairment of host defense. This sets them apart from drugs currently in use for treatment of such disorders, and points the way to potential therapeutic application. Indeed, we use intravenous LA infusions in patients who would benefit from epidural anesthesia/analgesia but are not candidates for the technique. We hope that this chapter will urge some readers to investigate these effects in more detail, because much more research is needed on basic mechanisms. What does seem clear is that $\mathrm{Na}^{+}$channel blockade plays only a limited, if any, role in these effects. Further research should determine which molecular determinants of the LA structure exert these effects and where the corresponding site of action is. This might eventually lead to development of new drugs, selective for treatment of these disorders, but without the "side effect" of $\mathrm{Na}^{+}$channel blockade.

Chapter 8 provides new insights into the mechanism of hPMN priming, and in addition suggest a mechanism by which LA may exert some of their anti-inflammatory actions. We have shown that platelet-activating factor (PAF) primes neutrophils through a pathway dependent on PTXinsensitive G proteins, PLC and PKC. PKC activation is both necessary and sufficient for this process. In addition, we show that clinically relevant concentrations of local anesthetics selectively inhibit priming, but not fMLP-induced activation. Ester-LA exerted the most profound inhibitory effect, whereas inhibitory potency of amide-LA increased with increased uncharged fraction. The main target site for LA in the PAF priming pathway is located upstream of PKC.

Finally we studied the preventive effects of epidural anesthesia on hypercoagulation in patients undergoing major orthopedic surgery, as reported in chapter 9 . The major findings of this study were twofold. First, the hypercoagulable state induced by major orthopedic surgery, which is not easily demonstrated by routine coagulation tests, is reliably identified by the CSA parameters PHT and CT. The third parameter, CITF, showed a tendency towards shortening; however, this effect was not significant. Second, this hypercoagulability is completely prevented in patients receiving epidural anesthesia. We found no significant differences between knee and hip surgery. In summary, major orthopedic surgery induces a notable hypercoagulability, which is reliably determined by CSA, and prevented by epidural anesthesia.

Further investigations should focus on several issues. First, selective interaction of LAs with Gaq-function has to be confirmed in other models and the mechanism of action needs to be defined. Second, the active part of the LA molecule responsible for this selective interaction with G protein 
function should be determined. Such studies will allow development of drugs based on LAs and possessing the beneficial effects noted, but lacking the "side effect" of Na channel blockade. Third, the non-Na channel effects of LAs in vivo should be defined in more detail, and their potential roles in modulating pathophysiologic roles should be investigated.

\section{Samenvatting en conclusies}

Dit proefschrift beschrijft de interacties van lokaal anesthetica met verschillende signaalcascades van G-eiwit-gekoppelde receptoren. Hoewel het natriumkanaal het voomaamste aangijpingspunt voor lokaal anesthetica is en de plaats waar hun analgetisch en anti-arrhythmisch effect tot stand komt, kunnen niet alle effecten van deze stoffen verklaard worden door natriumkanaal blokkade. Hun interacties met GPCR signaalcascades kan sommige "alternatieve" effecten van lokaal anesthetica (b.v. antithrombotische en anti-inflammatoire effecten) verklaren.

Zoals beschreven in Hoofdstuk 2 hebben recente onderzoekingen ons inzicht in G-eiwitgemedilerde transmembraan signaalvorming in grote mate verdiept. Het concept van een lineaire signaaltransductie (d.w.z. een receptor koppelend met eén G-eiwit dat én effector activeert) is onvoldoende om de nieuwere bevindingen te verklaren. Het merendeel van de seventransmembrane receptoren heeft interacties met verschillende G-eiwitten en genereert meerdere intracellulaire signalen. Interactie van een enkele receptor met een gegeven $\mathrm{G}$-eiwit in een bepaalde cel kan echter met een hoge mate van selectiviteit worden gereguleerd. G-eiwit-gemedielerde signaaltransductie kan gezien worden als een complex, zeer georganiseerd signaal netwerk met divergerende en convergerende transductie stappen bij ligand-receptor, receptor-G-eiwit, en Geiwit-receptor interacties. Hoewel de $\alpha$-subeenheid de meeste aandacht heeft gekregen vanwege de belangrijke rol in interacties met receptor en effector structuren, en G-eiwitten naar hun $\alpha$ subeenheid benoemd worden, is onze kennis van de rol van $\mathrm{G}_{p \gamma}$ aanmerkelijk verbeterd, van de aanname dat het cenvoudigweg $\mathrm{G}_{\alpha}$ verankerde en reguleerde, tot het aantonen dat de $\beta$ isoform in de $\beta \gamma$ dimeer de specificiteit van signaaloverdracht aan zowel effectors als receptoren kan bepalen.

Hoofdstuk 3 behandelde enkele aspekten van de werking van lokaal anesthetica die als onafhankelijk van natriumkanaal blokkade worden beschouwd. Lokaal anesthetica veroorzaken een beperkte mate van algehele anesthesie, en kunnen zodoende nuttig gebruikt worden om een anesthesie te "rekken" (b.v aan het einde van een ingreep). Ze bieden ook een merkbare mate van neuroprotectie. In combinatie met de hemodynamische stabiliteit die ze verschaffen, zijn ze derhalve van groot nut voor de neuroanesthesie. Hun vermogen om bronchiale reactiviteit te verminderen is erkend, al zijn de onderliggende mechanismen slecht begrepen. Tenslotte zijn deze middelen met succes gebruikt in verschillende andere klinische situaties, waaronder tinnitus, jeuk en migraine.

De Hoofdstukken 4 en 5 bechrijven de inhibitie door lokaal anesthetica van $\mathrm{ml}$ en $\mathrm{m} 3$ muscarinische acetylcholine receptoren na recombinante expressie in Xenopus oocyten. Hun effect op deze signaalcascades kan enkele van de effekten van lokaal anesthetica vermeld in Hoofdstuk 3 helpen verklaren. Als beschreven in Hoofdstuk 4, vonden we dat lokaal anesthetica m1 muscarinische receptoren na recombinante expressie in Xenopus oocyten inhiberen. Lidocaine remde in concentraties aanmerkelijk minder dan die benodigd om natriumkanalen te blokkeren. Dit remmende effekt is waarchijnlijk een gevolg van superadditieve interacties tussen een extracellulaire, polaire, niet-competitieve bindingsplaats op het muscarinische receptormolecuul, en een intracellulaire bindingsplaats, waarschijnlijk op het gekoppelde G-eiwit. Terwijl de intracellulaire site dezelfde lijkt te zijn op muscarinische, lysophosphatidaat en thromboxaan $\mathrm{A}_{2}$ receptoren, ontbreekt bij de lipidemediatoren het extracellulair polair lokaal anesthetica bindingsdomein. Hoofdstuk 5 beschrijft onze bevindingen dat lidocaine reversibel signaalvorming van $\mathrm{m} 3$ receptoren na recombinante expressie in Xenopus oocytes remt. De berekende $\mathrm{IC}_{50}(370$ $\mathrm{nM}$ ) is aanmerkelijk minder dan die benodigd voor het blokkeren van natriumkanalen. Echter, vergeleken met de remming van $\mathrm{ml}$ muscarinische signaalvorming $\left(\mathrm{IC}_{50} 18 \mathrm{nM}\right)$ is $\mathrm{m} 3$ 
signalvorming ongeveer 21 maal minder gevoelig voor lidocaine. Dit verschil is het meest eenvoudig verklaard door de afwezigheid van de belangrijke extracellulaire bindingsplaats voor geladen lokaal anesthetica die aanwezig is op de $\mathrm{ml}$ receptor. De $\mathrm{N}$-terminus en de derde extracellulaire bocht van het $\mathrm{ml}$ receptor molecule werden geidentificeerd als benodigd voor deze extracellulaire bindingsplaats voor geladen lokaal anesthetica. In tegenstelling, intracellulaire inhibitie van beide receptoren was zeer vergelijkbaar. Evenals $\mathrm{m} 1$ signaalvorming vindt $\mathrm{m} 3$ signaalvorming voornamelijk via $\mathrm{G}_{4}$ en $\mathrm{G}_{1}$ plaats; van $\mathrm{G}_{4}$ werd aangetoond dat het een waarschijnlijk aangrijpingspunt voor intracellulaire inhibitie door lokaananesthetica is. Samenvattend ondersteunen deze studies eerdere bevindingen dat lokaal anesthetica in klinisch relevante concentraties G-eiwit gekoppelde receptoren kunnen remmen. De interacties tussen de anesthetica en receptorpaden zijn complex en omvatten meerdere aangrijpingspunten op zowel receptor als op het gekoppelde G-eiwit. Gezien de belangrijke rol van $\mathrm{ml}$ en $\mathrm{m} 3$ muscarinische signaalvorming in hersenen en periferie is inhibitie door lokaal anesthetica van deze receptoren waarschijnlijk relevant. De klinische implicaties moeten verder onderzocht worden.

$\mathrm{Om}$ in meer detail het gemeenschappelijke intracellulaire aangrijpingspunt voor lokaal anesthetica binnen de signaalpaden van verschillende G-eiwit gekoppelde receptoren te beschrijven, bepaalden we (gebruikmakend van antisense methodologie) de G-eiwit $\alpha$ subeenheden gekoppeld aan deze receptoren. Als weergegeven in Hoofdstuk 6 toonden we aan dat LPA signaalvorming geremd werd door ropivacaine stereoisomeren op concentratie-afhankelijke en stereoselectieve wijze, hetgeen wijst op een eiwit als aangrijpingpunt voor ropivacaine. Deze remming was voornamelijk een resultaat van niet-competitief antagonisme. We vonden ook dat LPA signaalvorming vornamelijk wordt gemedieert door $\mathrm{G} \alpha_{4}$ en $\mathrm{G} \alpha_{0}, \mathrm{G} \alpha_{4}$ koppelt met zowel LPA, muscarinische en trypsine receptoren, en is cen belangrijk aangrijpingspunt voor intracellulaire inhibitie van G-eiwit gekoppelde receptoren door lokaal anesthetica. Samenvattend suggereren deze studies dat G-eiwit gekoppelde receptoren een frequent aangrijpingspunt voor lokaal anesthetica zijn. De concentraties gebruikt in dit onderzoek worden routinematig bereikt na lokale injectie van deze middelen. Remming van G-eiwit gekoppelde receptoren door lokaal anesthetica resulteert deels uit een intracellulair effect, hetwelk grotendeels verklaard kan worden door selectieve interactie met $\mathrm{G \alpha}_{\mathrm{a}}$ eiwit functie.

Hoofdstuk 7 beschrijft de effekten van lokaal anesthetica op ontsteking, coagulatic en wondgenezing. In dit hoofdstuk wordt een aantal interessante en mogelijk belangrijke "alternatieve" effekten van lokaal anesthetica besproken die niet te verklaren zijn door hun bekende antinociceptieve en antiarrhythmische effekten. De meest opmerkelijke waarneming is dat lokaal anesthetica in staat zijn pathologische veranderingen - zoals hypercoagulabiliteit of excessieve stimulatie van het ontstekingssysteem - te voorkomen, zonder een bloedingsneiging te induceren of het verdedigingssysteem te onderdrukken. Hierin zijn ze duidelijk anders dan de geneesmiddelen die momenteel in gebruik zijn voor behandeling van dergelijke aandoeningen en dit wijst de richting naar mogelijke therapeutische toepassing. Wijzelf gebruiken intraveneuze lokaal anesthetica in patiēnten die gebaat zouden zijn met epiduraal anesthesie/analgesie, maar geen kandidaten zijn voor de techniek. We hopen dat dit hoofdstuk enkele lezers zal aanzetten deze effekten in meer detail te onderzoeken, omdat veel meer onderzoek naar basale mechanismen noodzakelijk is. Wat duidelijk lijkt is dat natriumkanaal blokkade slechts een beperkte, of zelfs geen, rol speelt in deze effekten. Verder onderzoek moet aantonen welke moleculaire determinanten van de lokaal anesthetica struktuur deze effekten veroorzaken en waar de bijbehorende aangrijpingspunten zijn. Dit zou uiteindelijk kunnen leiden tot de ontwikkeling van nieuwe geneesmiddelen, selectief voor de behandeling van deze aandoeningen, maar zonder de "bijwerking " van natriumkanaal blokkade.

Hoofdstuk 8 verschaft nieuwe inzichten in het mechanisme van neutrofiel priming, en suggereert daarnaast een mechanisme waardoor lokaal anesthetica sommige van hun anti-inflammatoire effekten teweeg kunnen brengen. We toonden aan dat platelet-activating factor (PAF) neutrofielen primed via een signaalcascade afhankelijk van PTX-ongevoelige G-eiwitten, PLC en PKC. PKC activatie is zowel noodzakelijk als voldoende voor dit proces. Bovendien toonden we aan dat 
klinisch relevante concentraties van lokaal anesthetica selectief priming remmen, maar zonder effect zijn op fMLP-geinduceerde activatie. Ester lokaal anesthetica hadden het meest uitgesproken inhiberende effekt en inhiberende potentie van amide lokaal anesthetica werd hoger met de ongeladen fractie. Het belangrijkste aangrijpingpunt voor lokaal anesthetica in de PAF priming signaalcascade is gelokaliseerd boven PKC.

Tenslotte bestudeerden we de preventieve effekten van epiduraalanesthesie op hypercoagulatie in patienten die grote orthopedische ingrepen ondergingen, zoals beschreven in Hoofdstuk 9. De belangrijkste bevindingen van deze studie waren tweevoudig. In de eerste plaats is de door grote orthopedische chirurgie gelnduceerde hypercoagulabele toestand (die moeilijk aan te tonen is met routine coagulatie testen) betrouwbaar te identificeren met de CSA parameters PHT en CT. De derde parameter, CITF, toonde een neiging tot verkorting; dit was echter niet significant. In de tweede plaats is deze hypercoagulabiliteit volledig te voorkomen in patienten waarbij epiduraal anesthesie gebruikt wordt. We vonden geen significante verschillen tussen knie- en heupchirurgie. Samenvattend leidt grote orthopedische chirurgie tot een merkbare hypercoagulabiliteit, die betrouwbaar met CSA bepaald kan worden en voorkomen wordt door epiduraalanesthesie.

Verdere onderzoekingen zouden gericht moeten zijn op verschillende onderwerpen. In de eerste plaats moet selectieve interactie tussen lokaal anesthetica en $\mathrm{Ga}_{4}$ functie bevestigd worden in andere modellen en het werkingsmechanisme moet worden bepaald. In de tweede plaats moet het actieve onderdeel van het lokaalanestheticum molecuul, verantwoordelijk voor deze selectieve interactie met G-eiwit functie, worden geỉdentificeerd. Zulke studies maken de ontwikkeling mogelijk van geneesmiddelen gebaseerd op lokaal anesthetica en met de beschreven voordelen, maar zonder de "bijwerking" van natriumkanaal blokkade. In de derde plaats moeten de nietnatrium kanaal effekten van lokaal anesthetica in vivo in meer detail beschreven worden en hun mogelijke rol in de modulatie van pathofysiologische processen moet worden onderzocht. 


\section{ACKNOWLEDGMENTS}

The studies reported in this thesis were carried out in the Department of Anesthesiology at the University of Virginia, VA, USA between 1998 and 2001.

First, I would like to thank my promotor Marcel E. Durieux with whom I worked for the last three years. He introduced me to the basic science of anesthetic interactions with $\mathrm{G}$ protein-coupled receptor signaling pathways. With an incredible energy and lots of red pens he taught me how to write scientific manuscripts. He instructed me how to give presentations and how to discuss. All things considered he tried everything to make me an independent researcher -with more or less success-. Summarized, I certainly would not have been able to accomplish anything for this thesis without his help. He deserves at least as much credit for the work presented here as I do.

I wish to thank my co-workers, most of which are also co-authors on the papers presented here. In no particular order: Lars G. Fischer, Anne M. Byford, Carsten H. Ritter, Philipp Henle, Manuela de Klaver, Ganesan L. Kamatchi, Jacqueline M. Washington, Christian W. Honemann, Carrie Chan, Elizabeth Coleman, Kathrin S. Wieczorek, Andreas Berger, Ariane Gross, Niko Jelacin, Mary Smart, Sibylle Bayer, Katrin Kurz and Susanne Herroeder.

I am deeply indebted to Patrice Moonen, who spent a great deal of her time in secretarial support of this thesis.

I also wish to express my thanks to Roger A. Johns and Carl Lynch III, Chairs of the Department of Anesthesiology during the time that these studies were performed.

Sincere thanks go to AstraZeneca Pharmaceuticals, L.P. (Westborough, MA) for supplying QX314 and stereoisomers of ropivacaine; Dr. Bonner for the muscarinic acetylcholine receptor DNA; and Xylum Corporation for supplying the Clot Signature Analyzer.

I gratefully acknowledge PD Dr. med. Bernhard M. Graf and Prof. Dr. med. Eike Martin (Ruprecht-Karls-Universitalt Heidelberg, Germany) for their support.

I thank Cosmo A. DiFazio for sharing his outstanding expertise in molecular mechanisms of local anesthetics with me and for stimulating me to undertake this project.

The studies were financially supported by the Department of Anesthesiology, University of Heidelberg, Heidelberg, Germany, the German Research Society (DFG HO 2199/1-1), Bonn, Germany, the American Heart Association (Mid-Atlantic Affiliation) VHA 9920345U, Baltimore, MD, and the National Institutes of Health (GMS 52387), Bethesda, MD, USA. Supported in part by the 2000 Ben Covino Research Award, sponsored by AstraZeneca Pain Control, Sweden.

My gratitude goes to all those members of the Departments of Pharmacology and Anesthesiology at the University of Virginia and the University of Heidelberg for their willingness to share their time and knowledge with me.

I also would like to thank Frank Schmelzer and Dr. Britta Wolf for their moral encouragement.

The printing of this thesis was generously supported by ABBOTT B.V., BAXTER and ASTRAZENECA.

Finally, I am most grateful to my wife Silke, who spent an unbelievable amount of time with me in the laboratory, who was involved in most of the studies presented in this thesis, who was my moral support all the time and who had to surrender me all the time required to get this project accomplished. 


\section{LIST OF PUBLICATIONS}

\section{Peer reviewed published original articles}

- Schlack W, Hollmann M, Stunneck J, Thaemer V (1996) Effect of halothane on myocardial reoxygenation injury in the isolated rat heart. British Journal of Anaesthesia 76: 860-867

- Fischer LG, Hollmann MW, Horstman DG, Rich GF (2000) Cyclooxygenase inhibitors attenuate bradykinin induced vasoconstriction in septic isolated rat lungs. Anesthesia \& Analgesia 90: 625-631

- Hollmann M, Fischer LG, Byford AM, Durieux ME (2000) Local anesthetic inhibition of m1 muscarinic acetylcholine signaling. Anesthesiology 93 (2):497-509

- Hollmann MW. Durieux ME (2000) Local anesthetics and the inflammatory response: a new therapeutic indication? Anesthesiology 93 (3):858-875

- Hollmann MW, Durieux ME (2000) Local anesthetics: Effects on inflammation, wound healing and coagulation. Progress in Anesthesiology: 14 (18):291-304

- Hollmann MW, Durieux ME (2000) Local anesthetics: Effects on the central nervous system and bronchial reactivity. Progress in Anesthesiology: 14 (20):323-336

- Liu HT, Hollmann MW, Hőemann CW, Liu WH, Durieux ME (2001) Modulation of NMDA receptor function by ketamine and magnesium. Part 1: Effects of the compounds applied individually and in combination. Anesthesia \& Analgesia: 92:1173-1181

- Hollmann MW, Liu HT, Honemann CW, Liu WH, Durieux ME (2001) Modulation of NMDA receptor function by ketamine and magnesium. Part 2: Interactions with volatile anesthetics. Anesthesia \& Analgesia: 92:1182-1191

- Hollmann MW, Fischer LG, Berger A, Wieczorek K, Durieux ME (2001) Local anesthetic inhibition of lysophosphatidate signaling is mediated by interference with $\mathrm{G} \alpha_{Q}$ protein function. Molecular Pharmacology: 59:294-301

- Hollmann MW, Ritter CH, Henle P, de Klaver M, Kamatchi GL, Durieux ME (2001) Inhibition of $\mathrm{m} 3$ muscarinic acetylcholine receptors by local anesthetics. Br J Pharmacology: 133: 207-216

- Hollmann MW, Gross A, Jelacin N, Durieux ME (2001) Local anesthetic effects on priming and activation of human neutrophils. Anesthesiology 95: 113-22

- Hollmann MW, Wieczorek KS, Smart M, Durieux ME (2001) Epidural anesthesia prevents postoperative hypercoagulation in patients undergoing major orthopedic surgery. Regional Anesthesia \& Pain Medicine: 26: 215-22

- Fischer LG, Bremer M, Coleman EJ, Conrad B, Krumm B, Gross A, Hollmann MW, Mandell G, Durieux ME (2001) Lysophosphatidic acid signaling in human neutrophils is attenuated by local anesthetics. Anesthesia \& Analgesia: 92:1041-1047 
- Lo B, Hoenemann CW, Hollmann MW, Kohrs R, Polanowska-Grabowska RK, Gear ARL, Durieux ME (2001) Local anesthetic effect on coagulation does not result from interference with thromboxane signaling. Anesthesia \& Analgesia: in press

- Salmons VA, Hollmann MW, Washington JM, Durieux ME (2001) Effects of calcium and magnesium pretreatment on hyperkalemic cardiac arrest. European Journal of Anaesthesiology: (in review)

- Hollmann MW, DiFazio C, Durieux ME (2001) Calcium-signaling G protein-coupled receptors - A new site of local anesthetic action? Regional Anesthesia \& Pain Medicine: (in press)

- Hoenemann CW, Hollmann MW, Podranski T, Durieux ME (2001) Local anesthetic effects on thromboxane signaling. Anesthesia \& Analgesia: (in review)

\section{Abstracts}

- Schlack W, Schaefer S, Hollmann M, Stunneck J, Thaemer V (1994) Dissociation of systolic and diastolic ventricular function by an acute enhancement of the coronary perfusion pressure. Anaesthesist 43 Supplement 1: FV 19.3

- Schlack W, Stunneck J, Hollmann M, Hundt F, Schaefer S, Thaemer V (1995) Effect of milrinone on systolic and diastolic function of stunned myocardium. British Journal of Anaesthesia 74 Supplement 1: A.82

- Schlack W, Hollmann M, Stunneck J, Thaemer V (1995) Effects of halothane on myocardial reoxygenation injury. British Journal of Anaesthesia 74 Supplement 1: A.84

- Schlack W, Hollmann M, Stunneck J, Thaemer V (1995) Effects of halothane on myocardial reoxygenation injury. Anaesthesist $44: 892$

- Schlack W, Hollmann M, Stunneck J, Thaemer V (1995) Protection of the myocard during anoxia and reoxygenation. Zeitschrift fuer Kardiologie 84 Supplement 1: A.858

- Schlack W, Stunneck J, Hollmann M, Hundt F, Schaefer S, Thaemer V (1995) Effect of milrinone, adrenalin and quabain on diastolic ventricular function in stunned myocard. Anaesthesist 44 Supplement 1: PO 2.5

- Hollmann M, Fischer LG, Durieux ME (1999) Lidocain blockiert die Signalubertragung von muskarinen m1-Rezeptoren in Xenopus Oozyten. Anästhesiologie \& Intensivmedizin Abstractband DAK 99: FV 171.2

- Fischer LG, Hollmann M, Chan CK, Durieux ME (1999) Ketamin und sein Enantiomer R(-), aber nicht $\mathrm{S}(+)$ reduzieren den maximalen Stromfluss in kardialen Natrium-Kanâlen. Anästhesiologie \& Intensivmedizin Abstractband DAK 99: PO 381.34

- Hollmann M, Fischer LG, Durieux ME (1999) Lidocaine inhibits muscarinic ml receptor signaling in Xenopus Oocytes. British Journal of Anaesthesia 82 Supplement 1: A.385 
- Fischer LG, Hollmann M, Chan CK, Durieux ME (1999) Ketamine and its enantiomer R(-), but not $\mathrm{S}(+)$ reduce Peak current in human cardiac sodium channels. British Journal of Anaesthesia Volume 82 Supplement 1: A.387

- Fischer LG, Hollmann M, Chan CK, Durieux ME (1999) Ketamine reduces peak current in cardiac- but not in brain-subtype sodium channels. Anesthesiology 91 Supplement: A.410

- Hollmann M. Fischer LG, Durieux ME (1999) Local anesthetic inhibition of M1 muscarinic receptor functioning in Xenopus oocytes. Anesthesiology 91 Supplement: A.410

- Bruenger M, Dean-Mc Kinney TA, Sherer TB, Hollmann MW, Tuttle JB, Durieux ME (2000) Mechanisms of anesthetic inhibition of nerve growth factor secretion in stimulated smooth muscle cells. Anesthesia \& Analgesia 90 Supplement: S305

- Schuchardt K, Sherer TB, Dean-Me Kinney TA, Hollmann MW, Tuttle JB, Durieux ME (2000) Lidocaine decreases nerve growth factor secretion in bladder smooth muscle cells. Anesthesia \& Analgesia 90 Supplement: $\$ 460$

- Fischer LG, Conrad B, Krumm B, Hollmann MW, Durieux ME (2000) Time dependent attenuation by lidocaine of respiratory burst in human neutrophils primed with lysophosphatidic acid. Anesthesia \& Analgesia 90 Supplement: S405

- Fischer LG, Krumm B, Conrad B, Hollmann MW, Durieux ME (2000) Lysophosphatidic acid has a priming but not activating effect in human neutrophils. Anesthesia \& Analgesia 90 Supplement: S406

- Hollmann MW, Berger A, Fischer LG, Durieux ME (2000) Lidocaine inhibition of lysophosphatidate signaling is pH-dependent. Anesthesia \& Analgesia 90 Supplement: S425

- Hollmann MW, Berger A, Fischer LG, Durieux ME (2000) Lysophosphatidate and muscarinic $\mathrm{ml}$ receptor signaling is mediated by different $\mathrm{G}$ protein $\alpha$-subunits. Anesthesia \& Analgesia 90 Supplement: S426

- Hollmann MW, Graf BM, Martin E, Durieux ME (2000) Gaq ist ein intrazellulaerer Wirkort fuer Lokalanaesthetika in $\mathrm{G}$ protein gekoppelten Rezeptoren. Anaesthesiologie \& Intensivmedizin 41:385

- Ritter CH, Hollmann MW, Graf BM, Martin E, Durieux ME (2000) Unterschiede in der Lokalanaesthetika-Sensitivitaet zwischen muskarinen m1- und m3-Rezeptoren. Anaesthesiologie \& Intensivmedizin 41:423

- Jelacin N, Hollmann MW, Graf BM, Martin E, Durieux ME (2000) Lokalanaesthetika hemmen die metabolische Aktivitaet in geprimten Neutrophilen. Anaesthesiologie \& Intensivmedizin 41:424

- Hollmann MW, Berger A, Graf BM, Martin E, Durieux ME (2000) S(-)-Ropivacain inhibiert die Lysophosphatidat-Signaluebertragung signifikant geringer als $\mathrm{R}(+)$-Ropivacain oder Bupivacain. Anaesthesiologie \& Intensivmedizin 41:385

- Wieczorek K, Hollmann MW, Graf BM, Martin E, Durieux ME (2000) Lokalanaesthetika inhibieren die Lysophosphatidat-Signaluebertragung zeit- und $\mathrm{pH}$ abhaengig. Anaesthesiologie \& Intensivmedizin 41:385 
- Fischer LG, Conrad B, Krumm B, Hollmann MW, Durieux ME (2000) Lysophosphatidic acid signaling is attenuated by local anesthetics in human neutrophils. Anesthesiology 93 (3A):A822

- Hollmann MW, Wieczorek KS, Durieux ME (2000) Local anesthetic inhibition of lysophosphatidate signaling is mediated by Gaq protein function. Anesthesiology 93 (3A):A827

- Hollmann MW, Berger A, Hoenemann CW, Durieux ME (2000) Time-dependent inhibition of lysophosphatidate and thromboxane signaling by local anesthetics. Anesthesiology 93 (3A):A828

- Jelacin N, Hollmann MW, Gross A, Durieux ME (2000) Local anesthetics inhibit neutrophil priming. Anesthesiology 93 (3A):A829

- Ritter CH, Hollmann MW, Durieux ME (2000) Differences in sensitivity to local anesthetics of muscarinic $\mathrm{ml}$ and $\mathrm{m} 3$ receptors. Anesthesiology 93 (3A):A833

- Hollmann MW, Berger A, Fischer LG, Durieux ME (2000) Stereoselective effects of ropivacaine on lysophosphatidate signaling. Anesthesiology 93 (3A):A982

- Gross A, Durieux ME, Hollmann MW (2001) Determination of the platelet-activating factorinduced priming pathway in human neutrophils. Anesthesia \& Analgesia 92:S320

- Hollmann MW, Gross A, Durieux ME (2001) Lidocaine's site of action for inhibition of priming in human neutrophils. Anesthesia \& Analgesia 92:S321

- Hollmann MW, Henle P, Durieux ME (2001) Local anesthetic inhibition of muscarinic m3 and $\mathrm{ml}$ signaling by interference with Gaq subunit function. Anesthesia \& Analgesia 92:\$322

- Hollmann MW, Henle P, Durieux ME (2001) Local anesthetic inhibit mammalian Gaq protein function. Anesthesia \& Analgesia 92:S323

- Hollmann MW, Wieczorek K, Durieux ME (2001) Gaq is an intracellular target site for local anesthetics. Anesthesia \& Analgesia 92:S324

- Henle P, Durieux ME, Hollmann MW (2001) Extracellular domains mediating inhibition of muscarinic signaling by charged local anesthetics. Anesthesia \& Analgesia $92: \mathrm{S} 328$

- Hollmann MW, Lages B, Durieux ME (2001) Effect of Bupivacaine on coagulation as measured by the Xylum clot signature analyzer (CSA). Anesthesia \& Analgesia 92:S329

- Wieczorek K, Smart M, Durieux ME, Hollmann MW (2001) Epidural anesthesia prevents hypercoagulation in patients undergoing major orthopedic surgery. Anesthesia \& Analgesia 92:S345

- Herroeder S, Gross A, Durieux ME, Hollmann MW (2001) Lidocaine inhibits neutrophil priming in a time-dependent manner. European Journal of Anaesthesiology 18: 78

- Kurz K, Henle P, Durieux ME, Hollmann MW (2001) Ga, protein function is inhibited by intracellularly injected lidocaine. European Journal of Anaesthesiology 18: 77

- Henle P, Graf BM, Durieux ME, Martin E, Hollmann MW (2001) Inhibition des Săugetier Gaq Proteins durch Lokalanăsthetika. Anaesthesiologie \& Intensivmedizin 42:495 
- Wieczorek K, Graf BM, Durieux ME, Martin E, Hollmann MW (2001) CSA als neue Methode zur Bestimmung antikoagulatorischer Effekte von Lokalanästhetika. Anaesthesiologie \& Intensivmedizin 42:416

- Gross A, Graf BM, Durieux ME, Martin E, Hollmann MW (2001) Bestimmung des Plăttchenaktivierungs-Faktor (PAF)-induzierten „Priming ${ }^{4}$-Signalubertragungswegs in humanen Neutrophilen. Anaesthesiologie \& Intensivmedizin 42:444

- Gross A, Graf BM, Durieux ME, Martin E, Hollmann MW (2001) Charakterisierung des Wirkortes von Lidocain in PAF-induzierten „Priming"-Prozessen humaner Neutrophilen. Anaesthesiologie \& Intensivmedizin 42:452

- Henle P, Graf BM, Durieux ME, Martin E, Hollmann MW (2001) Die Rolle extrazellulärer Rezeptordomalnen für die Inhibition muskarinerger $\mathrm{ml}$ - und $\mathrm{m} 3$-Rezeptoren durch geladene Lokalanlisthetika. Anaesthesiologie \& Intensivmedizin 42:453

- Kurz K, Graf BM, Durieux ME, Martin E, Hollmann MW (2001) Die Gaq Proteinfunktion wird durch intrazellular injiziertes Lidocain gehemmt. Anaesthesiologie \& Intensivmedizin 42:453

- Wieczorek K, Graf BM, Durieux ME, Martin E, Hollmann MW (2001) Epiduralanăsthesie schutzt Patienten mit orthopaddischen Eingriffen vor postoperativer Hyperkoagulation. Anaesthesiologie \& Intensivmedizin 42:462

\section{Editorials}

- Hollmann MW, Durieux ME (2000) Prolonged actions of short acting drugs: local anesthetics and chronic pain. Regional Anesthesia \& Pain Medicine 25:337-9.

\section{Invited Review articles}

- Hollmann MW, Durieux ME, Graf BM (2001) Novel local anaesthetics an novel indications for local anaesthetics. Current Opinion in Anaesthesiology (in press)

- Herroeder S, Durieux ME, Hollmann MW (2002) Inflammatory responses after surgery. Hospital Medicine (in press)

\section{Books}

- Hollmann M: Experimentelle Untersuchungen der Wirkung von Halothan auf den myokardialen Reoxygenationsschaden. Aachen, Shaker Verlag, 1998 


\section{Curriculum Vitae}

The author of this thesis was born on November 1, 1968, in Neuss (Germany). He attended secondary school at the Stadtische Gymnasium in Norf.

From 1986 to 1989 he was trained as a computer programmer and system analyst at 3M Gemany in Neuss and graduated with summa cum laude. After a year working as a system analyst at $3 \mathrm{M}$ Gemany in Neuss, he commenced his studies in medicine at the University of Dusseldorf (Germany). He graduated cum laude in 1996. From 1992 to 1997 he completed his medical doctoral thesis in the laboratory of Prof. Dr. Volker Thalmer (Department of Heart and Circulation physiology) at the University of Dusseldorf (Germany). His doctoral thesis was honored with summa cum laude in 1997.

After two years of residency training in Anesthesiology at the University of Heidelberg (Germany), he went to the United States and worked from 1998 to 2001 in the laboratory of Marcel E. Durieux (Anesthesiology) at the University of Virginia, as a post-doctoral research fellow.

In 2001 he accompanied Prof. Marcel Durieux to establish a laboratory in the Department of Anesthesiology at the University of Maastricht (The Netherlands). To date he is resident in Anesthesiology at the University of Heidelberg (Germany) and research fellow in the Department of Anesthesiology at the University of Maastricht (The Netherlands). 


\section{SHAKER \\ VEALAG}

ISBN 3-8265-9627-7 